\title{
Entwicklung eines Fusionsassays basierend auf porenüberspannenden Membranen
}

\author{
Dissertation
}

\author{
zur Erlangung des \\ mathematisch-naturwissenschaftlichen Doktorgrades \\ „Doctor rerum naturalium“ \\ der Georg-August-Universität Göttingen
}

\author{
vorgelegt von \\ Ines Höfer \\ aus Einbeck
}

Göttingen 2011 
D7

Referentin: Prof. Dr. Claudia Steinem Korreferent: Prof. Dr. Jörg Schroeder

Tag der mündlichen Prüfung: 05.07.2011 
Meinem Vater 

Abstract. Fusion of biological membranes is a central requirement for many cellular processes. In recent years a great variety of fusion assays based on artificial membrane systems has been developed. Such reductionist approaches mainly account for our current knowledge on fusion processes. However, there are still a number of drawbacks associated with these assays. The aim of this thesis was the establishment of a new vesicle-planar membrane fusion assay to be able to gain insight into protein-mediated fusion processes. To achieve this goal, membranes suspending the pores of a highly ordered porous material were established, which have the advantage that they are very robust, mechanically stable and the membranes are accessible from both sides.

The results clearly demonstrate that large unilamellar vesicles can successfully be fused with pore-spanning membranes. Micro-black lipid membranes (micro-BLMs) were prepared by the painting-technique resulting in a hybrid lipid bilayer doped with Oregon Green DHPE. The addition of large unilamellar vesicles (600 $\mathrm{nm}$ in average diameter), doped with Texas Red DHPE, to the pore-suspending membrane allowed for the observation of single fusion events by means of fluorescence microscopy. Lipid mixing was followed by the distribution of the Texas Red fluorescence in the plane of the poresuspending membrane while simultaneously, quenching of the Oregon Green fluorescence due to Förster resonance energy transfer (FRET) between the Oregon Green and Texas Red dye was monitored. For the Texas Red distribution a diffusion coefficient of $D=(9 \pm 5) \mu \mathrm{m}^{2} / \mathrm{s}$ was determined. This value is in very good agreement with fluorescence recovery after photobleaching analyis.

By means of scanning ion conductance microsopy (SICM) a detailed elucidation of membrane topology before and after fusion was possible. It was shown that the porespanning membranes bent deeper into the pore due to the excess of additional lipid material after fusion of a vesicle.

The analysis of two different molecular recognition systems based on solvent-free porespanning membranes revealed the importance of membrane destabilization by insertion of a transmembrane anchor for the initiation of the fusion process. The interaction between two membranes doped with head-goup modified lipids mediated by the peptide $\mathrm{H}_{6}$ WGC yielded only low fusion rates. In contrast, the insertion of PNA-sequences coupled to the native SNARE-transmembrane domain resulted in very efficient fusion. The PNA sequences, identical in both membranes or complementary in vesicle and porespanning membrane, barely influenced the fusion efficiency. Destabilization of the vesicle appears to be the key to cause fusion with peptide-free pore spanning membranes. 



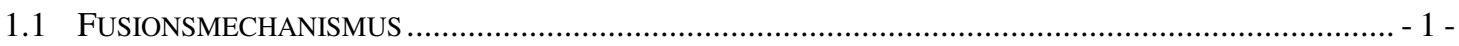

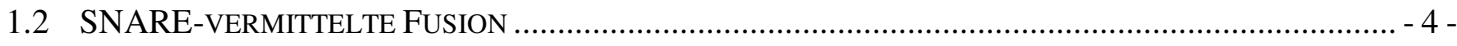

1.3 BIOMIMETISCHE MODELLMEMBRANEN ZUR UNTERSUCHUNG VON FUSIONSPROZESSEN................ - 5 -

1.4 SNARE-MIMETISCHE FUSIONSSYSTEME .................................................................. - 13 -

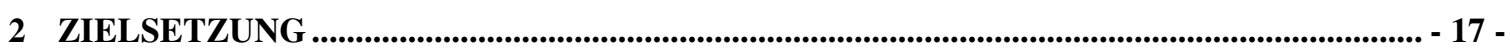

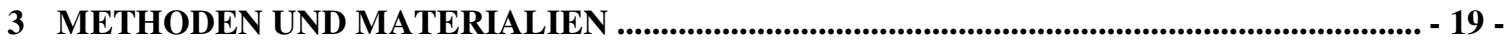

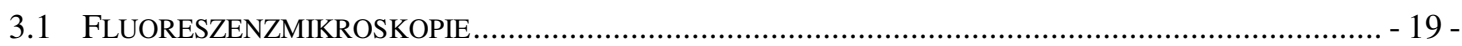

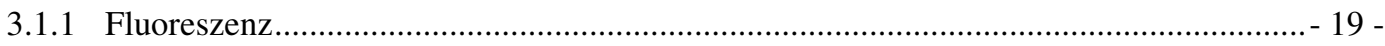

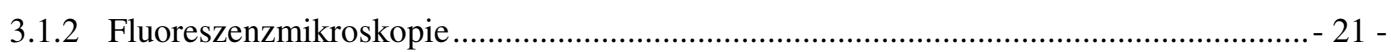

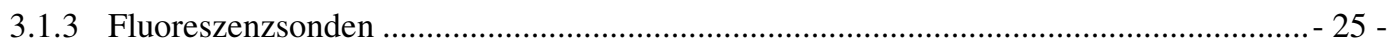

3.1.4 Förster Resonanz Energie Transfer (FRET) ........................................................ 26 -

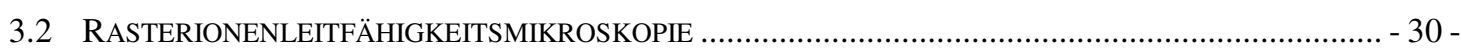

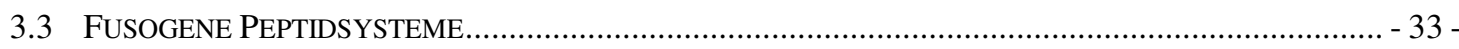

3.3.1 Das $\mathrm{H}_{6}$ WGC-Peptidsystem.................................................................................. 33 -

3.3.2 Molekulare Erkennung durch SNARE-analoge PNA-Peptidsysteme ............................ 35 -

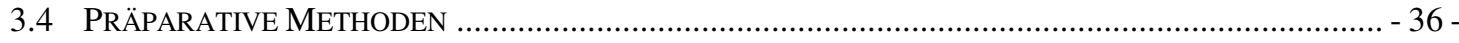

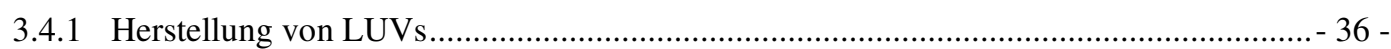

3.4.2 Herstellung von GUVs ......................................................................................... 37 -

3.4.3 Herstellung von porenüberspannenden Membranen ................................................ 38 -

3.4.4 Herstellung von micro-BLMs mittels Painting-Technik ................................................ 39 -

3.4.5 Herstellung von lösungsmittelfreien porenüberspannenden Membranen durch das

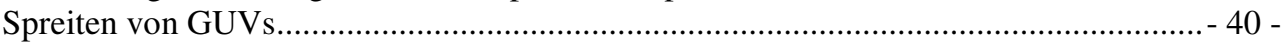

3.4.6 Durchführung der Fusionsexperimnente …....................................................... 40 -

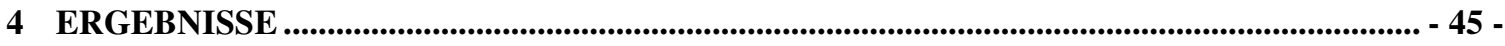

4.1 UNTERSUCHUNG DER LIPIDVERMISCHUNG WÄHREND DER FUSION VON LUVS MIT MICRO-BLMS

4.2 UNTERSUCHUNG DER VESIKELAUSSCHÜTTUNG WÄHREND DER FUSION VON LUVS MIT MICRO-BLMS

4.3 NACHWEIS DES VESIKELINHALTS IN GESCHLOSSENEN PORENTÖPFEN NACH DER FUSION VON VESIKELN MIT PORENÜBERSPANNENDEN MEMBRANEN... 
4.4 UNTERSUCHUNG DER MORPHOLOGIE VON PORENÜBERSPANNENDEN MEMBRANEN NACH DER FUSION VON LUVS MITTELS RASTERIONENLEIT-FÄHIGKEITSMESSUNGEN.

4.5 EINFLUSS MOLEKULARER ERKENNUNGSREAKTIONEN AUF DIE FUSION VON VESIKELN MIT PORENÜBERSPANNENDEN MEMBRANEN

4.5.1 Untersuchung der Fusion von Vesikeln mit porenüberspannenden Membranen vermittelt durch das Peptid $\mathrm{H}_{6} \mathrm{WGC}$.....

4.5.2 Untersuchung der Fusion von Vesikeln mit porenüberspannenden Membranen vermittelt durch SNARE-analoge PNA-Strukturen...... $-95-$

5.1 UNTERSUCHUNG DER LIPIDVERMISCHUNG WÄHREND DER FUSION VON LUVS MIT MICRO-BLMS $-109-$

5.2 UNTERSUCHUNG DER VESIKELAUSSCHÜTTUNG WÄHREND DER FUSION VON LUVS MIT MICRO-BLMS $-119-$

5.3 UNTERSUCHUNG DER MORPHOLOGIE VON PORENÜBERSPANNENDEN MEMBRANEN NACH DER FUSION VON LUVS MITTELS RASTERIONEN-LEITFÄHIGKEITSMESSUNGEN...... $-124-$

5.4 UNTERSUCHUNG DER FUSION VON VESIKELN MIT PORENÜBERSPANNENDEN MEMBRANEN VERMITTELT DURCH MOLEKULARE ERKENNUNG

5.5 BETRACHTUNG DER UNTERSCHIEDLICHEN FUSIONSSYSTEME IM KONTEXT DER MEMBRANSPANNUNGEN $-143-$ 




\section{Einleitung}

Die Ausbildung von Membranen ist einer der wichtigsten Schritte im Prozess der Entstehung von Leben. Die Hauptaufgabe der Lipiddoppelschichten liegt dabei vor allem in der Abtrennung verschiedener physiologischer Reaktionsräume zum Aufbau von Stoffgradienten oder elektrischen Potentialen. ${ }^{1}$ Der Stoffaustausch einer Zelle mit seiner Umgebung wird durch verschiedene Transportprozesse über die Membran, zum Beispiel durch Kanäle oder Transporter, gewährleistet. Zum Teil erfordern biologische Prozesse jedoch auch den schnellen Transfer großer Mengen an komplexen Substanzen wie beispielsweise Neurotransmittern. Dazu kann der Austausch zwischen zwei getrennten Kompartimenten ohne Vermischung mit dem umgebenden Medium durch Membranfusion realisiert werden. Zwei zuvor getrennte wässrige Kompartimente werden durch die Fusion von zwei Lipiddoppelschichten vereint. Dieser Weg des Austauschs spielt zum Beispiel bei der Reizweiterleitung am synaptischen Spalt oder bei der Infektion einer Zelle durch einen Virus eine zentrale Rolle. Das Verständnis der genauen Fusionsmechanismen bietet so zum Beispiel neue wertvolle Angriffsziele für Medikamente und Therapien. Aus diesem Grund steht die Untersuchung der Fusionsprozesse im Fokus vieler wissenschaftlicher Arbeiten. Die bisherigen Erkenntnisse und einige der Methoden, die dazu beigetragen haben, werden im Folgenden vorgestellt.

\subsection{Fusionsmechanismus}

Lipide ordnen sich in wässriger Lösung oberhalb einer kritischen Konzentration spontan zu Lipiddoppelschichten zusammen. Umso erstaunlicher ist, dass diese eigentlich stabilen Aggregate sich derartig umlagern können, dass im Rahmen der Fusion zwei Membranen zu einer einzigen Lipiddoppelschicht verschmelzen. Zu der wesentlichen Aufklärung des Mechanismus haben theoretische Arbeiten von Kozlov und Experimente von Chernomordik beigetragen. ${ }^{2-4}$ Das vorgeschlagene Konzept der Hemifusion als Übergangszustand auf dem Weg zur vollen Fusion ist bis heute weitestgehend als das gängige Modell zur Beschreibung des Fusionprozesses akzeptiert. In einem ersten Schritt 
wird der Kontakt zwischen den zwei getrennten Lipiddoppelschichten hergestellt (Abb. 1.1). In Röntgenstrukturanalysen wurde der charakteristische Abstand zwischen zwei Membranen mit biologisch relevanter, ungeladener Lipidzusammensetzung ermittelt. Wechselwirkungen, wie Van-der-Waals-Anziehungen, repulsive Hydratationkräfte sowie Membranunebenheiten, führen zu einem Gleichgewichtsabstand von $2-3$ nm. ${ }^{5,6}$

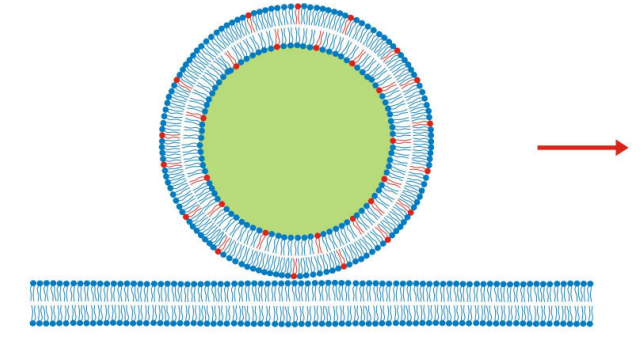

Andocken

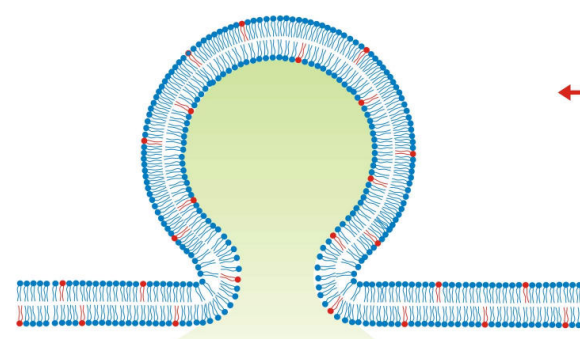

Komplette Fusion

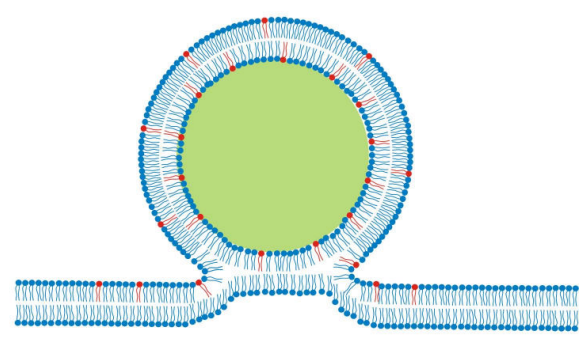

Hemifusion

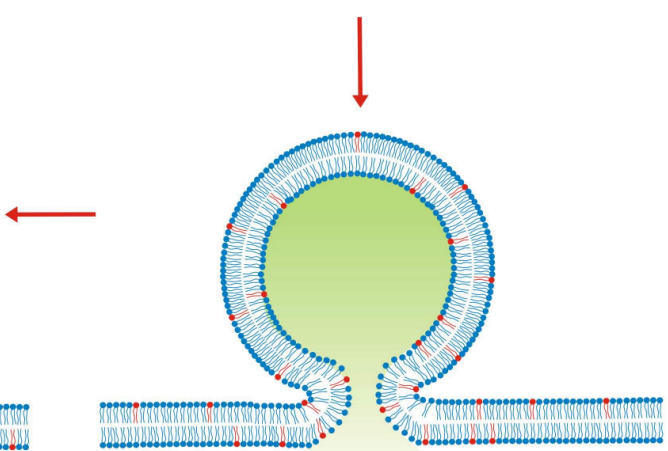

Bildung einer Fusionspore

Abb. 1.1 Schematische Darstellung der Intermediate, über die die Reorganisation der Lipide im Rahmen des Fusionsprozesses abläuft.

Wird dieser Abstand überwunden, können jeweils die beiden benachbarten Lipidmonoschichten der zwei zu fusionierenden Membranen miteinander wechselwirken und die Reorganisation der Lipide führt zu ihrer Vermischung. Die Ausbildung dieser lokalen Verbindung zwischen den beiden Membranen wird als Hemifusion bezeichnet. Dabei handelt es sich um einen Übergangszustand mit dem eine starke Verkümmung der Lipiddoppelschichten einhergeht. Dementsprechend muss eine hohe Energie aufgewendet werden, um eine Lipiddoppelschicht in eine derartige Konformation zu zwängen, wenn diese Krümmung nicht der entspricht, die ein Lipid in einer Monoschicht einnehmen würde. Die von einem Lipid favorisierte spontane Krümmung, die ein Lipid 
favorisiert, hängt von seiner Geometrie ab. Der Einfluss des Packungsparameters auf die Struktur des Lipidaggregats wurde 1975 von Israelachvili beschrieben. ${ }^{7}$ Bilden Kopfgruppe und die hydrophoben Seitenketten auf Grund ihres Raumbedarfs einen Zylinder, so wird eine möglichst planare Membranstruktur bevorzugt (Abb. 1.2). Wenn die Kopfgruppe einen wesentlich größeren Raumanspruch als die Fettsäurereste hat, wie im Fall von Lysophosphatidylcholinen, so nimmt die entsprechende Lipidmonolage eine positive Krümmung ein, in der die Kohlenwasserstoffketten näher zusammengerückt sind. Anders verhalten sich Lipide mit der entgegengesetzten Geometrie. In Phosphoethanolaminen zum Beispiel haben die hydrophoben Seitenketten einen höheren Raumbedarf als die Kopfgruppe und somit wird eine negative Krümmung bevorzugt, so dass die Kopfgruppen näher zusammen rücken. Der Einbau von Lipiden mit verschiedener Geometrie wird häufig genutzt, um die Fusionseigenschaften von Membranen zu modulieren. ${ }^{8-11}$

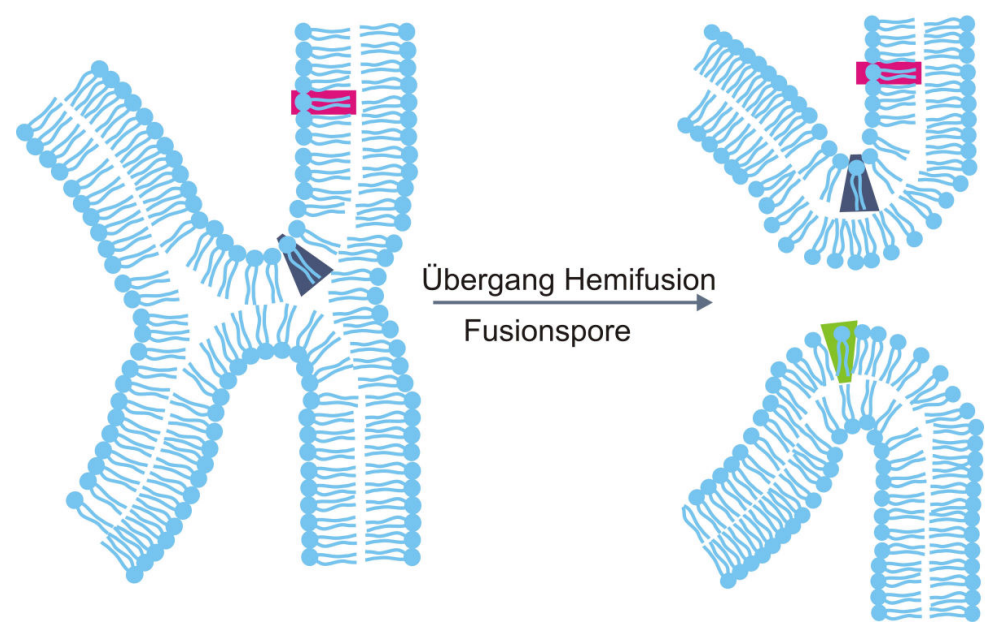

Negative Krümmung:

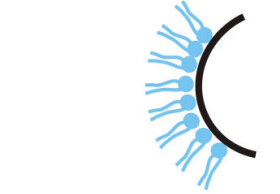

Positive Krümmung:

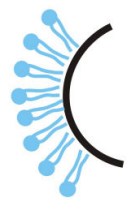

Abb. 1.2 Schematische Darstellung der eingenommenen Membrankrümmungen während der Fusion und die jeweilige Bevorzugung von Lipiden mit unterschiedlicher Geometrie.

Nach der Hemifusion wird der Fusionsprozess durch die Ausbildung einer Fusionspore komplementiert. Dazu muss eine weitere Reorganisation der Lipide erfolgen, so dass eine Vermischung der zuvor separierten äußeren Monoschichten der zwei fusionierenden Membranen erfolgt. Gleichzeitig geht mit der kompletten Fusion der zwei Lipiddoppelschichten auch die Vermischung der zuvor getrennten wässrigen Kompartimente einher. Zwischen Hemifusion und Porenbildung kann experimentell unterschieden werden, indem durch Fluoreszenzmarkierung sowohl die Membranen als auch der wässrige Vesikelinhalt sichtbar gemacht werden. Fluoreszenzmikroskopisch 
oder -spektrometrisch kann so zwischen den Intermediaten unterschieden werden. Während der Hemifusion tritt ausschließlich eine Vermischung der Lipide auf. Eine gleichzeitige Vermischung der Lipide und die Ausschüttung des Vesikelinhalts zeigt die komplette Fusion an. ${ }^{12}$ Auf diese Weise wird die Aufklärung des exakten Mechanismus angestrebt.

\subsection{SNARE-vermittelte Fusion}

Die Fusion zweier Membranen ist ein essentieller Schritt in vielen biologischen Prozessen wie der Reizweiterleitung am synaptischen Spalt, der Virusinfektion, Endound Exozytose und der Verschmelzung von Ei- und Spermazelle. ${ }^{13}$ Ihre präzise Regulation und das Überwinden der Energiebarriere zur Lipidreorganisation unter Erhalt der Barriereeigenschaften der Membran wird dabei durch verschiedene Proteine gewährleistet. Im Fall der Ausschüttung von Neurotransmittern in den synaptischen Spalt zur Reizweiterleitung an der Synapse wurden nach ihrer Entdeckung in den späten achtziger Jahren die SNARE-Proteine (soluble N-ethylmaleimide-sensitive-factor attachment receptor) als Schlüsselkomponenten identifiziert, die die Fusion von Vesikeln mit der synaptischen Membran initiieren. ${ }^{14}$ Im Wesentlichen wurden drei Proteine gefunden, die gemeinsam einen Komplex ausbilden und so die Fusion realisieren. SNARE-Proteine variieren stark in ihrer Größe und Struktur, zeichnen sich jedoch durch eine gemeinsame homologe Sequenz, das SNARE-Motiv, aus. Dabei handelt es sich um eine evolutionär hochkonservierte Struktur aus 60 - 70 Aminosäuren, in der sich eine Abfolge von sieben Aminosäuren wiederholt. ${ }^{15}$ Am besten charakterisiert sind die SNARE-Proteine Syntaxin, Synaptobrevin und SNAP-25 (synaptosomal-associated protein, $25 \mathrm{kDa}) .{ }^{16,17}$ Syntaxin und Synaptobrevin weisen je ein SNARE-Motiv auf, das über einen kurzen Linker und einen C-terminalen Transmembrananker an die Membran gebunden ist. Dabei ist Syntaxin in der synaptische Membran veranktert; Synaptobrevin bindet an die Vesikelmembran (Abb. 1.3). 


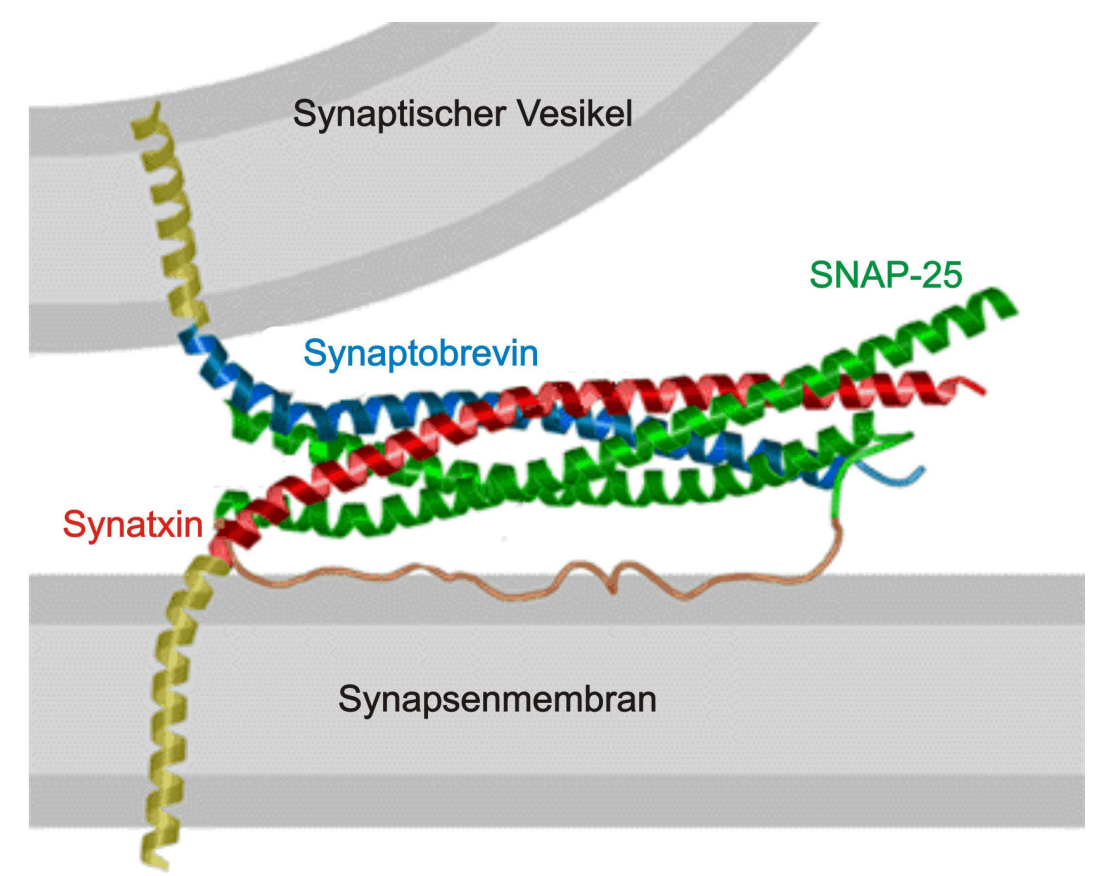

Abb. 1.3 Anordnung der SNARE-Proteine Syntaxin, Synaptobrevin und SNAP-25 im SNARE-Komplex, dessen Ausbildung den nahen Kontakt zwischen synaptischer Membran und Vesikelmembran herstellt und somit die Fusion einleitet. Die Struktur wurde 1998 von Fasshauer et al. röntgenkristallografisch bestimmt. $^{18}$

SNAP-25 hingegen weist zwei SNARE-Motive auf, die über einen flexiblen Linker miteinander verknüpft sind. Über einen Palmitoylrest in der Linkerregion wird SNAP-25 an die Synapsenmembran gebunden. Die SNARE-Motive bilden über hydrophobe Interaktion eine coiled-coil-Struktur aus und bilden so den SNARE-Komplex. Verschiedene Studien führten zu der Hypothese, dass dies in einen Reißverschlussähnlichen Mechanimus geschieht, in dem die Helices der SNARE-Proteine vom Membran-abgewandten N-Terminus zur Linkerregion schrittweise den SNARE-Komplex ausbilden. ${ }^{19-21}$ Durch die Verbindung der SNARE-Motive werden die Membranen in engen Kontakt zueinander gebracht und die Fusion eingeleitet.

\subsection{Biomimetische Modellmembranen zur Untersuchung von Fusionsprozessen}

Um neue Einblicke in Prozesse, die in und an Membranen stattfinden, zu gewinnen, bedient die Forschung sich häufig artifizieller Modellmembranen. Diese biomimetischen Systeme bieten den Vorteil, dass die Zusammensetzung von Lipiden, Proteinen und 
weiteren Membrankomponenten präzise kontrolliert werden kann und somit gezielt bestimmte Fragestellungen adressiert werden können. Über die Jahre haben sich im Wesentlichen drei große Gruppen von Modellmembransystemen etabliert. Neben Vesikeln in verschiedenen Größen mit Durchmessern von $20 \mathrm{~nm}$ bis $\mathrm{zu}$ mehreren Mikrometern, ${ }^{22}$ wird bei den planaren Membranen vor allem zwischen freitragenden und festkörperunterstützten Lipiddoppelschichten unterschieden. ${ }^{1}$ Die drei genannten Modelle werden im Folgenden vor allem vor dem Hintergrund ihrer Eignung zur Untersuchung der Membranfusion vorgestellt (Abb. 1.4). Außerdem soll ein relativ neuartiges artifizielles Lipiddoppelschichtsystem präsentiert werden, die porenüberspannenden Membranen.

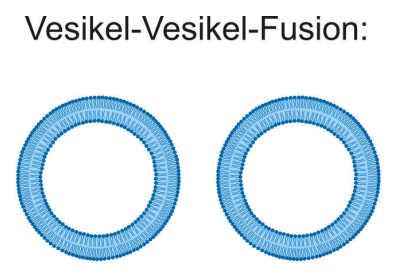

Fusion von Vesikeln mit freitragenden Membranen:

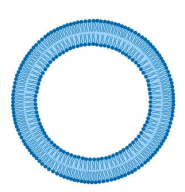

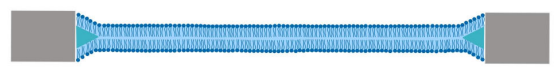

Fusion von Vesikeln mit festkörperunterstützten Membranen:

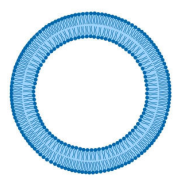

Abb. 1.4 Übersicht über etablierte Modellmembransysteme zur Untersuchung von Fusionsprozessen.

Vesikel:

$\mathrm{Zu}$ dem heutigen Wissen über Fusionsprozesse haben viele Analysen zur proteinfreien Fusion in den achtziger Jahren des letzten Jahrhunderts beigetragen. Ein Großteil dieser Studien basierte auf der Untersuchung der Vesikel-Vesikel-Fusion. ${ }^{23}$ Der Vorteil dieser sphärischen Membranmodelle liegt in der einfachen Herstellung und der leichten Variierbarkeit von Zusammensetzung und Größe. So kann durch Variation des Gehalts an negativ geladenen Lipiden leicht die Rolle von $\mathrm{Ca}^{2+}$-Ionen im Fusionsprozess untersucht werden. ${ }^{24} \mathrm{Im}$ Fall kleiner Vesikel mit einem Durchmesser von $20-100 \mathrm{~nm}$ ermöglicht die Kontrolle über Vesikelgrößen wiederum, den Einfluss der Vesikelgröße und somit -krümmung auf die Fusion zu eruieren. ${ }^{25-28}$ Zur Analyse der Lipidvermischung während der Vesikel-Vesikel-Fusion eignen sich lichtmikroskopische Verfahren in der 
Regel nicht, da die Vesikel so geringe Größen aufweisen, dass sie optisch nicht aufgelöst werden können. Mit Hilfe des Fluoreszenzspektrometers wird hingegen die mittlere Fluoreszenz der Vesikelsuspension detektiert. Dazu werden die Vesikel durch Einbau von Lipid-gekoppelten Fluoreszenzfarbstoffen markiert. Zum Einsatz kommen zum Beispiel zwei unterschiedliche Fluorophore, zwischen denen ein Energietransfer (Förster Resonanz Energie Transfer, FRET, Kapitel 3.1.4) stattfinden kann, so dass bei Anregung des einen Farbstoffs (Donor) die absorbierte Energie strahlungslos an den zweiten Farbstoff (Akzeptor) abgegeben wird. ${ }^{29}$

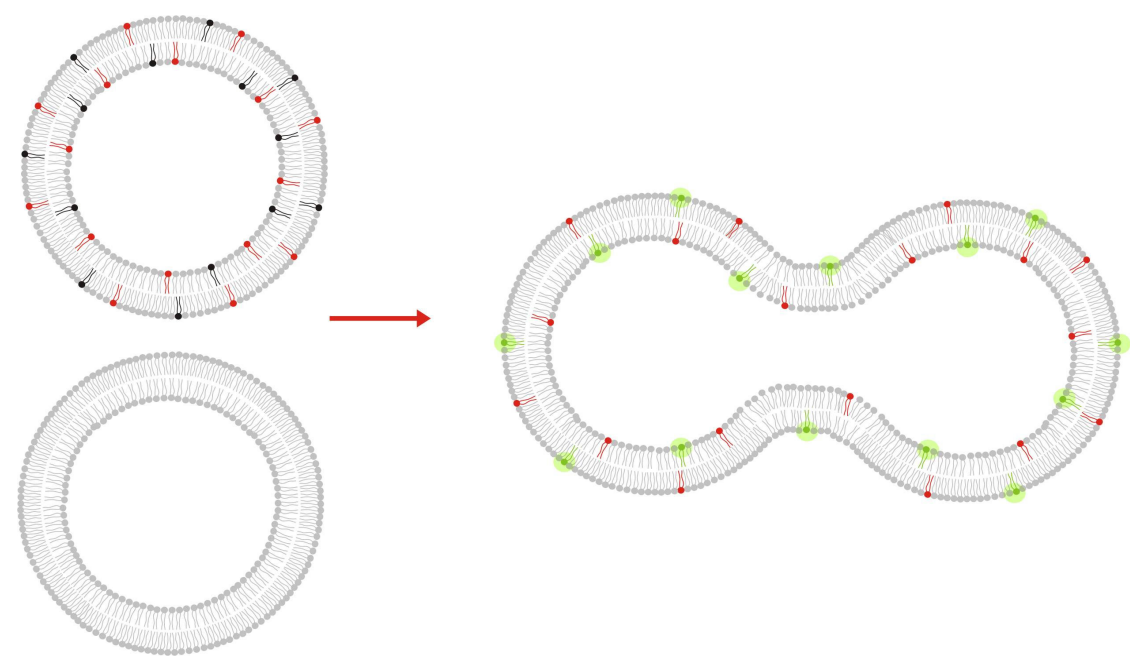

Abb. 1.5 Schematische Darstellung des Messprinzips mit dessen Hilfe die Lipidvermischung bei Zugabe der Fusion zweier Vesikel spektrofluorometrisch verfolgt werden kann. Ist das FRET-Paar in einen Vesikel eingebaut, so wird die Donorfluoreszenz gelöscht. Dies geschieht in Abhängigkeit des relativen Abstands der Farbstoffe zueinander, der über die Konzentrationen im Vesikel gesteuert werden kann. Nach der Fusion mit einem Farbstoff-freien Vesikel vergrößert sich der Abstand zwischen den Farbstoffen, so dass die Donorfluoreszenz weniger stark gelöscht wird und dadurch ansteigt.

Da dieser Energietransfer abstandsabhängig ist, wird die Donorfluoreszenz gelöscht, wenn Akzeptor und Donor in ausreichend hoher Konzentration in einen Vesikel eingebaut sind. Durch Fusion dieses Vesikels mit einem farbstofffreien Liposom wird der Abstand zwischen Donor und Akzeptor größer und die Löschung der Donorfluoreszenz geringer. Auf diese Weise kann das Voranschreiten der Lipidvermischung durch Beobachtung des zeitlichen Anstiegs der Donorfluoreszenzintensität verfolgt werden. Auf ähnliche Art können auch selbstlöschende Lipidfarbstoffe zur Detektion der Lipidvermischung eingesetzt werden. ${ }^{30}$ Die Schwierigkeit besteht jedoch darin, dass die Untersuchungen in Lösung durchgeführt werden und eine Mittelung über alle stattfindenden Ereignisse erfolgt. Des Weiteren können Mehrfachfusionen auftreten, die 
in diesen Messungen nicht von der erstmaligen Fusion unterschieden werden können. Insgesamt kann dadurch zwischen einzelnen Fusionsintermediaten nicht unterschieden werden bzw. die Kinetiken der einzelnen Schritte können nicht aufgelöst werden. Nur wenige Ausnahmen sind bekannt, in denen entweder durch Verwendung von sogenannten Riesenvesikeln, die mit ihrem Durchmesser von mehreren Mikrometern auch mit Hilfe optischer Methoden aufgelöst werden können, einzelne Fusionsintermediate sichtbar gemacht wurden. ${ }^{31,32}$ Durch Messungen an kleinen, optisch nicht auflösbaren Vesikeln in sehr kleinen konfokalen Volumina konnte wiederum von Cypionka et al. durch Kreuzkorrelationsspektroskopie zwischen verschiedenen Fusionsstadien unterschieden werden. ${ }^{33}$ Weiterhin besteht die Möglichkeit die Vesikel über Biotin-Avidin-Wechselwirkungen auf Festkörpern zu fixieren, um gezielt einzelne Vesikel zu beobachten. ${ }^{34-37}$ Um die Problematik von Ensemble-Messungen zu umgehen, gehen viele Forschungsgruppen dazu über, Einzelfusionsereignisse von Vesikeln mit planaren Membranen zu untersuchen.

\section{Festkörperunterstützte Membranen:}

Festkörperunterstützte Membranen können auf verschiedenen Substraten wie Glas, Silizium oder Gold präpariert werden. Durch ihren relativ engen Kontakt zu einer Festkörperunterlage zeichnen sich diese artifiziellen Lipiddoppelschichten durch eine hohe Langzeit- und mechanische Stabilität aus. In den letzten Jahren fand auch dieses Modellmembransystem immer häufiger Anwendung in der Untersuchung von Fusionsprozessen. Dabei bietet die Fusion von Vesikeln mit festkörperunterstützten Membranen die Möglichkeit Einzelfusionsereignisse zu untersuchen. ${ }^{38-41}$ Der Einsatz der TIRF-Mikroskopie (total internal reflection fluorescence) an Glas-unterstützten Membranen gewährleistet in den Untersuchungen eine sehr hohe axiale Auflösung, so dass die ortsabhängige Fluoreszenz sehr gut bestimmten Prozessen wie dem Andocken eines Vesikels oder der Lipidvermischung zugeordnet werden kann. ${ }^{38,} 42$ Die Beobachtung von einzelnen Vesikeln ermöglichte Domanska et al. und Wang et al. die Kinetiken der SNARE-vermittelten Fusion zu untersuchen. ${ }^{39,}{ }^{43}$ Beide Gruppen zeigten, dass die Reorganisation der Lipide, begonnen bei einem an die Membran gedockten Vesikel bis zur vollen Fusion, im Millisekundenbereich liegt. Diese schnellen Fusionsraten entsprechen denen, die für die exocytotische Fusion erwartet wird. Im Gegensatz dazu wurden komplette Fusionen in vorherigen Vesikelanalysen in einem 
Zeitintervall von mindestens 20 min gefunden. Eine derartig langsame Fusionskinetik kommt zum einen durch die statistische Betrachtung einer Vesikelpopulation und zum anderen durch eventuell stattfindende Mehrfachfusionen zustande. Außerdem werden die Kinetiken der Fusion durch die Diffusion der Vesikel zueinander beherrscht. Basierend auf einer festkörperunterstützten Membran versuchten Wang et al. durch gleichzeitige Fluoreszenzmarkierung von Membran und Vesikelinhalt die verschiedenen Intermediate während der Fusion eines Vesikels mit der planaren Lipiddoppelschicht zu visualisieren. Die Analyse der Diffusion des wässrigen Farbstoffs zeigte, dass dieser durch Risse in den Vesikeln entweicht und nicht wie erwartet im Zuge der Fusion ausgeschüttet wird. Dabei stellt sich die Frage, ob der Vesikelinhalt nach seiner Ausschüttung in der $2-3 \mathrm{~nm}$ dicken Wasserschicht zwischen Membran und Festkörper verstaut werden kann. Der enge Kontakt zur Substratoberfläche wirkt sich ebenfalls nachteilig auf die Untersuchung der Ausschüttung des Vesikelinhalts während der Fusion aus. Zwischen der Lipiddoppelschicht und der Substratoberfläche befindet sich zwar eine $1 \mathrm{~nm}$ dicke Wasserschicht, dennoch ist die Beobachtung der Vesikelausschüttung in dieses kleine Volumen erschwert. Mit optischen Methoden kann zum Beispiel nicht aufgelöst werden, auf welcher Seite der Vesikelinhalt ausgeschüttet wurde. Ein zweites wässriges Kompartiment auf der anderen Seite der Membran wäre für derartige Untersuchungen wünschenswert.

Die Membranen, die auf einem Festkörper präpariert werden, zeigen auf Grund des engen Kontakts zur Oberfläche eine relativ geringe Mobilität. Diese kann für Transmembranproteine noch weiter vermindert sein, wenn Proteinreste mit der Festkörperunterlage in Wechselwirkung treten. Um den Abstand zu erhöhen, entwickelten Wagner et al. eine Methode, um Polyethylenglykol-Abstandshalter zwischen Membran und Festkörper einzulagern. ${ }^{44}$ Auf diese Weise konnte die laterale Mobilität der rekonstituierten SNARE-Proteine erhöht werden. ${ }^{45}$

\section{Freitragende Membranen:}

Die Zugänglichkeit der Lipiddoppelschichten von beiden Seiten ist im System der freitragenden Membranen gegeben. Diese artifiziellen Lipiddoppelschichten zeichnen sich dadurch aus, dass eine Membran über eine $0.1-2 \mathrm{~mm}$ große Öffnung zwischen zwei Elektrolyt-gefüllten Kammern gespannt wird. Dabei werden freitragende Lipiddoppelschichten im Wesentlichen auf Grund der unterschiedlichen Herstellungs- 
prinzipien in zwei Kategorien unterteilt. Müller und Rudin entwickelten ein Verfahren zur Herstellung von freitragenden Membranen, in dem Lipide gelöst in einem nichtflüchtigen, apolaren Lösungsmittel über die Öffnung zwischen den zwei Elektrolytkammer gestrichen werden. ${ }^{46}$ In einem Prozess der Selbstorganisation, der auch als Ausdünnen bezeichnet werden kann, wird das Lösungsmittel in die Randbereiche der Apertur verdrängt und eine Lipiddoppelschicht ausgebildet (Abb. 1.6). Von diesem Prinzip leitet sich auch der synonyme Name Black Lipid Membranes (BLMs) ab. Das Ausdünnen des Lipid-Lösungsmittel-Tropfens über der Öffnung kann lichtmikroskopisch verfolgt werden. Durch die Reflektion des Lichts am Lösungsmittel leuchtet die Doppelschicht zunächst regenbogenfarben bis das Lösungsmittel komplett in die Randbereiche verdrängt wurde und die Lipiddoppelschicht schwarz erscheint.
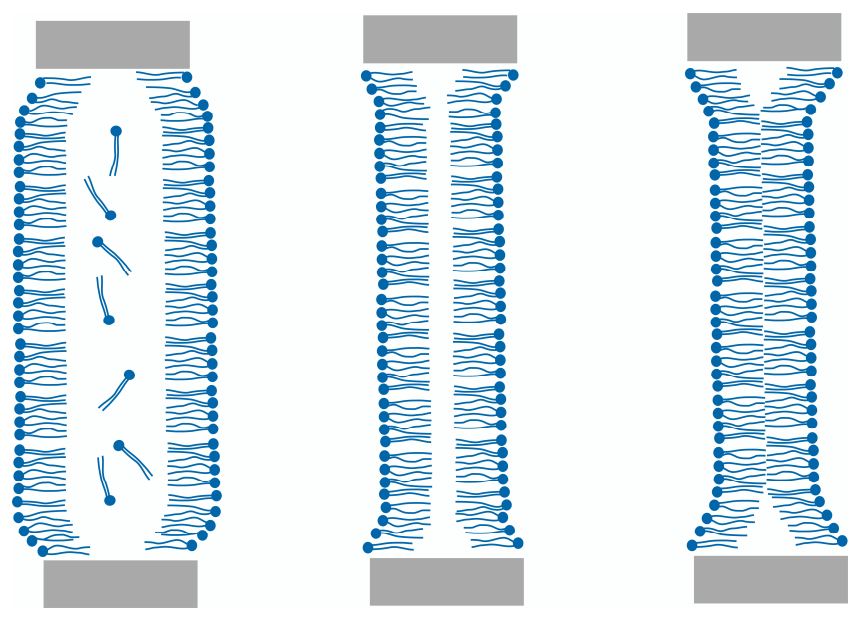

Abb. 1.6 Schematische Darstellung des Ausdünnprozesses, in dessen Verlauf eine BLM ausgebildet wird.

Der Einfluss des organischen Lösungsmittels kann durch das von Montal und Müller etablierte Präparationsverfahren minimiert werden. ${ }^{47}$ Dazu werden die zwei Kompartimente bis kurz vor die Öffnung mit Elektrolytlösung gefüllt, auf der Lipide gelöst in einem leicht flüchtigen Lösungsmittel wie Chloroform gespreitet werden. An der Luft-Wasser-Grenzfläche entstehen auf diese Weise in beiden Kompartimenten monomolekulare Lipidschichten, die durch langsames Anheben des Wasserpegels auf beiden Seiten zu einer Lipiddoppelschicht über der Apertur vereint werden.

Auf Grund der wässrigen Kompartimente auf beiden Seiten der Lipiddoppelschicht eignen sich freitragende Membranen sehr gut dazu elektrische Eigenschaften der Membran auch in Kombination mit bildgebenden Methoden während der Fusionsprozesse zu untersuchen. ${ }^{48,49}$ Für elektrische Messungen während der Fusion werden das 
Antibiotikum Nystatin und Ergosterol in die Vesikel eingebaut. Nystatin ist bekannt dafür, in Anwesenheit von Ergosterol Poren in der Membran zu bilden. Die Fusion des Vesikels mit einer Ergosterol-freien Membran, führt zunächst zu einem Anstieg der Leitfähigkeit der freitragenden Membran durch den Einbau des Nystatins, die auf Grund der Verdünnung des Ergosterols und der damit verbundenen Destabilisierung der Nystatinpore anschließend wieder abnimmt. ${ }^{50}$ Diese Methode wurde bisher vor allem zur Untersuchung der rein lipidischen Fusion genutzt. So konnte auf diese Weise zum Beispiel gezeigt werden, dass das osmotische Anschwellen eines Vesikels die Fusion fördert. ${ }^{51}$ Auch die Modulation der Fusionseigenschaften durch Zugabe von fusionsbeeinflussenden Substanzen kann durch die Zugänglichkeit beider Membranseiten sehr leicht analysiert werden. ${ }^{8}$ Der bedeutendste Nachteil dieses Systems besteht jedoch in der geringen Stabilität und daraus resultierenden schlechteren Reproduzierbarkeit der Experimente. $^{48}$

\section{Porenüberspannende Membranen:}

Die Vorteile von freitragenden und festkörperunterstützten Membranen in einem artifiziellen Membransystem zu kombinieren, um die jeweiligen Nachteile der bestehenden Modelle zu bewältigen, stand bei der Entwicklung der porenüberspannenden Membranen im Fokus. Die Grundlage für diesen biomimetischen Aufbau bilden poröse Aluminiumoxid- bzw. Siliziumsubstrate. Die Membranen überspannen in diesem System die Poren der siebartigen Strukturen, deren Durchmesser in einem Bereich von $60 \mathrm{~nm}$ bis $1.2 \mu \mathrm{m}$ variieren (Abb. 1.7).
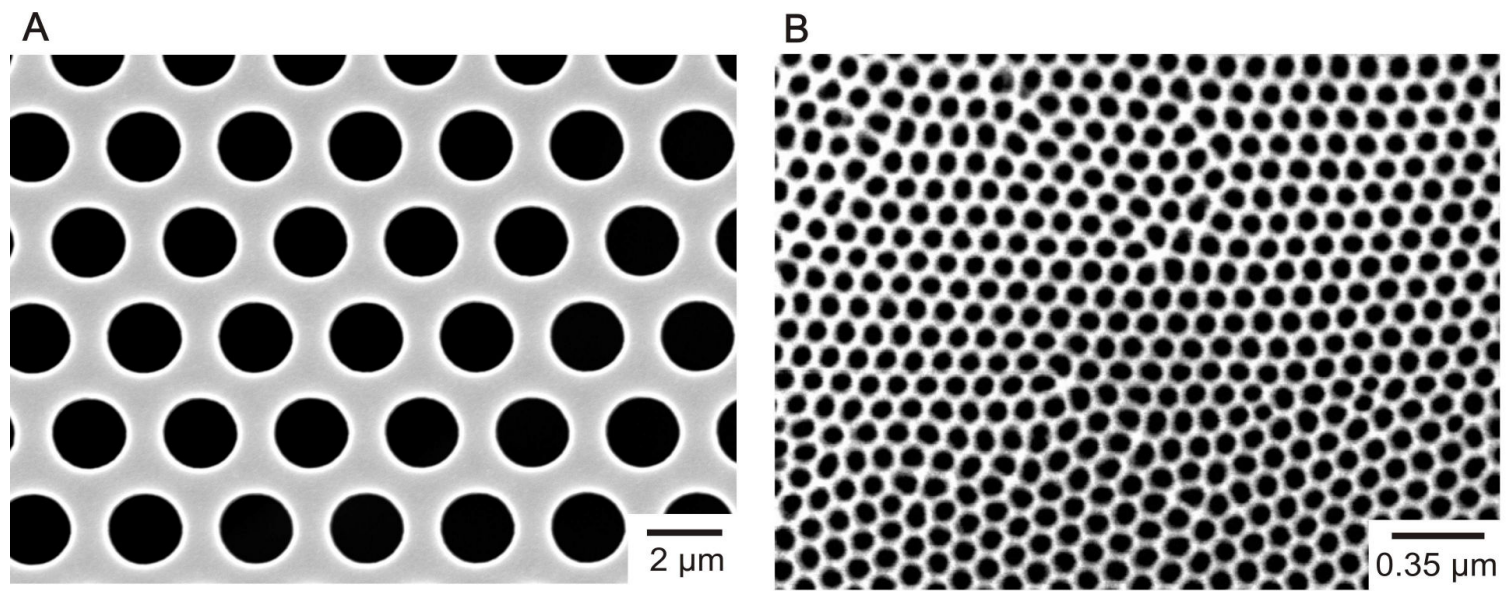

Abb. 1.7 Rasterelektronenmikroskopische Aufnahmen eines porösen Silizium-Substrats (A) mit einem Porendurchmesser von $d=2 \mu \mathrm{m}$ und eines porösen Aluminiumoxid-Substrats (B) mit einem Porendurchmesser von $d=60 \mathrm{~nm} .^{52}$ 
Für die Herstellung einer porenüberspannenden Lipiddoppelschicht werden die Substrate hydrophobisiert. Dies geschieht durch Aufbringen einer dünnen Titanschicht als Haftvermittler und einer Goldschicht sowie durch anschließende Chemisorption eines Thiolipids (Abb. 1.8). Die Ausbildung der Membran kann anschließend durch zwei etablierte Techniken erreicht werden.

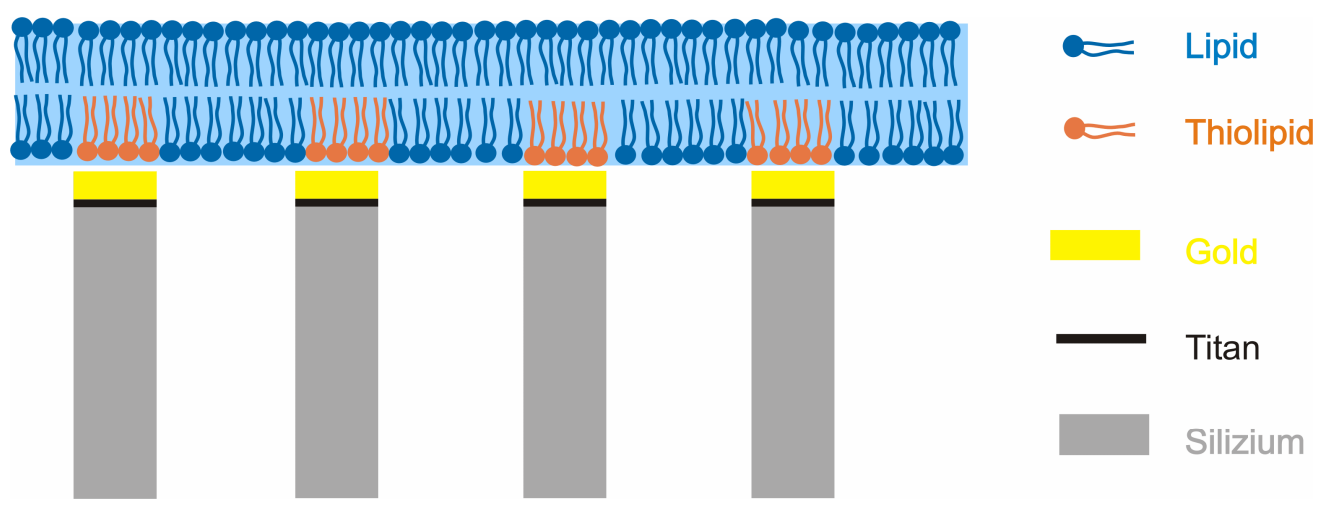

Abb. 1.8 Schematische Darstellung des Aufbaus von porenüberspannenden Membranen.

Zum einen wurde die Präparation aus Lipiden gelöst in einem organischen Lösungsmittel aus der von BLMs bekannten Painting-Technik abgeleitet. ${ }^{53-55}$ Der Nachteil dieser Methode liegt in dem Lösungsmittel, das $\mathrm{zu}$ Teilen in den porenüberspannenden Membranen verbleibt und einen erheblichen Einfluss auf die Eigenschaften der Membranen haben kann. Dementsprechend wurde zum anderen die Technik des Spreitens von Vesikeln auf den porösen Substraten etabliert. ${ }^{56}$

In verschiedenen Arbeiten wurde gezeigt, dass diese Art von Doppelschichten isolierende Schichten bilden, ${ }^{53,57}$ in denen die Lipide eine ähnliche laterale Mobilität zeigen, wie die Lipide von freitragenden Membranen und eine wesentlich höhere Mobilität als bei festkörperunterstützten Membranen. ${ }^{58}$ Außerdem wurde in diesen Studien die hohe Stabilität der porenüberspannenden Membranen nachgewiesen. Dieses neuartige biomimetische System wurde bis jetzt vor allem zur Charakterisierung von Ionenkanälen erfolgreich eingesetzt. ${ }^{59-62}$ Zur Untersuchung von Fusionsprozessen wurde der Aufbau der porenüberspannenden Membranen noch nicht genutzt. 


\subsection{SNARE-mimetische Fusionssysteme}

Maßgeblich zum heutigen Wissenstand über die Fusion von Lipiddoppelschichten hat die Untersuchung der $\mathrm{Ca}^{2+}$-vermittelten Interaktion mit Membranen, die negativ geladene Lipide enthalten, beigetragen. Um den Fusionsprozess und die genaue Rolle der SNAREProteine darin $\mathrm{zu}$ verstehen, wurden in der Vergangenheit immer häufiger SNAREanaloge Strukturen genutzt, um den Einfluss verschiedener struktureller Motive auf die Fusion zu analysieren. Dabei findet die Verbrückung zweier Lipiddoppelschichten durch Hybridisierung von DNA-Einzelsträngen ${ }^{63,} 64$ ebenso Anwendung wie SNAREmimetische Peptide, sich dadurch auszeichnen, dass sie ähnlich den SNARE-Proteinen eine coiled-coil-Struktur ausbilden können. Auf diese Weise kann der nahe Kontakt und die Fusion zwischen zwei Lipiddoppelschichten realisiert wird. ${ }^{65}$ In der vorliegenden Arbeit wurden zwei unterschiedliche Systeme analysiert, um Einflüsse der molekularen Erkennung auf den Fusionsmechanismus zu untersuchen. Zum einen wurde die LigandRezeptor-Wechselwirkung zwischen funktionalisierten Lipiden in der Membran und dem Nonapeptid $\mathrm{H}_{6}$ WGC genutzt, zum anderen wurde die Hybridisierung von PNAEinzelsträngen zur Verknüpfung von zwei Lipiddoppelschichten eingesetzt. Die beiden unterschiedlichen verwendeten Systeme zeichnen sich dadurch aus, dass beide die molekulare Erkennung außerhalb der Membran vermitteln. Sie unterscheiden sich gleichzeitig jedoch dadurch, dass die PNA-Peptide zusätzlich über einen Transmembrananker einen direkten Einfluss innerhalb der Lipiddoppelschicht ausüben.

Die Wechselwirkung von zwei Membranen vermittelt durch die Ligand-RezeptorInteraktion des Nonapeptids $\mathrm{H}_{6}$ WGC, dessen Aminosäuresequenz in Abb. 1.9 gezeigt ist, mit funktionalisierten Lipiden wurde erstmals von Schuy et al. beschrieben. ${ }^{66}$ Die SHGruppe des C-terminalen Cystein-Rest kann eine kovalente Bindung zu einem Maleimidfunktionalisierten Lipid aufbauen. Gleichzeitig können die sechs N-terminalen HistidinAminosäuren $\mathrm{Ni}^{2+}$-Ionen komplexieren, die über einen Nitrilotriessigsäure-Rest (NTA) an eine Lipidkopfgruppe gebunden sind. 


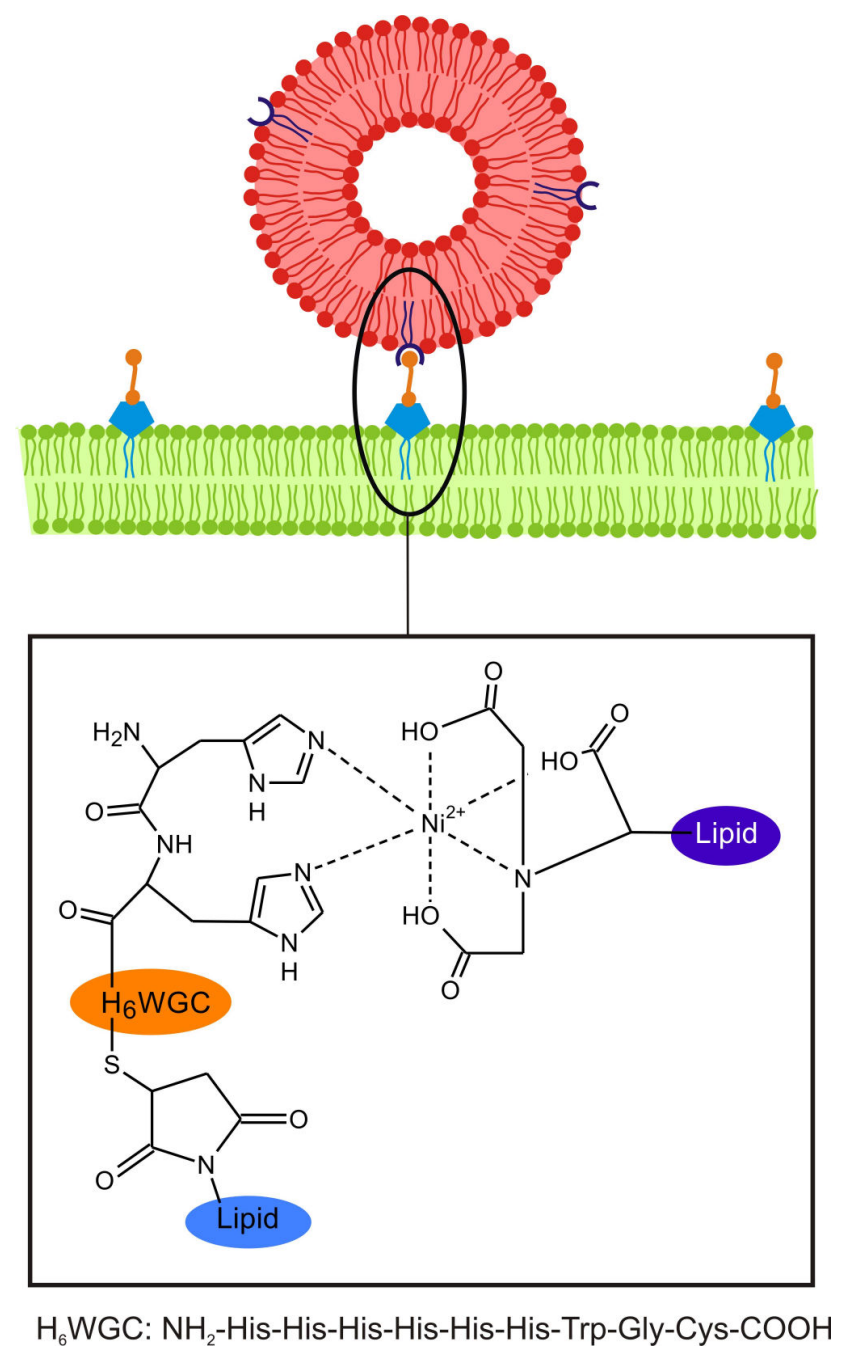

Abb. 1.9 Schematische Darstellung der Interaktion zweier Membranen vermittelt durch das Nonapeptid $\mathrm{H}_{6}$ WGC. Die in grün gezeigte Membran ist mit einem Maleimid-tragenden Lipid funktionalisiert, an welches das Peptid über den C-terminalen Cystein-Rest gebunden ist. Die Verbrückung zur zweiten, in rot dargestellten Membran erfolgt über die Komplexierung des $\mathrm{Ni}^{2+}$-Ions durch den N-terminalen His-tag des Peptids.

Auf diese Weise entsteht eine enge Verküpfung zwischen einer Maleimid- und einer NiNTA-funktionalisierten Membran. Lorenz et al. zeigten erstmals, dass dieses System der molekularen Erkennung auch fusogene Eigenschaften hat ${ }^{67}$, die in dieser Arbeit näher analysiert werden sollen.

Die Basenpaarung von zwei DNA-Einzelsträngen wird genutzt, um die Verbindung von zwei Membranen durch den SNARE-Komplex zu imitieren. Durch den Einbau von komplementären DNA-Einzelsträngen in zwei unterschiedliche Membranen können diese in engen Kontakt miteinander gebracht werden, wenn die DNA-Stränge zu einem Doppelstrang hybridisieren und so ähnlich dem bei SNARE-Proteinen beobachteten 
Reißverschluss-Mechanismus die Annäherung der Lipiddoppelschichten vermitteln. Dazu wurden zwei Vesikel durch Hybridisierung von DNA-Einzelsträngen verbrückt. ${ }^{63}$, ${ }^{64}$ Die DNA mit 12 - 42 ungepaarten Basen wurde dazu von Chan et al. an Lipide bzw. von Stengel et al. an Cholesterin gekoppelt und in die Membran eingebaut. Die Untersuchungen zeigten jeweils, dass die Kinetik des Fusionsprozesses von der Anzahl der DNA-Einzelstränge im Vesikel und von der Sequenz der DNA abhängig ist. In dieser Arbeit wurde die Hybridisierung von PNA (Peptid-Nukleinsäuren, peptide nucleic acid) in analoger Weise wie die oben beschriebene Paarung von DNA-Einzelsträngen zur molekularen Erkennung genutzt. PNA setzt sich aus den vier Nukleobasen Adenin, Cytosin, Guanin und Thymin zusammen, die nicht wie im Fall der DNA an ein Ribosephosphodiester-Rückgrat gebunden sind. $^{68}$ Die Basis bilden hierbei Aminoethylglycin-Einheiten, die über Amidbindungen miteinander verknüpft sind (Abb. $1.10)$.

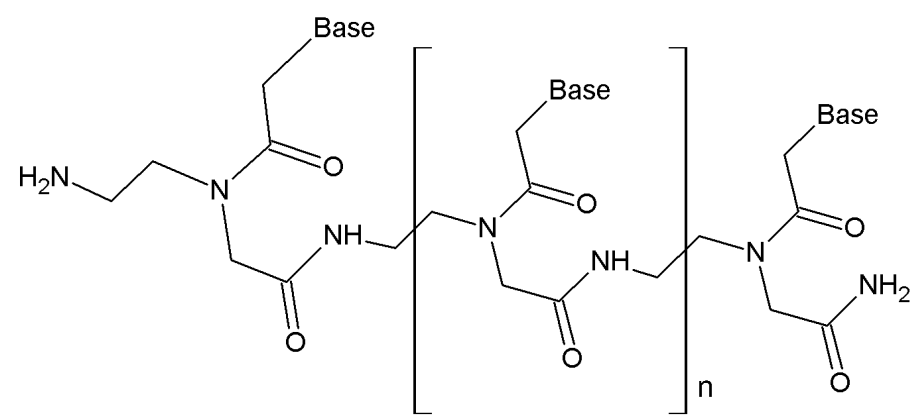

Abb. 1.10 Chemische Struktur eines PNA-Einzelstrangs. Als Basen können die Nukleobasen Adenin, Cytosin, Guanin und Thymin gebunden sein.

Dadurch entsteht ein neutrales pseudopeptidisches Rückgrat, an welches die Basen gebunden sind. Über die Basenpaarung können genau wie bei der DNA zwei komplementäre PNA-Einzelstränge zu einer Duplex zusammengeschlossen werden. Die hybridisierten PNA-Einzelstränge weisen dabei eine höhere Stabilität auf als die DNAAnaloga. In dieser Arbeit wurden PNA-Einzelstränge mit 10 Nukleobasen über die native SNARE-Linker- und Transmembranregion an die Membran angebunden und die fusogenen Eigenschaften untersucht (Abb. 1.11). 


\section{G TA G A T C A C TKR K Y W W K N LKM M IIL G VI CAIILIIIIVYFST}

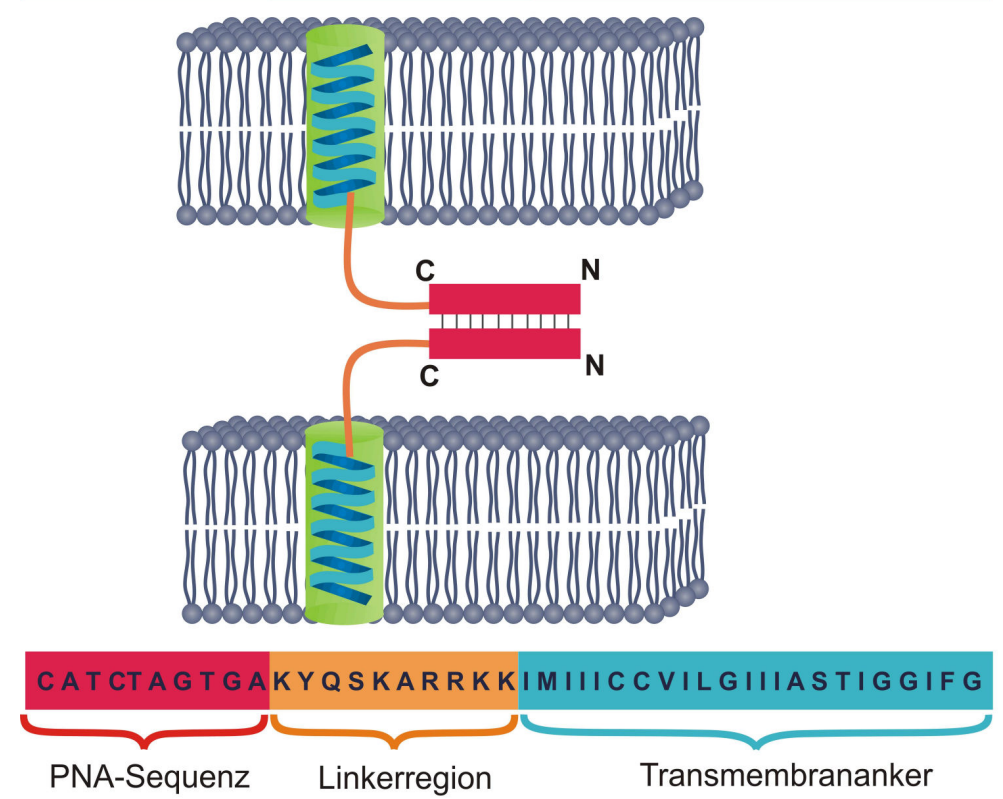

Abb. 1.11 Übersicht über die verwendeten PNA-Peptidkonstrukte und die Verbrückung zweier Membranen durch die PNA-Wechselwirkung. Die PNA-Peptide sind jeweils aus dem nativen Transmembrananker und der entsprechenden Linkerregion eines SNARE-Proteins aufgebaut. An den Linker ist der PNA-Einzelstrang gebunden. Die Basenfolge der beiden gezeigten Einzelstränge ist komplementär zueinander. 


\section{Zielsetzung}

Die Fusion biologischer Membranen stellt eine fundamentale Voraussetzung in vielen Transportprozessen wie zum Beispiel der Neurotransmitterausschüttung am synaptischen Spalt dar. Deshalb wird der exakte Mechanismus, über den die Verschmelzung zweier Lipiddoppelschichten abläuft, intensiv erforscht. Die Untersuchungen basieren dabei häufig auf artifiziellen, biomimetischen Membransystemen, deren Zusammensetzungen und Eigenschaften gut kontrolliert werden können, um gezielt verschiedene Fragestellungen $\mathrm{zu}$ adressieren. Diverse Limitierungen in den unterschiedlichen Anordnungen erschweren jedoch die präzise Verfolgung der einzelnen Intermediate im Fusionsmechanismus.

Porenüberspannende Membranen sind eine vielversprechende Alternative dar, um die Nachteile bestehender Modellmembransysteme zu bewältigen und Vorteile verschiedener etablierter Anordnungen $\mathrm{zu}$ kombinieren. Porenüberspannende Lipiddoppelschichten bieten eine ähnlich hohe Stabilität wie festkörperunterstützte Membranen. Gleichzeitig ist aber ähnlich den freitragenden Membranen die Zugänglichkeit zu zwei wässrigen Kompartimenten auf beiden Seiten der Lipiddoppelschicht gegeben. Dadurch können beide Membranseiten individuell adressiert werden und so Prozesse zum Beispiel unter Einfluss fusionsmodulierender Substanzen untersucht werden. Außerdem sollte durch den Aufbau die simultane Verfolgung der Lipidvermischung und der Ausschüttung des Vesikelinhalts während der Fusion ermöglicht werden. Porenüberspannende Membranen sollten aus diesen Gründen erstmals Anwendung in der Analyse von Fusionsprozessen finden.

Im Fokus dieser Arbeit stand die Etablierung eines neuartigen Assays, der die Untersuchung von Einzelfusionsereignissen mit porenüberspannenden Membranen erlaubt. Die Methode sollte ermöglichen, dass die Lipidvermischung und die Vesikelausschüttung während der Fusion simultan verfolgt werden können. Zusätzlich sollte die Funktionalität des geschaffenen Assays in der Untersuchung von Fusionsprozessen vermittelt durch molekulare Erkennung zweier unterschiedlicher Peptidsysteme unter Beweis gestellt werden. 
- 18 - 


\section{Methoden und Materialien}

\subsection{Fluoreszenzmikroskopie}

Die Fluoreszenzmikroskopie ist eine sehr wichtige Messmethode in der biologischen und biophysikalischen Forschung, da diese nicht-invasive Technik die Sichtbarmachung von Strukturen und Prozessen im Mikrometerbereich ermöglicht, die sonst für das menschliche Auge nicht aufzulösen wären.

\subsubsection{Fluoreszenz}

Fluoreszenz bezeichnet einen Prozess, bei dem ein elektronisch angeregtes Molekül durch spontane Emission eines Photons in seinen Grundzustand zurückkehrt. Die entsprechenden Energieniveaus und mögliche Übergänge zwischen unterschiedlichen Zuständen werden meist in einem sogenannten Jablonski-Diagramm dargestellt (Abb. 3.1 A). ${ }^{69,} 70$ Durch die Absorption eines Photons wird das Molekül aus dem elektronischen Grundzustand $S_{0}$ in den ersten angeregten Zustand $S_{1}$ überführt. Da in diesem Fall die Elektronenanregung auf einer wesentlich schnelleren Zeitskala geschieht als sich die elektronische Veränderung auf den Kern-Kern-Abstand im Molekül auswirken kann, erfolgt dieser Übergang, wie im Schema der Kernpotentialkurven (Abb. 3.1 B) gezeigt, vertikal. Der Übergang vollzieht sich entsprechend dem Franck-CondonPrinzip, das besagt, dass ein Übergang zwischen zwei Zuständen umso wahrscheinlicher ist, je ähnlicher sich die vibronischen Wellenfunktionen der beiden unterschiedlichen Zustände sind. Diese Wahrscheinlichkeit zeigt sich letztendlich in der Intensität eines Übergangs. Je größer der Überlapp der Wellenfunktion des Grundzustands mit der eines Schwingungsniveaus des ersten angeregten Zustands ist, umso intensiver wird dieser Übergang erscheinen. Demnach entspricht die Wellenlänge des Absorptionsmaximums im Spektrum eines fluoreszierenden Moleküls der Energie des wahrscheinlichsten Übergangs vom Grund- in den ersten angeregten Zustand. 

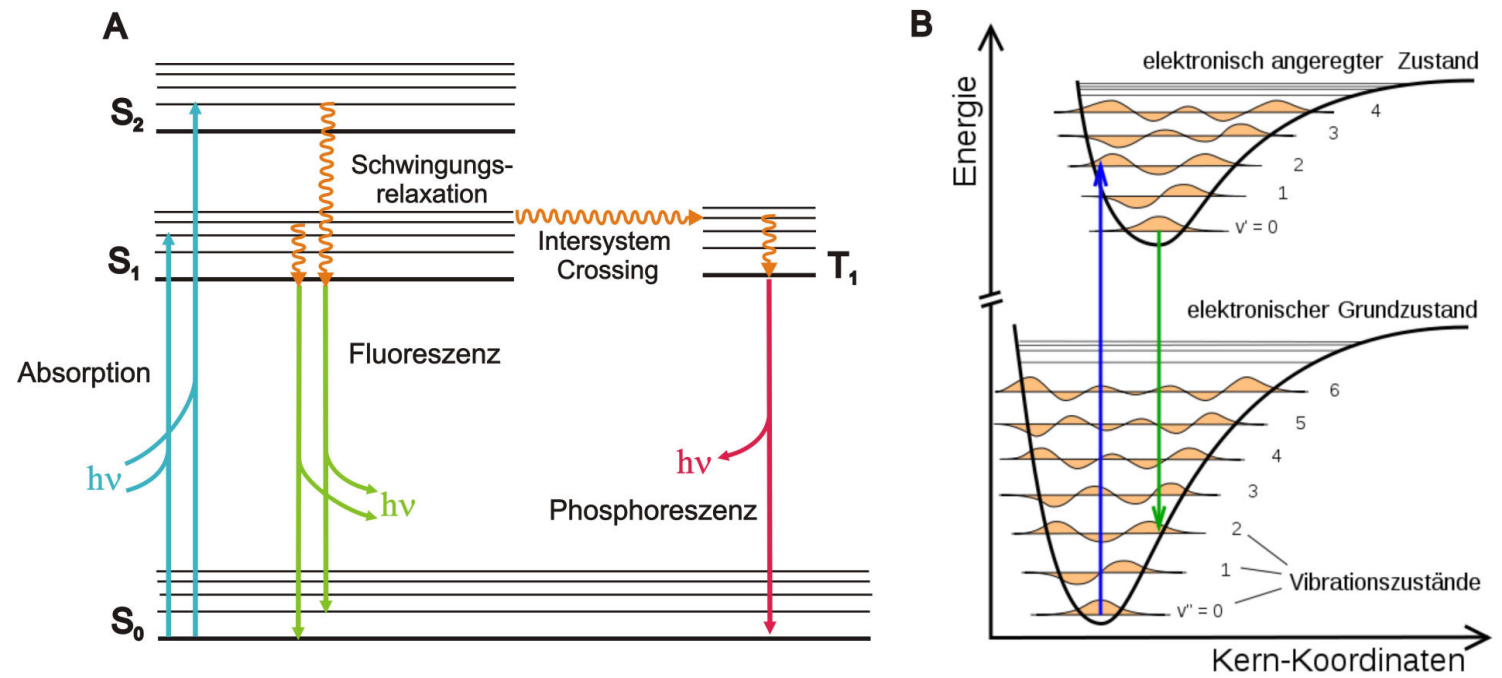

\begin{abstract}
Abb. 3.1 A Darstellung der möglichen strahlenden und strahlungslosen Übergänge zwischen den Energieniveaus $\mathrm{S}_{0}, \mathrm{~S}_{1}, \mathrm{~S}_{2}$ und den dazugehörigen Schwingungszuständen im Jablonski-Diagramm. B Darstellung der Kernpotentialkurven des elektronischen Grundzustandes und des elektronisch angeregten Zustandes. ${ }^{71}$
\end{abstract}

Aus dem entsprechenden Schwingungsniveau des $S_{1}$-Zustands erfolgt anschließend die Schwingungsrelaxation (internal conversion). Darunter wird die strahlungslose Abgabe von Energie verstanden, die durch Stöße mit anderen Molekülen erfolgt und dazu führt, dass das Molekül in den Schwingungsgrundzustand des ersten elektronisch angeregten Zustands übergeht. Der Energiebetrag, der jetzt noch im angeregten Molekül vorhanden ist, kann nicht weiter von der Umgebung aufgenommen werden. Dementsprechend erfolgt die Abregung zurück in den Grundzustand durch die spontane Emission eines Photons, dem Fluoreszenzlicht. Das emittierte Licht besitzt dabei eine höhere Wellenlänge als das absorbierte Licht, da ein Teil der Energie bereits durch die Schwingungsrelaxation an die Umgebung abgegeben wurde. Diese Verschiebung des Emissionsspektrums zu höheren Wellenlängen wurde erstmals im Jahr 1852 von Stokes beschrieben und ist als sogenannter Stokes-Shift bekannt ${ }^{69}$. Auch bei der Emission ist die Wahrscheinlichkeit für einen Übergang proportional zur Ähnlichkeit der Wellenfunktionen der jeweiligen Schwingungszustände, weil auch hier das FranckCondon-Prinzip gilt. Da zusätzlich im Fall der Emission für die meisten Moleküle ähnliche Übergänge favorisiert sind wie für die Absorption, verhalten sich Absorptionsund Emissionsspektrum meist spiegelbildlich zueinander und sind im Spektrum nur um den Stokes-Shift verschoben. 


\subsubsection{Fluoreszenzmikroskopie}

Mit Hilfe der Mikroskopie können Objekte abgebildet werden, deren Größe unter dem Auflösungsvermögen des menschlichen Auges liegt. Eine besondere Form stellt hierbei die Fluoreszenzmikroskopie dar, bei der das Phänomen der Fluoreszenz genutzt wird, um Strukturen im Mikroskop sichtbar zu machen. Dabei wird unterschieden zwischen der Epifluoreszenzmikroskopie und der Konfokalmikroskopie.

\section{Epifluoreszenzmikroskopie:}

Im Fall der Weitfeldmikroskopie wird das Licht einer Quecksilberdampf- oder Xenonlampe durch das Objektiv des Mikroskops auf die Probe fokussiert und somit die Fluoreszenz der Probe angeregt. Der schematische Aufbau eines Epifluoreszenzmikroskops ist in Abb. 3.2 gezeigt.

Das kontinuierliche Spektrum des Anregungslichts passiert zuerst den Anregungsfilter, der nur für den Wellenlängenbereich durchlässig ist, in dem die Probe Licht absorbiert. Anschließend trifft der Strahl auf einen Strahlteiler. Dabei handelt es sich um einen dichroitischen Spiegel, der kürzere Wellenlängen reflektiert und für längere Wellenlängen durchlässig ist. Der Strahlteiler leitet das Licht auf die Probe, dessen Fluoreszenz dadurch angeregt wird. Das emittierte Fluoreszenzlicht gelangt durch das Objektiv zurück zum dichroitischen Spiegel, der dieses durch den Stokes-Shift längerwellige Licht transmittiert. Der dahinterliegende Emissionsfilter garantiert, dass nur das Fluoreszenzlicht des gewählten Wellenlängenbereichs und kein Streulicht das Okular bzw. den Detektor erreicht. 


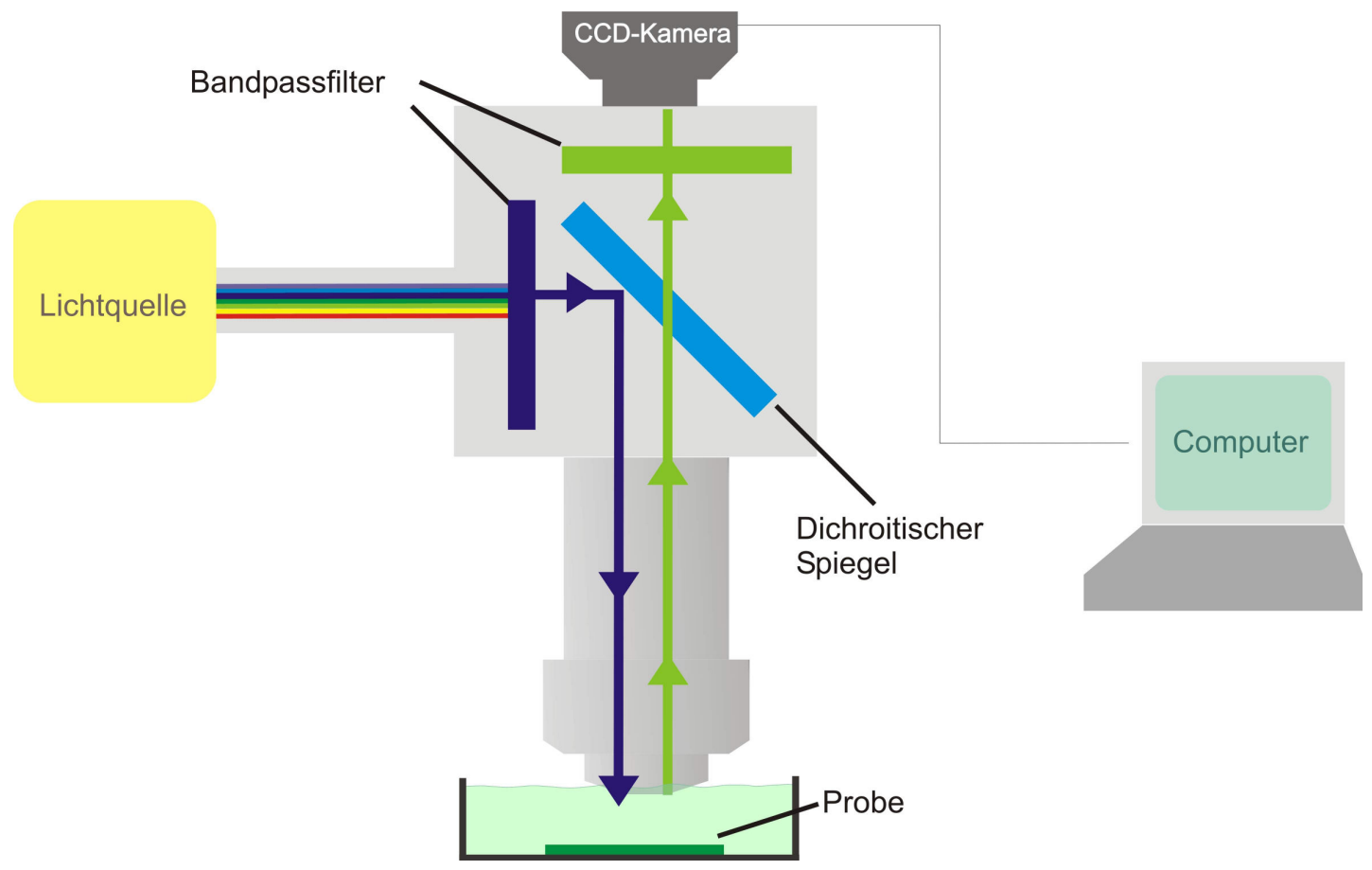

Abb. 3.2 Schematischer Aufbau und Strahlengang eines Epifluoreszenzmikroskops.

In der Natur sind häufig autofluoreszierende Strukturen zu finden. In dieser Arbeit wurde hingegen mit einem biomimetischen System gearbeitet, in dem lediglich Lipide und einfache Peptide verwendet wurden, die keine eigene Fluoreszenz zeigen. Aus diesem Grund wurden die Membranen mit fluoreszenzmarkierten Lipiden dotiert und auf diese Weise sichtbar gemacht. Auf die genaue Struktur und Auswahl der markierten Lipide wird in Kapitel 3.1.3 näher eingegangen.

Die Auflösung eines Epifluoreszenzmikroskops ist im Wesentlichen durch das AbbéLimit begrenzt. ${ }^{72}$ Die Beugung des Lichts an den optischen Komponenten des Mikroskops führt dazu, dass die Auflösungsgrenze bei etwa der Hälfte der Wellenlänge des beobachteten Lichts liegt. Dementsprechend beleuchtet der Lichtstrahl, der durch das Objektiv auf die Probe fokussiert wird, nicht einen beliebig kleinen Punkt, sondern einen gewissen Ausschnitt der Probe. Auf diese Weise wird auch ein Teil der Fluoreszenz außerhalb des Fokus angeregt. Dies verschlechtert die Bildqualität besonders, da optische Information auch aus den Ebenen ober- und unterhalb der Fokusebene den Detektor erreicht. Das heißt, dass sich das Fluoreszenzbild aus einer scharfen Abbildung aus der Fokusebene und unscharfen Abbildungen der Bildpunkte ober- und unterhalb der Brennebene zusammensetzt, wodurch das Erkennen von optischen Details erschwert ist. 


\section{Konfokalmikroskopie:}

Den Grundstein zur Verbesserung der Auflösung in der optischen Mikroskopie legte Minsky 1955 mit dem grundlegenden Konzept zur Entwicklung der Konfokalmikroskopie. ${ }^{73}$ Der Strahlengang eines Konfokalmikroskops unterscheidet sich im Wesentlichen von dem eines Weitfeldmikroskops durch die Einführung von zwei Lochblenden. Des Weiteren wird anstatt einer Quecksilberdampflampe das stärkere, kohärente Licht eines Lasers zur Beleuchtung der Probe genutzt.

Zuerst passiert das Laserlicht die erste Lochblende. Diese ist konfokal mit dem fokussierten Punkt auf der Probe und der zweiten Lochblende, die vor dem Detektor positioniert ist (Abb. 3.3). Der Begriff konfokal bedeutet, dass die Brennpunkte des Objektivs und die der beiden Lochblenden übereinstimmen. Mit diesem Prinzip lässt sich die Tiefenschärfe der Abbildung deutlich verbessern, da die Hintergrundfluoreszenz auf zwei Arten vermindert wird.

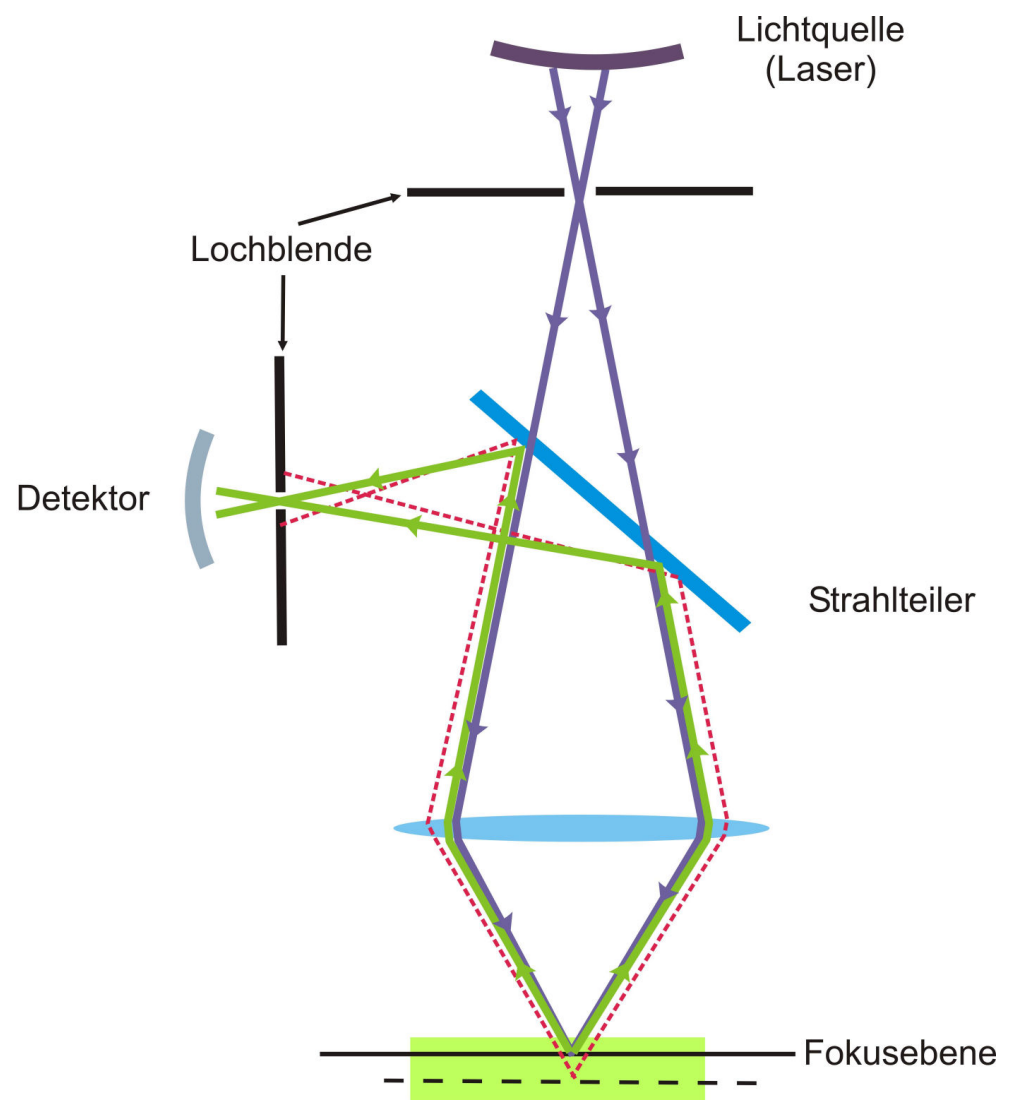

Abb. 3.3 Aufbau und Prinzip des Strahlengangs eines Konfokalmikroskops. Das Laserlicht passiert die erste Lochblende bevor es auf die Probe fokussiert wird. Die resultierende Fluoreszenzstrahlung wird auf die zweite Lochblende vor dem Detektor fokussiert. 
Zum einen wird ein kleinerer Bereich der Probe durch den fokussierten Laser beleuchtet, so dass die Beleuchtungsintensität außerhalb des Fokus geringer ist als bei einem Weitfeldmikroskop. Zum anderen ist ein Großteil der Fluoreszenz, die aus den Ebenen ober- und unterhalb der Brennebene kommt, nicht konfokal zu der Lochblende vor dem Detektor. Dadurch kann zwar das Fluoreszenzlicht von Strukturen, die nicht im Fokus liegen, die Lochblende erreichen; weil es jedoch nicht auf die Lochblende fokussiert ist, gelangt nur ein sehr geringer Teil dieser Emission auf den Detektor.

Da im Fall des Konfokalmikroskops im Gegensatz zum Weitfeldmikroskop nur ein Punkt der Probe beleuchtet wird, setzt sich ein Konfokalmikroskopbild aus einzelnen Bildpunkten zusammen, die abgerastert werden, indem das Laserlicht durch einen Spiegel nacheinander auf die verschiedenen Bildpunkte gelenkt wird. Aus diesem Grund wird diese Art der Mikroskopie auch als konfokale Laserrastermikroskopie (confocal laser scanning microscopy, CLSM) bezeichnet. Einen besonderen Vorteil der Konfokalmikroskopie stellt die signifikant verbesserte Auflösung entlang der optischen Achse dar. Diese ermöglicht ein Rastern der verschiedenen z-Ebenen eines Objekts und damit eine gute 3D-Illustration der Probe.

In dieser Arbeit wurde das Konfokalmikroskop LSM 710 (Carl Zeiss GmbH, Jena, Deutschland) verwendet. Die Aufnahmen wurden mit einem Tauchobjektiv mit 63 facher Vergrößerung und einer numerischen Apertur von 1.0 (W Plan-Apochromat, Carl Zeiss $\mathrm{GmbH}$, Jena, Deutschland) erhalten.

In den durchgeführten Fusionsexperimenten wurde ein Argon-Ionen-Laser mit einer Wellenlänge von $\lambda_{\mathrm{ex}}=488 \mathrm{~nm}$ genutzt, um die Fluoreszenz anzuregen. Die Emission wurde spektral getrennt und für Oregon Green DHPE in einem Bereich von $\lambda_{\text {em }}=500-$ $560 \mathrm{~nm}$ detektiert, während die Texas Red-Fluoreszenz bei $\lambda_{\mathrm{em}}=600-680 \mathrm{~nm}$ aufgenommen wurde. In Anwesenheit von Pyranin wurden zur Anregung drei verschiedene Laser benutzt, ein Diodenlaser mit einer Wellenlänge von $\lambda_{\mathrm{ex}}=405 \mathrm{~nm}$, ein Argon-Ionen-Laser mit einer Wellenlänge von $\lambda_{\mathrm{ex}}=488 \mathrm{~nm}$ und ein DPSS-Laser mit einer Wellenlänge von $\lambda_{\mathrm{ex}}=561 \mathrm{~nm}$. Das Fluoreszenzlicht wurde bei folgenden Wellenlängen detektiert: $\lambda_{\mathrm{em}}=430-510 \mathrm{~nm}$ (Pyranin), $\lambda_{\mathrm{em}}=515-554 \mathrm{~nm}$ (Oregon Green) und $\lambda_{\mathrm{em}}=660-750 \mathrm{~nm}$ (Texas Red). Nach Zugabe der Vesikellösung (Kapitel 3.4.6) wurden Zeitserien, sofern nicht anders angegeben, mit einer Zeitauflösung von 115 - $156 \mathrm{~ms}$ aufgenommen. 


\subsubsection{Fluoreszenzsonden}

Wie in Kapitel 3.1.2 beschrieben, wurden die verwendeten Membranen, mit fluorophormarkierten Lipiden dotiert, um sie für die Fluoreszenzmikroskopie sichtbar zu machen. Dazu wurde zum einen Texas Red DHPE (Texas Red 1,2-Dihexadecanoyl-snglycero-3-phosphoethanolamin, Abb. 3.4) verwendet, das in die Vesikelmembran eingebaut wurde. Dabei handelt es sich um ein synthetisches Phospholipid, das an der Kopfgruppe den Fluorophor Sulforhodamin 101 trägt.

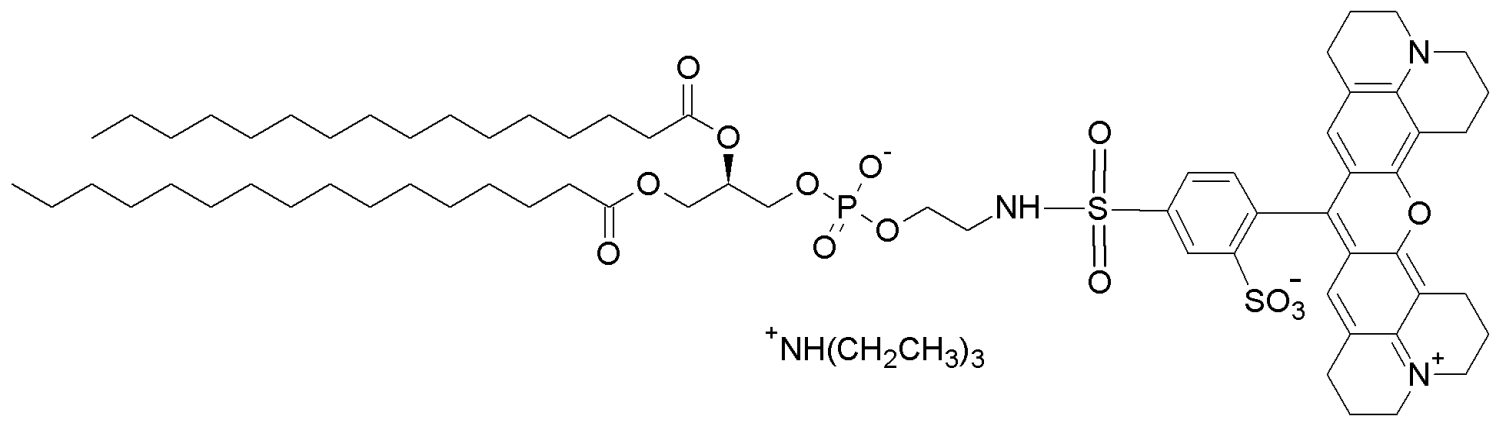

Abb. 3.4 Strukturformel von Texas Red DHPE (Triethylammonium-Salz), $\mathrm{C}_{74} \mathrm{H}_{117} \mathrm{~N}_{4} \mathrm{PS}_{2}$, $\mathrm{M}=1381.84 \mathrm{~g} / \mathrm{mol}$.

Das Absorptions- bzw. Emissionsmaximum von Texas Red DHPE liegt bei $\lambda_{\mathrm{ex}}=584 \mathrm{~nm}$ bzw. $\lambda_{\mathrm{em}}=607 \mathrm{~nm}$.

Zum anderen wurde die porenüberspannende Membran mit Oregon Green DHPE (Oregon Green 1,2-Dihexadecanoyl-sn-glycero-3-phosphoethanolamin, Abb. 3.5) markiert, einem Phospholipid, das an der Kopfgruppe ein Fluoresceinderivat trägt.

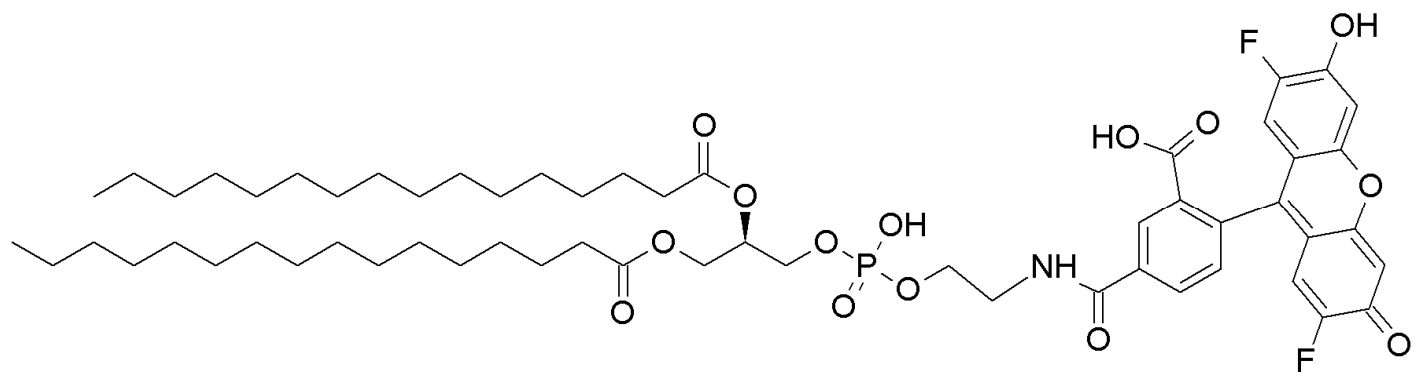

Abb. 3.5: Strukturformel von Oregon Green DHPE, $\mathrm{C}_{58} \mathrm{H}_{82} \mathrm{~F}_{2} \mathrm{O}_{14} \mathrm{P}, \mathrm{M}=1086.25 \mathrm{~g} / \mathrm{mol}$. 
Das Absorptionsmaximum von Oregon Green DHPE liegt bei $\lambda_{\mathrm{ex}}=496 \mathrm{~nm}$ und die maximale Emission bei $\lambda_{\mathrm{em}}=534 \mathrm{~nm}$. Die Spektren beider Fluorophore sind in Kapitel 3.1.4 aufgeführt.

Neben Lipid-gekoppelten Farbstoffen zur Dotierung der Membran wurde ein wasserlöslicher Farbstoff genutzt, um den Inhalt der Vesikel detektieren zu können. Dazu wurde Pyranin (Hydroxypyrentrisulfonsäure, HPTS) verwendet, das sich durch eine hohe Wasserlöslichkeit auszeichnet und nicht membrangängig ist. Dementsprechend wurde der Farbstoff bereits in anderen Fusionsexperimenten eingesetzt. ${ }^{74,75}$ Die Struktur und das Spektrum des Farbstoffs sind in Abb. 3.6 gezeigt. Das Emissionsmaximum liegt bei $\lambda_{\text {em }}=511 \mathrm{~nm}$. Die Absorption von Pyranin ist pH-abhängig; die beiden Absorptionsmaxima liegen in den in dieser Arbeit durchgeführten Experimenten bei einem $\mathrm{pH}-$ Wert von 7.4 bei $\lambda_{\mathrm{ex}}=405 \mathrm{~nm}$ und $\lambda_{\mathrm{ex}}=451 \mathrm{~nm}$.

A<smiles>O=S(=O)([O-])c1cc(O)c2ccc3c([Se][Na])cc(S(=O)(=O)[O-])c4ccc1c2c34</smiles>

B

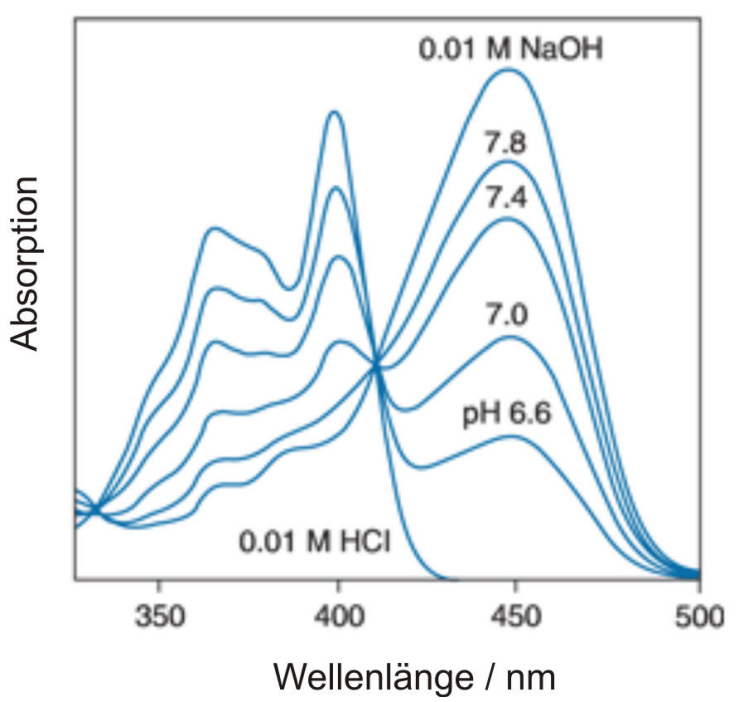

Abb. 3.6 A Strukturformel von Pyranin, $\mathrm{C}_{16} \mathrm{H}_{7} \mathrm{Na}_{3} \mathrm{O}_{10} \mathrm{~S}_{3}, \mathrm{M}=524.38 \mathrm{~g} / \mathrm{mol}$. B Spektren der PyraninAbsorption bei verschiedenen $\mathrm{pH}-$ Werten. ${ }^{76}$

\subsubsection{Förster Resonanz Energie Transfer (FRET)}

Der Förster Resonanz Energie Transfer (FRET) bezeichnet die strahlungslose Übertragung von Energie eines angeregten Farbstoffmoleküls (Donor) auf einen zweiten, nicht angeregten Farbstoff (Akzeptor). ${ }^{77}$ Dies bedeutet, dass die vom Donor absorbierte Lichtenergie in diesem Fall nicht als Fluoreszenzlicht abgegeben wird, sondern über Dipol-Dipol-Wechselwirkungen an den unangeregten Akzeptorfarbstoff transferiert wird. 
Dieser Vorgang ist in dem in Abb. 3.7 gezeigten Jablonski-Diagramm veranschaulicht. Zunächst erfolgt die Anregung des Donormoleküls durch Absorption in den ersten angeregten Zustand $\left(\mathrm{S}_{1}\right)$. Nach Abgabe eines gewissen Anteils der Energie durch Schwingungsrelaxation erfolgt keine spontane Emission, sondern der strahlungslose Transfer der Energie auf das im Grundzustand $\left(\mathrm{S}_{0}\right)$ befindliche Akzeptormolekül. Dieses wird dadurch in seinen ersten angeregten Zustand $\left(S_{1}\right)$ versetzt. Nach einer Abregung durch Schwingungsrelaxation wird die Energie vom Akzeptormolekül durch die spontane Emission von Photonen abgegeben. Als Konsequenz des FRET erfolgen also eine Löschung der Donorfluoreszenz und eine Aktivierung der Akzeptorfluoreszenz.

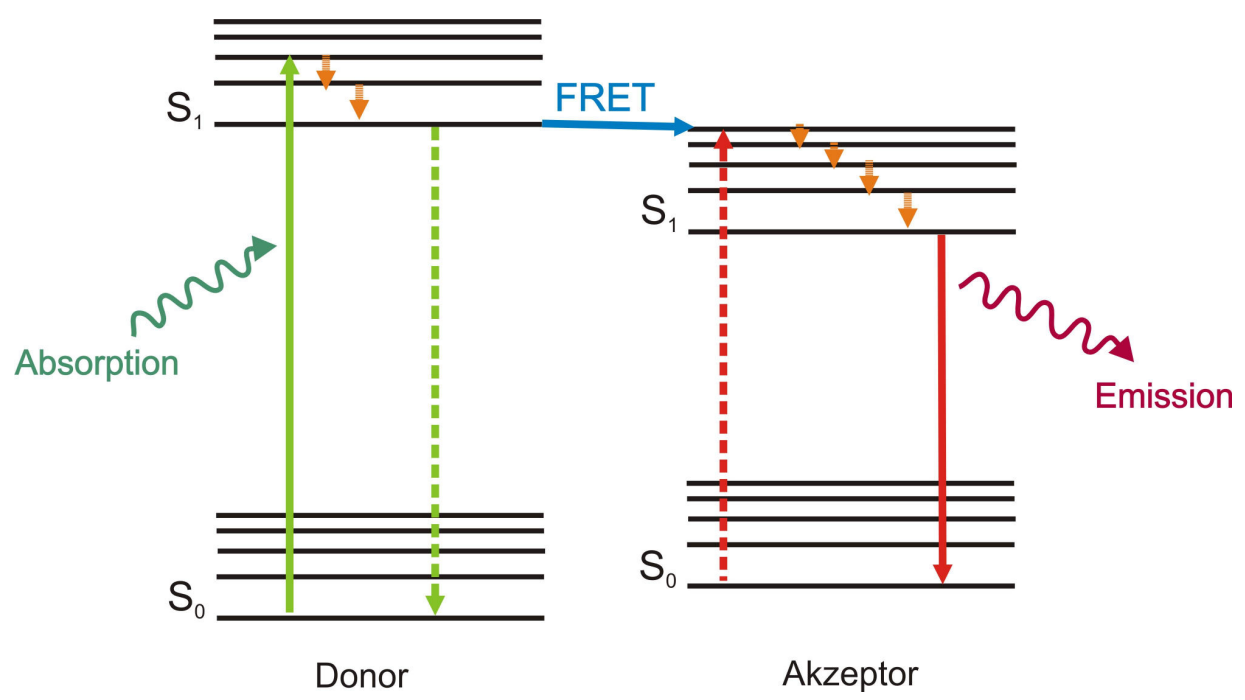

Abb. 3.7 Jablonski-Diagramm zur Veranschaulichung des FRET zwischen Donor und Akzeptor.

Damit ein Energietransfer stattfinden kann, muss die vom Donor abgegebene Energie in etwa der Energie entsprechen, die nötig ist, um den Akzeptor vom $\mathrm{S}_{0}$-Zustand in den $\mathrm{S}_{1^{-}}$ Zustand anzuregen. Dies ist gewährleistet, wenn das Emissionspektrum des Donorfarbstoffs signifikant mit dem Absorptionsspektrum des Akzeptormoleküls überlappt. Wie in dem Spektrum in Abb. 3.8 gezeigt, ist diese Bedingung im Fall der verwendeten Farbstoffe Oregon Green DHPE und Texas Red DHPE erfüllt. Bei dem vorliegenden FRET-Paar stellt dementsprechend Oregon Green den Donor und Texas Red den Akzeptor dar. 


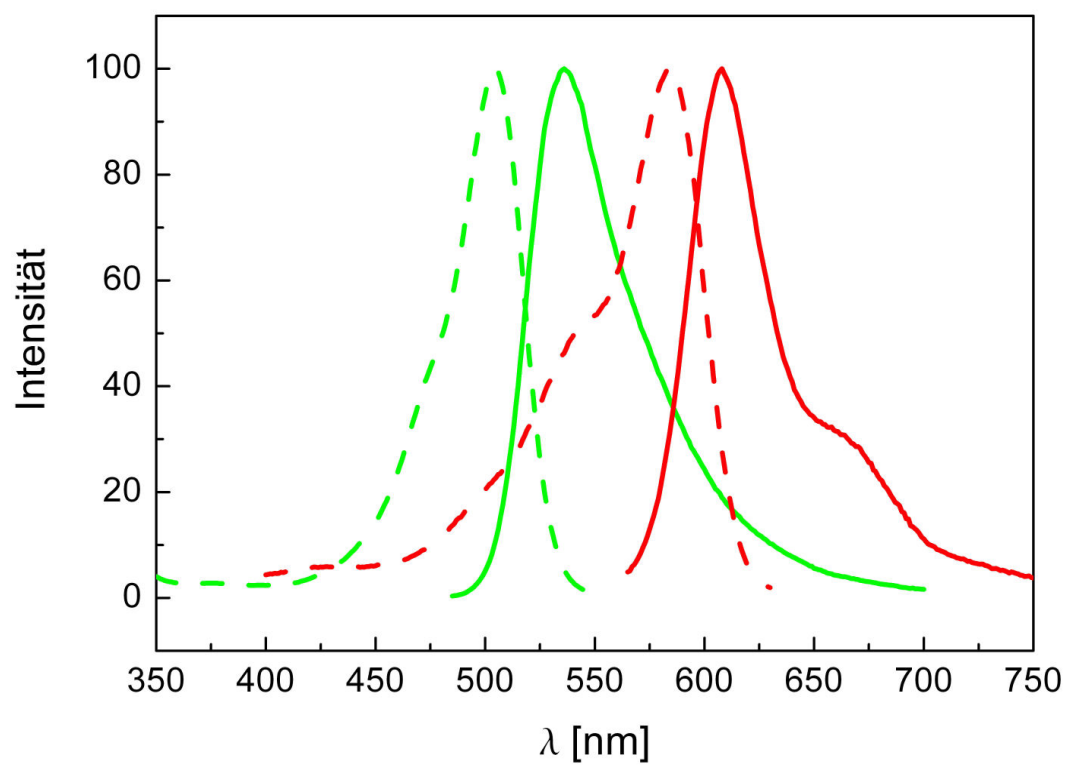

Abb. 3.8 Spektren der Farbstoffe Oregon Green DHPE (grün) und Texas Red DHPE (rot). Die gestrichelten Linien zeigen die Absorptionsspektren, während die durchgezogenen Linien die Emissionsspektren anzeigen. Die Emissionsbande des Oregon Green-Farbstoffs überlappt deutlich mit der Absorption des Texas Red-Farbstoffs, so dass die spektrale Voraussetzung für einen FRET gegeben ist.

Der wichtigste Parameter für das Auftreten des FRET-Effekts ist der Abstand von Donorund Akzeptormolekül. Dabei wird der Anteil der vom Donor absorbierten Photonen, deren Energie auf den Akzeptor übertragen wird, also die Rate des Energietransfers, als FRET-Effizienz bezeichnet. Im Fall der Wechselwirkung eines einzelnen Akzeptors pro Donor, nimmt die FRET-Effizienz mit der sechsten Potenz des Abstands zwischen Akzeptor und Donor ab:

$$
E=1-\left(\frac{F_{D A}}{F_{D}}\right)=\frac{1}{1+\left(\frac{R}{R_{0}}\right)^{6}}
$$

$E$ steht für die FRET-Effizienz und $R$ ist der Abstand zwischen Donor und Akzeptor. Die Parameter $F_{\mathrm{D}}$ und $F_{\mathrm{DA}}$ geben die Fluoreszenzintensität des Donor-Farbstoffs in Ab- und Anwesenheit des Akzeptors an. Der Förster-Radius $R_{0}$ ist charakteristisch für jedes FRET-Paar und entspricht dem Abstand, bei dem die FRET-Effizienz genau 50\% beträgt. 
Der Förster-Radius für Oregon Green und Texas Red wurde bisher nicht experimentell bestimmt, kann aber mit Hilfe von Gleichung 3-2 berechnet werden:

$$
R_{0}=2.108 \cdot\left(\kappa^{2} \cdot Q_{\mathrm{D}} \cdot n^{-4} \cdot J(\lambda)\right)
$$

Dabei beschreibt der Faktor $\kappa$ die relative räumliche Orientierung der Übergangsdipolmomente von Donor und Akzeptor zueinander. $\kappa^{2}$ ist definiert als:

$$
\kappa^{2}=(\cos \alpha-3 \cos \beta \cos \gamma)^{2}
$$

wobei $\alpha$ für den Winkel zwischen den Übergangsdipolmomenten von Donor und Akzeptor steht, $\beta$ für den Winkel zwischen dem Donor-Dipolmoment und dem Radialvektor und $\gamma$ für den Winkel zwischen dem Akzeptor-Dipolmoment und dem Radialvektor. Unter der Annahme, dass die Dipole schneller rotieren als die Lebenszeit des angeregten Zustands des Donors ist, kann für $\kappa^{2}$ ein Wert von 2/3 angenommen werden.

$Q_{\mathrm{D}}$ in G1. 3-2 ist die Quantenausbeute des Donors in Abwesenheit des Akzeptors. Der Brechungsindex $n$ des Mediums beträgt für Biomoleküle in wässriger Lösung 1.4. $J(\lambda)$ bezeichnet den spektralen Überlapp des Emissionsspektrums des Donors mit dem Absorptionsspektrum des Akzeptors und ist definiert als:

$$
J(\lambda)=\frac{\int_{0}^{\infty} F_{\mathrm{D}}(\lambda) \varepsilon(\lambda) \lambda^{4} \mathrm{~d} \lambda}{\int_{0}^{\infty} F_{\mathrm{D}}(\lambda) \mathrm{d} \lambda}
$$

Mit Hilfe dieser Gleichungen konnte der Förster-Radius des verwendeten FRET-Paares Oregon Green und Texas Red von Keller auf $R_{0}=6.27 \mathrm{~nm}$ bestimmt werden. ${ }^{78}$

Neben dem Überlapp von Donor- und Akzeptorspektrum, der Quantenausbeute des Donors und der relativen Lage ihrer Dipolmomente zueinander, ist also der Abstand zwischen Donor und Akzeptormolekül von entscheidender Bedeutung für das Auftreten des FRET-Effekts. Dementsprechend wird FRET oft als Indikator für die während der Fusion auftretende Lipidvermischung genutzt. 


\subsection{Rasterionenleitfähigkeitsmikroskopie}

Die in Kapitel 3.1 beschriebene Fluoreszenzmikroskopie ist eine in der Wissenschaft häufig genutzte Methode, die sich besonders dadurch auszeichnet, dass sie nicht invasiv ist und somit wenige Störeinflüsse der Technik auf die Probe wirken. Ein großer Nachteil besteht jedoch in der relativ schlechten Auflösung der Lichtmikroskopie, die durch das Abbé-Limit der optischen Komponenten gegeben ist. Je nach Wellenlänge des verwendeten Anregungslichts liegt das Auflösungsvermögen bei höchstens $200 \mathrm{~nm}$. Auflösungen bis in den Nanometerbereich können hingegen mit Methoden wie der Rasterelektronen- oder Rasterkraftmikroskopie erreicht werden. Die Messungen mit Hilfe des Rasterelektronenmikroskops müssen jedoch im Hochvakuum durchgeführt werden, was die Untersuchung von biologischen Proben erschwert. Besonders im Fall weicher Proben können bei der Rasterkraftmikroskopie hingegen Artefakte durch mechanische Wechselwirkungen zwischen Messspitze und Probe nicht ausgeschlossen werden. Deshalb wurde in dieser Arbeit zur weiteren Charakterisierung der porenüberspannenden Membranen vor und nach der Fusion eine relativ neue Technik verwendet, die Rasterionenleitfähigkeitsmikroskopie (scanning ion conductance microscopy, SICM). ${ }^{79}$ Mit dieser nicht-invasiven Methode können Auflösungen sowohl lateral als auch axial im Nanometerbereich erreicht werden.

Der schematische Aufbau eines SICM ist in Abb. 3.9 gezeigt. Eine mit Elektrolyt gefüllte Nanopipette wird in der Nähe der zu untersuchenden Probe positioniert. Die Probe wird dazu in ein ebenfalls mit Elektrolyt gefülltes Gefäß gebracht. Zwischen zwei Ag/AgClElektroden wird dann eine Spannung im Bereich einiger hundert Millivolt appliziert. Eine der Elektroden wird dabei in das Elektrolytbad getaucht, während die andere in der Pipette positioniert wird. Durch die Potentialdifferenz an den Elektroden fließen Ionen von der Badelektrode zur Pipettenelektrode oder umgekehrt. Der resultierende Ionenstrom passiert dabei die Pipettenöffnung. Da diese nur einen Durchmesser von mehreren Nanometern aufweist, wird der gemessene Strom hauptsächlich durch den Widerstand an der Spitze der Pipette bestimmt und liegt im Bereich von wenigen Nanoampere. Bei großen Abständen zwischen Messspitze und Probenoberfläche muss neben dem Pipettenwiderstand im System lediglich noch der Elektrolytwiderstand überwunden werden, der im Vergleich zum Pipettenwiderstand aber vernachlässigbar ist. 


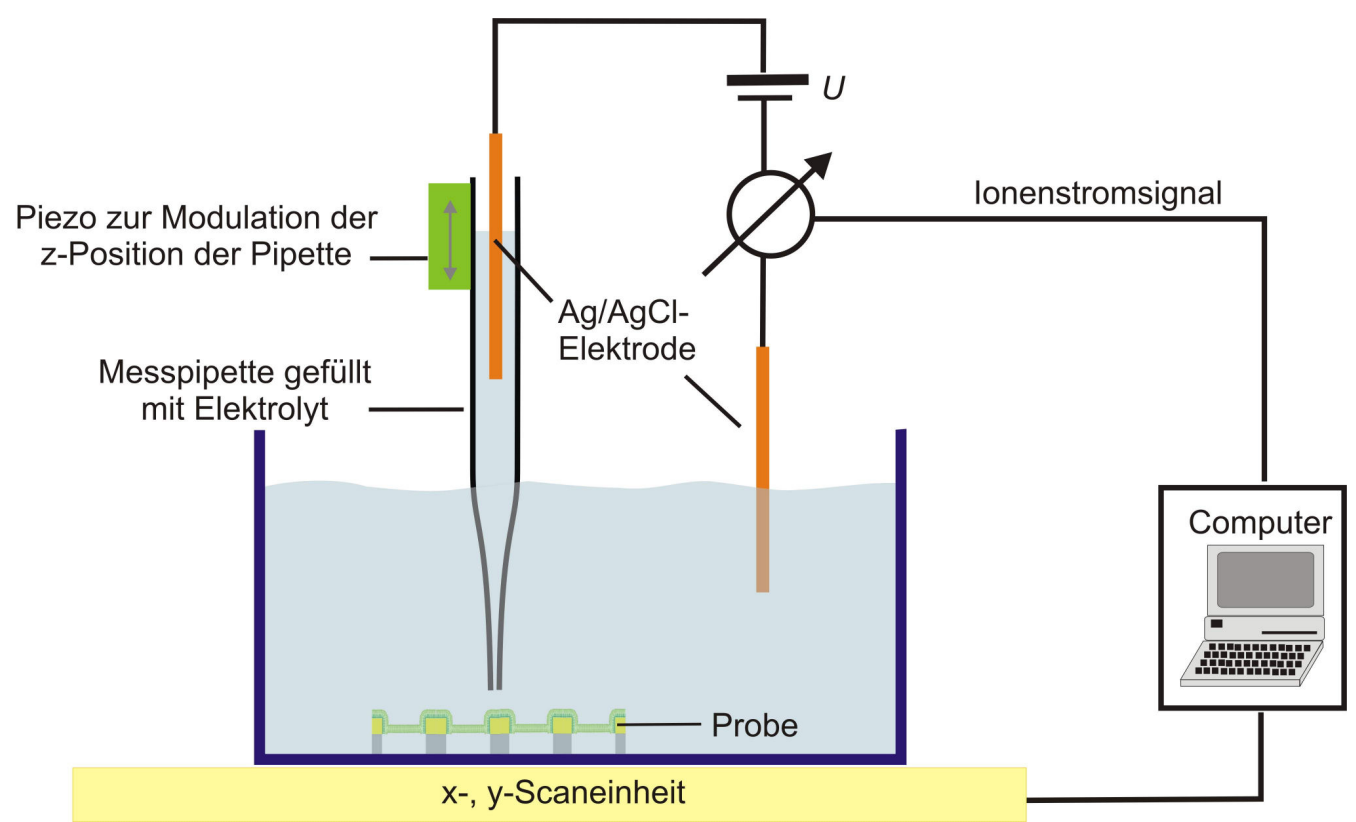

Abb. 3.9 Schematische Darstellung eines Rasterionenleitfähigkeitsmikroskops.

Nähert sich die Spitze aber der Oberfläche, so wird der Ionenfluss durch die Verkleinerung der Öffnung zwischen Spitze und Probenoberfläche reduziert. Somit wird neben dem Pipettenwiderstand ein weiterer, abstandsabhängiger Widerstand relevant, da der Ionenfluss durch die Verringerung der Austrittsmöglichkeiten vermindert ist. Dieses Phänomen wird in der SICM-Technik genutzt, um über die Änderung des Ionenflusses den Abstand zwischen Oberfläche und Pipette zu bestimmen und daraus Informationen über die Oberflächenstruktur des untersuchten Objekts zu gewinnen. Eine typische Strom-Abstandskurve bei einer Spannung von $U=100 \mathrm{mV}$ und einem maximalen Strom von $I_{\mathrm{sat}}=700 \mathrm{pA}$ basierend auf den geometrischen Überlegungen von Nitz et al. ist in Abbildung Abb. 3.10 gezeigt. ${ }^{80}$ Für die Berechnung wurde ein innerer Durchmesser der Spitze von $100 \mathrm{~nm}$ und ein äußerer Durchmesser von $170 \mathrm{~nm}$ angenommen. 


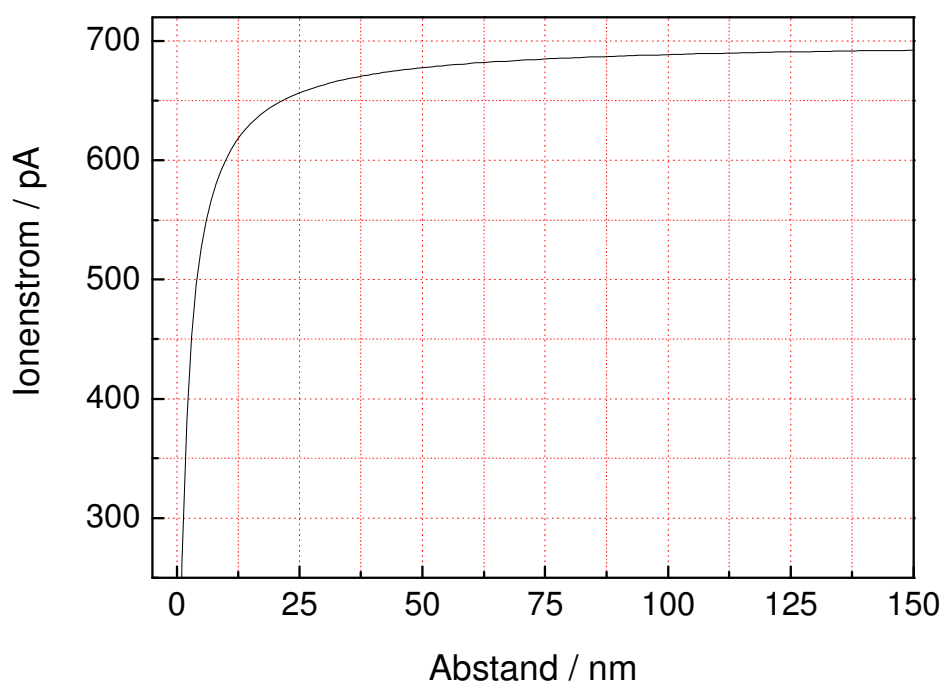

Abb. 3.10 Darstellung des Ionenstroms in Abhängigkeit des Abstands zwischen Pipettenspitze und Probenoberfläche. Als Grundlage für die Grafik dienen die theoretischen Betrachtungen eines SICMExperiments von Nitz et al. ${ }^{80}$

Der gemessene Ionenfluss wird mittels eines Strom-Spannungs-Wandlers in ein Stromsignal umgewandelt und an einen Computer weitergeleitet. Dieser erfasst das Signal und in einer Feedback-Schleife wird entsprechend die Spitze mittels eines PiezoMotors abgesenkt oder abgehoben. Auf diese Weise wird der Abstand zwischen Pipettenspitze und Probenoberfläche konstant gehalten, in dem die Pipette immer bei einem konstanten Strom (set point) gehalten wird. Aus den gemessenen axialen und lateralen Positionen der Pipette entsteht dann ein topografisches Bild der Probe.

Obwohl bei dieser Methode die mechanischen Wechselwirkungen bereits minimiert sind, können durch zusätzliche Modifikation des Messmodus Kollisionen der Pipette mit der Probe weiter verringert werden. Dazu wurde in dieser Arbeit im Hopping-Modus gearbeitet, der erstmals von Novak et al. beschrieben wurde. ${ }^{81}$ Dabei erfolgt keine kontinuierliche Feedback-Kontrolle. Stattdessen wird die Pipette von einem festgelegten Startpunkt aus der Probe genähert. Dabei wird jeweils der resultierende Strom gemessen. Die Pipette wird in Richtung der Probe bewegt, bis der zuvor definierte Stromwert (set point) erreicht ist. Die z-Position, bei der dies der Fall ist, wird als Höhe der Probe an diesem Bildpunkt registriert. Der piezo-Motor hebt dann die Pipette wieder zum Ausgangspunkt an und anschließend wird die Pipette zum nächsten Bildpunkt bewegt und von der Ausgangshöhe wieder bis zum set point an die Probe angenähert. 
In dieser Arbeit wurde mit dem ICnano (ionscope, London, U.K.) gearbeitet. Die Pipetten wurden aus Glaskapillaren (Borosilikat-Glas, Innendurchmesser $0.58 \mathrm{~mm}$, Außendurchmesser $1.0 \mathrm{~mm}$, mit Filament, Science Products, Hofheim, Deutschland) gefertigt. Dazu wurde ein Brown-flaming Elektroden-Puller (P-97, Sutter Instruments, Novato, CA) genutzt. Um die Vergleichbarkeit der Experimente zu gewährleisten, wurde immer in einem Bereich des totalen Widerstands von 150-500 M $\Omega$ gemessen und der set point jeweils bei $98 \%$ des Stromwertes gehalten.

\subsection{Fusogene Peptidsysteme}

Neben der $\mathrm{Ca}^{2}{ }^{+}$-vermittelten Fusion wurde in dieser Arbeit auch die Interaktion von Vesikeln mit porenüberspannenden Membranen, vermittelt durch zwei unterschiedliche Peptidsysteme, untersucht. Die Peptidsysteme werden im Folgenden vorgestellt.

\subsubsection{Das $\mathbf{H}_{6}$ WGC-Peptidsystem}

Das Nonapeptid $\mathrm{H}_{6}$ WGC (Abb. 3.11) mit der Summenformel $\mathrm{C}_{54} \mathrm{H}_{64} \mathrm{~N}_{22} \mathrm{O}_{11} \mathrm{~S}$ und einer molaren Masse von $\mathrm{M}=1229.29 \mathrm{~g} / \mathrm{mol}$ wurde freundlicherweise von der Arbeitsgruppe Janshoff (Universität Göttingen) zur Verfügung gestellt. In dieser Arbeit wurde das Peptid verwendet, um den Einfluss der molekularen Erkennung auf das Fusionsverhalten von Vesikeln mit porenüberspannenden Membranen zu untersuchen. Dazu wurden zwei verschiedene Ligand/Rezeptor-Wechselwirkungen ausgenutzt, um über das $\mathrm{H}_{6} \mathrm{WGC}$ Peptid zwei Membranen zu verbrücken.<smiles>CC(=O)NC(Cc1c[nH]cn1)C(=O)NC(Cc1c[nH]cn1)C(=O)NC(Cc1c[nH]cn1)C(=O)NC(Cc1c[nH]cn1)C(=O)NC(Cc1c[nH]cn1)C(=O)NC(Cc1c[nH]cn1)C(=O)NC(Cc1cc2ccccc2[nH]1)C(=O)NCC(=O)NC(CS)C(=O)O</smiles>

Abb. 3.11 Strukturformel des Nonapeptids $\mathrm{H}_{6} \mathrm{WGC}, \mathrm{C}_{54} \mathrm{H}_{64} \mathrm{~N}_{22} \mathrm{O}_{11} \mathrm{~S}, \mathrm{M}=1229.29 \mathrm{~g} / \mathrm{mol}$. 
Das Peptid wurde über den C-terminalen Cystein-Rest kovalent an ein Lipid gebunden, das in seiner Kopfgruppe eine Maleimid-Funktion trägt. ${ }^{82}$ In dem dazu verwendeten 1,2Dioleoyl-sn-glycero-3-phosphoethanolamin-N-[4-(p-maleimidomethyl)-cyclohexancarboxyamid] (MCC-DOPE) ist die Maleimid-Gruppe über einen CyclohexylAbstandshalter an das Phospholipid gekoppelt (Abb. 3.12). Das funktionale Lipid wurde in die porenüberspannenden Membranen eingebaut.

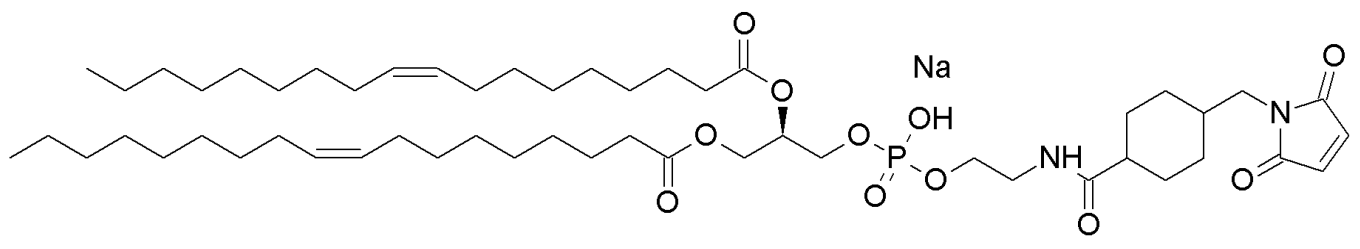

Abb. 3.12 Strukturformel von 1,2-Dioleoyl-sn-glycero-3-phosphoethanolamin-N-[4-(p-maleimidomethyl)cyclohexan-carboxyamid] (MCC-DOPE), $\mathrm{C}_{53} \mathrm{H}_{90} \mathrm{~N}_{2} \mathrm{NaO}_{11} \mathrm{P}, \mathrm{M}=985.25 \mathrm{~g} / \mathrm{mol}$.

Neben der kovalenten Verknüpfung am C-Terminus wurde der N-terminale His-Tag des Peptids genutzt, um eine koordinative Wechselwirkung mit einem $\mathrm{Ni}^{2+}$-chelatisierenden Lipid zu vermitteln. Dazu wurde 1,2-Dioleoyl-sn-glycero-3-[(N-(5-amino-1carboxypentyl)iminodiessigsäure)succinyl] (Ni-NTA-DOGS) verwendet, ein synthetisches Lipid, an dessen Kopfgruppe ein $\mathrm{Ni}^{2+}$-Ion komplexiert ist (Abb. 3.13).

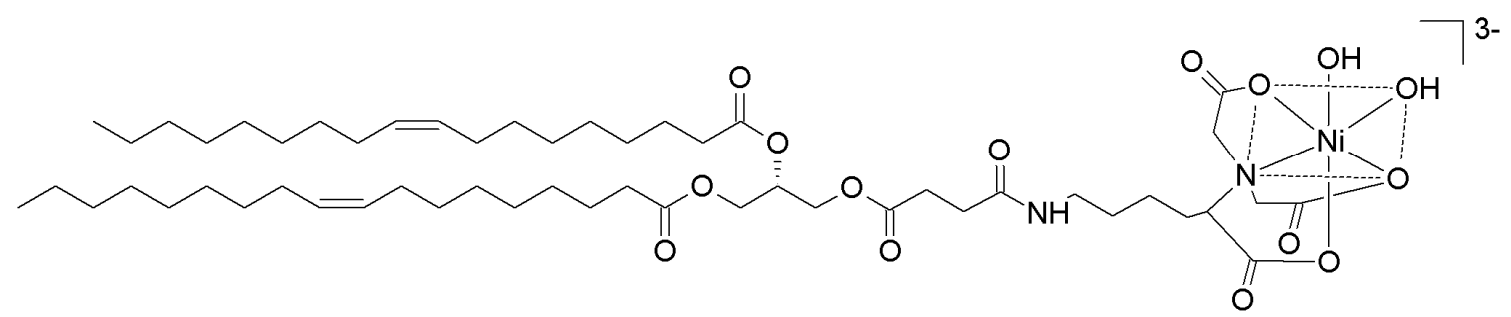

Abb. 3.13 Strukturformel von 1,2-Dioleoyl-sn-glycero-3-[(N-(5-amino-1-carboxypentyl)iminodiessigsäure)succinyl] (Ni-NTA-DOGS), $\mathrm{C}_{53} \mathrm{H}_{93} \mathrm{~N}_{2} \mathrm{O}_{15} \mathrm{Ni}, \mathrm{M}=1057.00 \mathrm{~g} / \mathrm{mol}$.

Zwei Koordinationsstellen des $\mathrm{Ni}^{2+}$-Ions sind frei und können von den Histidin-Resten des $\mathrm{H}_{6}$ WGC komplexiert werden. 


\subsubsection{Molekulare Erkennung durch SNARE-analoge PNA-Peptidsysteme}

Die molekulare Erkennung von SNARE-Proteinen wurde durch ein analoges PNAPeptidsystem imitiert. Die Peptide wurden freundlicherweise von Antonina Lygina (Arbeitsgruppe Diederichsen, Universität Göttingen) zur Verfügung gestellt. Die verwendeten Peptide setzten sich jeweils aus der nativen Transmembranregion eines SNARE-Proteins, der dazugehörigen Linkerregion und einer PNA-Sequenz zusammen (Abb. 3.14). Als Membrananker wurden die C-terminalen Enden von zwei unterschiedlichen SNARE-Proteinen aus menschlichen Nervenzellen genutzt. Zum einen wurden die 33 C-terminalen Aminosäuren des Syntaxin 1A und die 32 C-terminalen Aminosäuren des VAMP 2 verwendet, um daran die unterschiedlichen PNA-Sequenzen zu koppeln. In dieser Arbeit wurde dabei ausschließlich mit parallel orientierten PNASträngen gearbeitet, die insgesamt aus 10 PNA-Bausteinen aufgebaut waren. Die zwei verwendeten Sequenzen waren komplementär zueinander; die jeweilige Abfolge der Nukleobasen ist in Abb. 3.14 gezeigt.

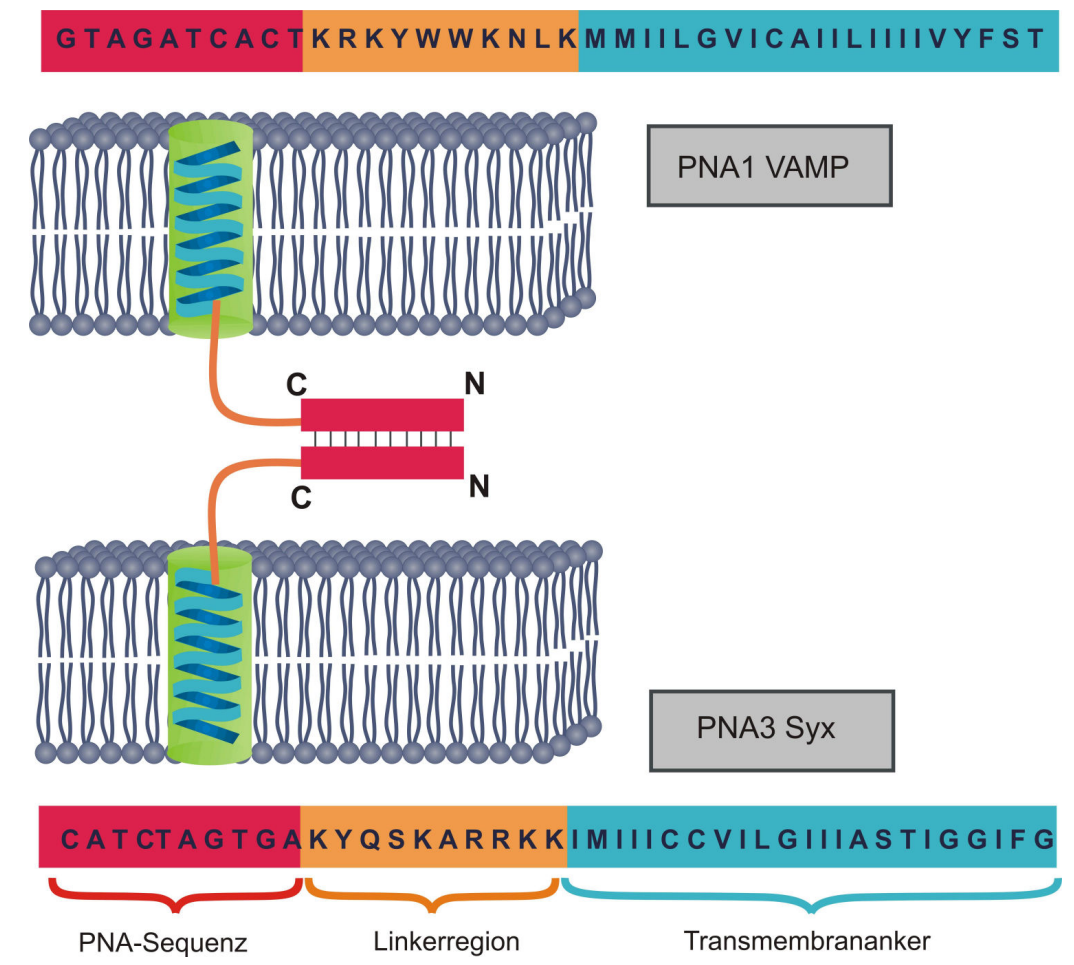

Abb. 3.14 Übersicht über die verwendeten PNA-Peptidkonstrukte und die Verbrückung zweier Membranen durch die PNA-Wechselwirkung. In dem Schema ist die Verknüpfung des Syntaxin 1A (Syx) Membranankers und des Linkers mit einer PNA-Sequenz (PNA3) dargestellt. Gleichzeitig ist die Sequenz des VAMP 2 Membranankers (VAMP) und Linkers mit der zu PNA3 komplementären PNA1 gezeigt. 
Im Folgenden wird die PNA-Struktur mit der Basenfolge GTAGATCACT als PNA1 und der Strang mit der Sequenz CATCTAGTGA als PNA3 bezeichnet. Außerdem trägt der Membrananker des Syntaxin 1A die Abkürzung Syx und der Proteinrest des VAMP 2 wird mit VAMP gekennzeichnet.

\subsection{Präparative Methoden}

\subsubsection{Herstellung von LUVs}

Um einzelne Fusionsereignisse mit Hilfe der Fluoreszenzmikroskopie auflösen zu können, wurden große unilamellare Vesikel (large unilamellar vesicles, LUVs) mit einem Durchmesser von ca. $600 \mathrm{~nm}$ verwendet. ${ }^{61}$ Diese wurden durch Extrusion auf folgende Art hergestellt. Zunächst wurde ein Lipidfilm präpariert, indem entsprechende Stammlösungen der Lipide in $\mathrm{CHCl}_{3}$ in ein Reagenzglas gegeben wurden. Die Lipidmenge eines Films betrug dabei, sofern nicht anders angegeben, $0.1 \mathrm{mg}$. Das organische Lösungsmittel wurde im Stickstoffstrom oberhalb der Phasenumwandlungstemperatur des jeweiligen Lipids bzw. Lipidgemisches verblasen und zur weiteren Trocknung wurde der Lipidfilm für mindestens $3 \mathrm{~h}$ ins Vakuum gegeben. Die Filme wurden bis zur Verwendung bei $4{ }^{\circ} \mathrm{C}$ gelagert. Zur Herstellung der Vesikel wurde der Lipidfilm mit $500 \mu \mathrm{L}$ Puffer versetzt. Nach einer Inkubationszeit von 20 min wurde die Suspension drei Mal im Abstand von 5 min mit einem Vortex-Mixer für $30 \mathrm{sec}$ geschüttelt. Auf diese Weise entstanden multilamellare Vesikel, die mit Hilfe eines Mini-Extruders (LiposoFast, Avestin, Ottawa, Kanada) in unilamellare Vesikel überführt wurden. Dazu wurde die Vesikelsuspension 31 Mal durch eine PolycarbonatMembran mit einer Porengröße von 1000 nm gedrückt.

Um PNA-Peptid-haltige LUVs herzustellen wurden die Peptide, gelöst in Trifluorethanol, in dem gewünschten Lipid/Peptid-Verhältnis der Lipidlösung zugesetzt. Es wurde analog zu der Präparation der Peptid-freien LUVs ein Lipidfilm und daraus Vesikel mittels Extrusion hergestellt.

Im Fall der Pyranin-gefüllten LUVs wurde der Lipidfilm mit einer Pyranin-Lösung (2.5 40 mM Pyranin, 200 mM Sucrose, 100 mM KCl, 10 mM MES, pH 6.5) quellen gelassen. Nach dem Extrudieren wurde die Vesikellösung mit einer Sephadex G-25 Säule (GE Healthcare, Buckinghamshire, UK) gesäult, um externes Pyranin zu entfernen. 


\subsubsection{Herstellung von GUVs}

Zur Herstellung von lösungsmittelfreien porenüberspannenden Membranen eignet sich das Spreiten von Vesikeln auf den funktionalisierten porösen Substraten. Dabei sollte die Vesikelgröße den Durchmesser der Poren überschreiten. Dazu wurden sogenannte unilamellare Riesenvesikel (giant unilamellar vesicles, GUVs) eingesetzt. GUVs sind Vesikel mit einem Durchmesser, der je nach Lipidzusammensetzung und Herstellungsmethode im Bereich mehrerer Mikrometer liegt. Eine Methode zur Präparation von GUVs ist die Elektroformation, die erstmals 1986 von Angelova und Dimitrov beschrieben wurde. ${ }^{83}$ Dieses Verfahren wurde über die Jahre modifiziert und wird heute standardmäßig zur Herstellung von GUVs verwendet. Voraussetzung für die Präparation der GUVs mittels Elektroformation sind zwei elektrisch leitende Oberflächen. In dieser Arbeit wurden dazu Indiumzinnoxid (indium tin oxide, ITO)beschichtete Objektträger verwendet. Auf der leitenden Schicht wurde ein Lipidfilm präpariert, indem das entsprechende Lipid gelöst in Chloroform (2-3 mg/ml) auf der leitenden Oberfläche verteilt wurde und das organische Lösungsmittel über Nacht im Vakuum entfernt wurde.

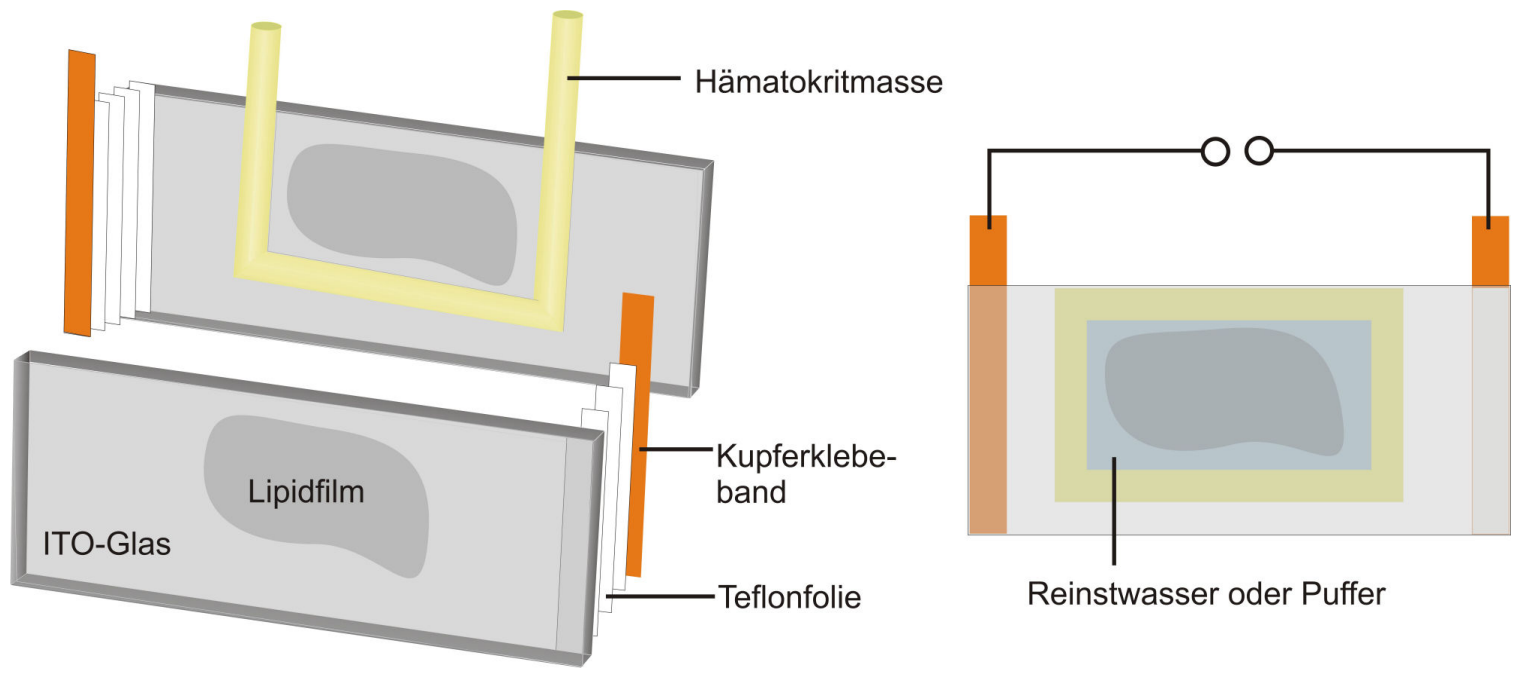

Abb. 3.15 Schematische Darstellung der Kammer zur Herstellung von GUVs mittels Elektroformation. Nach dem Zusammenbau der einzelnen Komponenten wird das durch Hämatokritmasse gebildete Reservoir mit Wasser oder Puffer gefüllt, verschlossen und die Kammer über die überstehenden Enden des Kupferklebebands an einen Frequenzgenerator angeschlossen.

Die Gesamtlipidmasse auf beiden Objektträgern betrug $0.2 \mathrm{mg}$. Nach dem Trocknen der Lipidfilme wurden beide Objektträger zu einer Kammer zusammengebaut, wie sie in Abb. 3.15 gezeigt ist. Als Abstandshalter dienten Streifen aus Teflonfolie, die 
übereinander jeweils auf einen der Ränder des Objektträgers geklebt wurden. Mit Hilfe von Hämatokritwachs wurde die Kammer abgedichtet. Dieser Teil der Kammer wurde zur Hydratisierung des Lipidfilms mit Reinstwasser gefüllt. Zur elektrischen Kontaktierung diente leitendendes Kupferklebeband, welches auf die Teflonabstandshalter geklebt wurde und durch den Zusammenbau der zwei ITO-Gläser in direktem Kontakt zur ITO-Beschichtung des jeweils gegenüberliegenden Objektträgers stand. Mit Hilfe eines Frequenzgenerators wurde eine sinusförmige Wechselspannung mit einer Frequenz von $12 \mathrm{~Hz}$ angelegt. Dabei wurde innerhalb der ersten halben Stunde die Spannung schrittweise erst um $0.01 \mathrm{mV}$ von $50 \mathrm{mV}$ auf $200 \mathrm{mV}$ und dann um $0.1 \mathrm{mV}$ auf 1.6 V erhöht. Die Spannung wurde für 2.5 h konstant gehalten. Anschließend wurde die Frequenz auf $5 \mathrm{~Hz}$ verringert und für 10 min eine Rechteckspannung angelegt.

Zur Untersuchung der Ausschüttung des Vesikelinhalts während der Fusion wurden zum Teil mit Farbstoff und Puffer gefüllte GUVs verwendet. Lange Zeit wurde davon ausgegangen, dass GUVs in Gegenwart von hohen Salzkonzentrationen nicht mit Hilfe der Elektroformation hergestellt werden können. Dies ist richtig für das oben angegebene Protokoll nach Angelova. Pott et al. stellten jedoch 2008 Parameter vor, mit deren Hilfe GUVs auch in salzhaltigen Puffern mittels Elektroformation erhalten werden können. ${ }^{84}$ Dabei muss die Frequenz auf $500 \mathrm{~Hz}$ erhöht werden. Die angelegte Spannung von $3 \mathrm{~V}$ wird für 1.5 h gehalten. Anschließend wird für 10 min eine Rechteckspannung von $50 \mathrm{~Hz}$ angelegt.

\subsubsection{Herstellung von porenüberspannenden Membranen}

Als Grundlage für die porenüberspannenden Membranen dienten poröse SiliziumnitridSubstrate (5 x $5 \mathrm{~mm}^{2}$, Porendurchmesser $1.2 \mu \mathrm{m}$, fluXXion, Eindhoven, Niederlande). Um darauf eine Membran präparieren zu können, musste die Oberfläche der Substrate hydrophobisiert werden. Dazu wurde die Oberseite der Siliziumnitridträger auf folgende Weise funktionalisiert. Zunächst wurden die Substrate im Argonplasma (Plasma Cleaner PDC 32 G-2, Harrick) für $10 \mathrm{~min}$ gereinigt. Danach wurde mit Hilfe eines Kathodenzerstäubers (Sputter Coater 108 auto, Cressington Scientific Instruments, Watford, UK) im Argonplasma zunächst eine Schicht von $2.5 \mathrm{~nm}$ Titan auf die Substrate aufgebracht. Diese diente als Haftvermittler zwischen der Siliziumnitridoberfläche und dem danach ebenfalls mit dem Sputter Coater aufgebrachten Gold mit einer Schichtdicke 
von $30 \mathrm{~nm}$. Anschließend wurden die Substrate direkt in die jeweilige Inkubationslösung gegeben. Zur Herstellung von micro-BLMs mit Hilfe der Painting-Technik ${ }^{54}$ (Kapitel 3.4.4) diente dazu eine 0.5 mM ethanolische Lösung von 1,2-Dipalmitoyl-sn-Glycero-3Phosphothioethanol (DPPTE). Um porenüberspannende Membranen durch das Spreiten von GUVs herzustellen (Kapitel 3.4.5), wurde die Oberfläche mit einer Lösung (0.1 mM in $n$-Propanol) von Cholesterylpolyethylenoxythiol (CPEO3) inkubiert. Die Substrate verblieben bei $4{ }^{\circ} \mathrm{C}$ für mindestens $12 \mathrm{~h}$ und höchstens 3 Tage in der jeweiligen Lösung.

\subsubsection{Herstellung von micro-BLMs mittels Painting-Technik}

Nach der Inkubation mit DPPTE wurden die Substrate zunächst mit Ethanol p.A. gespült, um nicht gebundenes DPPTE zu entfernen. Nach dem Einbau des Siliziumnitridträgers in die Messkammer (Abb. 3.16), erfolgte eine weitere zehnminütige Inkubation mit Ethanol p.A.. Dies diente zum Entfernen von Luft, die sich eventuell in den Poren gesammelt hat und die auf Grund der Oberflächenspannung von Wasser, bei direktem Kontakt des Substrats mit dem Puffer, in den Poren verblieben wäre. Dadurch wäre die Ausbildung einer porenüberspannenden Lipiddoppelschicht verhindert worden. Nach der Inkubation wurde das Ethanol durch vorsichtiges Spülen mit Puffer entfernt und anschließend die Lipidmischung in n-Dekan (2\% wt) auf das Substrat aufgebracht.
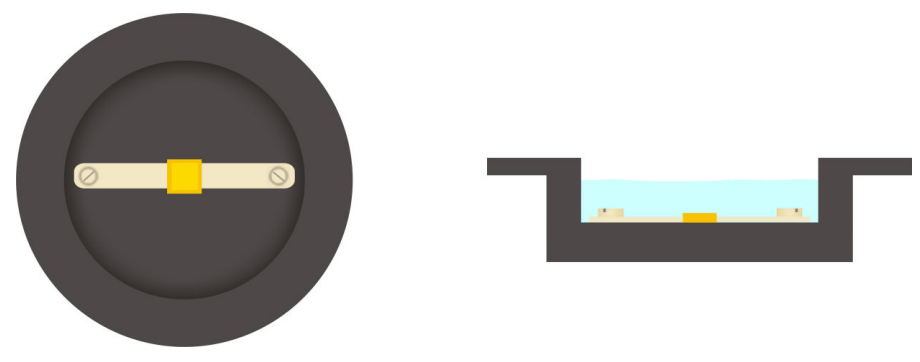

Abb. 3.16 Schematische Darstellung der Messkammer zur Präparation und Untersuchung von porenüberspannenden Membranen in der Aufsicht (links) und der Seitenansicht (rechts). Um das Porensubstrat zu fixieren, wurde es zwischen zwei Teflonhaltern eingeklemmt.

Dazu wurde eine kleine Menge des Lipid-Lösungsmittelgemisches mit einem Pinsel aufgenommen und über das Substrat gestrichen. In einem Selbstorganisationsprozess wird das Lösungsmittel in die Randbereiche verdrängt, während sich über den Poren überspannende Lipiddoppelschichten ausbilden. Um sicherzustellen, dass die Lipidlösung 
ausreichend ausgedünnt war, wurde nach dem Aufbringen des Lipids mindestens 30 min gewartet, bevor mit den micro-BLMs weitergearbeitet wurde.

\subsubsection{Herstellung von lösungsmittelfreien porenüberspannenden Membranen durch das Spreiten von GUVs}

Die funktionalisierten Substrate wurden mit $n$-Propanol gespült und 10 min mit $n$ Propanol inkubiert, um, wie in Kapitel 3.4.4 bereits beschrieben, eventuell vorhandene Luft aus den Poren zu entfernen. Danach wurde das $n$-Propanol gegen Puffer ausgetauscht. Schmitt zeigte in impedanzspektroskopischen Messungen, dass sich das kapazitive Verhalten nach Überführung einer CPEO3-Monoschicht aus Propanol in wässriges Medium innerhalb der ersten Stunde stark ändert. ${ }^{85}$ Der Grund dafür wurde in den Eigenschaften des Polyethylenoxy-Spacers gesucht, der möglicherweise in einem Medium wie Wasser mit einer relativ hohen Dielektrizitätskonstante eine andere Konformation einnimmt als in einem Medium mit einer geringeren Dielektrizitätskonstante wie Propanol. ${ }^{86}$ Die Überführung der CPEO3-Funktionalisierung von Propanol in Wasser könnte dementsprechend $\mathrm{zu}$ einer Konformationsänderung führen, mit der ein Aufrichten der CPEO3-Moleküle einhergeht. Auf Grund dieser Beobachtungen wurde jeweils nach Austausch des Propanols gegen Puffer $1 \mathrm{~h}$ gewartet. Anschließend wurden zu 3.5 mL Puffervolumen $150 \mu \mathrm{L}$ GUV-Lösung gegeben und für eine Stunde bei jeweils für das Peptid-System angegebener Temperatur (Kapitel 3.4.6) inkubiert. Der Fortschritt des Spreitens der GUVs auf dem porösen Substrat konnte fluoreszenzmikroskopisch überprüft werden. Nach Ausbildung porenüberspannender Membranen wurden überschüssige Vesikel durch Spülen mit dem jeweiligen Messpuffer entfernt.

\subsubsection{Durchführung der Fusionsexperimnente}

\subsubsection{1 $\mathrm{Ca}^{2+}$-vermittelte Interaktion von LUVs mit micro-BLMs}

Zur Untersuchung der $\mathrm{Ca}^{2+}$-vermittelten Fusion wurden micro-BLMs in $\mathrm{Ca}^{2+}$-haltigem Puffer (100 mM KCl, $20 \mathrm{mM} \mathrm{CaCl}_{2}, 10 \mathrm{mM}$ HEPES, pH 7.4) mittels der in Kapitel 3.4.4 beschriebenen Painting-Technik aus einer Lösung von DPhPC/POPE 2:1 mit $1-2$ mol\% 
Oregon Green DHPE in n-Dekan (2\% wt) präpariert. LUVs wurden mit einer Zusammensetzung aus POPC/POPS/Texas Red DHPE 78:20:2 (Kapitel 3.4.1) hergestellt. Dazu wurde ein Lipidfilm mit einer Lipidmenge von $0.1 \mathrm{mg}$ in $500 \mu \mathrm{L}$ Sucrose-haltigem Puffer (200 mM Sucrose, $100 \mathrm{mM} \mathrm{KCl,} 10 \mathrm{mM}$ MES, pH 6.5) resuspendiert und mit Hilfe der Extrusionsmethode in unilamellare Vesikel überführt. Zur Analyse der Wechselwirkungen zwischen LUVs mit micro-BLMs wurden $0.2-0.5 \mu \mathrm{L}$ Vesikellösung auf die micro-BLMs pipettiert und fluoreszenzmikroskopisch wie in Kapitel 3.1.2 beschrieben untersucht.

\subsubsection{2 $\mathrm{H}_{6}$ WGC-vermittelte Interaktion von LUVs mit porenüberspannenden Membranen}

Nachweis von $\mathrm{H}_{6} W G C$ in porenüberspannenden Membranen:

Um die erfolgreiche Anbindung des $\mathrm{H}_{6}$ WGC-Peptids an die Maleimid-funktionalisierten Lipide in den porenüberspannenden Membranen zeigen $\mathrm{zu}$ können, wurde die Wechselwirkung eines Fluoresceinisothiocyanat (FITC)-markierten Anti-His 6 -tagAntikörper mit dem freien His-tag des Peptids genutzt. Porenüberspannende Membranen wurden durch Spreiten von GUVs (DOPC/MCC-DOPE/Texas Red DHPE 96:2:2) in wässriger $\mathrm{Na}_{2} \mathrm{HPO}_{4}$-Lösung $(50 \mathrm{mM}, \mathrm{pH}=6.8)$ hergestellt. Diese Methode zur Herstellung porenüberspannender Membranen ist in Kapitel 3.4.5 ausführlich beschrieben. Danach wurden die $\mathrm{H}_{6} \mathrm{WGC}$-funktionalisierten porenüberspannenden Membranen mit dem Antikörper in einer Verdünnung von 1:250 für $2 \mathrm{~h}$ inkubiert. Anschließend wurde die Probe gespült und die FITC-Fluoreszenz des Antikörpers mit einem Argon-Ionen-Laser mit einer Wellenlänge von $\lambda_{\mathrm{ex}}=488 \mathrm{~nm}$ angeregt. Die Emission wurde in einem Bereich von $\lambda_{\mathrm{em}}=499-545 \mathrm{~nm}$ (FITC) und $\lambda_{\mathrm{em}}=600-$ $680 \mathrm{~nm}$ (Texas Red DHPE) detektiert.

Experimente zur Untersuchung der Membraninteraktion vermittelt durch $\mathrm{H}_{6} W G C$ :

Zur Untersuchung der $\mathrm{H}_{6} \mathrm{WGC}$-vermittelten Interaktion wurden porenüberspannende Membranen durch Spreiten von GUVs (DOPC/MCC-DOPE/Oregon Green DHPE 96:2:2) in wässriger $\mathrm{Na}_{2} \mathrm{HPO}_{4}$-Lösung (50 mM, pH = 6.8) hergestellt (Kapitel 3.4.5). Zum Spreiten wurde die Probe zunächst in Reinstwasser mit $20 \mathrm{mM} \mathrm{CaCl} \mathrm{Cl}_{2}$ bei einer Temperatur $55^{\circ} \mathrm{C}$ mit der GUV-Suspension inkubiert. Nach der Ausbildung von 
porenüberspannenden Membranen wurde die Probe zunächst in wässrige $\mathrm{Na}_{2} \mathrm{HPO}_{4}{ }^{-}$ Lösung $(50 \mathrm{mM}, \mathrm{pH}=6.8)$ überführt und überschüssige GUVs durch Spülen mit $\mathrm{Na}_{2} \mathrm{HPO}_{4}$-Lösung entfernt. Anschließend wurden die porenüberspannenden Membranen mit Peptid funktionalisiert. Dazu wurde das Peptid $\mathrm{H}_{6}$ WGC (100 $\mu \mathrm{M}$ in Reinstwasser) zu den porenüberspannenden Membranen gegeben und nach $1 \mathrm{~h}$ die nicht gebundenen Moleküle durch Spülen mit Puffer aus der Lösung entfernt. LUVs wurden mit verschiedenen Zusammensetzungen von DOPC/DOGS-Ni-NTA/Texas Red DHPE $98-X: 2: X($ mit $X=0-2)$ durch Extrusion präpariert. Dazu wurde ein Lipidfilm mit einer Lipidmenge von $0.1 \mathrm{mg}$ in $500 \mu \mathrm{L}$ wässriger $\mathrm{Na}_{2} \mathrm{HPO}_{4}$-Lösung $(50 \mathrm{mM})$ resuspendiert und mit Hilfe der Extrusionsmethode in unilamellare Vesikel überführt. Zur Analyse der Wechselwirkungen zwischen den LUVs mit porenüberspannenden Membranen wurden $0.5 \mu \mathrm{L}$ Vesikellösung auf die micro-BLMs pipettiert und fluoreszenzmikroskopisch wie in Kapitel 3.1.2 beschrieben untersucht.

\subsubsection{PNA-vermittelte Interaktion von LUVs mit porenüberspannenden Membranen}

Nachweis PNA-Peptide:

Um nachzuweisen, dass die verwendeten PNA-Peptid-Moleküle in Lipiddoppelschichten eingebaut werden, wurden wie in Kapitel 3.4.2 beschrieben, GUVs (DOPC/Oregon Green DHPE 98:2), mit dem Peptid VAMP PNA1 in einem Lipid/Peptid-Verhältnis von 200:1 hergestellt. Diese wurden dann mit Alexa Fluor 633-markierter DNA, die eine komplementäre Sequenz zu der Basenabfolge der PNA 1 zeigte, inkubiert. Dazu wurde die DNA in KCl-haltigem Puffer (100 mM KCl, $10 \mathrm{mM} \mathrm{HEPES,} \mathrm{pH} \mathrm{7.4)} \mathrm{mit} \mathrm{einer}$ Konzentration von $5 \mu \mathrm{M}$ gelöst und zu der GUV-Lösung gegeben, so dass ein fünffacher Überschuss an DNA im Vergleich zur vorhandenen PNA-Konzentration gewährleistet war. Nach einer zweistündigen Inkubationszeit wurde die GUV-DNA-Lösung für weitere zwei Stunden zum Spreiten auf ein CPEO3-funktionalisiertes poröses Substrat in KClhaltigem Puffer (100 mM KCl, 10 mM HEPES, pH 7.4) gegeben. Nach erfolgreicher Membranausbildung und Spülen der Probe zur Entfernung nicht gespreiteter GUVs, wurde die Fluoreszenz mit Hilfe des CLSM abgebildet. Dazu wurde die Oregon GreenFluoreszenz mit einem Laser der Wellenlänge $\lambda_{\mathrm{ex}}=488 \mathrm{~nm}$ angeregt und in einem Bereich von $\lambda_{\text {em }}=500-580 \mathrm{~nm}$ detektiert. Zur Anregung der Fluoreszenz des Alexa 
Fluor 633-Farbstoffs wurde ein Laser mit der Wellenlänge $\lambda_{\mathrm{ex}}=633 \mathrm{~nm}$ verwendet und die Emission bei $\lambda_{\mathrm{em}}=665-735 \mathrm{~nm}$ aufgenommen.

Experimente zur Untersuchung der Membraninteraktion vermittelt durch PNA-Peptide:

Die Basis zur Untersuchung der PNA-vermittelten Interaktion bildeten porenüberspannende Membranen, die durch Spreiten Peptid-haltiger GUVs präpariert wurden. Zur Herstellung von GUVs, in die PNA-Peptide insertiert waren, wurden zunächst kleine unilamellare Vesikel (small unilamellar vesicles, SUVs) mit der Ultraschallmethode hergestellt. Dazu wurde ein Lipidfilm (0.1 mg DOPC/Oregon Green DHPE 98:2, mit dem Peptid VAMP PNA1 in einem Lipid/Peptid-Verhältnis von 500:1) mit $500 \mu \mathrm{L}$ Reinstwasser erst 20 min und anschließend noch 2 mal 5 min inkubiert und dazwischen jeweils 30 s mit Hilfe eines Vortex-Mixers geschüttelt. Anschließend wurde die Vesikellösung zwei Mal für jeweils 15 min mit Ultraschall behandelt. Die wässrige Vesikellösung wurde dann auf die ITO-Gläschen getropft und das Wasser $3 \mathrm{~h} \mathrm{im}$ Vakuum entfernt. Anschließend wurden GUVs wie oben beschrieben mittels Elektroformation hergestellt. Zum Spreiten wurde die Probe in einem KCl-haltigen Puffer (100 mM KCl, $10 \mathrm{mM}$ HEPES, pH 7.4) bei einer Temperatur von maximal $35^{\circ} \mathrm{C}$ mit der GUV-Suspension inkubiert.

Peptid-haltige LUVs wurden mit Hilfe der Extrusionmethode präpariert. Der Einbau der PNA-Peptide erfolgte vor der Lipidfilmherstellung durch Zugabe der Peptide gelöst in Trifluorethanol zur der organischen Lipidlösung, aus welcher der Lipidfilm hergestellt wurde. Auf diese Weise wurden Lipidfilme mit einer Zusammensetzung von POPC/POPS/Texas Red 78/20/2 mit dem jeweilig angegebenen PNA-Peptid in einem Lipid/Peptid-Verhältnis von 500:1 erhalten. Der Lipidfilm mit einer Lipidmenge von $0.1 \mathrm{mg}$ wurde in $500 \mu \mathrm{L} \mathrm{KCl-haltigem} \mathrm{Puffer} \mathrm{(100} \mathrm{mM} \mathrm{KCl,} 10 \mathrm{mM}$ HEPES, pH 7.4) resuspendiert und mit Hilfe der Extrusionsmethode in unilamellare Vesikel überführt. Die Vesikellösung wurde dann im Verhältnis 1:4 mit KCl-haltigem Pufffer verdünnt. Zur Analyse der Wechselwirkungen zwischen den LUVs mit porenüberspannenden Membranen wurden $0.5 \mu \mathrm{L}$ der verdünnten Vesikellösung auf die micro-BLMs pipettiert und fluoreszenzmikroskopisch wie in Kapitel 3.1.2 beschrieben untersucht. 


\section{Ergebnisse}

Zur Untersuchung der Fusion biologischer Membranen stehen seit mehreren Jahren verschiedene in vitro-Assays zur Verfügung. Diverse Nachteile der bestehenden Modellmembransysteme limitieren jedoch die vollständige Aufklärung des Fusionsprozesses. Im Fokus der vorliegenden Arbeit stand daher die Entwicklung eines neuen Fusionsassays basierend auf porenüberspannenden Membranen. Dieser Aufbau soll schließlich genutzt werden, um die SNARE- und Viruspeptid-vermittelte Fusion zu erforschen. In den ersten Schritten der Entwicklung lag der Schwerpunkt auf der Etablierung geeigneter Versuchsbedingungen. Dementsprechend wurde zuerst die gut untersuchte $\mathrm{Ca}^{2+}$-vermittelte Fusion genutzt, um den Versuchsaufbau zu konzipieren und Methoden zur Untersuchung der Lipidvermischung und der Ausschüttung des wässrigen Vesikelinhalts zu finden.

Diese wurden dann eingesetzt, um den Einfluss der molekularen Erkennung auf die Fusion von Vesikeln mit porenüberspannenden Membranen zu untersuchen.

\subsection{Untersuchung der Lipidvermischung während der Fusion von LUVs mit micro-BLMs}

Die ersten durchgeführten Experimente zur Etablierung der Versuchsbedingungen, die in diesem Kapitel behandelt werden sollen, basierten auf sogenannten micro-black lipid membranes (micro-BLMs). Diese Art der porenüberspannenden Membranen zeichnet sich dadurch aus, dass diese mit Hilfe der Painting-Technik aus einer organischen Lösung der entsprechenden Lipide hergestellt werden. Dazu wurden die porösen Silizium-Substrate (Kapitel 1.3, Abb. 1.7) mit 1,2-Dipalmitoyl-sn-Glycero-3phosphothioethanol (DPPTE) funktionalisiert. Zur Beobachtung von Einzelfusionsereignissen wurden large unilamellar vesicles (LUVs) mit einem mittleren Durchmesser von $600 \mathrm{~nm}$ verwendet, ${ }^{61}$ die mit Hilfe der Fluoreszenzmikroskopie gut aufgelöst werden können. Die porösen Substrate wurden ebenfalls so gewählt, dass 
einzelne Poren lichtmikroskopisch sichtbar gemacht werden können und dementsprechend einen Porendurchmesser von $1.2 \mu \mathrm{m}$ aufwiesen.

Um Fusionsprozesse mittels Fluoreszenzmikroskopie beobachten zu können, mussten die Vesikel mit fluoreszenzmarkierten Lipiden dotiert werden. Im Gegensatz zu anderen Modellmembransystemen, wie BLMs und festkörperunterstützten Membranen, bestand die Notwendigkeit, auch die porenüberspannenden Membranen mittels Fluorophordotierung sichtbar $\mathrm{zu}$ machen. Während bei anderen Systemen die Möglichkeit besteht, die Qualität der Membran z. B. durch rasterkraftmikroskopische oder elektrische Messungen zu überprüfen, bot sich im Fall der micro-BLMs als einfachstes Mittel die Fluoreszenzmikroskopie an, um sicherzustellen, dass die beobachteten Vesikel mit einer intakten porenüberspannenden Membran fusionieren. Die beiden unterschiedlichen Fluorophore in Vesikel und micro-BLMs wurden so gewählt, dass im Fall der Fusion ein Förster Resonanz Energie Transfer (FRET) stattfindet. Dieser stellt ein gutes Indiz für das Auftreten der Lipidvermischung im Zuge der Fusion dar, weil nur in diesem Fall beide Farbstoffe die nötige räumliche Nähe gewinnen, damit ein Energietransfer stattfinden kann. Deshalb wurden die Vesikel mit Texas Red DHPE und die porenüberspannenden Membranen mit Oregon Green DHPE dotiert. Eine Übersicht über den Versuchsaufbau ist in Abb. 4.1 gezeigt.

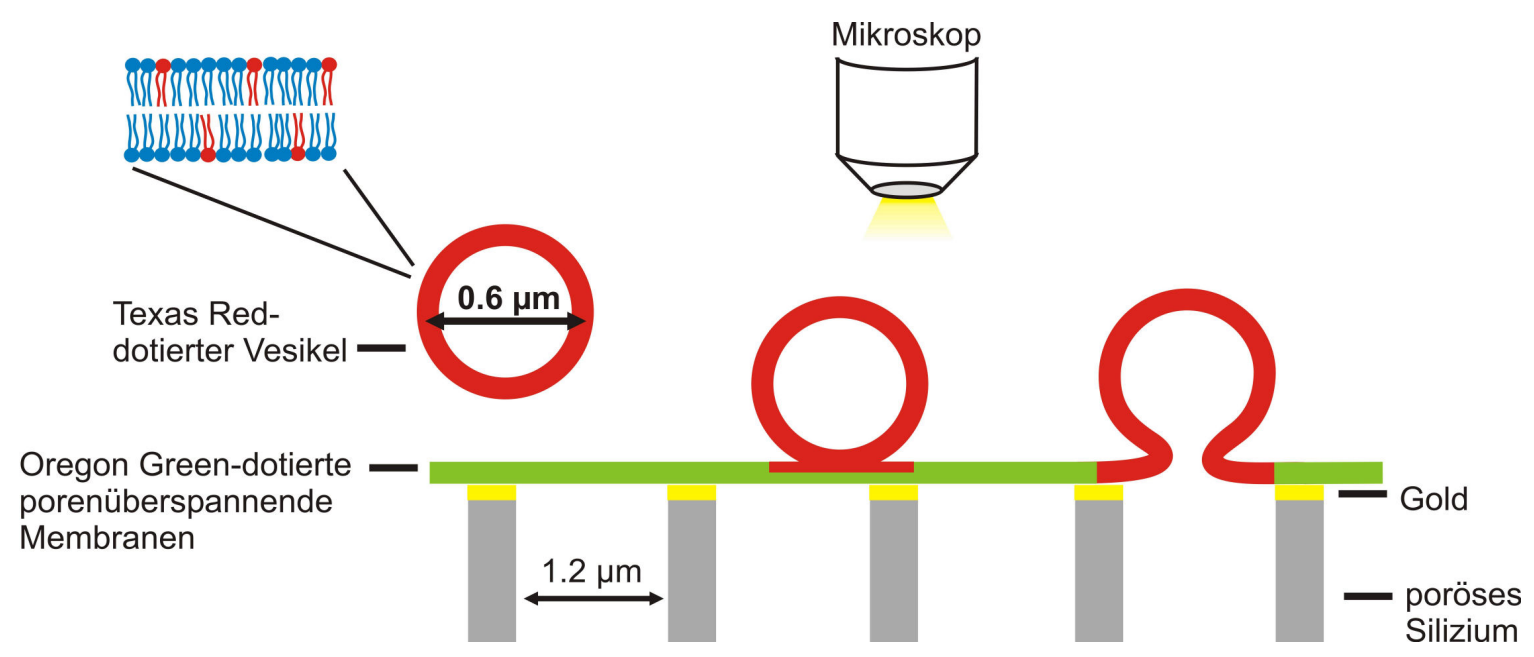

Abb. 4.1 Schematische Darstellung des Versuchsaufbaus zur Untersuchung der Fusion von Vesikeln mit porenüberspannenden Membranen. ${ }^{87}$ 
Im weiteren Verlauf der Entwicklung eines Fusionsassays basierend auf porenüberspannenden Membranen wurde eine Lipidmischung gesucht, mit der zum einen stabile micro-BLMs hergestellt werden können und die zum anderen zur $\mathrm{Ca}^{2+}$-vermittelten Fusion von large unilamellar vesicles (LUVs) mit diesem planaren Membransystem führt. Aus der Literatur ist bekannt, dass sich besonders 1,2-Diphytanoyl-sn-glycero-3-phosphocholin (DPhPC) eignet, um BLMs und auch micro-BLMs mit einer hohen Stabilität herzustellen. ${ }^{53,88}$ Aus diesem Grund wurde dies als Matrixlipid der micro-BLMs gewählt. Um die Fusionswahrscheinlichkeit zu erhöhen, wurde dem DPhPC ein gewisser Anteil 1-Palmitoyl-2-oleoyl-sn-glycero-3-phosphoethanolamin (POPE) beigemengt, da sich Phosphoethanolamine dadurch auszeichnen, dass sie die Membrankrümmung auf Grund ihrer Kegelgeometrie verändern und auf diese Weise Fusionsprozesse moduliert werden können. ${ }^{5}$ Zur Herstellung der LUVs wurde eine Mischung von 1-Palmitoyl-2-oleoyl-sn-glycero-3-phosphocholin (POPC) und 1-Palmitoyl-2-oleoyl-sn-glycero-3-phosphoserin (POPS) verwendet. Der Anteil an negativ geladenen Lipiden wurde gewählt, da durch sie die Wechselwirkungen zwischen Membran und fusogenen $\mathrm{Ca}^{2+}$-Kationen vermittelt werden und somit der Fusionsprozess begünstigt wird. ${ }^{89}$

Vor den Fusionsexperimenten wurde fluoreszenzmikroskopisch die erfolgreiche Ausbildung der porenüberspannenden Membranen überprüft. In der Aufnahme in Abb. 4.2 ist die Fluoreszenz von micro-BLMs gezeigt. Darin ist die siebartige Struktur des porösen Substrats $\mathrm{zu}$ erkennen. Bei den grünen Bereichen handelt es sich um porenüberspannende Membranen, die durch die Dotierung mit Oregon Green DHPE ein Fluoreszenzsignal zeigen. Auf den schwarz erscheinenden Porenstegen sollte sich ebenfalls eine Lipiddoppelschicht ausgebildet haben. Der Grund dafür, dass in diesen Bereichen kein Fluoreszenzsignal detektiert wird, liegt in dem engen Kontakt der Membran zu der Goldoberfläche auf den Stegbereichen. Metalle wie Gold löschen abstandsabhängig die Fluoreszenz. ${ }^{90,91}$ Auf diese Weise wird die Unterscheidung von Poren und Stegbereichen in der fluoreszenzmikroskopischen Aufnahme möglich. Die erfolgreiche Membranpräparation wird somit durch das Auftreten der Fluoreszenz in den Poren indiziert. Durch die schwarz erscheinende Pore in der rechten oberen Ecke in Abb. 4.2 wird deutlich, dass Poren, die nicht von einer Membran überspannt sind, kein Fluoreszenzsignal zeigen. 


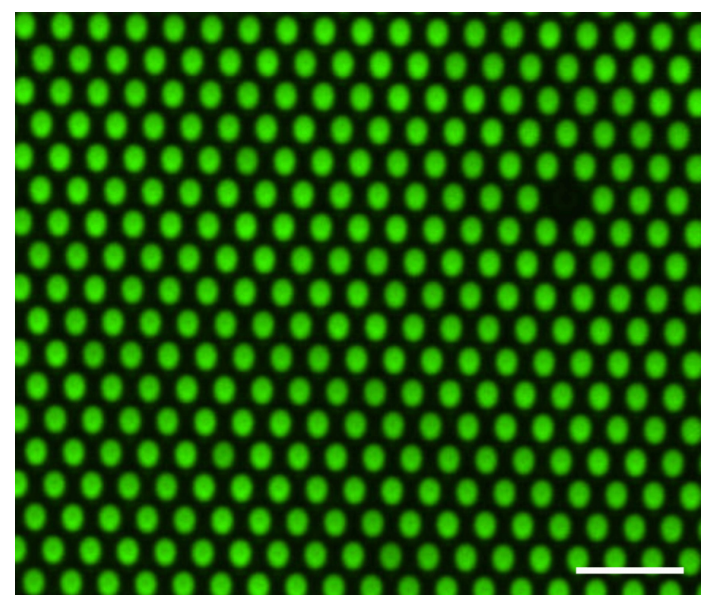

Abb. 4.2 Fluoreszenzmikroskopische Aufnahme von micro-BLMs (DPhPC/POPE 2:1, dotiert mit 1 mol\% Oregon Green) präpariert auf einem porösen Siliziumsubstrat mit Porendurchmessern von $1.2 \mu \mathrm{m}$. Der Maßstabsbalken entspricht $5 \mu \mathrm{m}$.

Nach der erfolgreichen Ausbildung von micro-BLMs wurden Vesikel zu der Probe gegeben, um deren Fusion mit den porenüberspannenden Membranen zu untersuchen. In Abb. 4.3 ist eine Abfolge von Fluoreszenzaufnahmen $\mathrm{zu}$ sehen, die ein typisches Fusionsereignis eines LUVs mit micro-BLMs vermittelt durch $\mathrm{Ca}^{2+}$-Ionen zeigen. Das emittierte Fluoreszenzlicht der Probe wurde spektral getrennt und in zwei unterschiedlichen Kanälen detektiert. In der Bildfolge sind die beiden Kanäle separat dargestellt. In grün ist der Kanal gezeigt, in dem die grüne Fluoreszenz der Oregon Green-dotierten micro-BLMs detektiert wurde (A), während in rot der Texas Red-Kanal abgebildet ist, in dem die Fluoreszenz der Vesikel erwartet wurde (B). In den ersten beiden Bildern ist im roten Kanal, gekennzeichnet durch den Pfeil, ein Texas Red-dotierter Vesikel zu sehen, der sich der porenüberspannenden Membran nähert. In der dritten Aufnahme ist dann zu erkennen, wie sich die Texas Red-Moleküle des Vesikels radial in der Fokusebene der planaren Membran verteilen. Dieses Ausbreiten des Farbstoffs in den micro-BLMs schreitet in den darauffolgenden Bildern weiter voran, bis sich die Moleküle des Vesikels so weit in der planaren Membran verteilt haben, dass keine Unterschiede in den Fluoreszenzintensitäten mehr zu erkennen sind. 

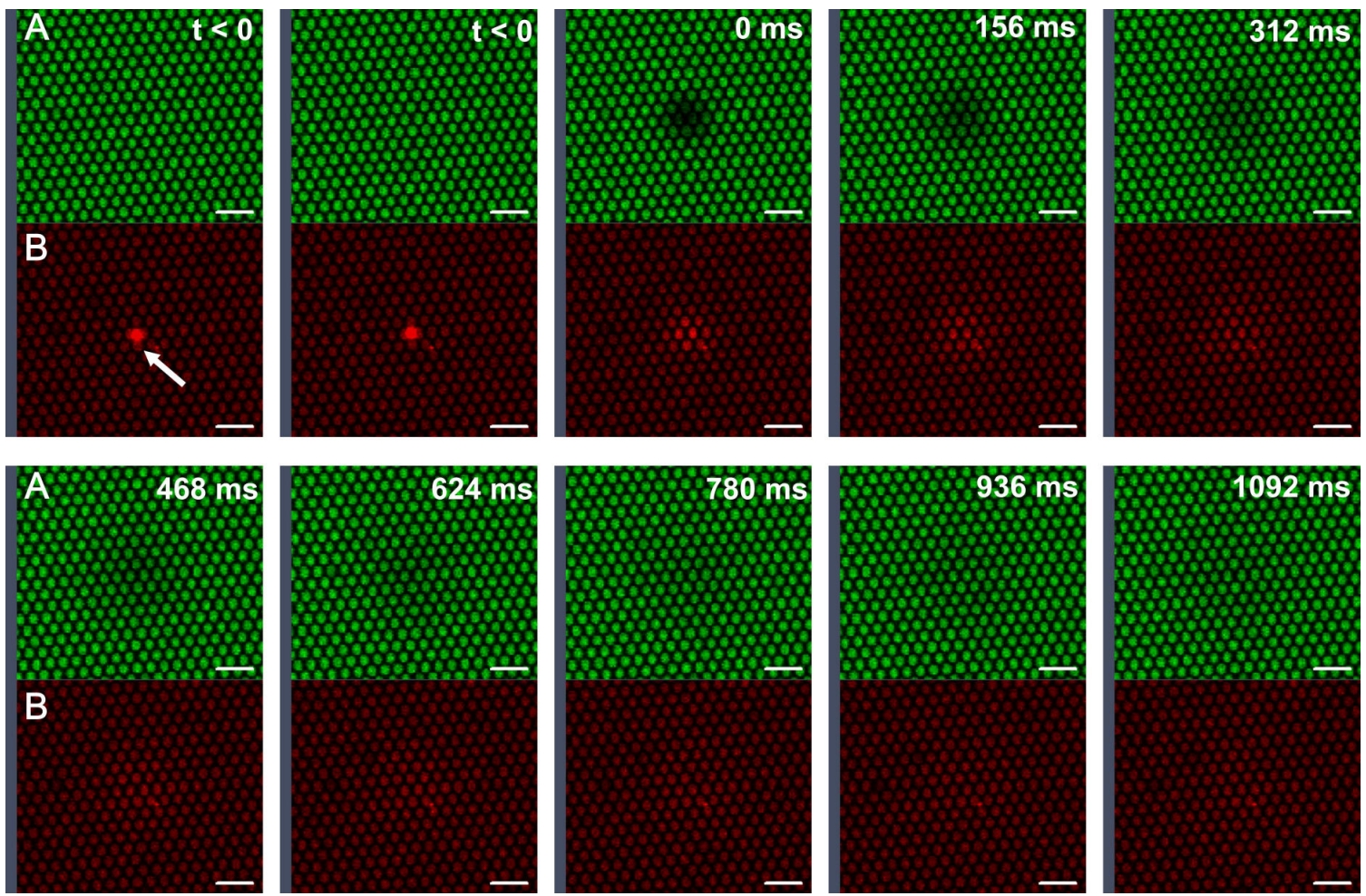

Abb. 4.3 Fluoreszenzmikroskopische Aufnahme der Fusion eines Vesikels (POPC/POPS/Texas Red 79:20:1, gefüllt mit $200 \mathrm{mM}$ Sucrose, $100 \mathrm{mM} \mathrm{KCl,} 10 \mathrm{mM} \mathrm{MES,} \mathrm{pH}=6.5$ ) mit micro-BLMs (DPhPC/POPE 2:1, dotiert mit $1 \mathrm{~mol} \%$ Oregon Green, Funktionalisierung: DPPTE) in $\mathrm{Ca}^{2+}$-Puffer (100 $\mathrm{mM} \mathrm{KCl}, 20 \mathrm{mM} \mathrm{CaCl}_{2}, 10 \mathrm{mM}$ HEPES, $\mathrm{pH}$ = 7.4). Die Emission der Fluorophore wurde spektral getrennt und in zwei unterschiedlichen Kanälen (A: Oregon Green, B: Texas Red) detektiert: Beim Auftreffen eines Vesikels auf die Membranoberfläche ist bei $t=0 \mathrm{~ms}$ die Löschung der Oregon Green-Fluoreszenz durch FRET zu erkennen (grün). Im Fall der Texas Red-Fluoreszenz (rot) ist zunächst der Vesikel zu erkennen (weißer Pfeil), der sich der Membranoberfläche nähert. Anschließend wird ab $t=0 \mathrm{~ms}$ die radiale Verteilung des Texas Red-Farbstoffs in der planaren Membran über die Zeit sichtbar. Der Maßstabsbalken entspricht $5 \mu \mathrm{m}$.

Diese Beobachtung wird der Vermischung der Lipide des Vesikels mit denen der microBLMs im Rahmen eines Fusionsereignisses zugeschrieben. Nach der Fusion findet eine laterale Diffusion statt, die zur weiteren Verteilung der Vesikellipide in den micro-BLMs führt.

Bei gleichzeitiger Betrachtung des Oregon Green-Kanals fällt auf, dass zunächst nur die micro-BLMs detektiert werden. In dem Moment, in dem die Texas Red-Moleküle im Zuge der Lipidvermischung in die planare Membran eintreten, also im dritten Bild, ist dann an der gleichen Stelle im grünen Kanal das Auftreten eines dunklen kreisförmigen Bereichs zu erkennen, dessen Durchmesser im Verlauf der Zeit größer wird und gleichzeitig an Dunkelheit verliert. Diese Beobachtung wurde auf einen auftretenden FRET-Effekt während der Fusion zurückgeführt. Anfangs treten sehr viele Texas Red- 
Moleküle an einer Stelle in die planare Membran ein, so dass sich plötzlich sehr viele Oregon Green-Moleküle in räumlicher Nähe zu einem FRET-Akzeptor befinden. Dementsprechend ist die Fluoreszenzlöschung sehr deutlich zu erkennen. Durch die anschließende Diffusion der Texas Red-Moleküle vergrößert sich der Abstand zwischen den einzelnen FRET-Paaren und die Löschung im beobachteten Bereich erscheint schwächer, da die fluoreszierenden Farbstoffmoleküle über die gelöschten überwiegen. Die Beobachtungen der Lipidvermischung werden auf eine stattgefundene Fusion zurückgeführt, dementsprechend wird im Folgenden der Begriff Fusion gleichbedeutend mit dem Begriff Lipidvermischung verwendet.

Zur Quantifizierung der Beobachtungen wurden die Fluoreszenzintensitäten aus den Aufnahmen extrahiert. Dazu wurde mit Hilfe der verwendeten Software ZEN (Carl Zeiss $\mathrm{GmbH}$, Jena, Deutschland) ein sogenannter region of interest (ROI) definiert (Abb. 4.4). Dieser wird um den Ursprung der Fusion zentriert. Die Größe richtet sich dabei nach der Größe des fusionierenden Vesikels. Der Radius liegt typischerweise in einem Bereich von $4 \mu \mathrm{m}$.
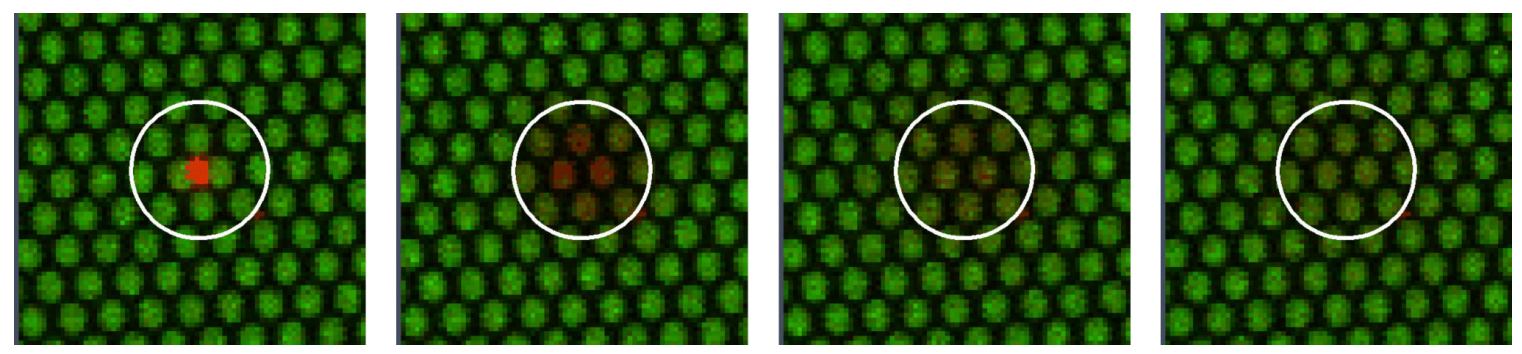

Abb. 4.4 Fluoreszenzmikroskopische Darstellung eines Einzelfusionsereignisses eines Vesikels mit porenüberspannenden Membranen. Der weiße Kreis markiert den ROI, der um das Zentrum der Fusion lokalisiert wurde.

Die über den ROI integrierten Fluoreszenzintensitäten $F$ werden von der Software für jeden Kanal ausgelesen und gegen die Zeit aufgetragen. Der Zeitverlauf der so gewonnenen Intensitäten ist in Abb. 4.5 gezeigt. In der Auftragung wurde die Zeitachse so skaliert, dass der Zeitpunkt $t=0 \mathrm{~s}$ dem Startpunkt der Fusion entspricht. Der anfängliche Anstieg der Texas Red-Fluoreszenz innerhalb der ersten drei Sekunden $(t<$ 0) ist auf das Annähern des Vesikels an die Membran in den Bereich des ROI zurückzuführen. Dadurch erhöht sich die gemittelte Intensität im ROI. Darauf folgt der exponentielle Abfall der Intensität bis auf den Anfangswert innerhalb von ca. acht Sekunden. 


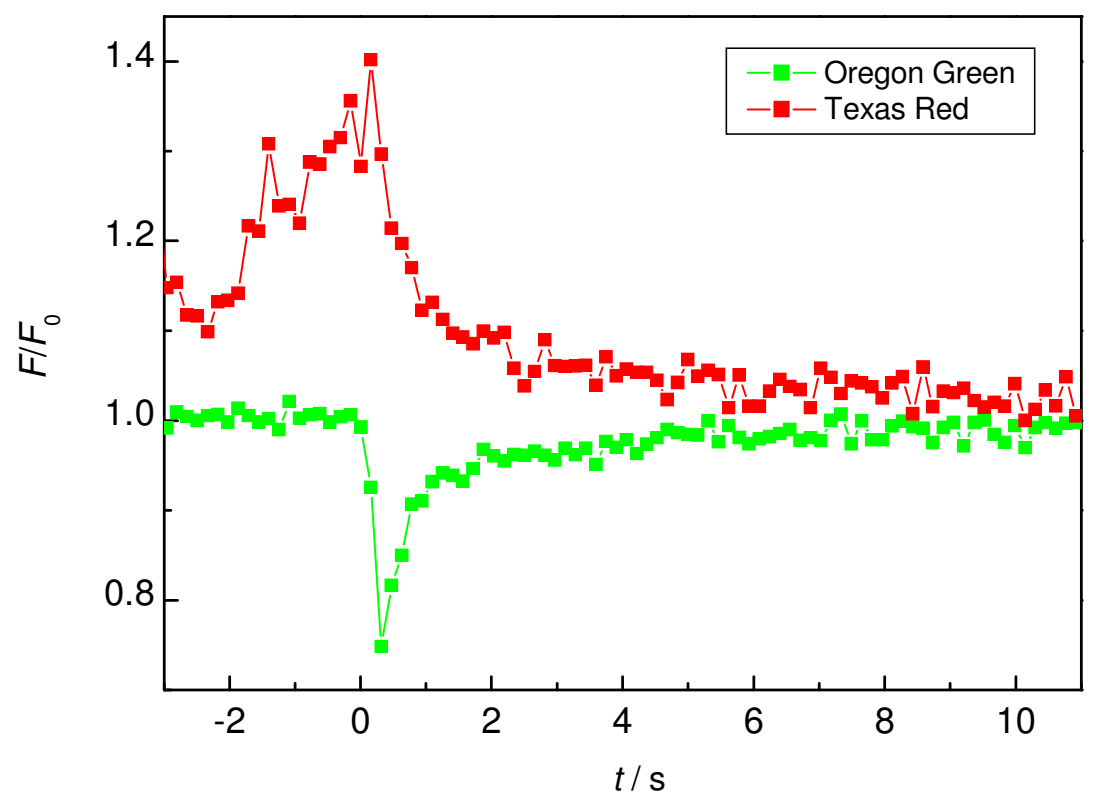

Abb. 4.5 Zeitlicher Verlauf der Fluoreszenzintensitäten von Oregon Green und Texas Red. Die gemittelten Intensitäten innerhalb eines definierten ROI wurden aus der in Abb. 1.2 gezeigten Zeitserie extrahiert. Zum Zeitpunkt der Fusion bei $t=0 \mathrm{~s}$ fällt die Intensität der Oregon Green-Fluoreszenz sprunghaft ab und steigt dann innerhalb von $3 \mathrm{~s}$ wieder auf den vor der Lipidvermischung gemessenen Ausgangswert an. Die Fluoreszenzintensität des Texas Red-Farbstoffs steigt zunächst an $(t<0)$ und fällt danach kontinuierlich ab bis die Ausgangsintensität, wie sie zu Beginn der Zeitserie gemessen wurde, wieder erreicht ist. Die Fluoreszenzintensität von Texas Red und Oregon Green wurde in dieser Darstellung auf den jeweiligen Ausgangswert $F_{0}$ vor der Fusion normiert.

Dieser wird dadurch hervorgerufen, dass die Texas Red-Moleküle im Zuge der Fusion in die micro-BLMs eingebaut werden und sich dann durch laterale Diffusion über das ganze Substrat verteilen. Dadurch verringert sich der Anteil von Farbstoffmolekülen im ROI so stark, dass anschließend kein Intensitätsunterschied vor und nach einem einzelnen Fusionsereignis im ROI zu erkennen ist.

Die Oregon Green-Intensität zeigt zum Zeitpunkt $t=0 \mathrm{~s}$, dem Startpunkt der Fusion, einen sprunghaften Abfall. Dieser ergibt sich aus dem effektiven Energietransfer direkt nach der Fusion. Mit zunehmendem Auseinanderdiffundieren der Texas Red-Moleküle sinkt der Anteil an FRET-Paaren im ROI und die Oregon Green-Intensität steigt in den darauffolgenden acht Sekunden wieder auf den Anfangswert.

Der zeitliche Verlauf der Fluoreszenzintensitäten spiegelt die Erwartungen bezüglich der Lipidvermischung im Zuge der Fusion wider. Zur weiteren Verifizierung, ob sich die Beobachtungen tatsächlich aus der Fusion eines Vesikels und der anschließenden Lipiddiffusion ergeben, wurden die Daten genutzt, um den Diffusionskoeffizienten der 
Vesikellipide in den porenüberspannenden Membran $\mathrm{zu}$ bestimmen. Für die Konzentrationsverteilung der Texas Red-Moleküle, die sich in zwei Dimensionen radial verteilen, kann ein Gauss-Profil angenommen werden, das sich mit der Zeit $t$ aufweitet: ${ }^{92}$

$$
C(r, t)=\frac{N}{4 \pi D t} \exp \left(\frac{-r^{2}}{4 D t}\right)
$$

Dabei ist $C(r, t)$ die Teilchenzahldichte an der Position $r$ zum Zeitpunkt $t$ und $D$ der Diffusionskoeffizient der Farbstoff-markierten Moleküle. Für die Fluoreszenzintensität im ROI gilt dann:

$$
I_{r_{\mathrm{ROI}}}(t)=A \int_{0}^{r_{\mathrm{ROI}}} 2 \pi r C(r, t) d r=A N\left[1-\exp \left(\frac{-r_{\mathrm{ROI}}^{2}}{4 D t}\right)\right]
$$

Zusätzlich wurde eine Konstante $F_{\mathrm{b}}$ eingeführt, durch welche die Hintergrundfluoreszenz berücksichtig wird, so dass keine Hintergrundkorrektur der Intensitätsprofile durchgeführt werden muss:

$$
I_{r_{\mathrm{ROI}}}(t)=A N\left[1-\exp \left(\frac{-r_{\mathrm{ROI}}^{2}}{4 D t}\right)\right]+F_{\mathrm{b}}
$$

Diese Gleichung kann an die Intensitätsverläufe der Texas Red-Fluoreszenz nach der Fusion, wie in Abb. 4.6 gezeigt, angepasst werden. Die Kurvenanpassung stimmt sehr gut mit den Daten überein und liefert einen Diffusionskoeffizienten von $D=(6.6 \pm 0.6) \mu \mathrm{m}^{2} / \mathrm{s}$. Insgesamt wurde so aus 46 Fusionsereignissen in sechs Experimenten ein mittlerer Diffusionskoeffizient von $D=(9 \pm 5) \mu \mathrm{m}^{2} / \mathrm{s}$ bestimmt. Dieser Wert entspricht den Ergebnissen einer FRAP-Studie zur Bestimmung der lateralen Diffusion in micro-BLMs, in der ebenfalls ein Diffusionskoeffizient von $\mathrm{D}=(9 \pm 5) \mu \mathrm{m}^{2} / \mathrm{s}$ gefunden wurde. ${ }^{93}$ Neben dem Auftreten des FRET-Effekts während der Fusion eines Vesikels mit micro-BLMs wurde somit der Diffusionskoeffizient als zweites Kriterium in Betracht gezogen, um Fusionsereignisse zu identifizieren. 


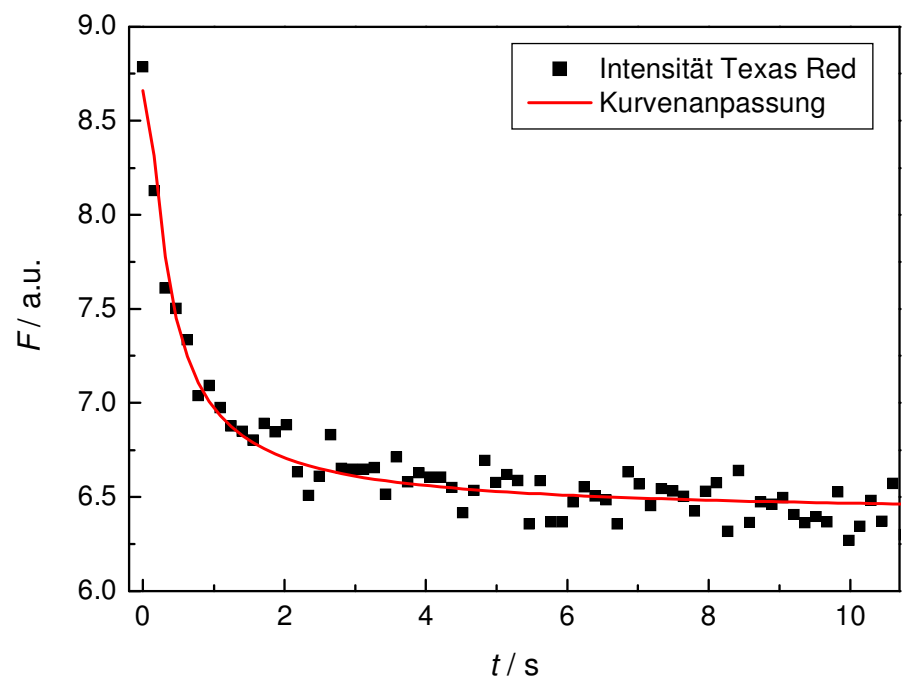

Abb. 4.6 Zeitlicher Verlauf der Texas Red-Fluoreszenzintensität nach der Fusion entsprechend dem in Abb. 4.5 gezeigten Texas Red-Intensitätsverlauf. Die Kurvenanpassung basierend auf Gl. 4-3 ergibt einen Diffusionskoeffizienten von $D=(6.6 \pm 0.6) \mu \mathrm{m}^{2} / \mathrm{s}$ für die Verteilung des Texas Red-Farbstoffs in der planaren Membran.

Im Gegensatz zu anderen Modellmembransystemen weisen porenüberspannende Membranen zwei unterschiedliche Arten von Lipidoppelschichten auf. Freitragende Membranen wechseln sich mit den festkörperunterstützen Hybridmembranen auf den Porenstegen, bestehend aus dem zur Funktionalisierung verwendeten Thiolipid und den zur Präparation der porenüberspannenden Membranen genutzten Lipid, ab. In diesem Zusammenhang stellt sich die Frage, wo die Vesikelfusion präferentiell stattfindet. In Abb. 4.7 sind zwei Beispiele gezeigt, die verdeutlichen, dass LUVs unter den gewählten Bedingungen sowohl mit dem membranüberspannten Teil der Pore (A) als auch mit der Membran auf dem Porensteg fusionieren (B). Dargestellt ist in den Abbildungen jeweils das Bild direkt vor der Fusion und direkt danach. Zwischen den zwei Aufnahmen liegen 160 ms. Der rote und grüne Kanal sind übereinandergelegt. Die Fusion mit Membranen im Porenbereich und auf den Stegen tritt in etwa mit gleicher Häufigkeit auf beiden Flächen auf. 

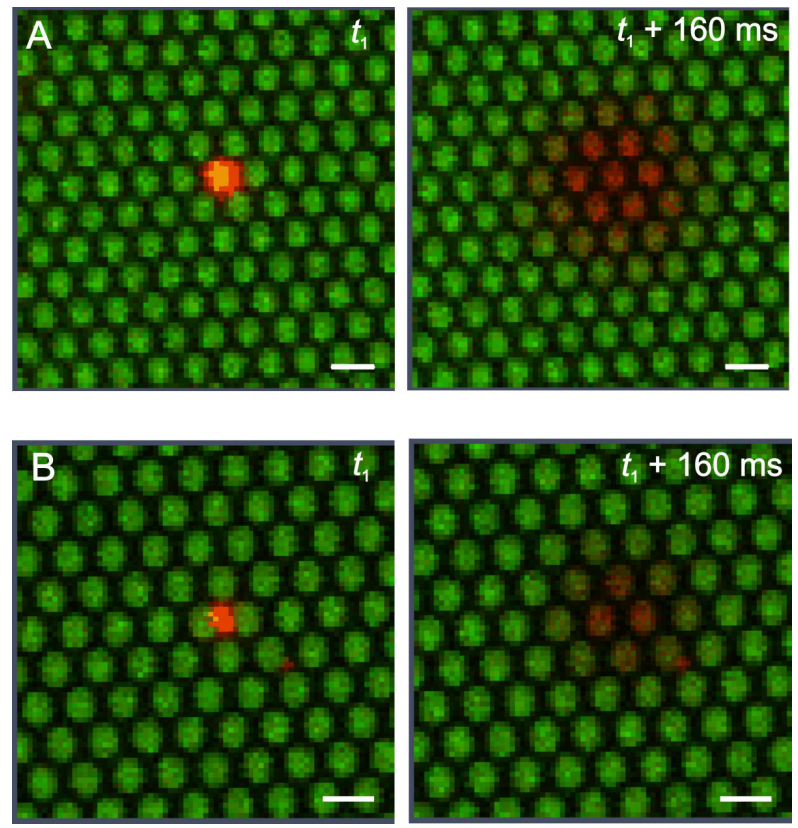

Abb. 4.7 Fluoreszenzmikroskopische Aufnahme der Fusion von Vesikeln (POPC/POPS/Texas Red 79:20:1, gefüllt mit $200 \mathrm{mM}$ Sucrose, $100 \mathrm{mM} \mathrm{KCl,} 10 \mathrm{mM} \mathrm{MES,} \mathrm{pH}$ = 6.5) mit micro-BLMs (DPhPC/POPE 2:1, dotiert mit $1 \mathrm{~mol} \%$ Oregon Green, Funktionalisierung: DPPTE) in $\mathrm{Ca}^{2+}$-Puffer (100 $\mathrm{mM} \mathrm{KCl}, 20 \mathrm{mM} \mathrm{CaCl} 2,10 \mathrm{mM}$ HEPES, $\mathrm{pH}=7.4)$ direkt über einer Pore (A) und im Stegbereich des Substrats (B): Gezeigt sind jeweils die Aufnahme direkt vor und nach der Fusion (in einem Zeitintervall von $160 \mathrm{~ms}$ ). Die Aufnahmen des roten und des grünen Kanals sind dabei übereinander gelegt. Der Maßstabsbalken entspricht $2 \mu \mathrm{m}$.

Zur Überprüfung der Spezifität der beobachteten Fusionsereignisse wurden Experimente in Abwesenheit von $\mathrm{Ca}^{2+}$-Ionen durchgeführt. In Abb. 4.8 sind Bilder einer Zeitserie vor und nach Zugabe von LUVs zu micro-BLMs in $\mathrm{Ca}^{2+}$-freiem Puffer gezeigt. In den drei Bildern vor und nach Vesikelzugabe und nach dem Spülen zeigt die grüne Fluoreszenz intakte micro-BLMs an. Gleichzeitig erscheint in den Aufnahmen des roten Kanals (unten) vor Vesikelzugabe und nach dem Spülen gar kein Signal. Nach der Vesikelzugabe sind lediglich vereinzelte Vesikel in der fokalen Ebene zu sehen. Der zeitliche Verlauf der Fluoreszenzintensität, der durch Integration des Texas Red-Signals über die gesamte aufgenommene Fläche erhalten wurde, ist in Abb. 4.7 dargstellt. Darin ist zu erkennen, dass das Texas Red-Signal konstant bleibt, bis die Intensität nach Vesikelzugabe stetig ansteigt. Nach dem Entfernen überschüssiger Vesikel wird dann wieder der Wert der Ausgangsintensität erreicht. Somit ist weder in den Fluoreszenzaufnahmen noch im Intensitätsprofil ein Anstieg der Texas Red-Intensität vor und nach Vesikelinkubation zu erkennen. 

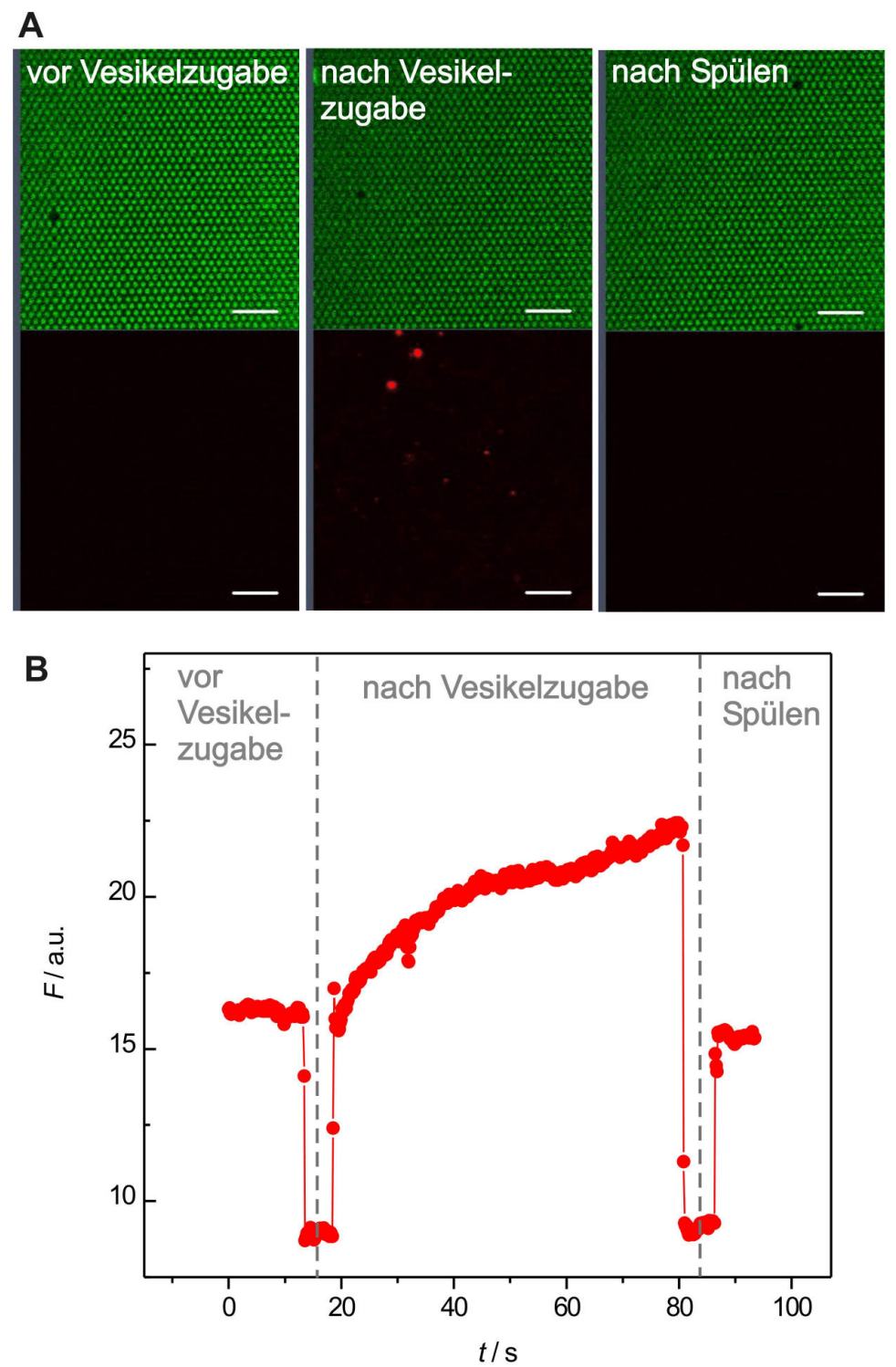

Abb. 4.8 A Fluoreszenzmikroskopische Aufnahmen von micro-BLMs (DPhPC/POPE 2:1, dotiert mit 2 mol\% Oregon Green, Funktionalisierung: DPPTE) in $\mathrm{Ca}^{2+}$-freiem Puffer $(100 \mathrm{mM} \mathrm{KCl}, 10 \mathrm{mM}$ HEPES, pH 7.4) zur Überprüfung der Spezifität der gewählten Fusionbedingungen. Die Bilder wurden vor und nach der Zugabe von LUVs (POPC/POPS/Texas Red 78:20:2, gefüllt mit $200 \mathrm{mM}$ Sucrose, $100 \mathrm{mM} \mathrm{KCl,} 10$ $\mathrm{mM}$ MES, $\mathrm{pH}=6.5$ ) zu den micro-BLMs aufgenommen. Anschließend wurden die Vesikel durch Spülen entfernt, um eventuelle Intensitätsveränderungen der micro-BLMs im Texas Red-Kanal zu prüfen. Der Maßstabsbalken entspricht $10 \mu \mathrm{m}$. B Zeitprofil der Texas Red-Fluoreszenzintensität integriert über den gesamten Bildbereich der in A gezeigten Aufnahme. Vor Vesikelzugabe und nach Spülen mit Puffer bleibt die Intensität auf einem konstanten Niveau. Nur nach Vesikelzugabe ist zwischenzeitlich ein Anstieg der Texas Red-Fluoreszenz zu erkennen.

Aus diesem Grund wurden die Vesikel abschließend entfernt um nachweisen zu können, dass es zu keinem Einbau von Vesikellipiden in die porenüberspannenden Membran und dem damit verbundenem Intensitätsanstieg kam. Da weder einzelne Fusionsereignisse 
während der Messung noch ein Anstieg der Texas Red-Fluoreszenzintensität oder Abfall der Oregon Green Intensität zu beobachten sind, kann davon ausgegangen, dass keine Fusion stattgefunden hat. Dies legt den Schluß nahe, dass die POPC/POPS-LUVs spezifisch nur in Anwesenheit von $\mathrm{Ca}^{2+}$-Ionen fusionieren.

Des Weiteren wurde untersucht, welchen Einfluss die Präparationsmethode auf die Fusionsereignisse hat. Durch die Painting-Technik wird ein gewisser Teil an organischem Lösungsmittel in das System eingebracht. Obwohl während des sogenannten Ausdünnens, dem Membranbildungsprozess, das Lösungsmittel in die Randbereiche des Substrats verdrängt werden sollte, kann der Verbleib eines gewissen Anteils an Restlösungsmittel in der Lipiddoppelschicht nicht ausgeschlossen werden. Aus diesem Grund können die micro-BLMs nicht als lösungsmittelfrei angesehen werden. Im Gegensatz dazu kann bei der Herstellung von porenüberspannenden Membranen durch die Technik des Spreitens von GUVs auf organisches Lösungsmittel verzichtet werden (Kapitel 3.4.5). Dementsprechend handelt es sich dabei um lösungsmittelfreie porenüberspannende Membranen. Diese wurden herangezogen, um den Einfluss des Lösungsmittels auf die $\mathrm{Ca}^{2+}$-vermittelte Fusion von LUVs mit micro-BLMs zu untersuchen. Die Experimente zeigten, dass identisch hergestellte LUVs nicht mit lösungsmittelfreien porenüberspannenden Membranen fusionieren.

Somit konnte erfolgreich gezeigt werden, dass die Fusion von LUVs mit micro-BLMs spezifisch durch $\mathrm{Ca}^{2+}$-Ionen vermittelt werden kann und dass dieser Prozess durch das verbliebene Lösungsmittel begünstigt wird. Die gewählte Fluoreszenzdotierung eignet sich gut, um Fusionsereignisse durch FRET zu identifizieren und die resultierende Texas Red-Verteilung in den micro-BLMs lässt sich der Lipiddiffusion im Anschluss an die Fusion zuordnen. Mit diesen Erkenntnissen konnten weitere Aspekte der Fusion, wie die in Kapitel 4.2 behandelte Vesikelausschüttung, von Vesikeln mit porenüberspannenden Membranen untersucht werden. 


\subsection{Untersuchung der Vesikelausschüttung während der Fusion von LUVs mit micro-BLMs}

In einigen in vitro-Assays zur Untersuchung der Fusion von biologischen Membranen wird berichtet, dass der Inhalt des Vesikels nicht auf der dem Vesikel gegenüberliegenden Seite der Membran ausgeschüttet wird, sondern zum Teil seitlich durch das Reißen der Membranen entweicht. ${ }^{43}$ In anderen Analysen beschränken die experimentellen Möglichkeiten die exakte Lokalisierung des Vesikelinhalts. ${ }^{48}$ Der Vorteil der porenüberspannenden Membranen besteht darin, dass durch geschlossene Porenböden kleine Kompartimente unterhalb der Membran geschaffen werden können, in denen der Vesikelinhalt aufgefangen und mit Hilfe der Konfokalmikroskopie nachgewiesen werden kann. Dies sollte einen eindeutigen Beweis für die Fusion der LUVs mit den micro-BLMs und der damit verbundenen Vesikelausschüttung geben.

Zunächst musste ein geeigneter wasserlöslicher Farbstoff gefunden werden, um den Inhalt der Vesikel fluoreszenzmikroskopisch detektieren zu können. Der Farbstoff 8Aminonaphthalin-1,3,6-trisulfonsäure ist spektral gut von den beiden anderen Farbstoffen im System getrennt, so dass es bei der Verwendung dieses Farbstoffs keine Überschneidung der Fluoreszenzsignale geben sollte. Allerdings reichte die Laserintensität des zur Verfügung stehenden Diodenlaser mit $\lambda_{\mathrm{ex}}=405 \mathrm{~nm}$ nicht aus um den Farbstoff, dessen Absorptionsmaximum bei $\lambda_{\mathrm{ex}}=353 \mathrm{~nm}$ liegt, genügend anzuregen Das Spektrum von 3',6'-Dihydroxy-1-oxospiro[2-benzofuran- 3,9'-xanthen]-5-carbonsäure (Carboxyfluorescein) hingegen zeigt eine relativ starke Überschneidung mit dem Spektrum von Oregon Green. Des Weiteren konnte ein fusionsveränderndes Verhalten nicht ausgeschlossen werden, da sich der Farbstoff in die Membran einlagerte. Deshalb wurde auch dieser Farbstoff als ungeeignet angesehen. Schließlich wurde 8Hydroxypyren-1,3,6-trisulfonsäure (HPTS, Pyranin) gewählt, um den wässrigen Inhalt der LUVs sichtbar zu machen. Die Pyraninemission weist zwar einen gewissen Überlapp mit der Oregon Green-Fluoreszenz auf, konnte aber mit den zur Verfügung stehenden Lasern gut angeregt werden und zeigte in den Experimenten auch keine Wechselwirkung mit der Membran.

Anfänglich wurden Versuche basierend auf porösen Substraten mit geöffneten Poren wie in Kapitel 4.1 durchgeführt, um einen Vergleich der Beobachtungen mit den gezeigten Experimenten zur Lipidvermischung zu ermöglichen. In Abb. 4.9 ist die Bildabfolge 
eines typischen Fusionsereignisses eines Pyranin-gefüllten LUVs mit micro-BLMs gezeigt. Zusätzlich zu dem bereits in den Experimenten zur Lipidvermischung (Kapitel 4.1) gezeigten grünen (B) und roten Kanal (C) ist nun in blau die Pyranin-Fluoreszenz (A) zu sehen. Die beiden lipidgekoppelten Farbstoffe Oregon Green und Texas Red zeigen das gleiche Verhalten wie in den Experimenten zur Lipidvermischung (Kapitel 4.1). Der Vesikel nähert sich zunächst den micro-BLMs und infolge der Fusion verteilt sich der Texas Red-Farbstoff in der planaren Membran, während im Oregon Green-Kanal die FRET-bedingte Löschung des grünen Farbstoffs zu sehen ist. Der Vesikel kann nun ebenfalls im blauen Kanal verfolgt werden. Dabei ist zu beobachten, dass in der dritten Aufnahme der gezeigten Zeitserie die blaue Fluoreszenz schwächer und der fluoreszierende Kreis, der den Vesikel darstellt, kleiner wird. Dieses langsame Verschwinden der Pyranin-Fluoreszenz innerhalb von 230 ms wurde der Ausschüttung des Vesikelinhalts auf die andere Seite der planaren Membran während der Fusion zugeordnet. Im Gegensatz zu den reinen Lipidvermischungsexperimenten ist der Vesikel auch im grünen Kanal sichtbar. Dies kann auf die Überschneidung der Pyranin-Emission mit dem Oregon Green-Kanal zurückgeführt werden. In den Experimenten konnte eine vollständige Eliminierung des Pyranin-Signals aus dem grünen Kanal nicht realisiert werden. In diesem Fall ist der spektrale Überlapp aber zu vernachlässigen, da das Pyranin-Signal nicht durch die Oregon Green-Fluoreszenz gestört wird und trotz des Anteils an Pyranin-Fluoreszenz im Oregon Green-Kanal, die für die Untersuchung entscheidende Oregon Green-Löschung gut zu erkennen ist. 

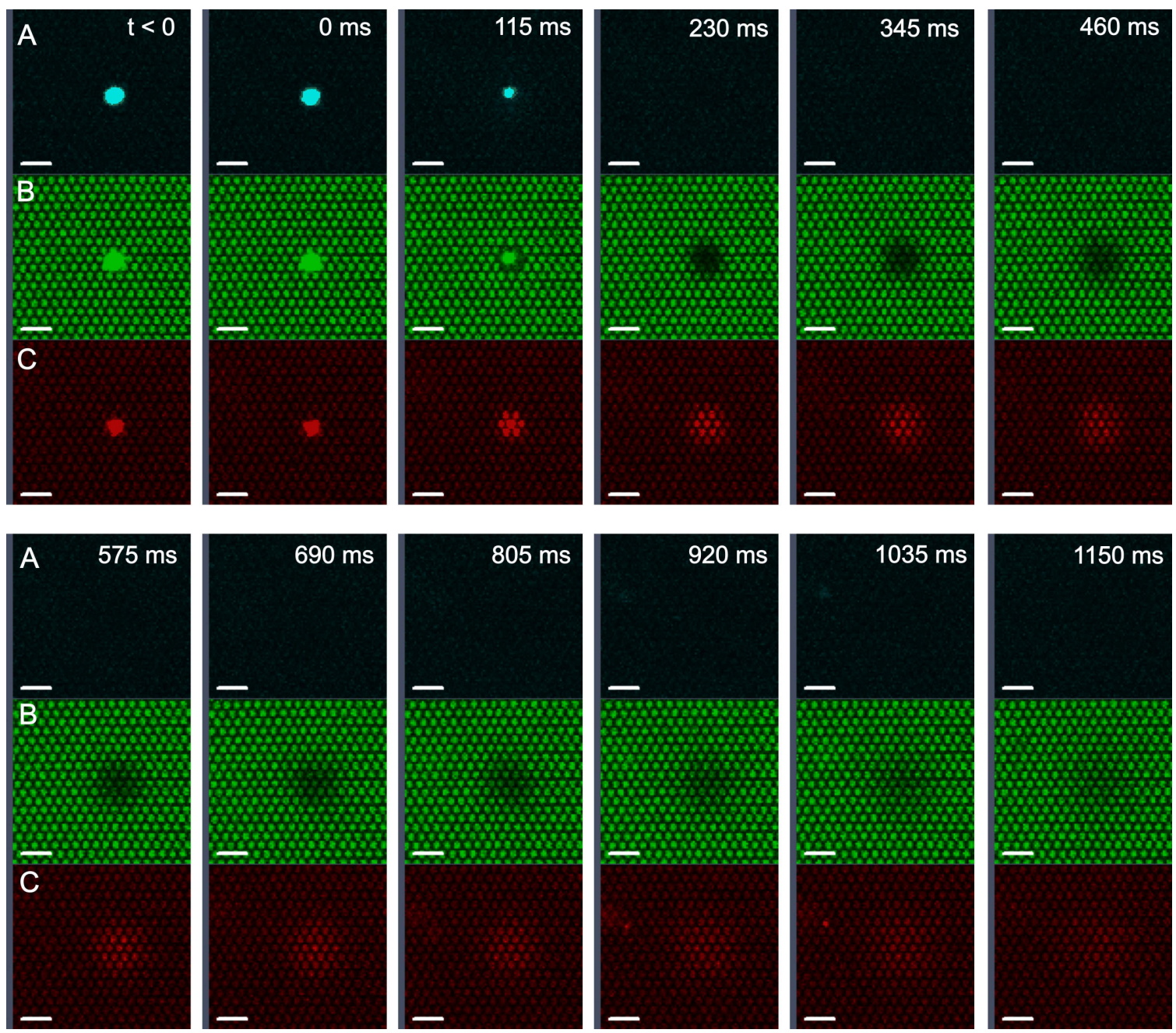

Abb. 4.9 Fluoreszenzmikroskopische Aufnahme der Fusion eines Vesikels (POPC/POPS/Texas Red 78:20:2, gefüllt mit $2.5 \mathrm{mM}$ Pyranin, $200 \mathrm{mM}$ Sucrose, $100 \mathrm{mM} \mathrm{KCl}, 10 \mathrm{mM}$ MES, $\mathrm{pH}=6.5$ ) mit microBLMs (DPhPC/POPE 2:1, dotiert mit 2 mol\% Oregon Green, Funktionalisierung: DPPTE) in $\mathrm{Ca}^{2+}$-Puffer $\left(100 \mathrm{mM} \mathrm{KCl}, 10 \mathrm{mM} \mathrm{CaCl}_{2}, 10 \mathrm{mM}\right.$ HEPES, $\left.\mathrm{pH}=7.4\right)$. Die Emission wurde spektral getrennt und in drei unterschiedlichen Kanälen detektiert (Pyranin $(\mathbf{A})$, Oregon Green $(\mathbf{B})$, Texas Red $(\mathbf{C})$ ). A: Vor der Fusion ist die Pyranin-Fluoreszenz des Vesikels zu erkennen, die Fluoreszenzintensität verschwindet dann $(t=0 \mathrm{~ms})$ innerhalb von $230 \mathrm{~ms}$ vollständig. B: Beim Auftreffen eines Vesikels auf die Membranoberfläche ist die Fluoreszenzlöschung durch FRET zu erkennen. C: Im Fall der roten Fluoreszenz ist die Verteilung des Texas Red-Farbstoffs in der planaren Membran sichtbar. Der Maßstabsbalken entspricht $5 \mu \mathrm{m}$.

Aus den Fluoreszenzbildern wurden durch Integration der Fluoreszenzsignale im ROI, der um das Fusionsereignis zentriert wurde, die Zeitprofile der Intensitäten extrahiert. Die Verläufe der Oregon Green- und der Texas Red-Fluoreszenz in Abb. 4.10 entsprechen den Beobachtungen und den Zeitprofilen der Lipidvermischungsexperimente. Der sprunghafte Abfall bei $t=0 \mathrm{~s}$ und langsame Wiederanstieg der Oregon GreenFluoreszenz fällt zusammen mit dem exponentiellen Abfall der Texas Red-Intensität. 


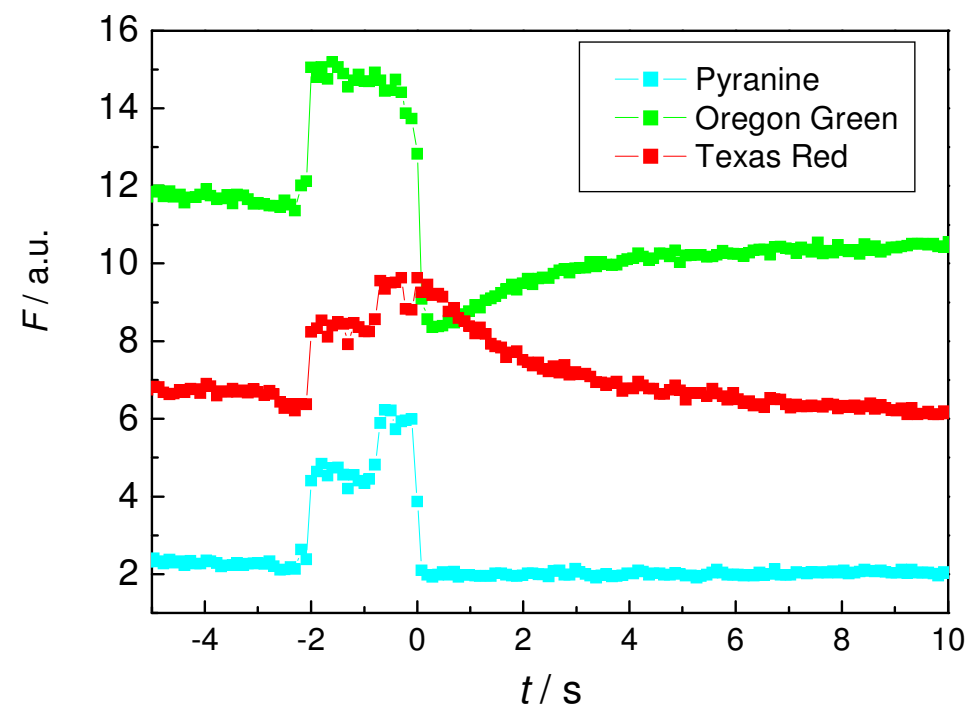

\begin{abstract}
Abb. 4.10 Zeitlicher Verlauf der Fluoreszenzintensitäten von Pyranin, Oregon Green und Texas Red. Die gemittelten Intensitäten innerhalb eines definierten ROIs wurden aus der in Abb. 4.9 gezeigten Zeitserie extrahiert. Zum Zeitpunkt der Fusion bei $t=0 \mathrm{~s}$ fällt die Pyranin-Intensität innerhalb von $230 \mathrm{~ms}$ auf ihren Ursprungswert zurück. Die Intensität der Oregon Green-Fluoreszenz nimmt ebenfalls sprunghaft ab und steigt dann innerhalb von ca. 5 Sekunden wieder an. Die Fluoreszenzintensität des Texas Red-Farbstoffs zeigt ab $t=0 \mathrm{~s}$ eine exponentielle Abnahme.
\end{abstract}

$\mathrm{Zu}$ dem gleichen Zeitpunkt in dem die Lipidvermischung durch den Abfall des Oregon Green- und Texas Red-Signals indiziert wird, ist im Pyranin-Kanal das Verschwinden der Pyranin-Fluoreszenz zu erkennen. Dabei sinkt die Intensität innerhalb von $230 \mathrm{~ms}$ auf den Anfangswert ab. Der zwischenzeitliche Anstieg der Oregon Green-Fluoreszenz $2 \mathrm{~s}$ vor dem Beginn der Fusion kann durch den Überlapp der Pyranin-Fluoreszenz in den grünen Kanal erklärt werden.

Zur weiteren Analyse der Ergebnisse wurde, auch im Fall der Experimente zur Vesikelausschüttung, durch Anpassung von Gl. 4-3 an das Intensitätsprofil der roten Fluoreszenz der Diffusionskoeffizient der Texas Red-Moleküle bestimmt (Abb. 4.11). Die Kurvenanpassung zeigt eine gute Übereinstimmung mit den Daten und liefert einen Diffusionskoeffizienten von $D=(11 \pm 1) \mu \mathrm{m}^{2} / \mathrm{s}$ für die Verteilung der Texas RedMoleküle in den micro-BLMs. Aus der Auswertung aller beobachteten Ereignisse konnte ein mittlerer Wert von $D=(14 \pm 9) \mu \mathrm{m}^{2} / \mathrm{s}(n=82)$ bestimmt werden. 


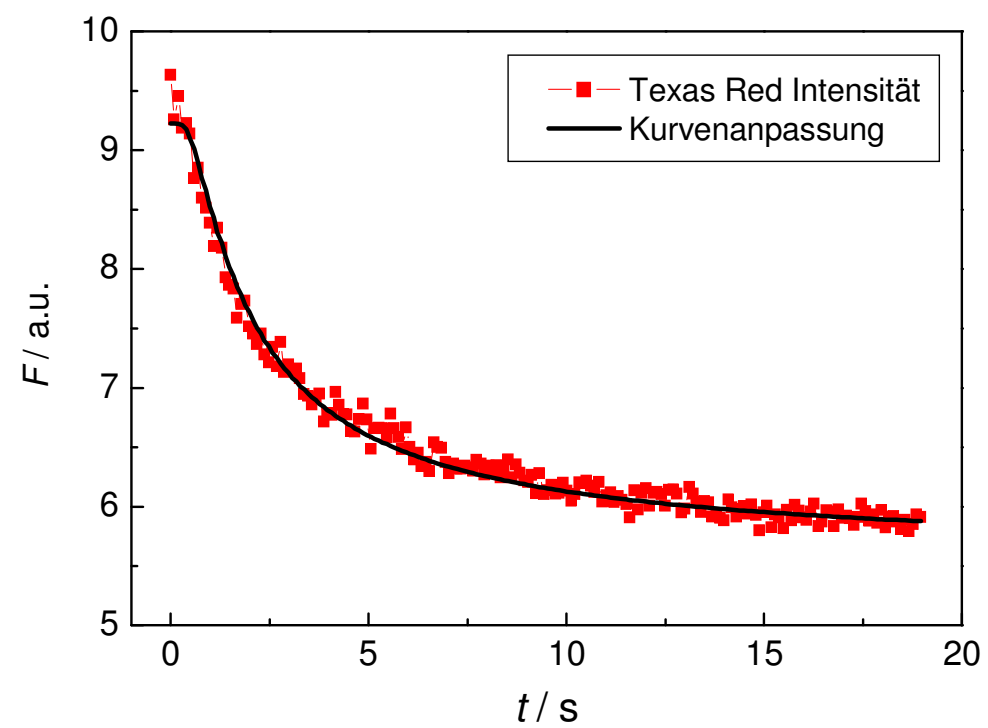

Abb. 4.11 Zeitlicher Verlauf der Texas Red-Fluoreszenzintensität nach der Fusion. Die Kurvenanpassung basierend auf Gleichung 4-3 liefert einen Diffusionskoeffizienten von $D=(11 \pm 1) \mu \mathrm{m}^{2} / \mathrm{s}$ für die Verteilung des Texas Red-Farbstoffs in der planaren Membran.

\subsection{Nachweis des Vesikelinhalts in geschlossenen Porentöpfen nach der Fusion von Vesikeln mit porenüberspannenden Membranen}

Zum Nachweis, dass die in Kapitel 4.2 dargestellten Beobachtungen der Ausschüttung des Vesikelinhalts während der Fusion zuzuschreiben sind und nicht durch Vesikelreißen oder ähnliches verursacht werden, wurden weitere Experimente mit micro-BLMs basierend auf porösen Silizium-Substraten mit geschlossenen Porenböden durchgeführt. Der Vesikelinhalt, der im Zuge der Fusion auf der anderen Seite der Membran ausgeschüttet werden sollte, kann somit in diesen Porentöpfen aufgefangen werden und mit Hilfe der Konfokalmikroskopie nachgewiesen werden können.

Zunächst mussten geeignete Bedingungen gefunden werden, unter denen der wässrige Fluoreszenzfarbstoff zweifelsfrei in den geschlossenen Poren nachgewiesen werden kann. Dazu wurden verschiedene Überlegungen gemacht, um die Abmessungen der Poren und die Farbstoffkonzentration festzulegen. Zunächst muss beachtet werden, dass die Poren einen bestimmten Durchmesser besitzen müssen, damit der Laserstrahl des Konfokalmikroskops ausreichend tief in die Poren eindringen und dort die Fluoreszenz 
anregen kann. Der Strahl wird durch das Objektiv auf die Probe fokussiert. Dabei besitzt jedes Objektiv einen charakteristischen Öffnungswinkel $\sigma$, der sich zusammen mit dem Brechungsindex $n$ des Mediums, in dem gemessen wird, in der numerischen Apertur NA widerspiegelt:

$$
N A=n \cdot \sin \sigma
$$

Je größer die numerische Apertur ist, desto größer ist der Öffnungswinkel. Dadurch kann der Laserstrahl nicht so weit in die Pore fokussiert werden wie bei kleineren numerischen Aperturen, da das Licht in einem flacheren Winkel auf das Substrat trifft und dann an den Porenkanten gebrochen wird (Abb. 4.12).

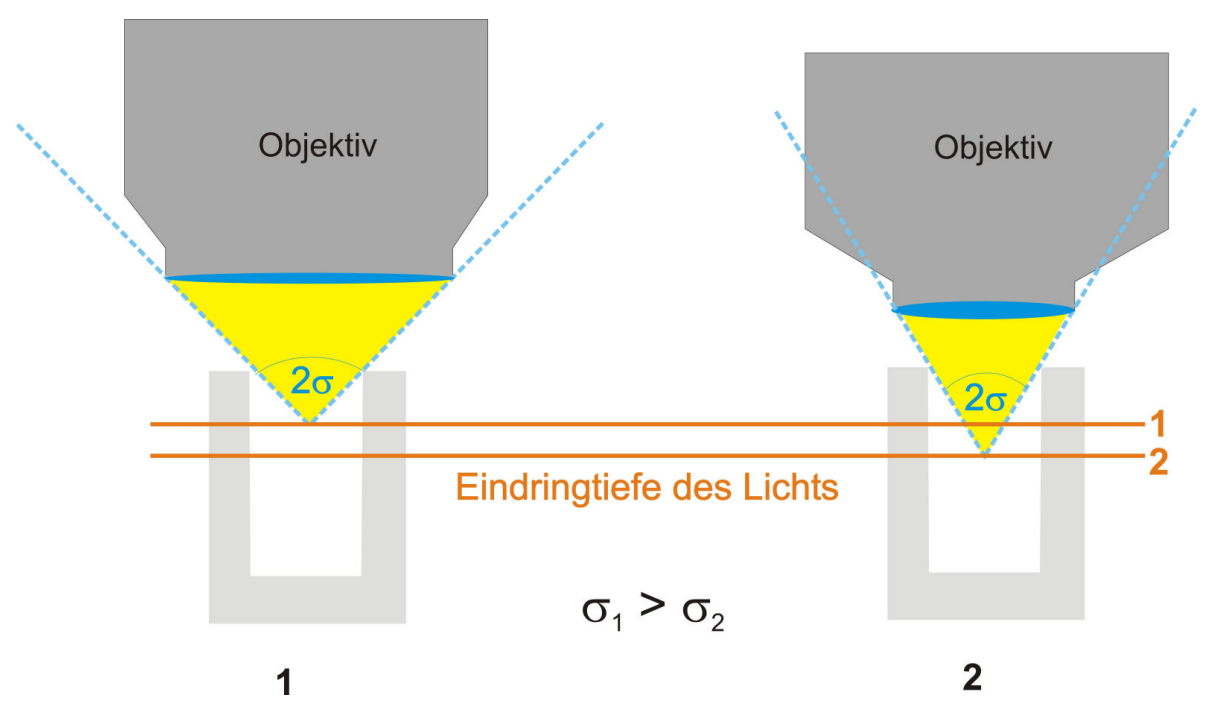

\begin{abstract}
Abb. 4.12 Schematische Darstellung zweier Objektive 1 und 2 mit unterschiedlicher numerischer Apertur zur Verdeutlichung, wie im Fall der Porensubstrate die Eindringtiefe des Lichts durch den Öffnungswinkel des Objektivs beeinflusst wird.
\end{abstract}

Dadurch wird die Eindringtiefe limitiert. Aus einfachen geometrischen Überlegungen wurde ein Mindestporendurchmesser von $2 \mu \mathrm{m}$ festgelegt (Kapitel 7), damit die Fluoreszenz bis zu einer Tiefe von mehreren Mikrometern in den Poren detektiert werden kann. Daraus ergibt sich der zweite Parameter, der für den erfolgreichen Nachweis des fluoreszierenden Vesikelinhalts in den geschlossenen Poren erfüllt sein muss. Die axiale Auflösung eines Konfokalmikroskops ist je nach Wellenlänge des verwendeten Laserlichts und Eigenschaften der optischen Komponenten auf ungefähr $1 \mu \mathrm{m}$ begrenzt. Dementsprechend erscheint eine Membran, obwohl ihre Dicke nur $5 \mathrm{~nm}$ beträgt, mit einer Ausdehnung von ca. $1 \mu \mathrm{m}$ in den Aufnahmen des Konfokalmikroskops. Die Tiefe der Kavitäten sollte somit größer als $1 \mu \mathrm{m}$ sein, damit die Fluoreszenz, die aus dem 
Inneren der Pore kommt, deutlich von der Membranfluoreszenz unterschieden werden kann. Gleichzeitig sollte die Porentiefe nicht zu groß gewählt werden, da auf diese Weise das Volumen stark ausgeweitet wird und dass die stärkere Verdünnung des fluoreszenzmarkierten Vesikelinhalts im Fall größerer Poren den Nachweis der Fluoreszenz erschwert.

In den durchgeführten Versuchen wurden Substrate mit einer hexagonalen Porenstruktur verwendet, die quadratische Poren mit einem Durchmesser von $8 \mu \mathrm{m}$ und eine Tiefe von $10 \mu \mathrm{m}$ aufwiesen. Die Porensubstrate wurden freundlicherweise von Dr. Stefan Schweizer (Universität Halle) zur Verfügung gestellt. In dem Fall, dass ein einzelner Vesikel mit einem Durchmesser von $600 \mathrm{~nm}$ mit einer Pore fusioniert, ist eine Verdünnung des wässrigen Farbstoffs im Vesikel um den Faktor 700 zu erwarten. Wird angenommen, dass der Farbstoff mit einer Konzentration von $5 \mathrm{mM}$ in den Vesikeln vorliegt, wird in den Poren nach der Fusion eine Konzentration von $0.03 \mathrm{mM}$ erreicht.

Auf Basis der beschriebenen Parameter wurde folgender Vorversuch durchgeführt. Das Substrat mit den geschlossenen Porenböden wurde mit Pyraninlösung der entsprechenden Konzentration von $0.03 \mathrm{mM}$ inkubiert und anschließend wurde eine fluoreszenzdotierte porenüberspannende Membran mittels der Painting-Technik präpariert. Nach dem Ausdünnen der Membran, wurde überschüssiges Pyranin über der Lipiddoppelschicht mit Puffer weggespült und anschließend wurden Bilder in den verschiedenen axialen ZEbenen des Substrats aufgenommen, um dreidimensionale Informationen der untersuchten Probe zu erhalten. In Abb. 4.13 ist das Ergebnis eines sogenannten ZStapels gezeigt. Dabei ist zunächst die Aufnahme aus einer ausgewählten Z-Ebene dargestellt. Am oberen Rand wurde aus den einzelnen Daten des Z-Stapels das Bild, das von der Y-Achse entlang der roten Linie und der Z-Ache aufgespannt wird, zusammengesetzt. Analog dazu ist am rechten Bildrand die XZ-Ebene gezeigt. In grün ist die Oregon Green-Fluoreszenz der porenüberspannenden Membran zu erkennen, während die Pyranin-Fluoreszenz in magenta dargestellt ist. In den meisten Poren liegt sowohl Oregon Green- als auch Pyranin-Fluoreszenz vor. In den XZ- und YZ-Schnitten ist $\mathrm{zu}$ erkennen, dass das Pyraninsignal auch unterhalb der Oregon Green-Fluoreszenz lokalisiert ist. Die Messungen zeigen, dass sich die Oregon Green-Fluoreszenz über einen Bereich von $4.3 \mu \mathrm{m}$ erstreckt. Im selben Bereich ist auch das Pyranin-Signal sichtbar. Dieses erstreckt sich aber noch weitere $7.4 \mu \mathrm{m}$ tief in die Pore. Neben überspannten Bereichen können auch Poren ohne Membran identifiziert werden. Ein Beispiel ist durch 
den roten Kreis gekennzeichnet. Entsprechende Poren weisen weder Oregon Green- noch Pyranin-Fluoreszenz auf. Des Weiteren treten aber auch Fälle auf, in denen zwar eine Membran über der Pore beobachtet wird, jedoch kein Pyranin in der Pore nachgewiesen werden kann (blauer Kreis).

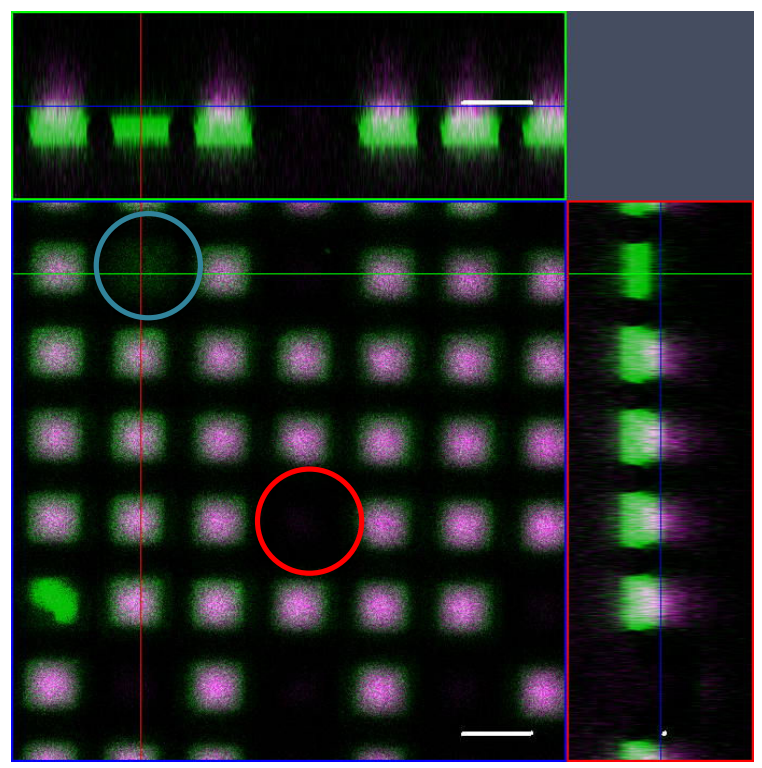

Abb. 4.13: Fluoreszenzmikroskopische Aufnahme eines Porensubstrats mit geschlossenen Porenböden (Porenmaße: $8 \times 8 \times 10 \mu \mathrm{m}^{3}$ ) gefüllt mit $0.03 \mathrm{mM}$ Pyraninlösung. Die Poren sind mit Oregon Greendotierten micro-BLMs überspannt (DPhPC/POPE 2:1 mit $1 \mathrm{~mol} \%$ Oregon Green, Funktionalisierung: DPPTE). Die Pyranin-Fluoresezenz ist in magenta dargestellt, das Oregon Green-Signal ist in grün zu erkennen. In der Mitte ist das Bild aus einer Z-Ebene dargstellt. Am oberen Bildrand ist der Schnitt durch die Ebenen entlang der grünen Linie zu sehen. Analog dazu ist am rechten Bildrand der Z-Schnitt entlang der roten Linie zu erkennen. Das Fluoreszenzsignal der porenüberspannenden Membran erstreckt sich dabei in Z-Richtung über $4.3 \mu \mathrm{m}$. Die Pyranin-Emission wurde über einen Z-Bereich von $11.7 \mu \mathrm{m}$ detektiert. Der Maßstabsbalken entspricht $10 \mu \mathrm{m}$.

Diese Beobachtung kann darauf zurückgeführt werden, dass die Pore wahrscheinlich schon während der Inkubation mit Pyraninlösung nicht mit Farbstoff gefüllt war. Dies könnte zum Beispiel dadurch bedingt sein, dass sich Luft in der entsprechenden Pore befand und die wässrige Farbstofflösung auf Grund der Oberflächenspannung des Wassers nicht in die Kavität eindringen konnte. Im anschließenden Painting-Prozess bildete sich dann wahrscheinlich an der bestehenden Luft-Wasser-Grenzfläche eine porenüberspannende Monoschicht aus.

Nachdem gezeigt werden konnte, dass der Farbstoff unter den gewählten Bedingungen gut in den membranüberspannten Kompartimenten nachgewiesen werden kann, wurden auf dieser Grundlage Fusionsexperimente durchgeführt. Dazu wurden Oregon Greendotierte porenüberspannende Membranen mittels Painting-Technik und Texas Red- 
dotierte, Pyranin-gefüllte LUVs mit einem Durchmesser von $600 \mathrm{~nm} \mathrm{zu}$ der Probe gegeben. In Abb. 4.14 ist eine entsprechende Zeitserie gezeigt. Das hier abgebildete Fusionereignis ist vor allem durch die Texas Red-Verteilung in der planaren Membran zu identifizieren, da der Vesikel lediglich im roten Kanal detektiert wurde (weißer Pfeil). Nach der Annäherung des Vesikels $(t<0)$ verteilen sich die Lipide des Vesikels innerhalb einer Pore.
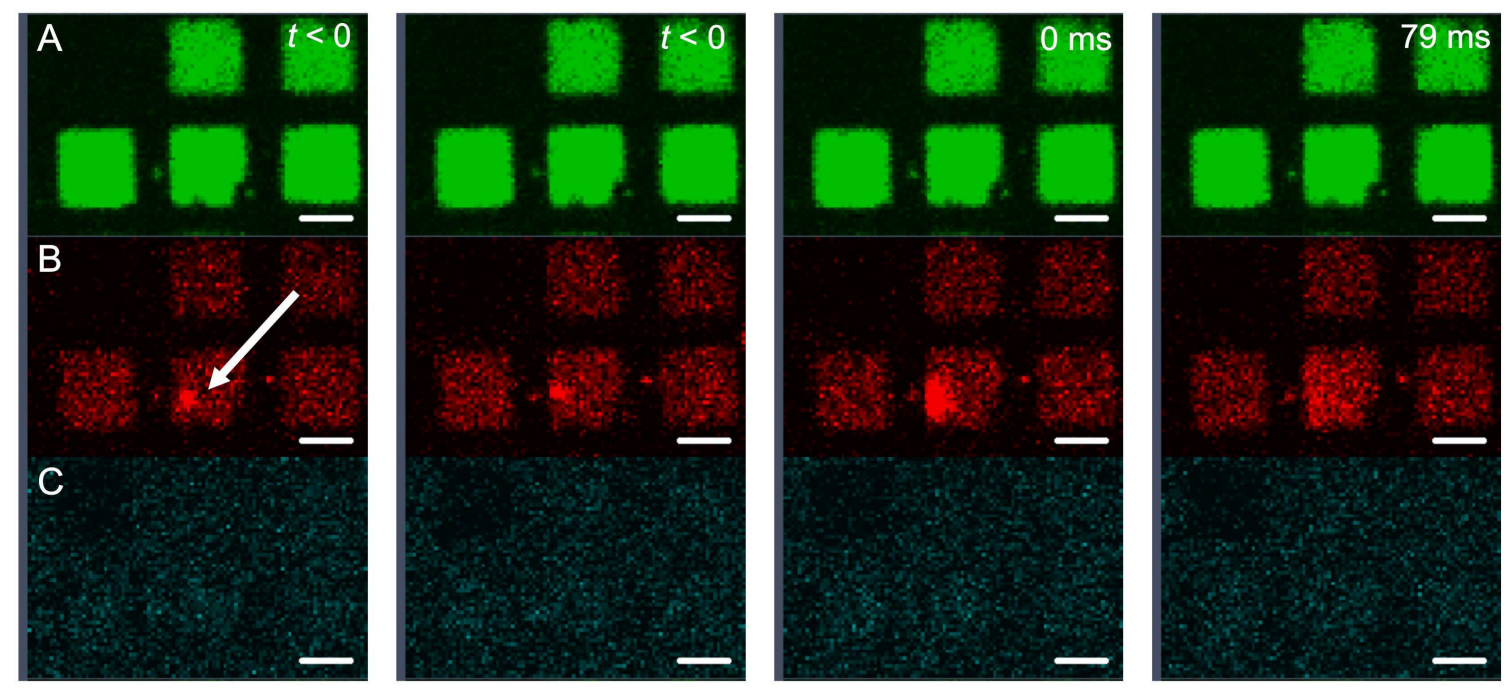

Abb. 4.14 Fluoreszenzmikroskopische Aufnahme der Interaktion eines LUVs (POPC/POPS/Texas Red 78:20:2, gefüllt mit $40 \mathrm{mM}$ Pyranin, $200 \mathrm{mM}$ Sucrose, $100 \mathrm{mM} \mathrm{KCl}, 10 \mathrm{mM}$ MES, pH = 6.5) mit microBLMs (DPhPC/POPE 2:1, dotiert mit 2 mol\% Oregon Green, Funktionalisierung: DPPTE) in Ca ${ }^{2+}$-Puffer $(100 \mathrm{mM} \mathrm{KCl}, 10 \mathrm{mM} \mathrm{CaCl}$, $10 \mathrm{mM}$ HEPES, $\mathrm{pH}=7.4)$. Die micro-BLMs wurden auf einem porösen Siliziumsubstrat mit geschlossenen Porenböden präpariert (Maße der Pore: $8 \times 8 \times 10 \mu^{3}$ ). Die Emission wurde spektral getrennt und in drei unterschiedlichen Kanälen detektiert (Pyranin (A), Oregon Green (B), Texas Red (C)). Während im blauen Kanal lediglich Hintergrundfluoreszenz und im grünen Kanal die micro-BLMs zu erkennen sind, kann im roten Kanal ein Vesikel beobachtet werden, dessen Fusion mit den micro-BLMs bei $t=0 \mathrm{~ms}$ durch die Verteilung des roten Farbstoffs in der planaren Membran indiziert wird. Der Maßstabsbalken entspricht $5 \mu \mathrm{m}$.

Daraus resultiert in den zeitabhängigen Fluoreszenzprofilen (Abb. 4.15) für den Texas Red-Kanal ein exponentieller Abfall, wie er zuvor auch in den Lipidvermischungsexperimenten beobachtet wurde. Die Pyraninfluoreszenz zeigt in den Aufnahmen der Zeitserie nur ein Hintergrundrauschen, während im grünen Kanal die porenüberspannenden Membranen zu sehen sind. In keinem der Kanäle kann jedoch die Pyranin-Fluoreszenz des im roten Kanal sichtbaren Vesikels identifiziert werden. Außerdem ist auch keine FRET-bedingte Löschung der Oregon Green-Fluoreszenz im Zuge der Fusion auszumachen. Auch in den Zeitprofilen der Fluoreszenzintensitäten 
zeigt sich über die Zeit keinerlei Veränderung, sondern beide Signale bleiben bei einem konstanten Wert.

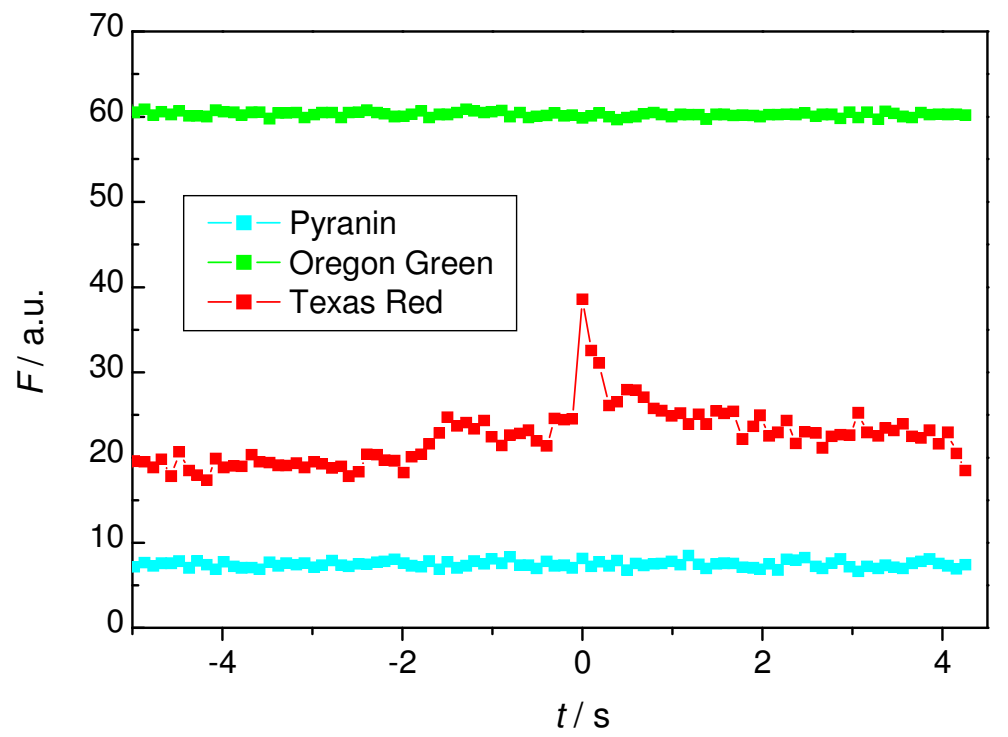

\begin{abstract}
Abb. 4.15 Zeitlicher Verlauf der Fluoreszenzintensitäten von Pyranin, Oregon Green und Texas Red. Die gemittelten Intensitäten innerhalb eines definierten ROIs wurden aus der in Abb. 4.14 gezeigten Zeitserie extrahiert. Zum Zeitpunkt der Fusion bei $t=0 \mathrm{~s}$ fällt die Texas-Red innerhalb von ungefähr $2 \mathrm{~s}$ auf ihren Ursprung zurück. Die Intensität der Pyranin- und der Oregon Green-Fluoreszenz zeigen über den gesamten beobachteten Zeitraum keinerlei Veränderung.
\end{abstract}

Um zu überprüfen, ob der wässrige Farbstoff während des Fusionsprozesses dennoch in das untere geschlossene Kompartiment gelangen konnte, wurden vor und nach Zugabe der Vesikel jeweils Z-Stapel im blauen und grünen Kanal aufgenommen und miteinander verglichen (Abb. 4.16). Es ist zu erkennen, dass die Membran sowohl vor und nach der Zugabe von Vesikeln zu sehen ist und dabei mit einer Dicke von 2.9 bzw. $2.6 \mu \mathrm{m}$ erscheint. Obwohl in den Zeitserien, die nach der Vesikelzugabe von der entsprechenden Stelle aufgenommen wurden, deutlich zu erkennen ist, dass die Vesikel zumindest im roten Kanal eine Lipidvermischung zeigen und somit auch ihren Inhalt in die Poren unter der Membran entleeren sollten, kann in den Kompartimenten kein Pyraninfarbstoff detektiert werden. 

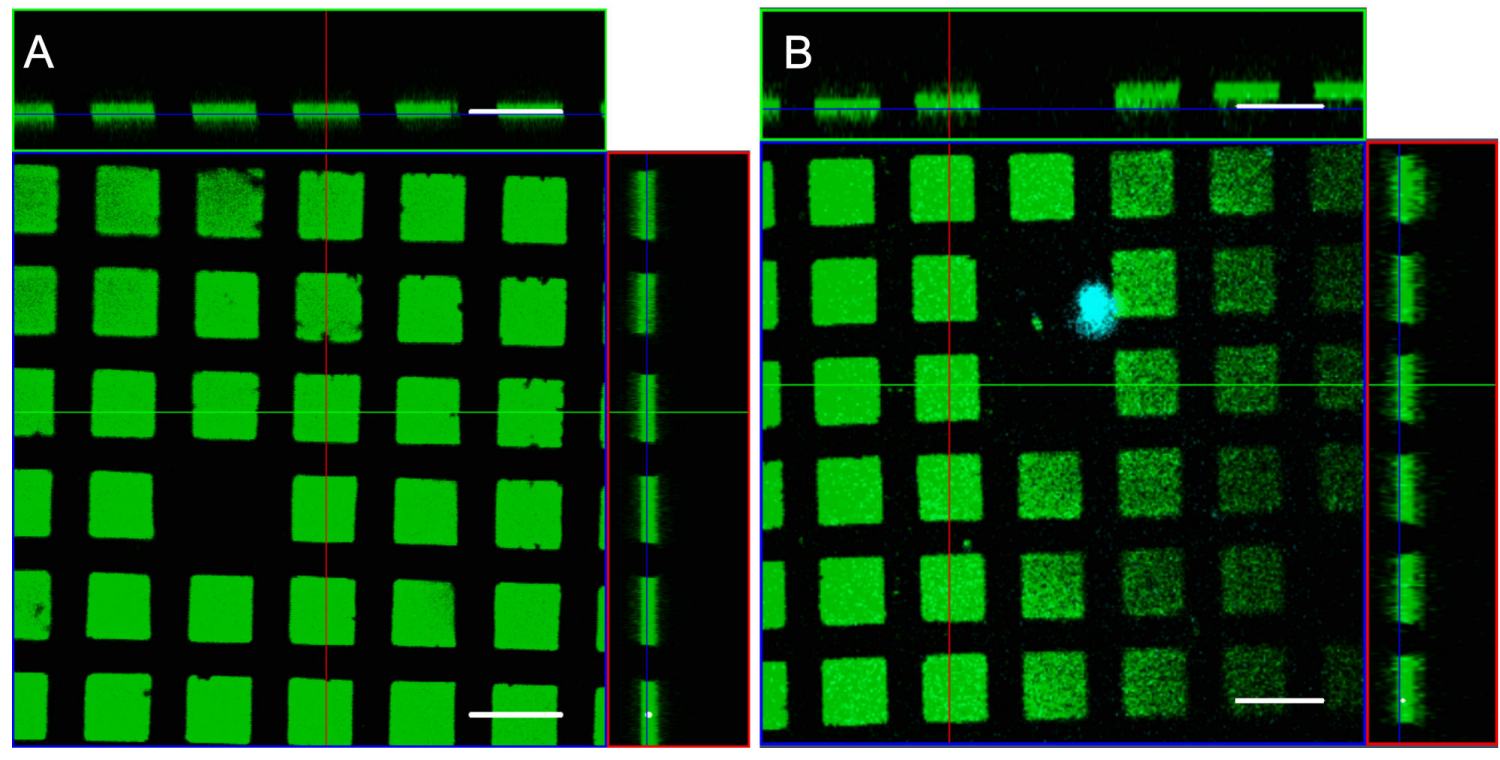

Abb. 4.16 Fluoreszenzmikroskopische Aufnahme eines Porensubstrats $\left(8 \times 8 \times 10 \mu \mathrm{m}^{3}\right)$ vor $(\mathbf{A})$ und nach (B) der Zugabe von LUVs (POPC/POPS/Texas Red 78/20/2, gefüllt mit $40 \mathrm{mM}$ Pyranin, $200 \mathrm{mM}$ Sucrose, $100 \mathrm{mM} \mathrm{KCl}, 10 \mathrm{mM}$ HEPES, $\mathrm{pH}$ = 7.4). Die Poren sind mit Oregon Green-dotierten micro-BLMs überspannt (DPhPC/POPE 2:1 mit $1 \mathrm{~mol} \%$ Oregon Green, Funktionalisierung: DPPTE), die in grün dargestellt sind. In blau ist die Pyraninfluoreszenz gezeigt. Vor der Zugabe von Pyranin-gefüllten LUVs ist kein Pyraninsignal zu sehen, nach der Zugabe wird im blauen Kanal lediglich eine schwache Hintergrundfluoreszenz sichtbar. Der Maßstabsbalken entspricht $10 \mu \mathrm{m}$.

Obwohl bereits die vierfache Menge an wasserlöslichem Farbstoff im Vergleich zu der in den Vorversuchen angenommenen Konzentration eingesetzt wurde, kann kein Pyranin in den Poren nachgewiesen werden.

Ein großes Problem stellt dabei vor allem die geringe Fotostabilität des gewählten Farbstoffs dar. Dadurch wird ein Großteil des Pyranins im Vesikel bereits während der Annäherung an die Membranoberfläche zerstört, so dass dieser im blauen Kanal kaum zu erkennen ist. Deshalb wurde in einem nächsten Schritt die Fusion von Pyranin-gefüllten GUVs mit den porenüberspannenden Membranen untersucht. Auf diese Weise wird die Menge des Vesikelinhalts, der potenziell in die geschlossenen Porentöpfe ausgeschüttet wird, erhöht. Der Verdünnungsfaktor für den Farbstoff, der im Fall der Fusion eines GUVs mit einem Durchmesser von $d=5 \mu \mathrm{m}$ in eine Pore mit den Abmessungen $8 \times 8 \times$ $10 \mu \mathrm{m}^{3}$ ausgeschüttet wird, ist 350 fach geringer als bei der Fusion eines LUVs mit einem Durchmesser von $d=600 \mathrm{~nm}$. Eine Schwierigkeit besteht allerdings darin, dass GUVs weder für die Säulenchromatographie geeignet sind noch zentrifugiert werden 
können, um den externen Farbstoff, der nach der Vesikelherstellung die GUVs umgibt, zu entfernen. Deshalb wurde der GUV-Lösung DPX ( $p$-Xylen-bis-Pyridiniumbromid) zugegeben. Dabei handelt es sich um ein Kation, das die Fluoreszenz von verschiedenen wasserlöslichen Farbstoffen löscht. Da DPX nicht membrangängig ist, wird durch die Zugabe zu der GUV-Lösung die Fluoreszenz außerhalb der GUVs gelöscht, während das von den GUVs eingeschlossene Pyranin weiterhin fluoresziert. Auf diese Weise konnte in den Fusionexperimenten mit Pyranin-haltigen GUVs das Signal/Rausch-Verhältnis stark verbessert werden. In Abb. 4.17 ist ein typisches Einzelfusionsereignis eines GUVs mit porenüberspannenden Membranen basierend auf den geschlossenen Porensubstraten gezeigt. In den ersten beiden Aufnahmen erreicht der GUV die Substratoberfläche bevor ab dem dritten Bild die Verteilung des Texas Red-Farbstoffs in der porenüberspannenden Membran und die Löschung der Oregon Green-Fluoreszenz zu beobachten ist. Dies legt den Schluss nahe, dass eine Lipidvermischung im Zuge der Fusion stattgefunden hat. Zusätzlich ist der Verlust der Pyranin-Fluoreszenz zu erkennen ist. Das Pyranin-Signal ist nach 506 ms verschwunden. Während es im zweiten Bild noch deutlich sichtbar ist, kann in der dritten Aufnahme nur noch ein sehr schwaches Signal detektiert werden. Im vierten Bild ist die Pyranin-Fluoreszenz gar nicht mehr sichtbar. Wie bereits in den Experimenten zur Vesikelauschüttung, die mit den geöffneten Porensubstraten durchgeführt wurden (Kapitel 4.2), ist der Vesikel durch einen spektralen Überlapp zwischen Pyranin und Oregon Green auch im grünen Kanal sichtbar. Anders als in den bisherigen Beobachtungen zur Vesikelausschüttung, ist bei Betrachtung des blauen Kanals im dritten Bild ein leichter blauer Schleier über dem Substrat zu erkennen. Dieser tritt offentsichtlich simultan mit der Verteilung der Texas Red-Fluoreszenz und der Oregon Green-Löschung auf, die die Lipidvermischung indizieren sollten. Diese Verteilung der Pyranin-Fluoreszenz scheint oberhalb der porenüberspannenden Membran lokalisiert zu sein, da die Struktur der fluoreszenzlöschenden Porenstege nicht zu erkennen ist. Würde das Signal aus Ebenen unterhalb der planaren Membran stammen, so wäre zu erwarten, dass keine homogene Fluoreszenzwolke zu detektierten ist, sondern, dass auch im blauen Kanal das Muster der Poren zu erkennen wäre. 

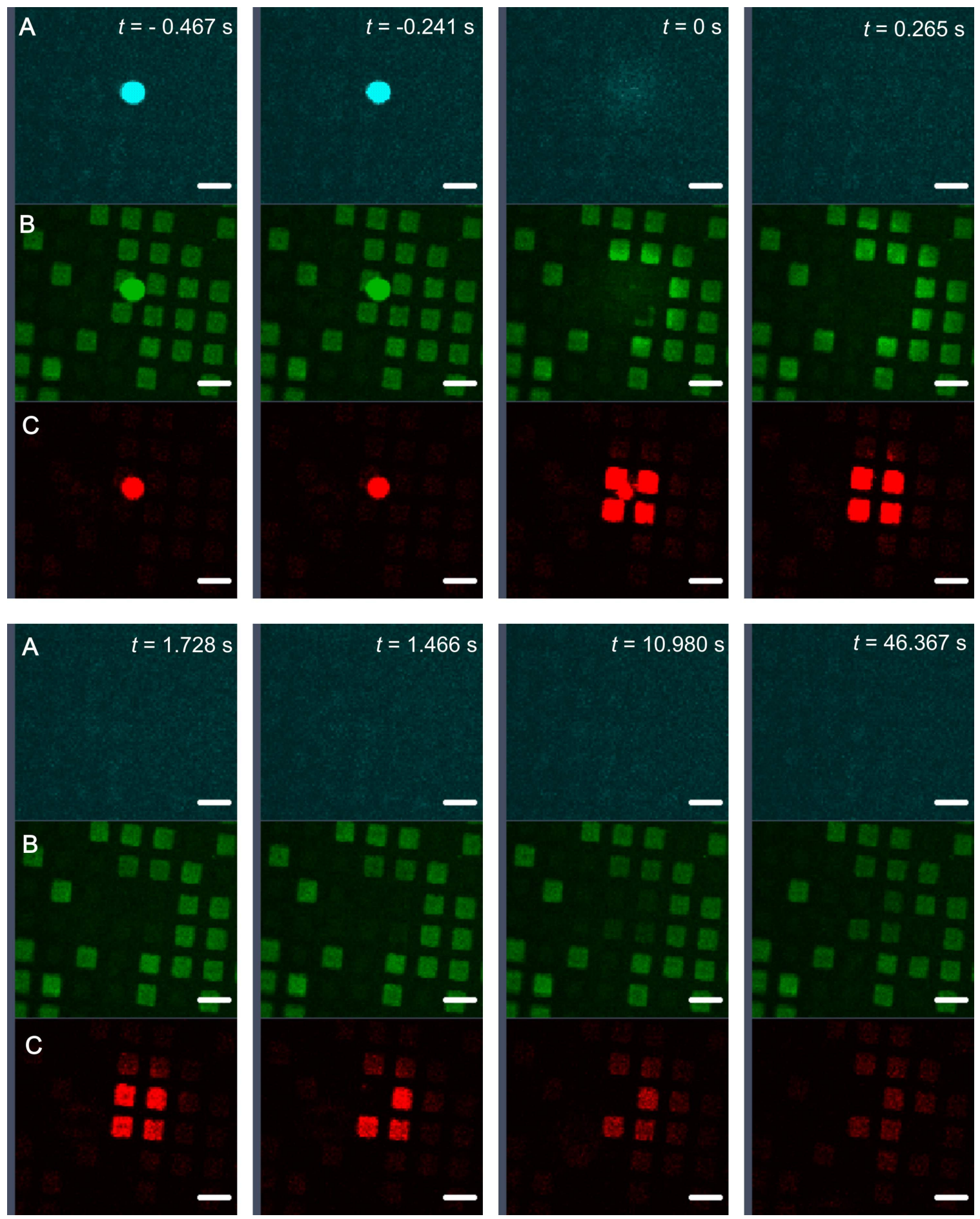

Abb. 4.17 Fluoreszenzmikroskopische Aufnahme der Fusion eines GUVs (DPhPC/Texas Red 98:2, gefüllt mit $5 \mathrm{mM}$ Pyranin, $200 \mathrm{mM}$ Sucrose, $100 \mathrm{mM} \mathrm{KCl}, 10 \mathrm{mM}$ MES, $\mathrm{pH}=6.5$ ) mit micro-BLMs (DPhPC/POPE 2:1, dotiert mit 2 mol\% Oregon Green, Funktionalisierung: DPPTE) in $\mathrm{Ca}^{2+}$-Puffer (100 $\mathrm{mM} \mathrm{KCl}, 10 \mathrm{mM} \mathrm{CaCl}, 10 \mathrm{mM}$ HEPES, $\mathrm{pH}=7.4)$. Die micro-BLMs wurden auf einem porösen Siliziumsubstrat mit geschlossenen Porenböden präpariert (Maße der Pore: $8 \times 8 \times 10 \mu \mathrm{m}^{3}$ ). Die Emission wurde spektral getrennt und in drei unterschiedlichen Kanälen detektiert (Pyranin (A), Oregon Green (B), Texas Red $(\mathbf{C})$ ). In allen drei Kanälen ist ein Vesikel zu erkennen. Bei $t=0 \mathrm{~s}$ wird die Verteilung des roten Farbstoffs in der planaren Membran und die simultane Löschung der Oregon Green-Fluoreszenz sichtbar. Gleichzeitig verschwindet die Pyraninfluoreszenz. Während im dritten Bild noch eine schwache Fluoreszenzwolke zu erkennen ist, wird ab $t=0.265 \mathrm{~s}$ im blauen Kanal nur noch Hintergrundfluoreszenz detektiert. Der Maßstabsbalken entspricht $10 \mu \mathrm{m}$. 
In dem Zeitprofil der Fluoreszenzintensitäten, aus der in Abb. 4.17 gezeigten Zeitserie werden die Beobachtungen der Lipidvermischung und der Pyraninausschüttung widergespiegelt. Die Texas Red-Intensität zeigt nach ihrem Anstieg einen exponentiellen Abfall. Die Rückkehr auf den Ursprungswert kann in dem gezeigten Zeitprofil nicht beobachtet werden, was an der großen Menge an Texas Red-Molekülen, die in die planare Membran durch die Fusion des sehr großen GUVs liegen kann. Dadurch ist über einen sehr langen Zeitraum eine erhöhte rote Intensität auszumachen, da die Verteilung der vielen Farbstoffmoleküle über das gesamte Substrat länger dauert. Die Oregon Green-Fluoreszenz zeigt zum Zeitpunkt der Fusion auf Grund der FRET-bedingten Fluoreszenzlöschung einen sprunghaften Abfall und einen anschließenden Wiederanstieg des Signals. Die Pyranin-Fluoreszenz fällt innerhalb von $0.5 \mathrm{~s}$ auf seinen Ausgangswert zurück.

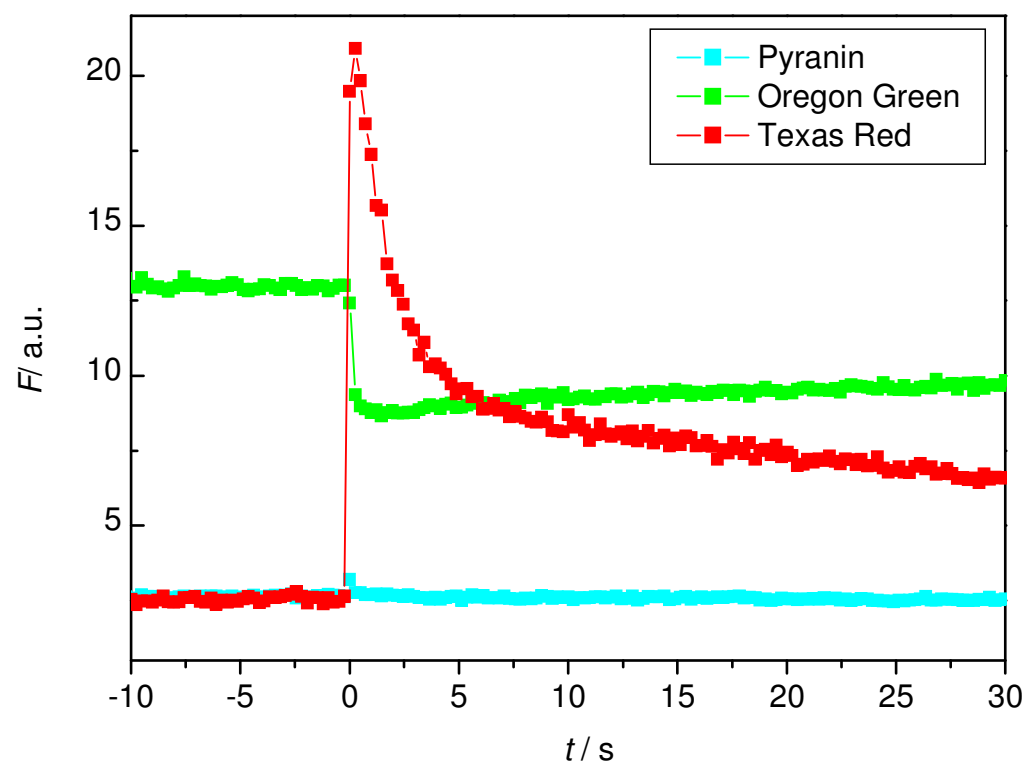

\begin{abstract}
Abb. 4.18 Zeitlicher Verlauf der Fluoreszenzintensitäten von Pyranin, Oregon Green und Texas Red. Die gemittelten Intensitäten innerhalb eines definierten ROIs wurden aus der in Abb. 4.17 gezeigten Zeitserie extrahiert. Zum Zeitpunkt der Fusion bei $t=0 \mathrm{~s}$ fällt die Texas-Red-Fluoreszenz exponentiell ab. Die Intensität der Pyranin- und der Oregon Green-Fluoreszenz zeigen einen sprunghaften Abfall, der im Fall des grünen Signals eine Regeneration auf seinen Ausgangswert erkennen lässt.
\end{abstract}

Ein Vergleich der Z-Stapel, die vor und nach der Fusion von GUVs aufgenommen wurden, zeigt, dass kein Pyranin in den Kompartimenten unter der Membran zu finden ist. In beiden Aufnahmen ist lediglich die in grün gezeigte porenüberspannende Membran zu sehen. Die Lipiddoppelschicht erscheint dabei in der Aufnahme vor Vesikelzugabe 
$2.0 \mu \mathrm{m}$ und danach $1.4 \mu \mathrm{m}$ dick. Vor Vesikelzugabe ist gar kein Pyranin-Signal detektierbar, während danach Pyranin-Fluoreszenz zu erkennen ist. Diese wird allerdings nur als Hintergrundrauschen oberhalb der Membran sichtbar. Ein eindeutiges Signal aus dem Inneren der membranüberspannten Kompartimente kann nicht ausgemacht werden und lässt darauf schließen, dass kein wasserlöslicher Farbstoff in die Poren ausgeschüttet wurde.
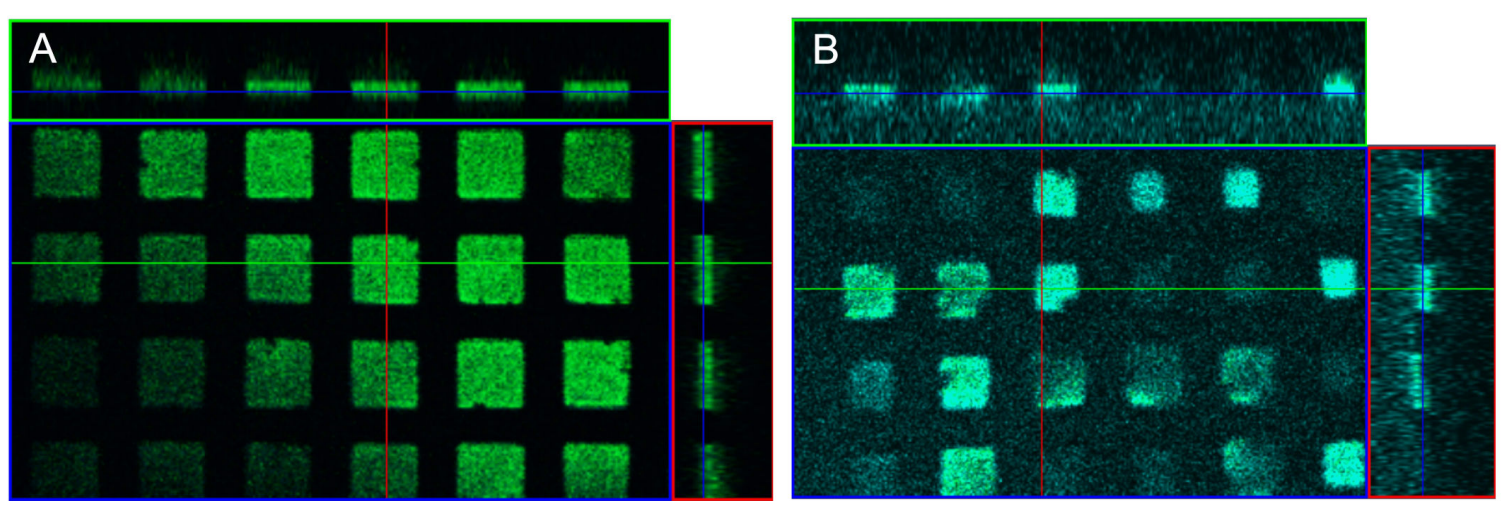

Abb. 4.19 Fluoreszenzmikroskopische Aufnahme eines Porensubstrats $(8 \times 8 \times 10 \mu \mathrm{m})$ vor (A) und nach (B) der Zugabe von GUVs, die mit den porenüberspannenden Membranen fusionieren. Die Poren sind mit Oregon Green-dotierten micro-BLMs überspannt (DPhPC/POPE 2:1 mit 1 mol\% Oregon Green, Funktionalisierung: DPPTE), die in grün dargestellt ist. In blau ist die Pyraninfluoreszenz gezeigt. Vor der Zugabe von pyranin-gefüllten LUVs (DPhPC/Texas Red 98:2, gefüllt mit 5 mM Pyranin, $200 \mathrm{mM}$ Sucrose, $100 \mathrm{mM} \mathrm{KCl}, 10 \mathrm{mM}$ HEPES, $\mathrm{pH}=7.4$ ) ist kein Pyraninsignal zu sehen. Nach der Zugabe wird im blauen Kanal lediglich eine schwache Hintergrundfluoreszenz sichtbar.

Diese einzelne Aufnahme, in der die Verteilung der Pyranin-Fluoreszenz oberhalb der Membran zu erkennen ist (Abb. 4.17), legt die Vermutung nahe, dass der wässrige Farbstoff in den Poren nicht nachgewiesen werden kann, weil dieser dort nicht ankommt. Durch das Reißen der Vesikelmembran während des Fusionprozesses könnte der Vesikelinhalt unter Umständen auch an den Seiten in das obere wässrige Kompartiment entweichen. Dabei stellt sich die Frage, ob dies in jedem Fall geschieht, also unabhängig von der Vesikelgröße ist oder ob es sich dabei um ein Phänomen handelt, das lediglich im Fall von GUVs auftritt. Die Beobachtung, dass GUVs im Gegensatz zu LUVs in den durchgeführten Experimenten auch unspezifisch mit porenüberspannenden Membranen in Abwesenheit eines Fusogen fusionieren, wurde in anderen Versuchen zur Untersuchung der Peptid-vermittelten Fusion gemacht (siehe Kapitel 4.5.1.2).

Daraufhin wurde die Spezifität der Fusion der GUVs mit micro-BLMs basierend auf den geschlossenen Porensubstraten überprüft. Dazu wurden zwei verschiedene Experimente 
durchgeführt. Zunächst wurde die $\mathrm{Ca}^{2+}$-Abhängigkeit der Fusion analysiert. Pyraningefüllte GUVs wurden zu porenüberspannenden Membranen in $\mathrm{Ca}^{2+}$-freiem Puffer gegeben. Trotz des Fehlens eines fusogenen Stoffes wurden in diesem Fall Fusionereignisse beobachtet. Zusätzlich wurde das gleiche Experiment mit offenen Porensubstraten durchgeführt und auch dabei wurde eine unspezifische Fusion in Abwesenheit eines fusogenen Stoffes beobachtet.

Die fehlende Spezifität der Lipidvermischungsbeobachtungen könnte ein Indiz dafür sein, dass im Fall der GUVs gar keine Fusion stattfindet. Wenn im Zuge dessen ein Vesikelreißen oder ähnliches eintritt, so wird der Vesikelinhalt nicht in die unter der Membran liegenden Kompartimente ausgeschüttet und kann somit auch nicht dort nachgewiesen werden.

Gleichzeitig konnte die Vesikelausschüttung in die Porentöpfe auch nicht während der Fusion von LUVs mit den porenüberspannenden Membranen beobachtet werden. Eine mögliche Erklärung dafür liefert die geringe Vesikelgröße und somit das geringe Volumen an Farbstofflösung, dass nach der Fusion in den geschlossenen Poren stark verdünnt ist und demnach nicht mehr nachgewiesen werden kann. Abschließend konnte im Rahmen dieser Arbeit allerdings keine endgültige Klärung dieses Sachverhalts gefunden werden. 


\subsection{Untersuchung der Morphologie von porenüberspannenden Membranen nach der Fusion von LUVs mittels Rasterionenleit- fähigkeitsmessungen}

Durch die Fusion jedes Vesikels mit micro-BLMs wird zusätzliches Lipidmaterial in das die porenüberspannenden Membran eingebaut. Dieses Material muss zusätzlich im System untergebracht werden. Die Frage, die sich dabei stellt, ist, ob sich durch die Fusion von LUVs mit micro-BLMs die Topologie der Membran soweit ändert, als dass diese Änderungen mit Hilfe einer Oberfächen abbildenden Methode detektiert werden können. Dafür wurde die Technik der Rasterionenleitfähigkeitsmikroskopie (scanning ion conductance microscopy, SICM) genutzt, da sie im Gegensatz $\mathrm{zu}$ anderen topologischen Messverfahren, wie zum Beispiel der Rasterkraftmikroskopie, die Probe vollkommen kontaktfrei abrastert und dabei trotzdem Auflösungen sowohl lateral als auch axial im Bereich von 10 - 100 nm liefert.

Zunächst soll gezeigt werden, dass sich die Methode der Rasterionenleitfähigkeitsmikroskopie eignet, um porenüberspannende Membranen abzubilden. In einer exemplarischen Grafik in Abb. 4.20 A ist die SICM-Aufnahme von porenüberspannenden Membranen präpariert mittels Painting-Technik auf einem porösen Substrat mit Porendurchmessern von $1.2 \mu \mathrm{m}$ zu sehen. Dabei zeigt sich, dass im Wesentlichen zwei Bereiche mit signifikant unterschiedlichen Höhen differenziert werden können. Die Porenstege des porösen Substrats heben sich deutlich von den tieferliegenden membranüberspannten Poren ab. Diese Beobachtung kann auf den engen Kontakt der Membran zur Goldoberfläche des Porensubstrats zurückgeführt werden. Die Schichtdicke des Goldes beträgt ca. $80-90 \mathrm{~nm}$ (Abb. 4.20 C). Bei der Inkubation mit 1,2-Dipalmityl-sn-glycero-3-phospothioethanol (DPPTE) binden die Thiolipide nicht nur entlang der Goldfläche an den horizontalen Flächen des Substrats, sondern auch vertikal an der Goldschicht entlang. Es wird angenommen, dass durch die Wechselwirkung der Lipide mit den hydrophoben Resten des DPPTE die Lipiddoppelschicht der Goldoberfläche in die Pore hinein folgt (Abb. 4.20 B). Dadurch würde ein Höhenunterschied zwischen Porensteg und porenüberspannender Membran entstehen. Dieser wird im Folgenden auch als Porentiefe bezeichnet. Die SICM-Aufnahmen dieser Arbeit und die darin sichtbaren Höhenunterschiede zwischen Stegbereichen und porenüberspannenden Membranen lassen den Schluß zu, dass die Membranen sich wie 
vermutet anordnen. Ähnliche Befunde lieferten bereits SICM-Analysen von Böcker et $a l .{ }^{94}$ und AFM-Untersuchungen sowohl von Mey et al. ${ }^{95}$ als auch von Hennesthal et al. ${ }^{96}$
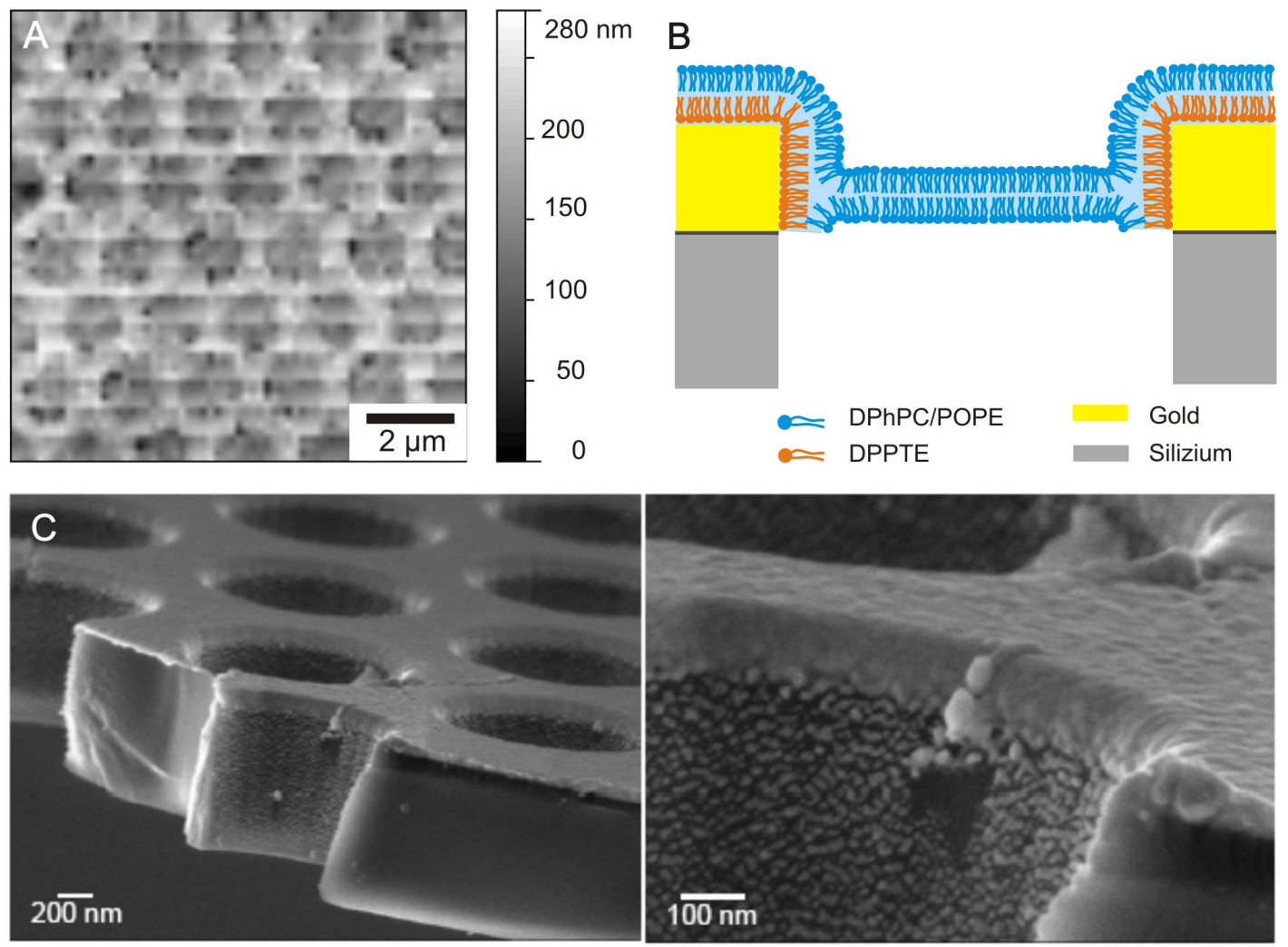

Abb. 4.20 A SICM-Aufnahme einer porenüberspannenden Membran. Die Bildgröße beträgt $10 \times 10 \mu \mathrm{m}^{2}$ mit einer Auflösung von $512 \times 512$ Pixel. B Schematische Darstellung einer porenüberspannenden Membran, die der Funktionalisierung entlang der Goldschicht in die Pore folgt. C Rasterelektronenmikroskopische Aufnahmen von porösem Silizium mit einem Porendurchmesser von $1.2 \mu \mathrm{m}$, auf das eine $60 \mathrm{~nm}$ dicke Schicht Gold aufgedampft wurde. Deutlich ist der Unterschied zwischen Siliziumnitrid- und der darüberliegenden Goldschicht zu erkennen Die Rasterelektronenmikroskopbilder wurden der Veröffentlichung von Mey et al. entnommen. ${ }^{95}$

Dass die gemessenen Porentiefen tatsächlich porenüberspannenden Membranen zuzuordnen sind, zeigt ein Vergleich mit nicht überspannten Poren, wie sie am unteren Bildrand in Abb. 4.21 A gezeigt sind. In der Abbildung ist eine SICM-Aufnahme von einem membranüberspannten Porensubstrat dargestellt. Darin erscheinen die zwei offenen Poren in schwarz, da diese, wie der Höhenskala zu entnehmen ist, eine Tiefe von über $11 \mu \mathrm{m}$ zeigen. Die übrigen Poren hingegen zeigen Tiefen im Bereich von ungefähr $100 \mathrm{~nm}$. Dies wird auch dem dazugehörigen Höhenprofil entlang der Abb. 4.21 A gezeigten roten Linie deutlich. Während die SICM-Spitze bis zu $11.5 \mu \mathrm{m}$ tief in die nicht von einer Membran überspannten Poren eindringen kann, heben sich die zwei 
dazwischenliegenden membranüberspannten Poren mit Tiefen von maximal $200 \mathrm{~nm}$ von dem Stegbereich ab.
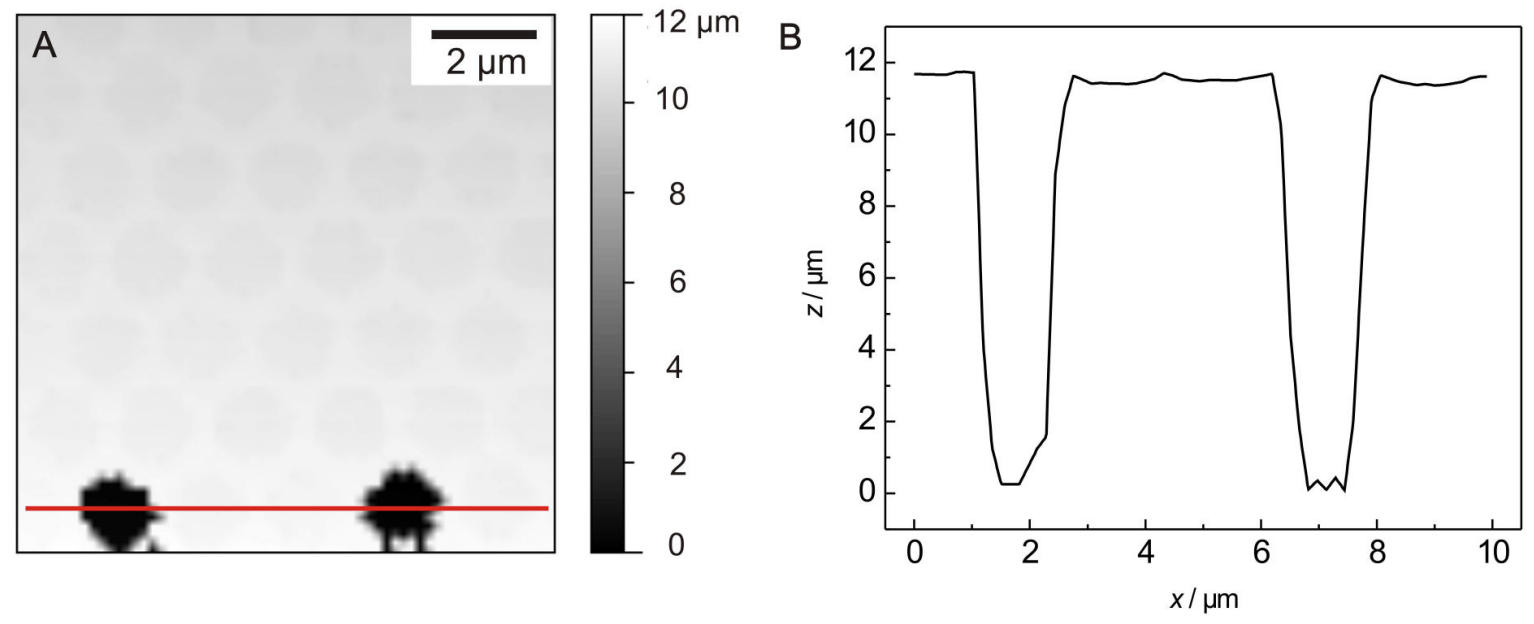

Abb. 4.21 A SICM-Aufnahme von porenüberspannenden Membranen. In der Abbildung sind deutlich die in einem hellgrauen Farbton dargestellten Bereiche des porösen Substrats zu erkennen, die von einer Membran überspannt sind und sich von den in schwarz gezeigten offenen Poren zu unterscheiden. Die Bildgröße beträgt $10 \times 10 \mu \mathrm{m}^{2}$ mit einer Auflösung von $512 \times 512$ Pixel. B Das Höhenprofil entlang der in A gezeigten roten Linie zeigt die Höhenunterschiede zwischen membranüberspannten und offenen Poren. In dem Bereich $x=1-2.6 \mu \mathrm{m}$ und $x=6.2-7.9 \mu \mathrm{m}$ werden Höhenunterschiede von bis zu $11.5 \mu \mathrm{m}$ detektiert, wohingegen im Bereich $x=2.6-6.2 \mu \mathrm{m}$ jeweils zweimal eine wesentlich geringere Vertiefung mit maximal $200 \mathrm{~nm}$ zu erkennen ist.

Diese Befunde zeigen, dass membranüberspannte und offene Poren deutlich voneinander $\mathrm{zu}$ unterscheiden sind und somit die nachfolgend beschriebenen Beobachtungen auf Veränderungen der Membrantopologie zurückgeführt werden können.

Um die Veränderung der Oberflächenstruktur von micro-BLMs nach der Fusion von Vesikeln zu untersuchen, wurden zunächst von einer Probe vor der Fusion an verschiedenen Stellen SICM-Aufnahmen durchgeführt. Um den beschriebenen Höhenunterschied quantifizieren zu können, wurde über jede einzelne Pore ein Höhenprofil gelegt und die Differenz zwischen Steg und porenüberspannender Membran ausgelesen. Dazu wurden, wie in Abb. 4.22 C gezeigt, jeweils die zwei höchsten Punkte zwischen den Poren und der tiefste Punkt in der Pore bestimmt. Aus den zwei höchsten Punkten wurde der Mittelwert gebildet und durch die Subtraktion des tiefsten Werts anschließend die Höhendifferenz berechnet. Die Porentiefen eines Experiments sind in einem Histogramm in Abb. 4.22 D zusammengefasst. In diesem Fall variieren die Werte zwischen $45-85 \mathrm{~nm}$. 
Nach der erfolgreichen Abbildung der porenüberspannenden Membranen vor der Fusion mit Vesikeln, wurde die Probe mit LUVs inkubiert und anschließend mit $\mathrm{Ca}^{2+}$-Puffer gespült, um überschüssige Vesikel zu entfernen. Dass unter diesen Bedingungen Fusion der Vesikel mit porenüberspannenden Membranen stattfindet, wurde in den Experimenten zur Lipidvermischung fluoreszenzmikroskopisch belegt (Kapitel 4.1). Die Probe wurde dann wieder an verschiedenen Stellen mit dem SICM abgerastert, um topographische Bilder der Membran nach der Fusion zu erhalten.
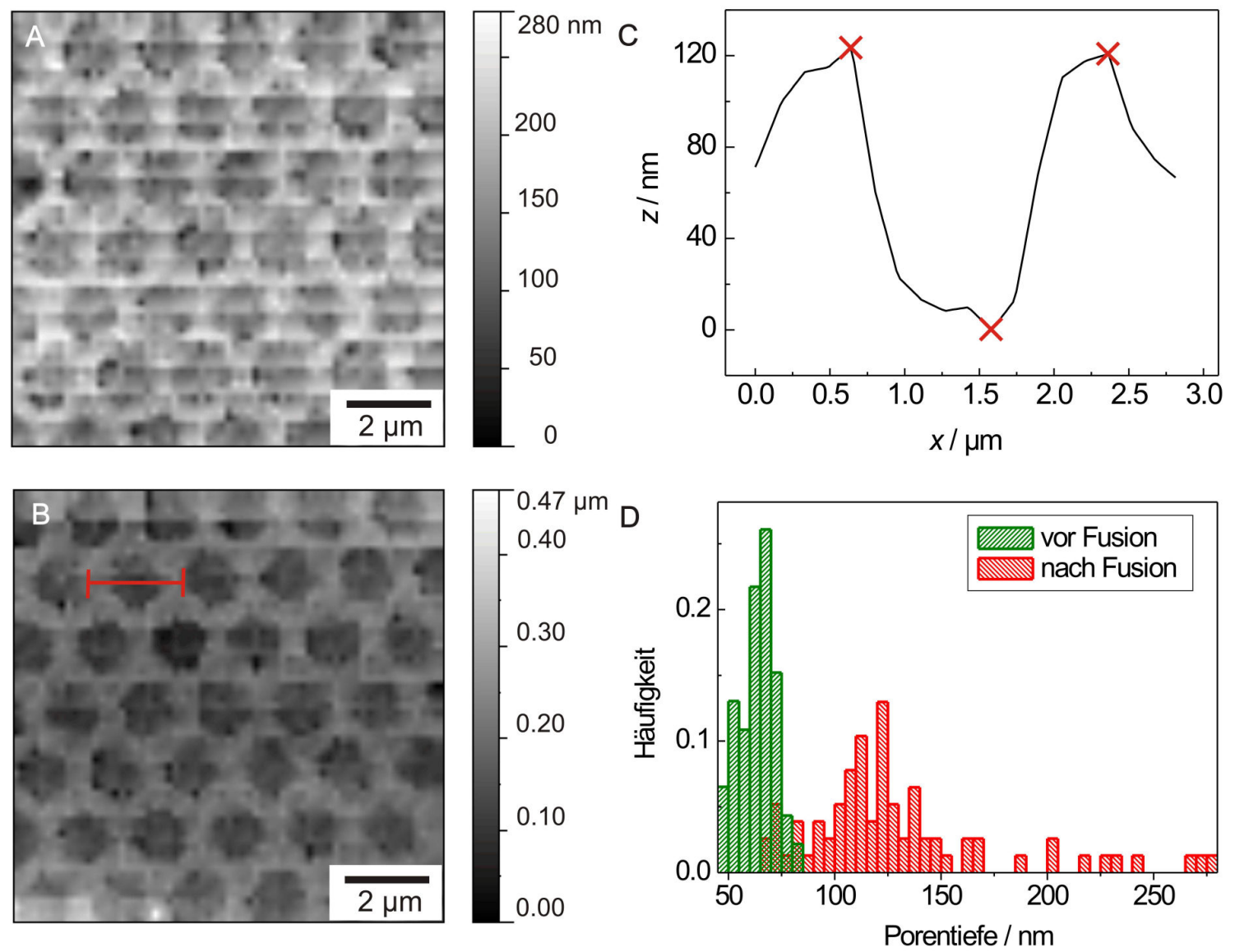

Abb. 4.22 SICM-Aufnahmen von micro-BLMs (DPhPC/POPE 2:1, dotiert mit 1 mol\% Oregon Green, Funktionalisierung: DPPTE) vor (A) und nach (B) der Fusion mit LUVs (POPC/POPS/Texas Red 79:20:1, gefüllt mit $200 \mathrm{mM}$ Sucrose, $100 \mathrm{mM} \mathrm{KCl}, 10 \mathrm{mM}$ MES, $\mathrm{pH}=6.5)$ in $\mathrm{Ca}^{2+}$-Puffer $(100 \mathrm{mM} \mathrm{KCl}, 20 \mathrm{mM}$ $\mathrm{CaCl}_{2}, 10 \mathrm{mM}$ HEPES, $\mathrm{pH}$ = 7.4). Nach der Aufnahme der porenüberspannenden Membranen wurden diese für 20 Minuten mit LUVs inkubiert und anschließend wurden überschüssige Vesikel mit $\mathrm{Ca}^{2+}$-Puffer entfernt und die Probe nochmals mit dem SICM abgebildet. Das Linienprofil (C, Profil entlang der roten Linie in B) zeigt den Höhenunterschied zwischen porenüberspannender Membran und Porensteg. Aus den zwei höchsten Punkten dieses Profils wurde der Mittelwert gebildet und die Differenz zum tiefsten Punkt gebildet. Auf diese Weise wurde die Tiefe bestimmt, in der die Membran eine Pore überspannt. Die Differenzen für alle aufgenommenen Poren wurden dann in einem Histogramm (D) für die Aufnahmen vor (grün) und nach (rot) Fusion zusammengefasst. 
Dabei wurde versucht, die Membran an den gleichen Stellen abzubilden wie vor der Fusion. Abb. 4.22 B zeigt, dass die micro-BLMs nach Vesikelinkubation tiefer in den Poren liegen als es vor der Fusion der Fall war. Die Auswertung der Höhenprofile ergab dabei Höhenunterschiede zwischen Membran und Steg in einem Bereich von $65-$ $280 \mathrm{~nm}$.

Um sicherzugehen, dass die Zugabe der Vesikel in Sucrose-haltigem Puffer oder das Spülen mit $\mathrm{Ca}^{2+}$-haltigem Puffer keinen Einfluss auf die Topografie der porenüberspannenden Membranen haben, wurde ein Kontrollexperiment durchgeführt. Dazu wurde die Probe zunächst mit Hilfe des SICM vermessen, anschließend mit Sucrose-haltigem Puffer ohne LUVs inkubiert und mit $\mathrm{Ca}^{2+}$-haltigem Puffer gespült. Anschließend wurden erneut SICM-Messungen durchgeführt. Die Analyse der Höhendifferenzen vor und nach dieser Prozedur zeigt keinen signifikanten Unterschied. Die Porentiefen reichten vor der Durchführung der Kontrolle von 45 - 85 nm, während danach Werte in einem Bereich von 45 - $95 \mathrm{~nm}$ bestimmt wurden. Die Histogramme der Porentiefen vor und nach der Fusion sowie die der Kontrolle sind in Abb. 4.23 nochmals gegenübergestellt.

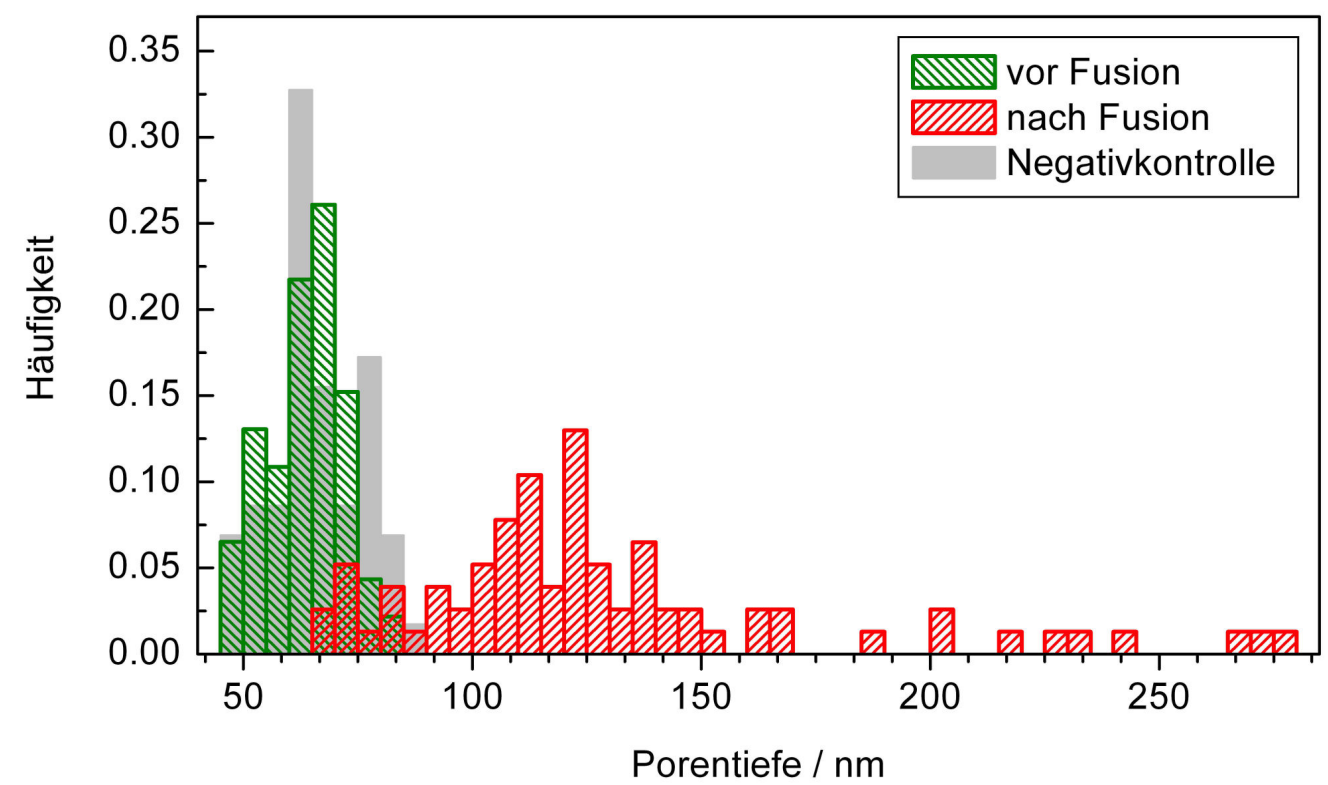

Abb. 4.23 Histogramm der in den SICM-Aufnahmen eines Experiments bestimmten Porentiefen vor und nach der Fusion von LUVs mit porenüberspannenden Membranen und im Kontrollexperiment. 
Die Erhöhung der Porentiefe nach der Fusion konnte in jedem durchgeführten Versuch nachgewiesen werden. Allerdings variierte in den individuellen Experimenten das Ausmaß der Porenvertiefung. Dies wird deutlich in der Gegenüberstellung der Histogramme zweier verschiedener Proben (Abb. 4.24). Während in einem Fall die Porentiefen lediglich von 76 - $114 \mathrm{~nm}$ auf $104-154 \mathrm{~nm}$ (A) im Zuge der Fusion ansteigen, findet sich in dem anderen Experiment eine Veränderung von 81 - $119 \mathrm{~nm}$ auf 190 - 268 nm. Die Tiefenänderung ist vermutlich eine Funktion der Anzahl an Fusionsereignissen in dem entsprechenden Beobachtungsbereich. Während der Zugabe der Vesikel kann der Abstand dieser Vesikel zur Probe variieren, so dass die Zeit, die die Vesikel benötigen, um an die Oberfäche der micro-BLMs zu diffundieren, unterschiedlich sein kann. Dadurch differiert die Anzahl an Vesikeln, die während der Inkubationszeit die Möglichkeit zur Fusion haben. Mit der unterschiedlichen Fusionswahrscheinlichkeit weicht auch das beobachtete Ausmaß der Porenvertiefung ab. Diese Vermutung soll in Kapitel 5.3 ausführlicher diskutiert werden.
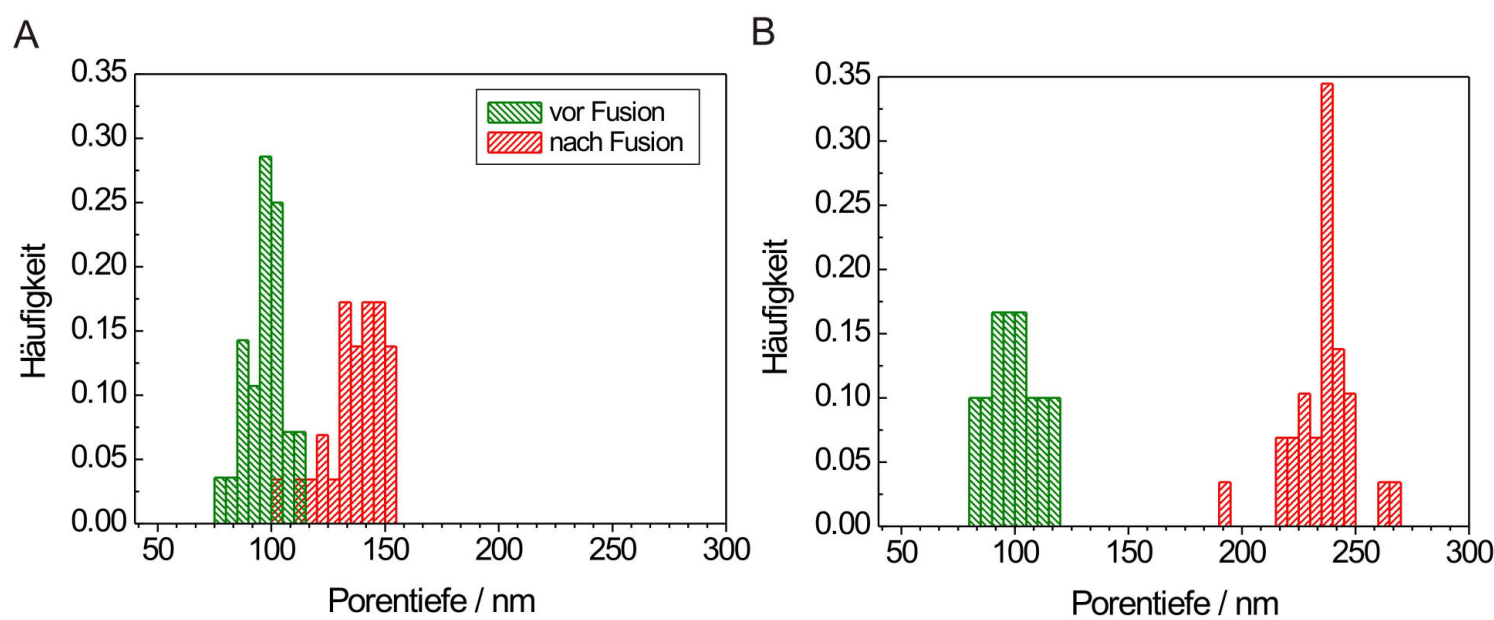

\begin{abstract}
Abb. 4.24 Histogramme mit den Porentiefen von porenüberspannenden Membranen vor (grün) und nach (rot) der Fusion von LUVs. Die dazugehörigen SICM-Messungen wurden an zwei unterschiedlichen Proben (A und B) durchgeführt. Die Darstellung soll verdeutlichen, dass zwar in jedem Experiment eine Vertiefung der porenüberspannenden Membran festgestellt wurde, diese aber nicht über alle Experimente gemittelt werden konnte, da die Vergrößerung der Porentiefe je nach Experiment unterschiedlich ausfiel.
\end{abstract}

Dass die Vertiefung der porenüberspannenden Bereich durch die Fusion in den Experimenten variierte, zeigt, dass dieser Prozess diffusionskontrolliert abläuft. Insgesamt konnte mit Hilfe des SICM dennoch erstmals der Verbleib des zusätzlichen Lipidmaterials in planaren Membranen gezeigt werden. Die Unterschiede in den Höhendifferenzen vor und nach der Fusion von LUVs mit micro-BLMs zeigen, dass sich 
die Vesikellipide in die porenüberspannende Membran einbauen und die Vergrößerung der Membranfläche dadurch kompensiert wird, dass sich die Membranen tiefer in die Pore ziehen.

\subsection{Einfluss molekularer Erkennungsreaktionen auf die Fusion von Vesikeln mit porenüberspannenden Membranen}

Häufig werden in der Forschung zur Untersuchung der Fusion von Membranen Modellsysteme zur molekularen Erkennung genutzt, um neue Einblicke in den Prozess der Fusion zu gewinnen. ${ }^{65,97-99}$ Der Vorteil dieser biomimetischen Erkennungseinheiten besteht darin, dass durch gezielte Modifikationen zum Beispiel Intermembranabstände, Art der Transmembraneinheit bzw. der Erkennungseinheit verändert und somit der jeweilige Einfluss auf die Fusion untersucht werden können. Erkenntnisse aus diesen Analysen können dann zur weiteren Aufklärung der SNARE- bzw. Viruspeptidvermittelten Fusion beitragen. In der vorliegenden Arbeit wurde dabei mit zwei unterschiedlichen molekularen Erkennungssytemen gearbeitet, auf die im Folgenden getrennt eingegangen werden soll. Im Gegensatz zu den in Kapitel 4.1 beschriebenen Experimenten mit lösungsmittelhaltigen micro-BLMs, wurde in den Studien zur molekularen Erkennung dazu übergegangen, lösungsmittelfreie porenüberspannende Membranen durch das Spreiten von GUVs herzustellen. Diese bieten den Vorteil, dass Störeinflüsse durch Lösungsmittelreste in der Lipiddoppelschicht vermieden werden und somit die biologischen Bedingungen besser imitiert werden können. Des Weiteren bietet diese Methode eine bessere Möglichkeit, um Peptide in porenüberspannenden Membranen $\mathrm{zu}$ rekonstituieren. ${ }^{56}$ Außerdem wurde jeweils mit $\mathrm{Ca}^{2+}$-freiem Puffer gearbeitet, um einen Einfluss dieses Fusogens auszuschließen. 


\subsubsection{Untersuchung der Fusion von Vesikeln mit porenüberspannenden Membranen vermittelt durch das Peptid $\mathrm{H}_{6}$ WGC}

\subsubsection{Nachweis von $\mathrm{H}_{6}$ WGC in porenüberspannenden Membranen}

Wie in Kapitel 3.3.1 beschrieben erfolgt die molekulare Erkennung im Fall des Peptids $\mathrm{H}_{6}$ WGC zum einen über die Bindung des His-Tags an über NTA an Lipide gekoppelte $\mathrm{Ni}^{2+}$-Ionen und zum anderen über die Ausbildung einer kovalenten Bindung zwischen Maleimid-modifizierten Lipiden und der Thiolgruppe des Cysteins. Ein Schema dieser zu etablierenden Anordnung ist in Kapitel 1.2 in Abb. 1.9 gezeigt. Der Versuchsablauf wurde folgendermaßen gestaltet. Zunächst wurde eine Maleimid-haltige porenüberspannende Membran präpariert, in dem GUVs, aufgebaut aus 1,2-Dioleoyl-snglycero-3-phosphocholin (DOPC), 1,2-Dioleoyl-sn-glycero-3-phosphoethanolamin-N-[4(p-maleimidomethyl)-cyclohexan-carboxyamid] (MCC-DOPE) und Oregon Green DHPE in einem Verhältnis von 96:2:2, auf einem mit CPEO3 funktionalierten porösen Substrat gespreitet wurden. Nach erfolgreicher Ausbildung einer porenüberspannenden Membran erfolgte die Inkubation mit dem Peptid, dessen Überschuß nach der kovalenten Anbindung an die Maleimid-haltigen Lipide durch Spülen entfernt wurde. Anschließend wurden dann LUVs, ebenfalls aus DOPC aufgebaut mit $2 \%$ Texas Red DHPE und variablen Teilen an 1,2-Dioleoyl-sn-glycero-3-[(N-(5-amino-1-carboxypentyl)iminodiessigsäure)succinyl] (Ni-NTA-DOGS), mit einem mittleren Durchmesser von $600 \mathrm{~nm}, \mathrm{zu}$ den porenüberspannenden Membranen gegeben. So konnte die durch das Peptid vermittelte Interaktion zwischen den Lipiddoppelschichten untersucht werden. Das sorgfältige Entfernen von überschüssigem Peptid gewährleistete dabei, dass keine Bindungsstellen an den Vesikeln bereits vor der Membran-Membran-Interaktion von freiem Peptid besetzt wurde.

Zunächst wurde die erfolgreiche Anbindung des Nonapeptids an die Maleimid-haltigen porenüberspannenden Membranen überprüft. Dazu wurde die Wechselwirkung eines Anti-His-Antikörpers mit dem freien His-Tag des an die Membran gebundenen Peptids ausgenutzt. Der zur Verfügung stehende Antikörper war FITC-markiert, so dass die Bindung des $\mathrm{H}_{6}$ WGC an die Lipiddoppelschicht indirekt über den Nachweis der FITCFluoreszenz in den porenüberspannenden Membranen bewiesen werden konnte. Um eine $\mathrm{zu}$ starke Überlagerung der Fluoreszenzsignale $\mathrm{zu}$ verhindern, wurden die 
porenüberspannenden Lipiddoppelschichten nicht mit Oregon Green DHPE mit Texas Red DHPE dotiert.

In Abb. 4.25 sind Fluoreszenzbilder der peptidfunktionalisierten porenüberspannenden Membran vor und nach Inkubation mit dem FITC-markierten Anti-His-tag-Antiköper zu sehen. Vor der Zugabe des Antikörpers ist die Membran nur im Texas Red-Kanal (rechts) sichtbar, während im grünen Kanal (links) keine FITC-Fluoreszenz detektiert wird. Nach der Anbindung des Antikörpers an die Membran und Spülen zur Entfernung von ungebundenen Antikörpermolekülen, wurde die Membran erneut fluoreszenzmikroskopisch untersucht. Die Aufnahmen nach Antikörperzugabe zeigen wie schon zuvor die rote Fluoreszenz der Texas Red-dotierten Membran. Zusätzlich ist auch die grüne FITC-Fluoreszenz des Antikörpers im Bereich der Membran zu erkennen. Diese Beobachtung spricht für eine erfolgreiche irreversible Bindung des Peptids an die Maleimid-haltige Membran.
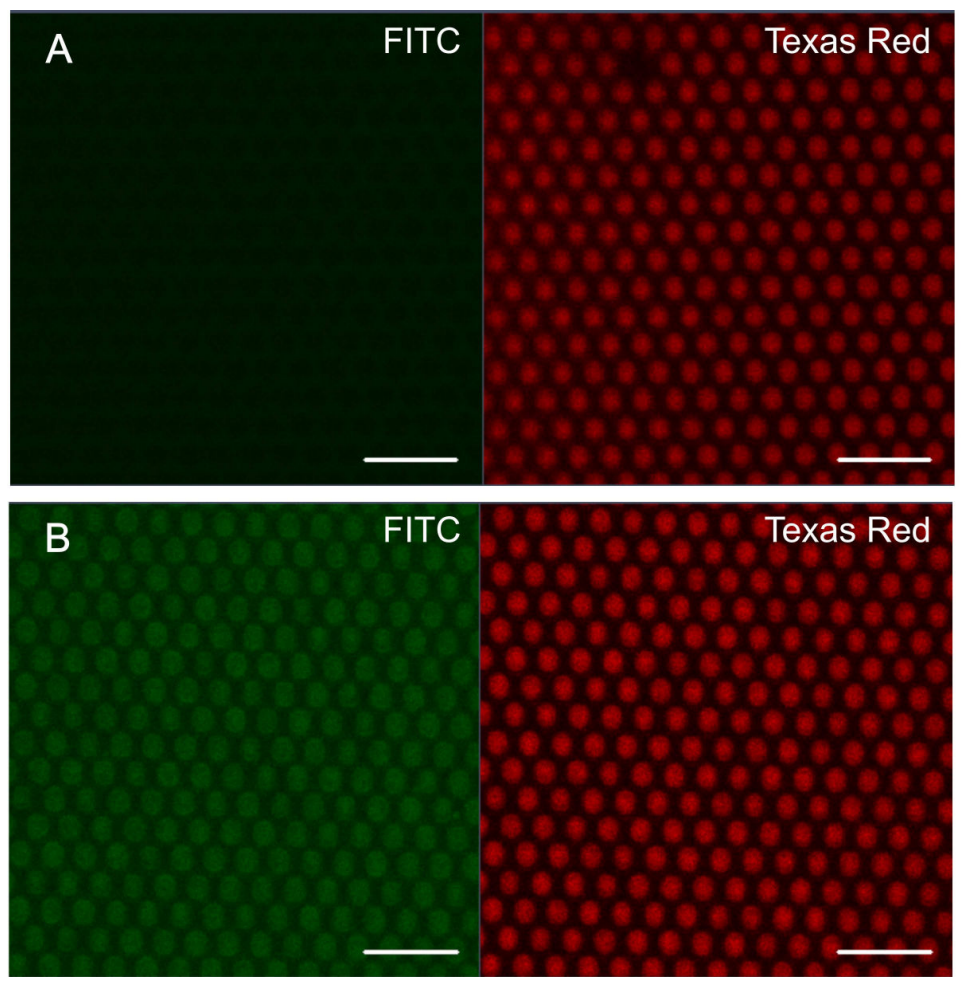

Abb. 4.25 Fluoreszenzmikroskopische Aufnahmen der Texas Red-Fluoreszenz (rechts) und der FITCAntikörper-Fluoreszenz (links) einer porenüberspannenden Membran (durch Spreiten von GUVs: POPC:MCC-DOPE:Texas Red DHPE, 96:2:2) in wässriger Lösung (50 mM Na $\left.2 \mathrm{HPO}_{4}, \mathrm{pH}=6.8\right)$ nach Funktionalisierung mit $\mathrm{H}_{6} \mathrm{WGC}$ vor (A) und nach (B) Anti-His 6 -tag-Antikörper Inkubation. Der Maßstabsbalken entspricht $5 \mu \mathrm{m}$. 
Um ausschließen zu können, dass der Antikörper unspezifisch mit der Membran wechselwirkt, wurde ein Kontrollexperiment durchgeführt. Dazu wurden porenüberspannende Membranen, die zwar das Maleimid-haltige Lipid enthielten jedoch nicht mit dem Nonapeptid $\mathrm{H}_{6}$ WGC funktionalisiert wurden, ebenfalls vor und nach Zugabe des Anti-His 6 -tag-Antikörpers fluoreszenzmikroskopisch abgebildet (Abb. 4.26).
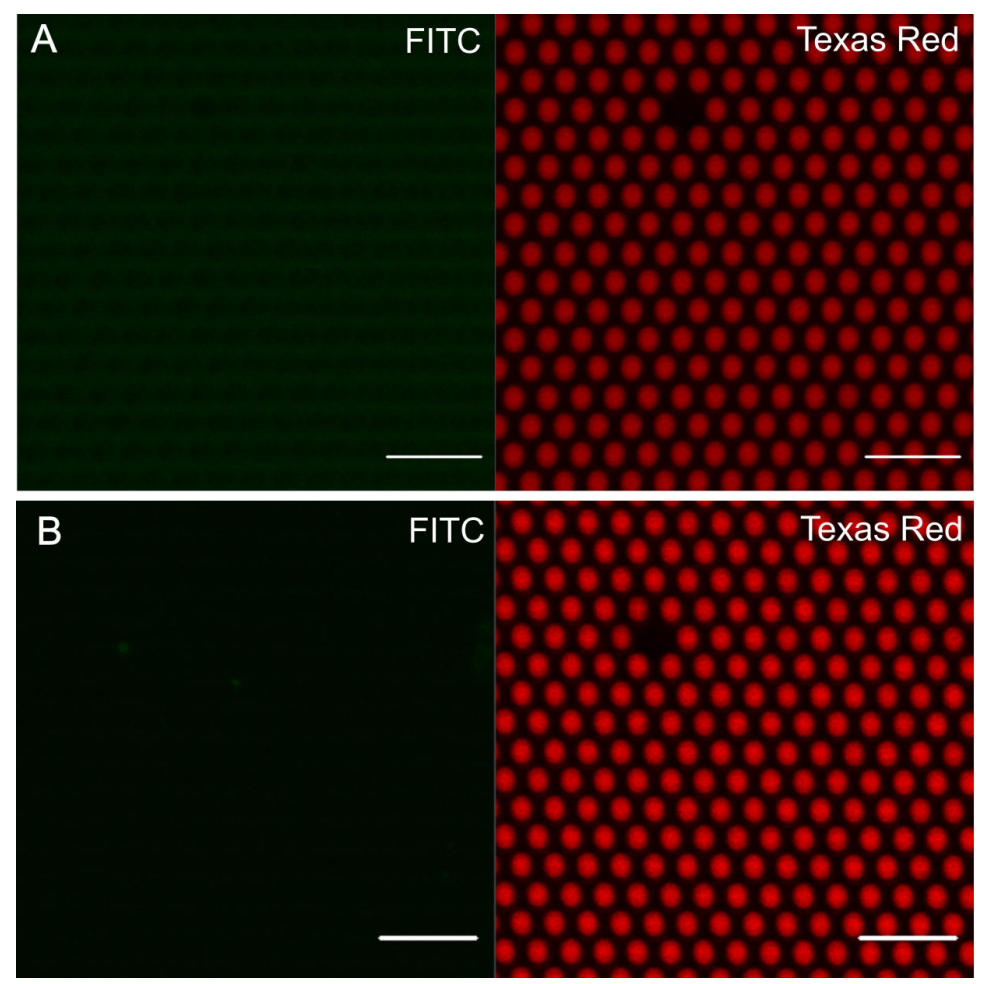

Abb. 4.26 Fluoreszenzmikroskopische Aufnahmen der Texas Red- Fluoreszenz (rechts) und der FITCAntikörper-Fluoreszenz (links) einer porenüberspannenden Membran (durch Spreiten von GUVs: POPC:MCC-DOPE:Texas Red DHPE, 96:2:2) in wässriger Lösung (50 mM Na $2 \mathrm{HPO}_{4}, \mathrm{pH}=6.8$ ) ohne Funktionalisierung mit $\mathrm{H}_{6} \mathrm{WGC}$ vor (A) und nach (B) Anti-His ${ }_{6}$-tag-Antikörper Inkubation. Der Maßstabsbalken entspricht $5 \mu \mathrm{m}$.

Vor und nach Zugabe des Antikörpers zeigt die Texas Red-Fluoreszenz intakte porenüberspannende Membranen an. Die grüne Fluoreszenz des FITC-markierten Antikörpers ist in keinem der beiden Fälle zu beobachten. Daher kann davon ausgegangen werden, dass der Antikörper spezifisch an das in der porenüberspannenden Membran verankerte Peptid bindet und somit als Nachweis für die erfolgreiche Wechselwirkung des Maleimids in der Lipidkopfgruppe mit dem $\mathrm{H}_{6}$ WGC angesehen werden kann. 


\subsubsection{Untersuchung der Fusion von LUVs mit porenüberspannenden Membranen vermittelt durch das Peptid $\mathrm{H}_{6} \mathrm{CGW}$}

Um die Notwendigkeit des molekularen Erkennungsmechanismus für die Interaktion und somit die Spezifität des $\mathrm{H}_{6}$ WGC-vermittelten Fusionsprozesses von LUVs mit den porenüberspannenden Membranen zu überprüfen, wurden diverse Kontrollexperimente durchgeführt. Zunächst wurden Ni-NTA-DOGS-haltige LUVs zu MCC-DOPE-haltigen porenüberspannenden Membranen gegeben. Diese Membranen wurden zur Kontrolle in diesem Fall nicht mit dem Fusionspeptid inkubiert. Von drei verschiedenen Substraten wurden insgesamt 22 Zeitserien mit einer Länge von 35-60 s aufgenommen. Dabei wurden in nur einer Zeitserie insgesamt vier Fusionsereignisse detektiert. Als Fusion wird hier die Vermischung der Vesikellipide mit denen der porenüberspannenden Membran bezeichnet, die, wie bereits in Kapitel 4.1 beschrieben, durch die radiale Verteilung der Texas Red-Fluroeszenz in den porenüberspannenden Membranen und die simultane Löschung der Oregon Green-Fluoreszenz angezeigt wird.

Zur weiteren Kontrolle wurden $\mathrm{zu} \mathrm{H}_{6} \mathrm{WGC}$-funktionalisierten porenüberspannenden Membranen Ni-NTA-DOGS-freie LUVs gegeben, so dass es nicht zu einer spezifischen Wechselwirkung von Vesikel und porenüberspannender Membran kommt. In sieben Zeitserien mit einer Länge von jeweils ungefähr $30 \mathrm{~s}$ von einer Probe wurde nur ein Fusionsereignis beobachtet, weshalb auch dieses Experiment genauso wie das zuvor beschriebene als negativ angesehen werden kann.

Nachdem so nachgewiesen wurde, dass die Beobachtungen zur Wechselwirkung von $\mathrm{H}_{6}$ WGC mit Maleimid- bzw. Ni-NTA-funktionalisierten Membranoberflächen nicht durch unspezifische Fusionsereignisse verfälscht sein können, wurde anschließend der Einfluss der Rezeptordichte, das heißt des Ni-NTA-Gehalts in der Membran, auf die Interaktion zwischen Vesikeln mit porenüberspannenden Membranen vermittelt durch $\mathrm{H}_{6} \mathrm{WGC}$ untersucht.

Dazu wurden nach Zugabe der Vesikel zu den porenüberspannenden Membranen alle Vesikel, die nach dem Start der Zeitserie in Wechselwirkung mit der Membran traten, beobachtet und die jeweilige Interaktion kategorisiert. Dabei wurden die Fusionsereignisse hauptsächlich an Hand des zeitlichen Verlaufs der Fluoreszenzintensitäten im ROI charakterisiert. Insgesamt konnten neben den klassischen Fusionsereignissen, das heißt wie in Kapitel 4.1 beschrieben der radialen Verteilung der 
Texas Red-Fluoreszenz in den porenüberspannenden Membranen und der simultanen Oregon Green-Löschung, vier weitere Verläufe der Fluoreszenzintensität indentifiziert werden. Auf die verschiedenen Ergebnisse wird im Folgenden getrennt eingegangen.

In den meisten Fällen wurden bei den untersuchten Proben Ereignisse beobachtet, bei denen ein Vesikel an die Membran bindet, anschließend jedoch weder eine Fusion noch ein Wiederablösen zeigt (Abb. 4.27, Ereignis I). Die Fluoreszenzintensität von Texas Red innerhalb des ROI zeigt dementsprechend in dem Moment, in dem der Vesikel den Ausschnitt des ROIs erreicht und an die Membran bindet, einen sprunghaften Anstieg. Die erhöhte Fluoreszenzintensität bleibt bis zum Ende der Zeitserie bestehen, da der Vesikel bis zum Schluss unverändert an der Membran gebunden bleibt. Die Oregon Green-Fluoreszenz zeigt im gesamten Verlauf keine Veränderung.

\section{Ereignis I:}
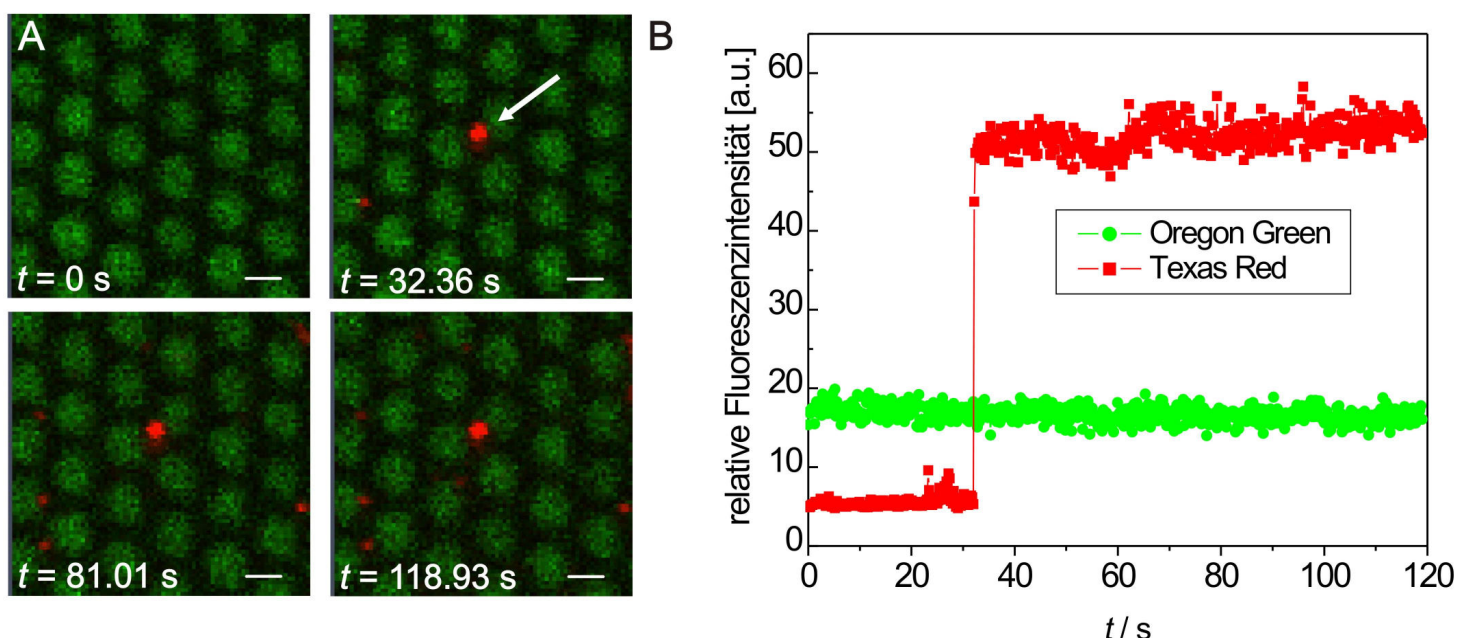

Abb. 4.27 A Fluoreszenzmikroskopische Aufnahme der Oregon Green-Fluoreszenz einer porenüberspannenden Membran hergestellt durch Spreiten von GUVs (DOPC/MCC-DOPE/Oregon Green, 96:2:2, Funktionalisierung des Substrats: CPEO3) sowie der Texas Red-Fluoreszenz eines LUVs (DOPC/Ni-NTA-DOGS/Texas Red, 97.9:0.1:2). Die porenüberspannende Membran wurde vor der LUVZugabe mit $\mathrm{H}_{6}$ WGC $(14 \mu \mathrm{M})$ funktionalisiert. Der Pfeil kennzeichnet den betrachteten Vesikel. Beim Start der Aufnahme ( $t=0 \mathrm{~s}$ ) ist der LUV zunächst nicht an der Membran gebunden. Anschließend diffundiert der Vesikel in die Fokusebene und bindet bei $t=32.36 \mathrm{~s}$ an die porenüberspannende Membran und zeigt dann keine Veränderung bis zum Ende der Zeitserie. Der Maßstabsbalken entspricht $1 \mu \mathrm{m}$. B Zeitlicher Verlauf der Fluoreszenzintensitäten von Oregon Green und Texas Red. Die gemittelten Intensitäten innerhalb eines definierten ROI wurden aus der in A gezeigten Zeitserie extrahiert. Zum Zeitpunkt der Anbindung des Vesikels an die porenüberspannende Membran bei $t=32.36 \mathrm{~s}$ steigt die Texas RedFluoreszenz sprunghaft an und bleibt bis zum Ende der Zeitserie konstant auf diesem erhöhten Wert.

Neben der Beobachtung, dass ein Vesikel dauerhaft an die Membran gebunden bleibt, wurde auch beobachtet, dass ein Vesikel zunächst bindet und sich nach einer gewissen 
Zeit wieder von der Membran löst und dann aus der Fokusebene und somit auch aus dem ROI diffundiert (Abb. 4.28, Ereignis II). Wie im vorher beschriebenen Fall zeigt die Texas Red-Fluoreszenzintensität im zeitlichen Verlauf zunächst einen sprunghaften Anstieg. Nach etwa 40 s fällt das Signal dann wieder auf den Ursprungswert zurück, was auf die Diffusion des Vesikels aus dem Fokus zurückzuführen ist. Die Oregon GreenFluoreszenz zeigt über die Zeit nur einen leichten Abfall, der auf ein Fotobleichen zurückzuführen ist.

\section{Ereignis II:}
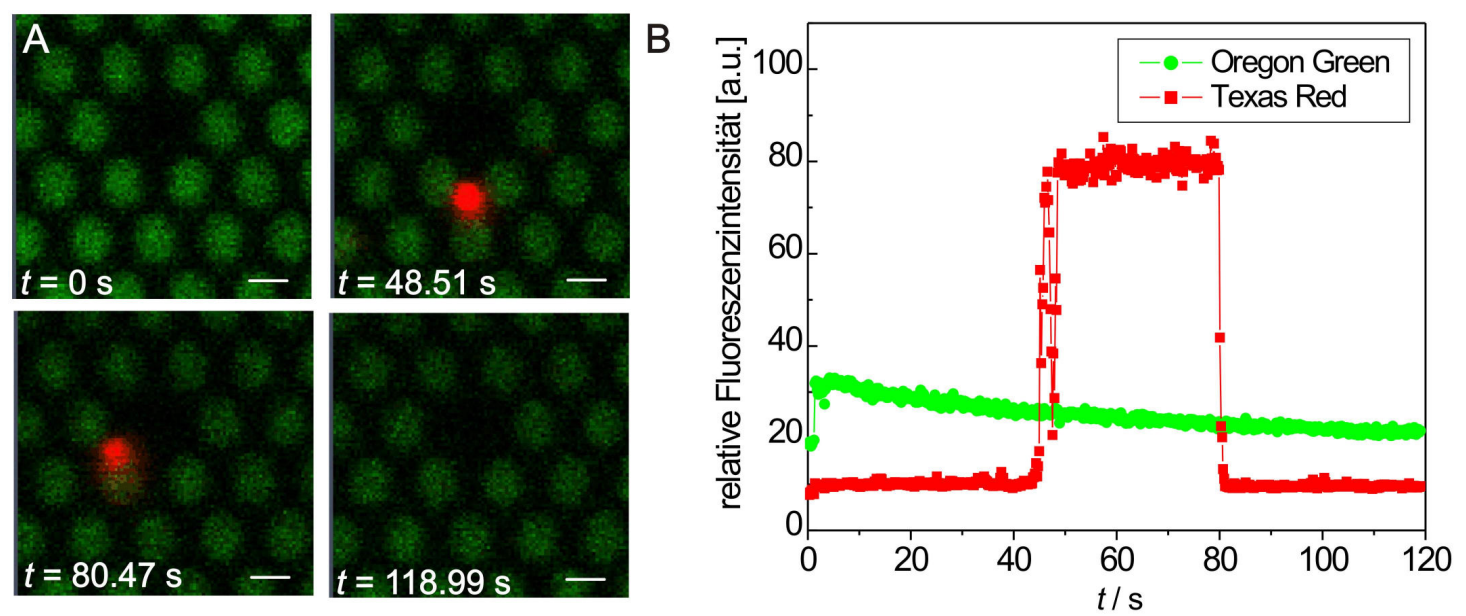

Abb. 4.28 A Fluoreszenzmikroskopische Aufnahme der Oregon Green-Fluoreszenz einer porenüberspannenden Membran hergestellt durch Spreiten von GUVs (DOPC/MCC-DOPE/Oregon Green, 96:2:2, Funktionalisierung des Substrats: CPEO3) sowie der Texas Red-Fluoreszenz eines LUVs (DOPC/Ni-NTADOGS/Texas Red, 96:2:2). Die porenüberspannende Membran wurde vor der LUV-Zugabe mit $\mathrm{H}_{6} \mathrm{WGC}$ $(14 \mu \mathrm{M})$ funktionalisiert. Der Pfeil kennzeichnet den betrachteten Vesikel. Beim Start der Aufnahme $(t=0$ s) ist der LUV zunächst nicht an die Membran gebunden. Anschließend diffundiert der Vesikel in die Fokusebene und bindet bei $t=48.51 \mathrm{~s}$ an die porenüberspannende Membran und bleibt dort verankert, bis er sich bei $t=80.47 \mathrm{~s}$ wieder von der Membran löst und aus dem Fokus diffundiert. Der Maßstabsbalken entspricht $1 \mu \mathrm{m}$. B Zeitlicher Verlauf der Fluoreszenzintensitäten von Oregon Green und Texas Red. Die gemittelten Intensitäten innerhalb eines definierten ROI wurden aus der in A gezeigten Zeitserie extrahiert. Zum Zeitpunkt der Anbindung des Vesikels an die porenüberspannende Membran bei $t=48.51 \mathrm{~s}$ steigt die Texas Red-Fluoreszenz sprunghaft an und bleibt konstant bis der Vesikel wieder aus der Fokusebene diffundiert. Dies führt bei $t=80.47 \mathrm{~s}$ zu einer plötzlichen Abnahme des Texas Red-Signals auf seinen Ursprungswert.

Im dritten Fall kann ähnliches wie bei der Anbindung und dem anschließenden Ablösen des Vesikels beobachtet werden (Abb. 4.29, Ereignis III). Jedoch bleibt in diesem Fall ein Teil der Texas Red-Fluoreszenz zurück. Dies zeigt sich zum einen in den Fluoreszenzaufnahmen, in denen erst der gebundene Vesikel zu sehen ist, der dann verschwindet und an dessen Stelle ein Teil der Texas Red-Moleküle zurückbleibt, die in 
einem kleineren runden Bereich angeordnet sind. Diese Beobachtungen werden auch im Intensitätsprofil der Texas Red-Fluoreszenz widergespiegelt. Im Gegensatz zu dem Profil des Verlaufs in Abb. 4.28 fällt hier die Intensität nicht auf den Anfangswert zurück, sondern bleibt bis zum Ende der Aufnahme konstant auf einem Wert der signifikant größer ist als die Fluoreszenzintensität zu Beginn der Aufnahme.

\section{Ereignis III:}
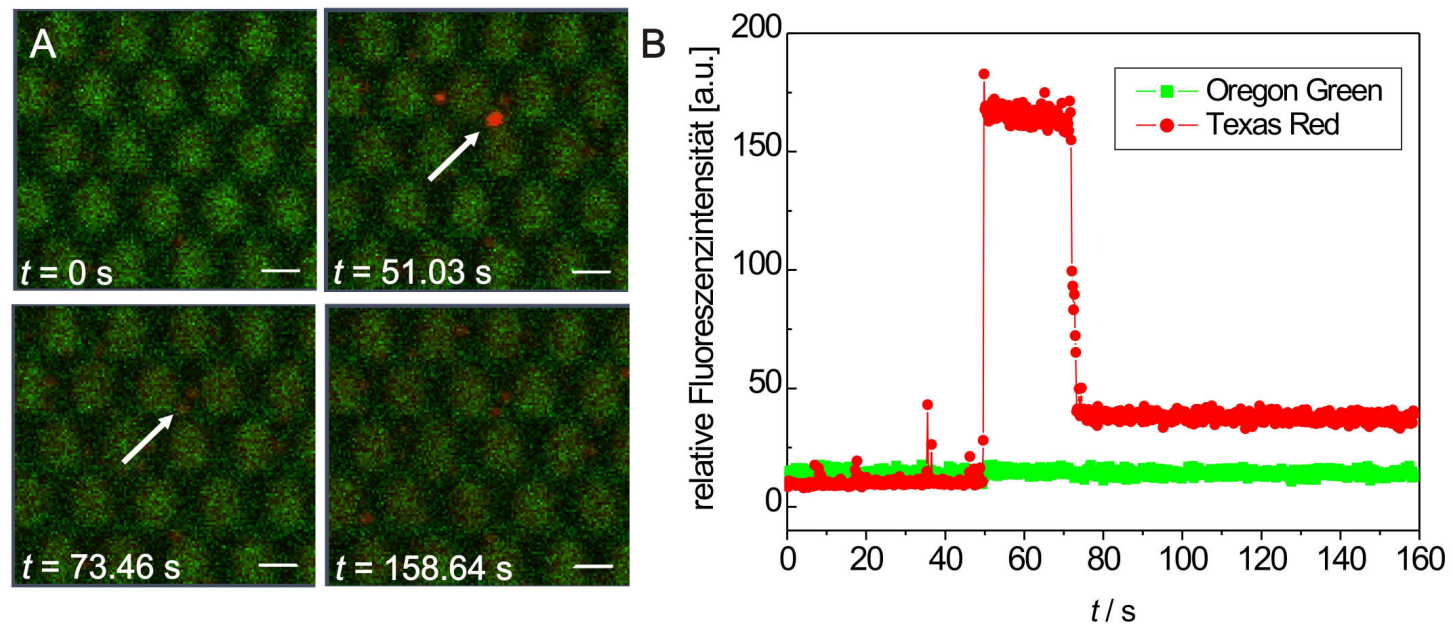

Abb. 4.29 A Fluoreszenzmikroskopische Aufnahme der Oregon Green-Fluoreszenz einer porenüberspannenden Membran hergestellt durch Spreiten von GUVs (DOPC/MCC-DOPE/Oregon Green, 96:2:2, Funktionalisierung des Substrats: CPEO3) sowie der Texas Red-Fluoreszenz eines LUVs (DOPC/Ni-NTADOGs/Texas Red, 96:2:2). Die porenüberspannende Membran wurde vor der LUV-Zugabe mit $\mathrm{H}_{6} \mathrm{WGC}$ $(14 \mu \mathrm{M})$ funktionalisiert. Der Pfeil kennzeichnet den betrachteten Vesikel. Beim Start der Aufnahme $(t=0$ s) ist der LUV zunächst nicht an die Membran gebunden. Anschließend diffundiert der Vesikel in die Fokusebene und bindet bei $t=51.03 \mathrm{~s}$ an die porenüberspannende Membran und bleibt dort verankert, bis bei $t=73.46 \mathrm{~s}$ schlagartig ein Großteil der Texas Red-Fluoreszenzintensität verschwindet und nur ein kleiner, runder Bereich an roter Fluoreszenz zurückbleibt. Dieser bleibt bis zum Ende der Zeitserie unverändert. Der Maßstabsbalken entspricht $1 \mu \mathrm{m}$. B Zeitlicher Verlauf der Fluoreszenzintensitäten von Oregon Green und Texas Red. Die gemittelten Intensitäten innerhalb eines definierten ROI wurden aus der in A gezeigten Zeitserie extrahiert. Zum Zeitpunkt der Anbindung des Vesikels an die porenüberspannende Membran bei $t=51.03 \mathrm{~s}$ steigt die Texas Red-Fluoreszenz sprunghaft an und bleibt konstant, bis ein Teil der Texas Red-Intensität des Vesikels verschwindet. Dies führt zu einer plötzlichen Abnahme des Texas Red-Signals bei $t=73.46 \mathrm{~s}$ auf einen Wert, der höher liegt als der Ursprunswert.

Die vorangegangenen Verläufe der Abb. 4.27 - Abb. 4.29 sind vorwiegend auf die Anbindung von Vesikeln an die Membran zurückzuführen und sind dementsprechend von den Fusionsereignissen, das heißt der Lipidvermischung indiziert durch die radiale Texas Red-Verteilung in den porenüberspannenden Membranen und die Oregon GreenLöschung, die in diesen Experimenten ebenfalls beobachtet wurden, abzugrenzen. Ein Beispiel der vollständigen Lipidvermischung ist in Abb. 4.30 gezeigt (Ereignis IV). 


\section{Ereignis IV:}
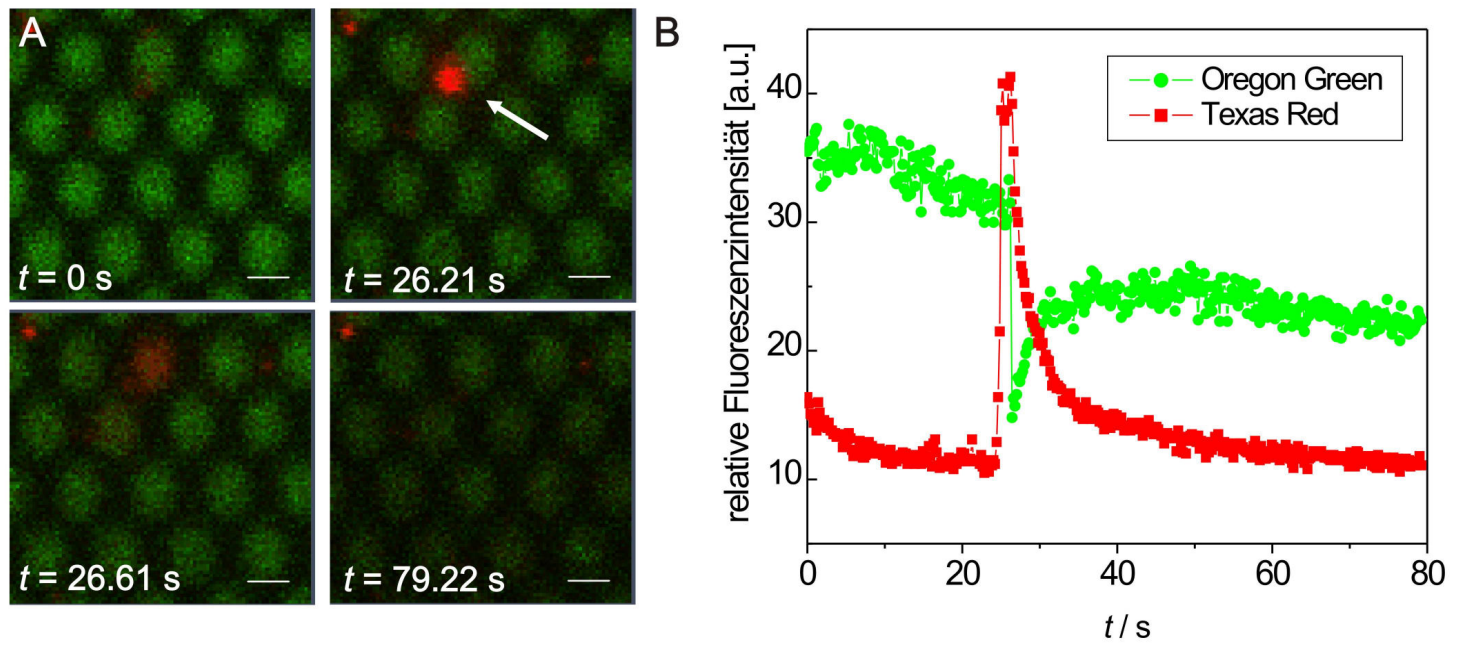

Abb. 4.30 A Fluoreszenzmikroskopische Aufnahme der Oregon Green-Fluoreszenz einer porenüberspannenden Membran hergestellt durch Spreiten von GUVs (DOPC/MCC-DOPE/Oregon Green, 96:2:2, Funktionalisierung des Substrats: CPEO3) sowie der Texas Red-Fluoreszenz eines LUVs (DOPC/Ni-NTA-DOGS/Texas Red, 97:1:2). Die porenüberspannende Membran wurde vor der LUVZugabe mit $\mathrm{H}_{6}$ WGC $(14 \mu \mathrm{M})$ funktionalisiert. Der Pfeil kennzeichnet den betrachteten Vesikel. Beim Start der Aufnahme $(t=0 \mathrm{~s})$ ist der LUV zunächst nicht an die Membran gebunden. Anschließend diffundiert der Vesikel in die Fokusebene und bindet bei $t=26.21 \mathrm{~s}$ an die porenüberspannende Membran und darauffolgend zeigen die Texas Red-Moleküle bei $t=26.61 \mathrm{~s}$ eine radiale Verteilung in der porenüberspannenden Membran. Der Maßstabsbalken entspricht $1 \mu \mathrm{m}$. B Zeitlicher Verlauf der Fluoreszenzintensitäten von Oregon Green und Texas Red. Die gemittelten Intensitäten innerhalb eines definierten ROI wurden aus der in A gezeigten Zeitserie extrahiert. Zum Zeitpunkt der Anbindung des Vesikels an die porenüberspannende Membran bei $t=26.21 \mathrm{~s}$ steigt die Texas Red-Fluoreszenz sprunghaft an und fällt anschließend exponentiell auf ihren Ursprungswert zurück. Diese Abnahme korreliert zeitlich mit einer sprunghaften Verringerung und einem anschließenden Wiederanstieg des Oregon Green-Signals.

Die Beobachtungen entsprechen den Ergebnissen, die bereits in den Experimenten der $\mathrm{Ca}^{2+}$-vermittelten Fusion von LUVs mit micro-BLMs gefunden wurden (Kapitel 4.1). Die Texas Red-Moleküle verteilen sich radial in der Fokusebene der planaren Membran. Dies wird auch in den Intensitätsprofilen sichtbar, in denen die Texas Red-Fluoreszenz nach einem sprunghaften Anstieg im Zuge der Fusion einen exponentiellen Abfall auf den Ausgangwert zeigt. Aus den Zeitverläufen der Texas Red-Fluoreszenzintensität wurde, wie in Kapitel 4.1, beschrieben der Diffusionskoeffizient für die Verteilung der Lipide des Vesikels in den porenüberspannenden Membranen ermittelt. Dieser wurde im Mittel zu $D=(0.4 \pm 0.3) \mu \mathrm{m}^{2} / \mathrm{s}(n=20)$ bestimmt.

Neben dieser vollständigen Vermischung der Lipide wurden auch Ereignisse beobachtet, in denen zwar auch die Verteilung des Texas Red-Farbstoffs in den porenüberspannenden 
Membran auftritt, ein Teil der rot fluoreszierenden Vesikelmembran jedoch zurückbleibt (Abb. 4.31, Ereignis V). Dies wird auch in dem zeitlichen Intensitätsprofil deutlich, da die Texas Red-Fluoreszenz nach ihrem exponentiellen Abfall nicht wieder auf ihren Ursprungswert zurückfällt, sondern konstant auf einem erhöhten Intensitätsniveau bleibt.

\section{Ereignis $V$ :}
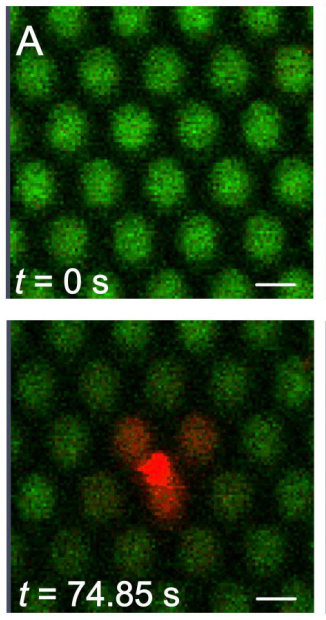
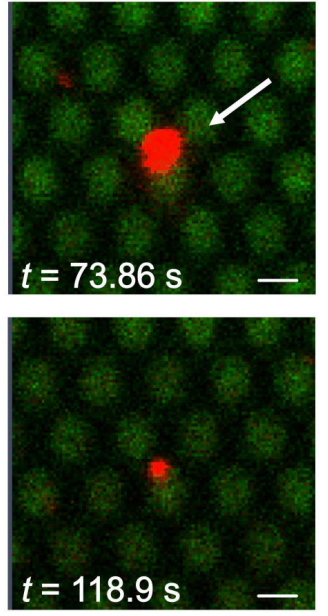

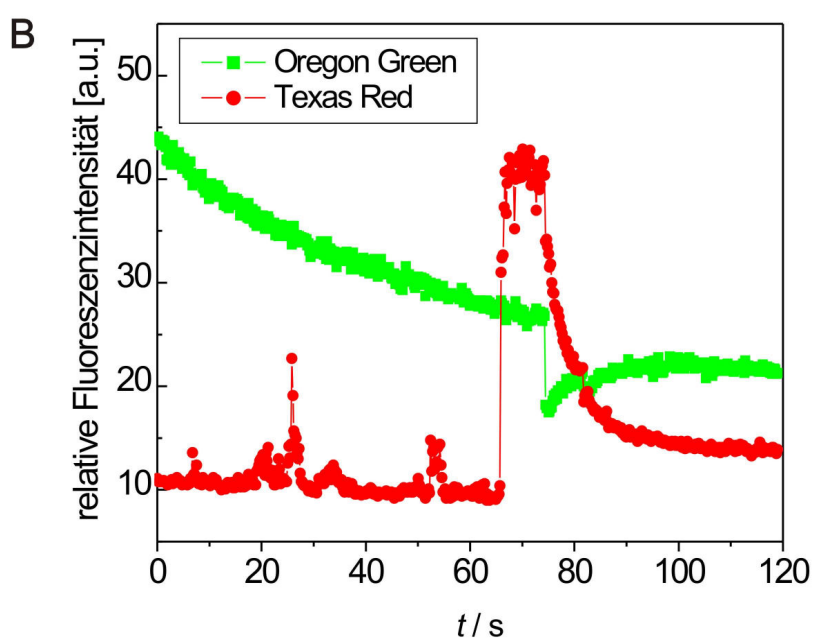

Abb. 4.31 A Fluoreszenzmikroskopische Aufnahme der Oregon Green-Fluoreszenz einer porenüberspannenden Membran hergestellt durch Spreiten von GUVs (DOPC/MCC-DOPE/Oregon Green, 96:2:2, Funktionalisierung des Substrats: CPEO3) sowie der Texas Red-Fluoreszenz eines LUVs (DOPC/Ni-NTA-DOGS/Texas Red, 96:2:2). Die porenüberspannende Membran wurde vor der LUVZugabe mit $\mathrm{H}_{6}$ WGC $(14 \mu \mathrm{M})$ funktionalisiert. Der Pfeil kennzeichnet den betrachteten Vesikel. Beim Start der Aufnahme ( $t=0 \mathrm{~s}$ ) ist der LUV zunächst nicht an die Membran gebunden. Anschließend diffundiert der Vesikel in die Fokusebene und bindet bei $t=73.86 \mathrm{~s}$ an die porenüberspannende Membran und anschließend zeigt die Texas Red-Fluoreszenz bei $t=74.85 \mathrm{~s}$ eine radiale Verteilung in der porenüberspannenden Membran. Dabei bleibt ein kreisförmiger Teil der Texas Red-Fluoreszenz zurück, der bis zum Ende der Zeitserie unverändert bleibt. Der Maßstabsbalken entspricht $1 \mu \mathrm{m}$. B Zeitlicher Verlauf der Fluoreszenzintensitäten von Oregon Green und Texas Red. Die gemittelten Intensitäten innerhalb eines definierten ROI wurden aus der in A gezeigten Zeitserie extrahiert. Zum Zeitpunkt der Anbindung des Vesikels an die porenüberspannende Membran bei $t=73.86 \mathrm{~s}$ steigt die Texas RedFluoreszenz sprunghaft an und fällt anschließend exponentiell ab bis zu einem Wert, der etwas höher liegt als das Ausgangssignal der roten Fluoreszenz. Diese Abnahme korreliert zeitlich mit einer sprunghaften Verringerung und anschließendem Wiederanstieg des Oregon Green-Signals.

Mit Hilfe der beschriebenen Kategorisierung der unterschiedlichen Vesikel-MembranWechselwirkungen konnte eine statistische Analyse durchgeführt werden. Dabei wurde die Abhängigkeit der Häufigkeit eines Ereignisses vom Ni-NTA-Gehalt in den Vesikeln bestimmt. Die Auftragung des prozentualen Anteils an entsprechenden Fluoreszenzverläufen in Abhängigkeit der Ni-NTA-Rezeptoren in der Vesikelmembran ist in Abb. 4.32 gezeigt. 


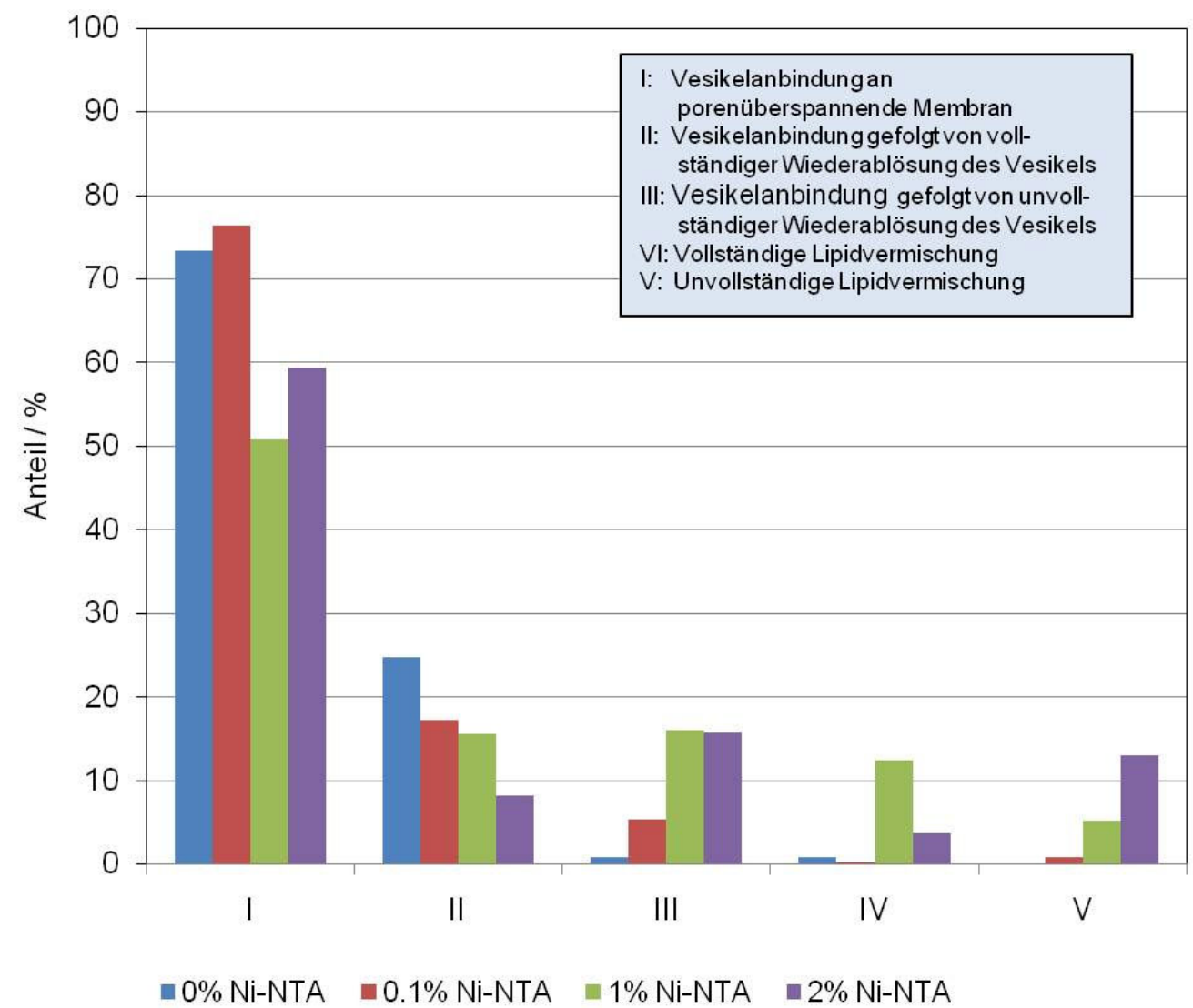

Abb. 4.32 Statistische Auswertung der unterschiedlichen beobachteten Ereignisse, wenn die Interaktionen zwischen Maleimid-dotierten porenüberspannenden Membranen und Ni-NTA-haltigen Vesikeln durch das Fusionspeptids $\mathrm{H}_{6}$ WGC vermittelt wird. Die Häufigkeiten sind in dem Diagramm für die unterschiedlichen Ni-NTA-Konzentrationen in den Vesikeln aufgeführt. Dabei entsprechen alle beobachteten Ereignisse für eine Ni-NTA-Konzentration $100 \%$. Die Kategorisierung der Ereignisse wurde oben ausführlich beschrieben. Die Gesamtzahl an gezählten Ereignissen betrug: $n=113$ für $0 \%$ Ni-NTA, $n=377$ für $0.1 \%$ Ni-NTA, $n=250$ für $1 \%$ Ni-NTA und $n=820$ für $2 \%$ Ni-NTA.

Ist kein Ni-NTA-Rezeptor in den Vesikeln vorhanden, so wird fast ausschließlich die Anbindung der Vesikel an die porenüberspannenden Membranen beobachtet (Ereignis I III). In etwa einem Viertel der Fälle erfolgt dann eine anschließende Wiederablösung des Vesikels. Mit steigendem Ni-NTA-Gehalt nimmt die Anzahl der reinen Vesikelanbindung ab und es sind vermehrt Fusionsereignisse zu beobachten. Mit zwölf Prozent Anteil an Ereignissen, tritt vollständige Fusion (Ereignis IV) am häufigsten im Fall von 1 mol\% Ni-NTA auf. Eine unvollständige Fusion mit verbleibender Restintensität (Ereignis V) ist vor allem bei einem Ni-NTA-Gehalt von 2 mol\% Ni NTA zu beobachten. Dieses Ereignis macht $13 \%$ der insgesamt bei dieser Konzentration auftretenden Ereignisse aus. Obwohl eine Tendenz der Abhängigkeit der 
Fusionswahrscheinlichkeit vom Ni-NTA-Gehalt zu erkennen ist, ist dennoch der Anteil an Vesikelanbindungen an die Membran mit mindestens über $82 \%$ (Ereignisse I, II und III) für jede untersuchte Ni-NTA-Konzentration sehr hoch. Dies wird auch in dem in Abb. 4.33 gezeigten Histogramm deutlich, in dem die Ereignisse I, II und III zusammengefasst sind zur Vesikelanbidung und die Ereignisse IV und $\mathrm{V}$ als Fusionsereignisse zusammengezählt wurden. Des Weiteren zeigt diese Auswertung, dass nur ab einer Ni-NTA-Konzentration von $1 \%$ Fusionsereignisse in signifikanter Anzahl von $18 \%$ (1\% Ni-NTA) bzw. $17 \%$ (2\% Ni-NTA) bezogen auf die Gesamtzahl an beobachteten Ereignissen detektiert werden können.

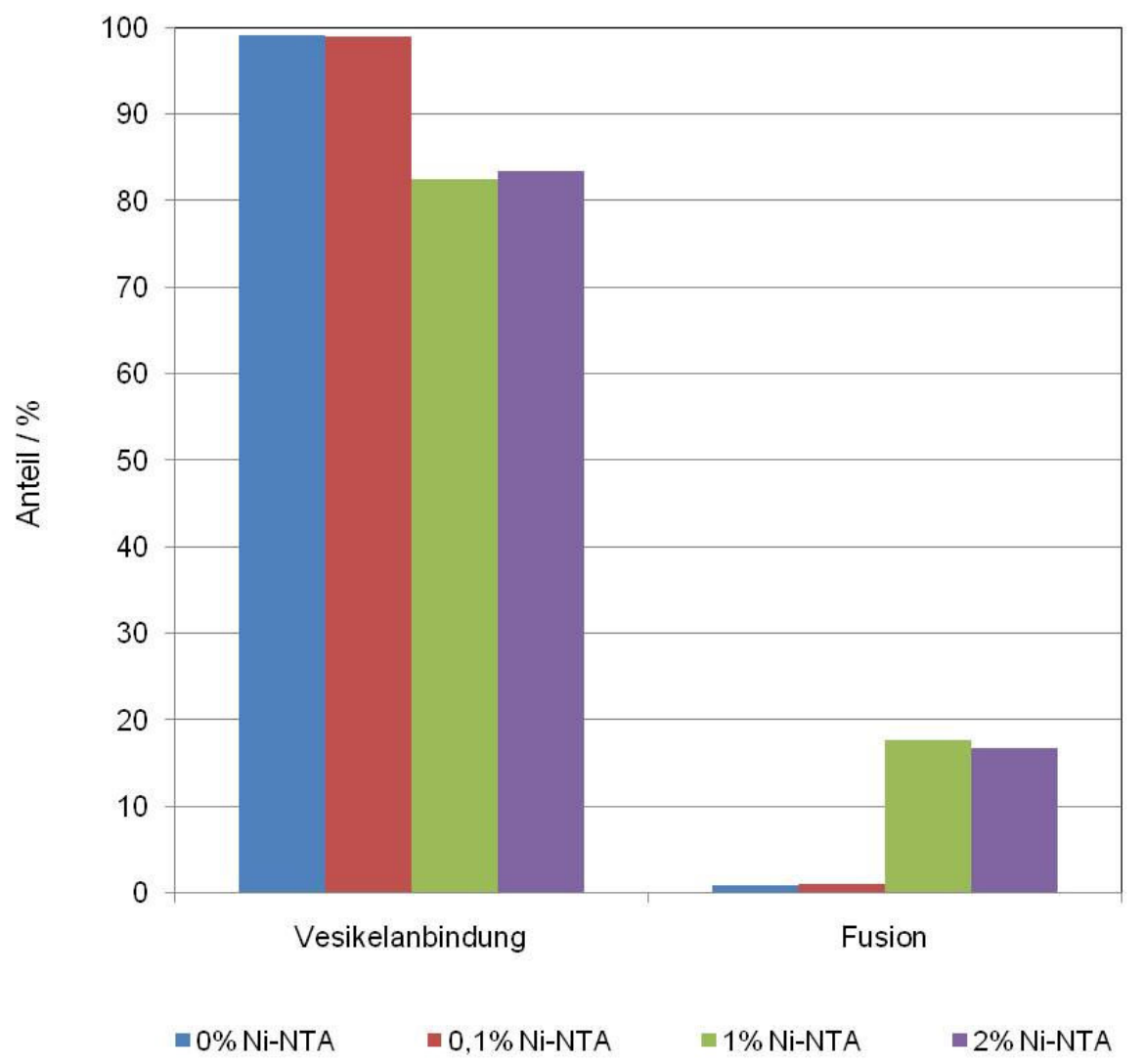

\begin{abstract}
Abb. 4.33 Statistische Auswertung der unterschiedlichen beobachteten Ereignisse, wenn die Interaktionen zwischen Maleimid-dotierten porenüberspannenden Membranen und Ni-NTA-haltigen Vesikeln durch das Fusionspeptids $\mathrm{H}_{6}$ WGC vermittelt wird. In dem Histogramm wurden die Ereignisse I, II und III zusammengefasst unter Vesikelanbindung, während die Ereignisse IV und V in der Kategorie Fusion zusammengezählt wurden. Die Häufigkeiten sind in dem Diagramm für die unterschiedlichen Ni-NTAKonzentrationen in den Vesikeln aufgeführt. Dabei entsprechen alle beobachteten Ereignisse für eine NiNTA-Konzentration $100 \%$. Die Gesamtzahl an gezählten Ereignissen betrug: $n=113$ für $0 \%$ Ni-NTA, $n=377$ für $0.1 \%$ Ni-NTA, $n=250$ für $1 \%$ Ni-NTA und $n=820$ für $2 \%$ Ni-NTA.
\end{abstract}

Zur weiteren Verdeutlichung des Einflusses der Rezeptordichte in den Vesikeln auf das Bindungs- und Fusionsverhalten wurde in dem Diagramm in Abb. 4.34 eine andere 
Darstellungsweise gewählt. In diesem Fall wurde jeweils ein Ereignistyp einzeln betrachtet und der Anteil der Ereignisse, der bei einer bestimmten Konzentration auftrat, wurde auf die Gesamtzahl der Ereignisse dieser Kategorie normiert. Daraus ergeben die die Wahrscheinlichkeiten, welcher Ni-NTA-Gehalt am ehesten zu der entsprechenden Interaktion führt.

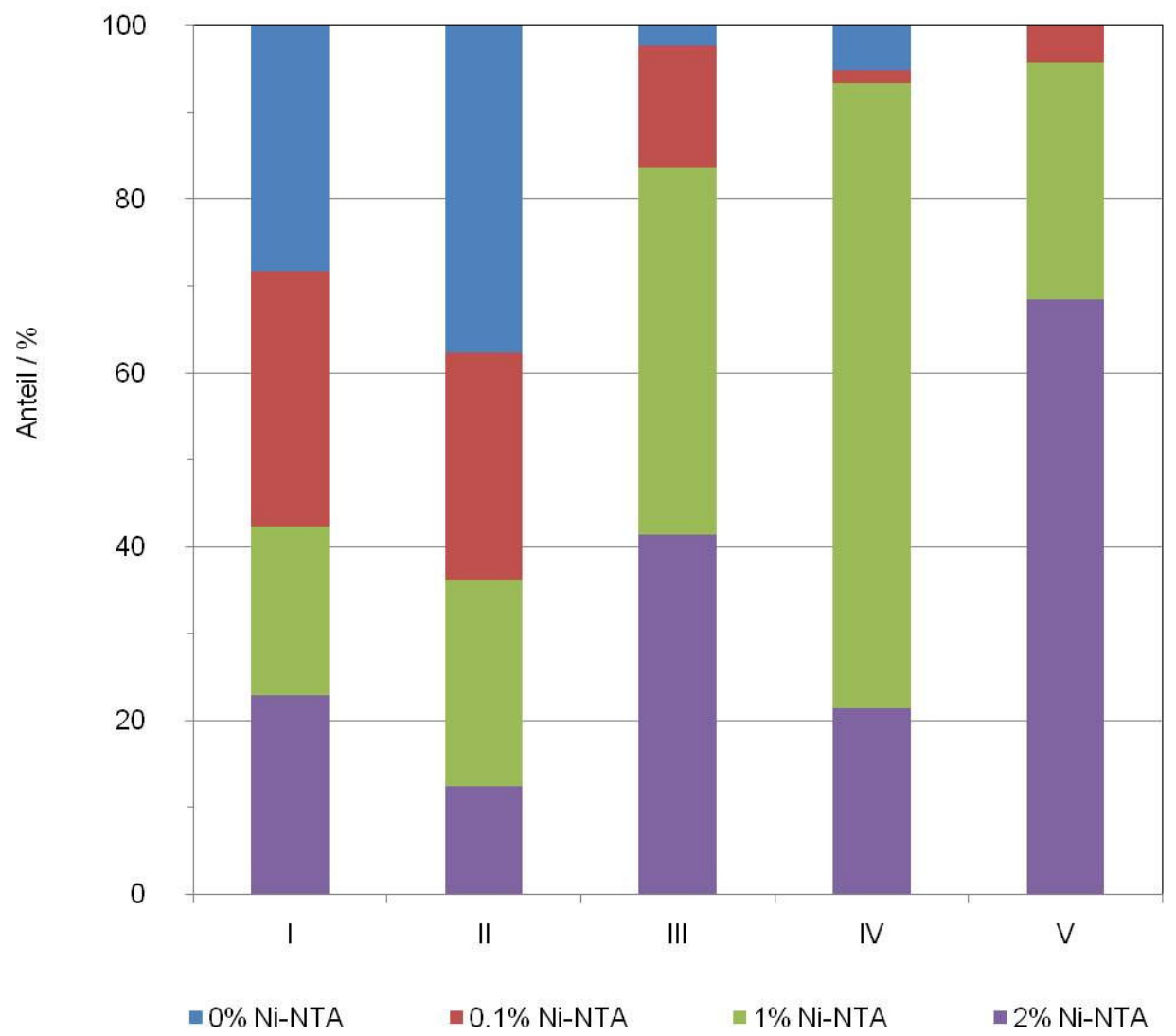

Abb. 4.34 Statistische Auswertung der unterschiedlichen auftretenden Interaktionen zwischen Maleimiddotierten porenüberspannenden Membranen und Ni-NTA-haltigen Vesikeln vermittelt durch die Wechselwirkung des Fusionspeptids $\mathrm{H}_{6}$ WGC. Die Gesamtzahl an gezählten Ereignissen betrug: $n=113$ für $0 \%$ Ni-NTA, $n=377$ für $0.1 \%$ Ni-NTA, $n=250$ für $1 \%$ Ni-NTA und $n=820$ für $2 \%$ Ni-NTA.

Im Diagramm wird deutlich, dass reine Andockprozesse bei allen untersuchten Ni-NTAKonzentrationen mit ähnlicher Wahrscheinlichkeit auftreten. Reine Fusionereignisse sind dagegen mit einer Wahrscheinlichkeit von über $60 \%$ bei einem Gehalt von 1 mol\% NiNTA eher zu erwarten als bei den restlichen untersuchten Konzentrationen. Daneben sind Ereignisse mit zurückbleibender Texas Red-Intensität (Ereignis III und V) mit über $40 \%$ bzw. über $65 \%$ am ehesten bei der höchsten eingesetzten Ni-NTA-Dichte von 2 mol\% beobachten. 


\subsubsection{Untersuchung der Fusion von GUVs mit porenüberspannenden Membranen vermittelt durch das Peptid $\mathrm{H}_{6} \mathrm{CGW}$}

Zusätzlich zu den durchgeführten Studien mit LUVs wurden auch Experimente zur Fusion von GUVs mit porenüberspannenden Membranen durchgeführt. Auf diese Versuche soll nun näher eingegangen werden, um die abweichende Interaktion von GUVs im Gegensatz zu LUVs mit porenüberspannenden Membranen aufzuzeigen. Die Versuche wurden analog $\mathrm{zu}$ den in Kapitel 4.5.1.2 beschriebenen Messungen durchgeführt. Dabei konnte festgestellt werden, dass GUVs unspezifisch mit porenüberspannenden Membranen fusionieren. In 27 Zeitserien mit einer Länge von 30 $60 \mathrm{~s}$ wurden nach Peptidfunktionalisierung der porenüberspannenden Membran 33 Fusionsereignisse detektiert. In Abwesentheit von $\mathrm{H}_{6} \mathrm{WGC}$ wurden in 21 Zeitserien mit einer Länge von 30 - 40 s insgesamt 19 Fusionsereignisse gezählt. Daraus kann geschlussfolgert werden, dass die Fusion von GUVs mit porenüberspannenden Membranen in diesem Fall unabhängig vom Fusogen stattfindet. Aus diesem Grund wurde die Fusion von GUVs mit porenüberspannenden Membranen nicht weiter untersucht. Dennoch soll im Folgenden ein Fusionsereignis gezeigt werden, das belegt, dass GUVs nicht nur unspezifisch fusionieren, sondern vermutlich zusätzlich so viel Lipidmaterial in die porenüberspannenden Membranen eintragen, so dass diese reißen.

Das Fusionereignis eines GUVs mit einem Ni-NTA-Gehalt von $2 \%$ mit $\mathrm{H}_{6} \mathrm{WGC}$ funktionalisierten porenüberspannenden Membranen ist in Abb. 4.35 gezeigt. Wie in den bisher beschriebenen Fluoreszenzaufnahmen wird auch hier die Vermischung der Vesikellipide mit porenüberspannenden Membranen durch die radiale Texas RedFluoreszenz in der Ebene der porenüberspannenden Membranen und durch die simultane Oregon Green-Löschung indiziert. 

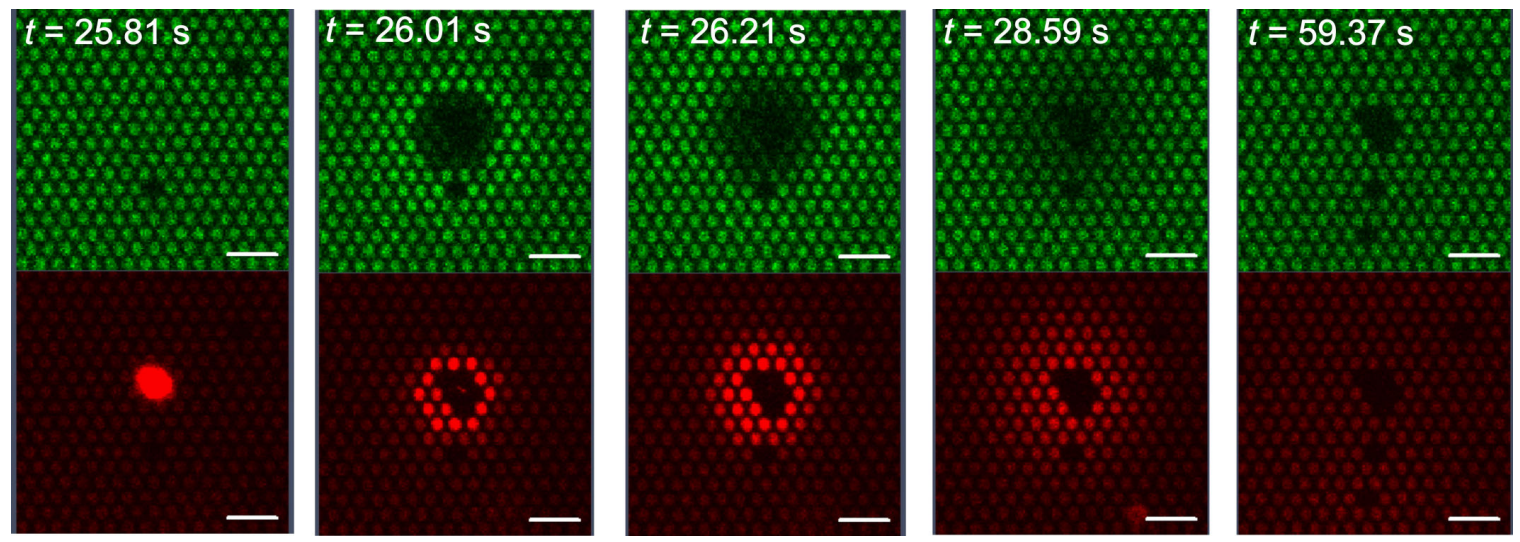

Abb. 4.35 Fluoreszenzmikroskopische Aufnahme der Fusion eines GUVs (POPC/Ni-NTA-DOGS/Texas Red 96:2:2) mit einer porenüberspannenden Membran hergestellt durch Spreiten von GUVs (DOPC/MCCDOPE/Oregon Green, 96:2:2, Funktionalisierung des Substrats: CPEO3). Die porenüberspannende Membran wurde vor der Vesikel-Zugabe mit $\mathrm{H}_{6}$ WGC $(14 \mu \mathrm{M})$ funktionalisiert. Der GUV nähert sich der Membran $(t=25.81 \mathrm{~s})$ und zeigt darauffolgend ab $t=26.01 \mathrm{~s}$ eine radiale Verteilung der Texas RedMoleküle in der porenüberspannenden Membran. Gleichzeitig ist im grünen Kanal die Löschung der Oregon Green-Fluoreszenz zu erkennen. Im Zentrum der Fusion erscheinen nach dem Ereignis einige Poren sowohl im grünen als auch im roten Kanal schwarz. Der Maßstabsbalken entspricht $5 \mu$ m.

Der exponentielle Abfall der roten Fluoreszenz und der sprunghafte Abfall und langsame Wiederanstieg des grünen Signals innerhalb des ROI werden ebenfalls in dem Intensitätsprofil der Fluoreszenz widergespiegelt (Abb. 4.36).

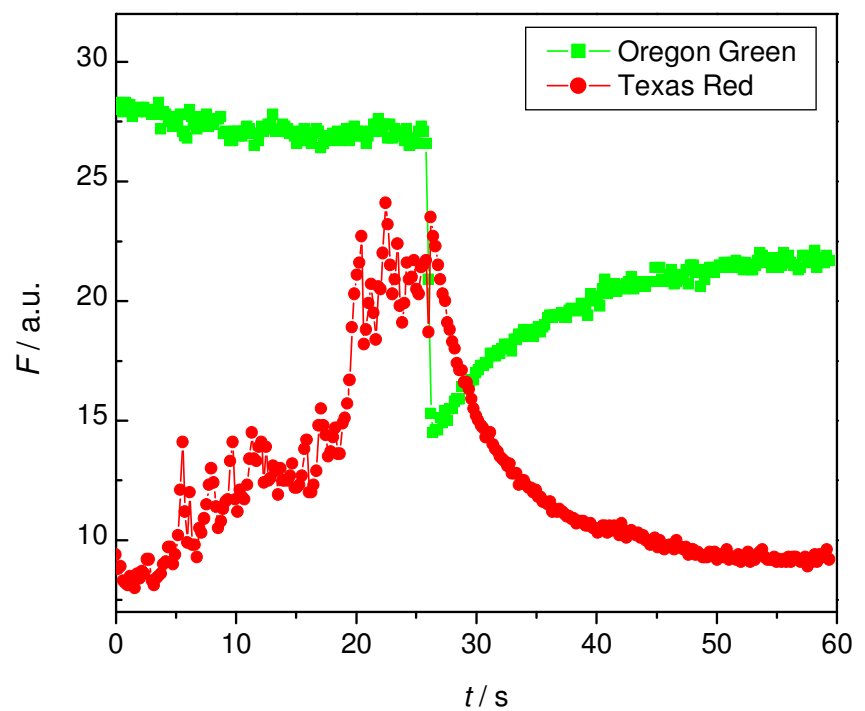

Abb. 4.36 Zeitlicher Verlauf der Fluoreszenzintensitäten von Oregon Green und Texas Red. Die gemittelten Intensitäten innerhalb eines definierten ROI wurden aus der in Abb. 4.36 gezeigten Zeitserie extrahiert. Zum Zeitpunkt der Fusion des GUVs mit porenüberspannenden Membranen bei $t=26.01 \mathrm{~s}$ zeigt die Texas Red-Fluoreszenz einen exponentiellen Abfall, der mit der sprunghaften Verminderung und dem darauffolgenden Wiederanstieg des Oregon Green-Signals korreliert. 
Wird die Größe des ROIs nun kleiner gewählt, so dass nur die Poren, deren Fluoreszenz verschwindet, darin berücksichtigt werden, so ergibt sich das in Abb. 4.37 gezeigte Intensitätsprofil. Die Fluoreszenzintensität fällt im Zeitprofil schlagartig ab und bleibt bis zum Ende der Zeitserie konstant auf einem sehr niedrigen Wert nahe null ohne einen Wiederanstieg zu zeigen.
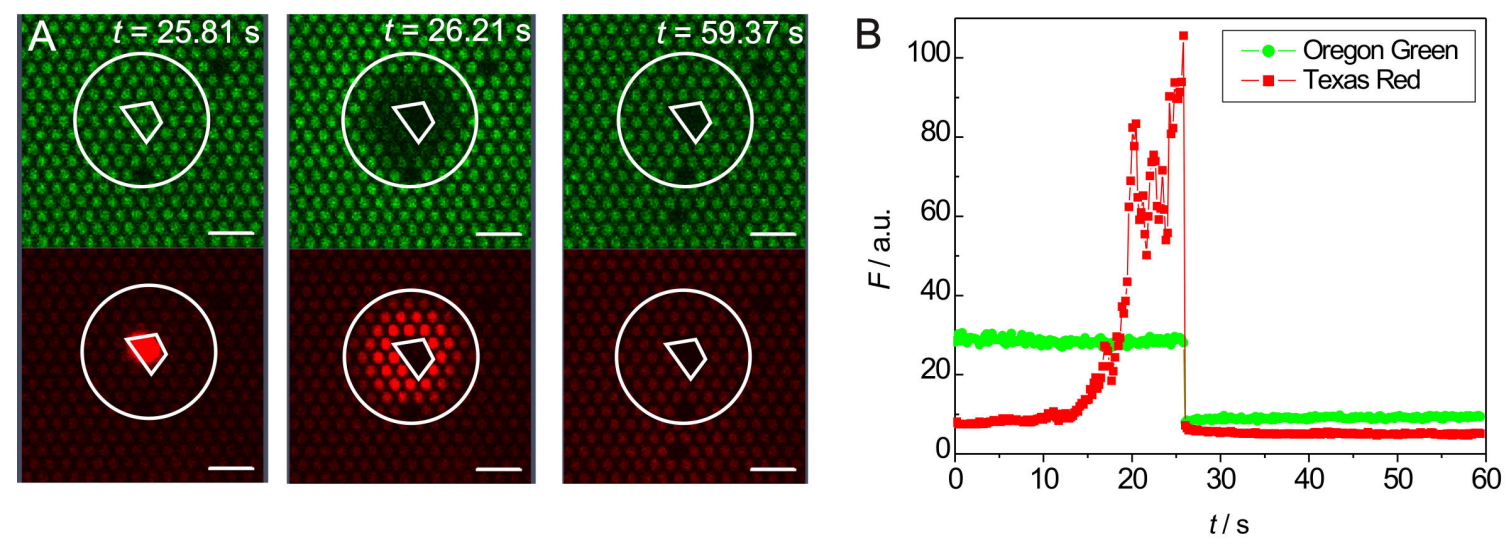

Abb. 4.37 A Fluoreszenzmikroskopische Aufnahme der bereits in Abb. 4.35 gezeigten Zeitserie, welche die Fusion eines GUVs mit porenüberspannenden Membranen zeigt. Von den zwei eingezeichneten ROIs (weiß) entspricht der größere, kreisrunde dem ROI, aus dem die in Abb. 4.36 dargestellten Zeitprofile extrahiert wurden. Wird der ROI entsprechend kleiner gewählt und um die schwarz erscheinenden Poren im Zentrum gelegt, so wird das in B gezeigt Profil der Oregon Green- und Texas Red-Fluoreszenz erhalten. Der sprunghafte Abfall beider Signale bei $t=26.01 \mathrm{~s}$ auf einen Wert von annähernd null verdeutlicht, dass die Fluoreszenz in diesem Bereich im Zuge der Fusion komplett verschwindet und legt die Vermutung nahe, dass die Fusion des GUVs zum Reißen der porenüberspannenden Membranen führt. Der Maßstabsbalken entspricht $5 \mu \mathrm{m}$.

Diese Beobachtungen wurden dem Reißen der Membran über den entsprechenden Poren zugeschrieben. Vereinzelt konnten derartige Phänomene bereits sowohl in den Experimenten zur Fusion von LUVs mit micro-BLMs als auch zur Fusion von LUVs mit porenüberspannenden Membranen verfolgt werden. Mit einer Häufigkeit von $55 \%$ mit einem Ausmaß von 1 - 10 gerissenen Poren, scheint dieses Ereignis charakteristisch für die Fusion von GUVs mit porenüberspannenden Membranen zu sein. 


\subsubsection{Untersuchung der Fusion von Vesikeln mit porenüberspannenden Membranen vermittelt durch SNARE-analoge PNA-Strukturen}

Das in Kapitel 4.5.1 beschriebene Fusionspeptid $\mathrm{H}_{6}$ WGC induziert die Membranfusion vor allem durch die Verbrückung und der damit verbundenen Vermittlung eines engen Kontakts der zwei Lipiddoppelschichten zueinander. Der Einfluss von Membranverankerungen und Ausbildung von spezifischen Peptidkomplexen, wie sie im Fall der fusogenen SNARE-Proteinen auftreten, konnte mit diesem Modellmembransystem nicht untersucht werden. Das $\mathrm{H}_{6}$ WGC-System beschränkt sich auf die molekulare Erkennung außerhalb der Membran, wodurch die Lipiddoppelschichtintegrität erhalten bleibt. Durch die Verwendung von membranverankerten PNA-Peptiden hingegen wird eine molekulare Erkennung außerhalb der Membran mit dem Einbau einer Helix in die Lipiddoppelschicht, der mit strukturellen Veränderungen der Membran einhergeht, verknüpft. Die verwendeten Peptide sind, wie in Kapitel 3.3.2 ausführlich beschrieben, aus dem nativen Membrananker der SNARE-Proteine Syntaxin und Synaptobrevin, einer peptidischen Linkerregion und komplementären PNA-Strängen mit 10 Nukleobasen aufgebaut. Es sollte untersucht werden, ob die molekularen Interaktionen der SNARE-Proteine während der Fusion mit analogen PNA-Peptiden nachgeahmt werden können und welche strukturellen Einflüsse auf den Fusionsprozess wirken. Die unterschiedlichen Peptide wurden zum einen in GUVs rekonstituiert (VAMP PNA1), aus denen schließlich durch Spreiten porenüberspannende Membranen präpariert wurden. Zum anderen wurden die Peptide in LUVs (Syx PNA3 bzw. Syx PNA1 bzw. VAMP PNA1) eingebaut, die anschließend zur Untersuchung von Einzelfusionsereignissen $\mathrm{zu}$ den porenüberspannenden Membranen gegeben wurden. Die Namen der verwendeten PNAPeptide geben an, welche PNA-Sequenz verwendet wurde (Kapitel 3.3.2), wobei PNA1 und PNA3 komplementär zueinander sind. Zusätzlich kann aus dem Terminus abgelesen werden, ob die Transmebraneinheit von Syntaxin (Syx) oder Synaptobrevin (VAMP) verwendet wurde. 


\subsubsection{Nachweis des Einbaus von PNA-Strukturen in porenüberspannende Membranen}

Die erfolgreiche Rekonstitution der PNA-Konstrukte in porenüberspannende Membranen wurde durch Bindung von fluoreszenzmarkierter DNA nachgewiesen. Dazu wurden PNA-Peptid-haltige GUVs vor dem Spreiten mit Alexa Fluor 633-gekoppelter DNA, deren Sequenz komplementär zu der verwendeten PNA-Basenabfolge war, inkubiert. Ein Vergleich der Fluoreszenzaufnahmen von PNA-haltigen und PNA-freien porenüberspannenden Membranen ist in Abb. 4.38 gezeigt.
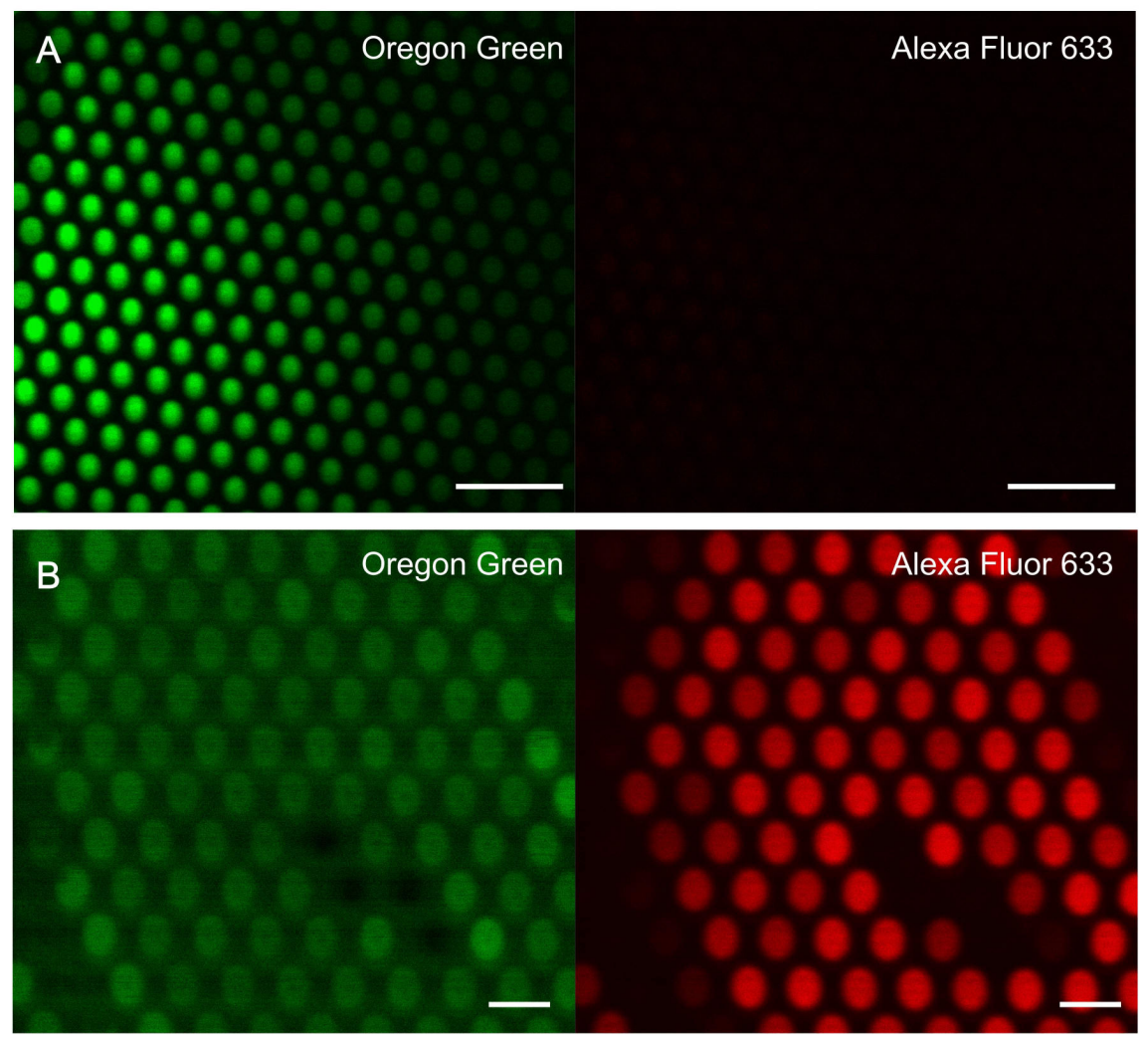

Abb. 4.38 Fluoreszenzmikroskopische Aufnahmen von porenüberspannendenen Membranen auf einem CPEO3-funktionalisierten porösen Substrat in Puffer (100 mM KCl, $10 \mathrm{mM}$ HEPES, pH 7.4). Die Membranen wurden durch Spreiten von GUVs (DOPC/Oregon Green 98:2) ohne PNA-Peptid (A) und mit VAMP PNA1 (Lipid/Peptid 200:1) (B) erhalten. Vor dem Spreiten wurden beide GUV-Populationen mit Alexa Fluor 633-markierter DNA inkubiert, um über die Anbindung der DNA an die komplementäre PNA in den porenüberspannenden Membranen die erfolgreiche Rekonstitution des PNA-Peptids zu zeigen. Sowohl in $\mathbf{A}$ als auch in $\mathbf{B}$ ist deutlich die grüne Fluoreszenz der porenüberspannenden Membran zu erkennen, während die Alexa Fluor 633-Fluoreszenz nur im Fall der PNA-haltigen Membran detektiert werden kann. Der Maßstabsbalken entspricht $5 \mu \mathrm{m}$ (A) bzw. $2 \mu \mathrm{m}$ (B). 
Um die membranüberspannten Bereiche des Substrats indentifizieren zu können, wurden die Lipiddoppelschichten mit Oregon Green DHPE dotiert. Die grüne Fluoreszenz zeigt, dass sich sowohl aus den peptidfreien als auch den VAMP PNA1-haltigen GUVs porenüberspannende Membranen gebildet haben. Neben der Oregon Green-Fluoreszenz wurde das Alexa Fluor 633-Signal der DNA detektiert. Ist kein VAMP PNA1 in der Membran vorhanden, so sollte keine Alexa Fluor 633-Fluoreszenz nachgewiesen werden, da keine spezifische Bindung der komplementären DNA an die PNA-freie Membran erfolgen sollte. Die Negativ-Kontrolle mit der reinen DOPC-Membran (Abb. 4.38 A) zeigt, dass keine unspezifische Bindung an die PNA-freie Lipiddoppelschicht erfolgt, wie die fehlende rote Fluoreszenz der Probe beweist. Die erfolgreiche Rekonstitution des VAMP PNA1 in die porenüberspannenden Membranen kann somit durch den Nachweis der Alexa Fluor 633-Fluoreszenz verifiziert werden. In der Aufnahme in Abb. 4.38 B ist deutlich die rote Fluoreszenz im Bereich der porenüberspannenden Lipiddoppelschicht zu erkennen. Die spezifische Anbindung der fluoreszenzmarkierten komplementären DNA an die porenüberspannende Lipiddoppelschicht ist ein eindeutiges Indiz für den erfolgreichen Einbau des VAMP PNA1-Peptids in das Membransystem.

Ein Vergleich der Signale im grünen Kanal der porenüberspannenden Membran mit und ohne Peptid zeigt, dass die Oregon Green-Fluoreszenz im Fall der gebundenen DNA wesentlich dunkler erscheint als die der porenüberspannenden Membranen ohne VAMP PNA1. Dies kann auf einen spektralen Überlapp von Oregon Green-Emission und Alexa Fluor 633-Absorption zurückgeführt werden. Der resultierende FRET-Effekt führt dann bei Binden des Alexa Fluor 633-Farbstoffs an die Membran zu einer Verringerung der Oregon Green-Emission. Das Auftreten des abstandsabhängigen Energietransfers kann als weiteres Indiz für die membrannahe Bindung der DNA an die porenüberspannende Lipiddoppelschicht gesehen werden, da die FRET-Effizienz mit der sechsten Potenz des Abstands der zwei Farbstoffe abnimmt.

\subsubsection{Untersuchung der Fusion von LUVs mit porenüberspannenden Membranen vermittelt durch SNARE-analoge PNA-Strukturen}

Nach dem erfolgreichen Nachweis der PNA-Moleküle in den porenüberspannenden Membranen wurde im nächsten Schritt die Fusion von LUVs mit porenüberspannenden Membranen vermittelt durch die PNA-Interaktion untersucht. Zum Beweis der Spezifität 
dieser Interaktion wurden zunächst peptidfreie LUVs zu peptidfreien porenüberspannenden Membranen gegeben und analysiert, ob diese auch ohne PNAErkennung miteinander interagieren. Da in den aufgenommenen Zeitserien weder ein Anstieg der Texas Red-Intensität in den porenüberspannenden Membranen noch Einzelfusionsereignisse zu detektieren waren, kann geschlossen werden, dass die Vesikel nicht unspezifisch mit den porenüberspannenden Membranen fusionieren.

Zur Analyse der molekularen Erkennung wurden die in Kapitel 3.3.2 beschriebenen PNA-Peptide in Vesikel- und porenüberspannende Membran eingebaut. Die porenüberspannenden Membranen wurden dazu aus VAMP PNA1-haltigen-GUVs präpariert, während in den Vesikeln Syx PNA3 rekonstitutiert wurde, welches die zu PNA1 komplementäre PNA3 trägt. In Abb. 4.39 A ist eine Zeitreihe gezeigt, in der ein typisches Fusionsereignis zu sehen ist. Nach der Annäherung des Vesikels, die im roten Kanal $\mathrm{zu}$ beobachten ist $(t<0)$, wird die Vermischung der Vesikellipide mit den porenüberspannenden Membranen ab $t=50 \mathrm{~ms}$ durch die radiale Texas Red-Verteilung in der planaren Membran und die simultane Oregon Green-Löschung angezeigt.
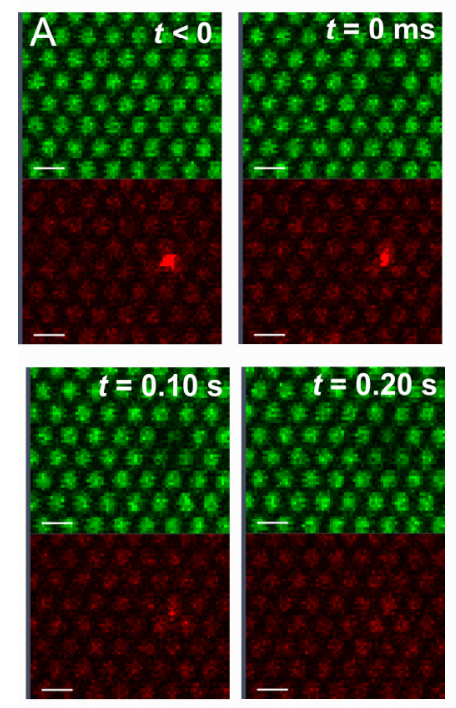
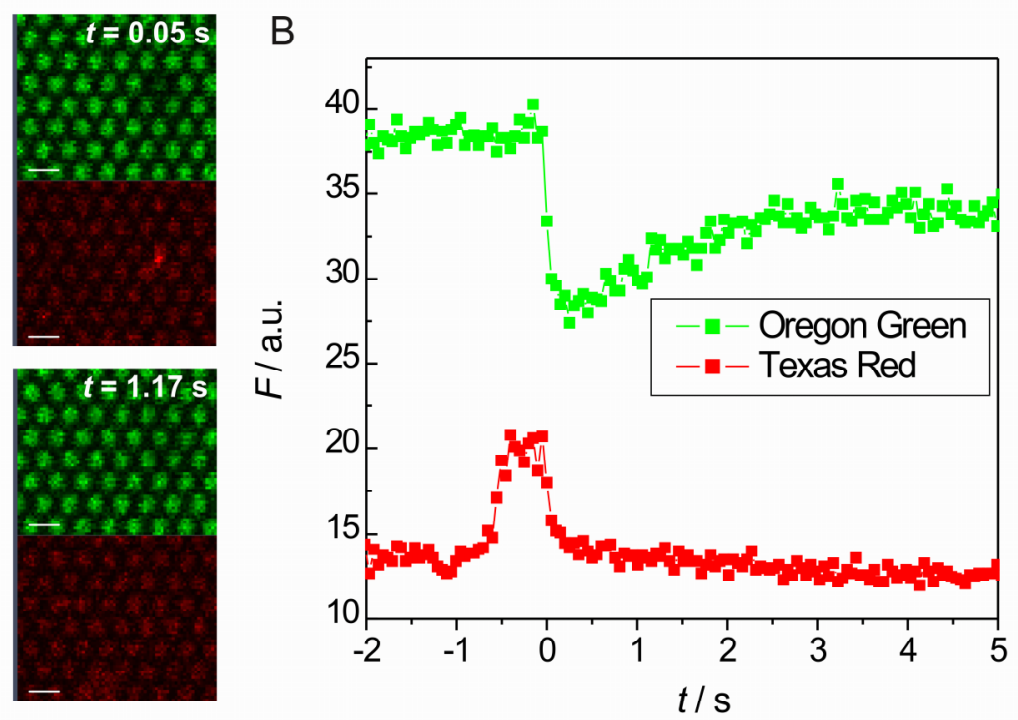

Abb. 4.39 A Fluoreszenzmikroskopische Aufnahme der Fusion eines Vesikels (POPC/POPS/Texas Red 78:20:2, mit Syx PNA3 im Verhältnis Lipid/Peptid 500:1) mit porenüberspannenden Membranen (DOPC/Oregon Green 98:2, VAMP PNA 1 im Verhältnis Lipid/Peptid $500: 1$, Funktionalisierung des Substrats: CPEO3) in KCl-Puffer (100 mM KCl, $10 \mathrm{mM} \mathrm{HEPES,} \mathrm{pH} \mathrm{=} \mathrm{7.4).} \mathrm{Beim} \mathrm{Auftreffen} \mathrm{eines}$ Vesikels auf die Membranoberfläche ist bei $t=50 \mathrm{~ms}$ die Löschung der Oregon Green-Fluoreszenz durch FRET zu erkennen (grün). Im Fall der Texas Red-Fluoreszenz (rot) ist zunächst der Vesikel zu sehen, der sich der Membranoberfläche nähert und anschließend wird ab $t=0.05 \mathrm{~s}$ die radiale Verteilung des Texas Red-Farbstoffs in der planaren Membran über die Zeit sichtbar. Der Maßstabsbalken entspricht $2 \mu \mathrm{m}$. B Zeitprofil der Fluoreszenzintensitäten der in A gezeigten Zeitserie. Zum Zeitpunkt $t=50 \mathrm{~ms}$ ist der sprunghafte Abfall und anschließende Wiederanstieg der Oregon Green-Intensität sowie der exponentielle Abfall des Texas Red-Signals erkennbar. 
Im Zeitprofil der Fluoreszenzintensitäten (B) wird das Fusionsereignis durch den exponentiellen Abfall des Texas Red-Signals bei $t=0.05 \mathrm{~s}$ angezeigt. Außerdem führt die Lipidvermischung im Zuge der Fusion zu einem sprunghaften Abfall und langsamen Wiederanstieg auf den Ausgangswert des Oregon Green-Signals. Die Analyse des Texas Red-Intensitätsabfalls wurde wie in Kapitel 4.1 beschrieben durchgeführt und aus den Daten durch Kurvenanpassung ein Diffusionskoeffizient von $D=(3 \pm 3) \mu \mathrm{m}^{2} / \mathrm{s}(n=58)$ für die Verteilung der Texas Red-Moleküle in den porenüberspannenden Membranen bestimmt.

Neben den oben gezeigten Experimenten wurden unterschiedliche Kombinationen von PNA-Sequenzen und Transmembranankern verwendet, um den Einfluss dieser strukturellen Merkmale auf das Fusionsverhalten der Vesikel zu analysieren.

In der Regel wurde VAMP PNA1 in GUVs insertiert, aus denen die porenüberspannenden Membranen präpariert wurden. Gleichzeitig wurden unterschiedliche PNA-Moleküle in die Vesikel eingebaut. Die Resultate sind in Tab. 1 zusammengefasst und Ergebnissen gegenübergestellt, die von Antonina Lygina (Arbeitsgruppe Diederichsen, Universität Göttingen) in einem Vesikel-Vesikel-Assay erhalten wurden. In den Untersuchungen zur Vesikelfusion wurden die Peptide in zwei unterschiedliche Vesikelpopulationen eingebaut. Die Liposomen hatten einen Durchmesser von $100 \mathrm{~nm}$ und eine der Populationen wurde mit einem FRET-Paar dotiert, während die andere ohne Fluoreszenzdotierung blieb. Über Untersuchungen der FRETEffizienz mit Hilfe eines Spektrofluorometers konnte dann die Fusion der Farbstofffreien Vesikelpopulation mit den FRET-markierten Vesikeln analysiert werden. In diesem Vesikel-Assay konnte nur im Fall der Kombination von VAMP PNA1-haltigen mit Syx PNA3-haltigen Vesikeln die Fusion indiziert durch Lipidvermischung beobachtet werden. In dem in dieser Arbeit etablierten Assay basierend auf porenüberspannenden Membranen weichen die Beobachtungen ab. Fusionsereignisse wurden nicht nur in Experimenten mit komplementärer PNA gefunden. Wurden Peptide mit gleicher PNA aber unterschiedlichen Transmembranankern (VAMP PNA1/Syx PNA1) in die Membranen eingebaut, so wurde ebenfalls die Lipidvermischung zwischen LUVs und porenüberspannenden Membranen beobachtet. Das Gleiche gilt für die Kombination von gleichen Peptiden. In diesem Fall wurde die Wechselwirkung von VAMP PNA1 mit VAMP PNA1 untersucht. Im Gegensatz zu den in Kapitel 4.5.1.2 beschriebenen Versuchen zur Untersuchung der Intermembranwechselwirkung induziert durch das 
Peptid $\mathrm{H}_{6}$ WGC, wurden in den PNA-vermittelten Experimenten hauptsächlich reine Fusionsereignisse und kaum Anbindungsprozesse beobachtet. Aus diesem Grund stand in dieser Studie vor allem die Analyse der Fusionsvorgänge im Fokus. Zur Quantifizierung wurde die durchschnittliche Anzahl an Fusionsereignissen in den aufgenommenen Zeitserien bestimmt.

Tab. 1 Gegenüberstellung der Ergebnisse eines Vesikel-Vesikel-Assays mit den Ergebnissen des Assay basierend auf porenüberspannenden Membranen zur PNA-vermittelten Fusion. Dabei wurden die Beobachtungen zunächst nur qualitativ zusammengefasst zu Experimenten, in denen Fusion beobachtet wurde $(\bullet)$ und Experimenten, in denen keine Fusion beobachtet werden konnte $(\times)$.

\begin{tabular}{|c|c|c|c|}
\hline $\begin{array}{c}\text { porenüberspannende } \\
\text { Membran }\end{array}$ & Vesikel & Vesikel-Assay & Einzelfusions-Assay \\
\hline VAMP PNA1 & Syx PNA3 & & \\
\hline VAMP PNA1 & Syx PNA1 & - & \\
\hline VAMP PNA1 & VAMP PNA1 & - & \\
\hline leer & Syx PNA3 & - & \\
\hline VAMP PNA1 & leer & - & \\
\hline VAMP PNA1 & $\begin{array}{c}\text { Syx PNA3 } \\
+5 \text { mol\% LPC }\end{array}$ & leer & $\times$ \\
\hline leer & & & $\times$ \\
\hline
\end{tabular}

Zur Auszählung der Ereignisse wurde in Zusammenarbeit mit Prof. Dr. Burkhard Geil (Institut für Physikalische Chemie, Göttingen) eine Software entwickelt, um mittels einer Pixelanalyse die Fusion von Vesikeln mit einzelnen Poren zu identifizieren. Darin wurden zunächst die Intensitäten der grünen Fluoreszenz in einer aufgenommenen Zeitserie ausgelesen (Abb. 4.40). Über die Definition eines Schwellenwertes für die Fluoreszenzintensität konnten dann einzelne Poren lokalisiert und von den Porenstegen 
unterschieden werden. Anschließend wurden für jede einzelne Pore die Fluoreszenzintensitäten von Texas Red und Oregon Green in jeder einzelnen Aufnahme einer Zeitserie extrahiert. Als Ergebnis wurde für jede Pore ein Intensitätsprofil erhalten, das dann nach Fusionsereignissen abgesucht werden konnte. Die Fusion eines Vesikels mit den porenüberspannenden Membranen konnte dabei durch einen sprunghaften Anstieg der Texas Red-Intensität, die mit einem sprunghaften Abfall des Oregon GreenSignals korreliert, lokalisiert werden.
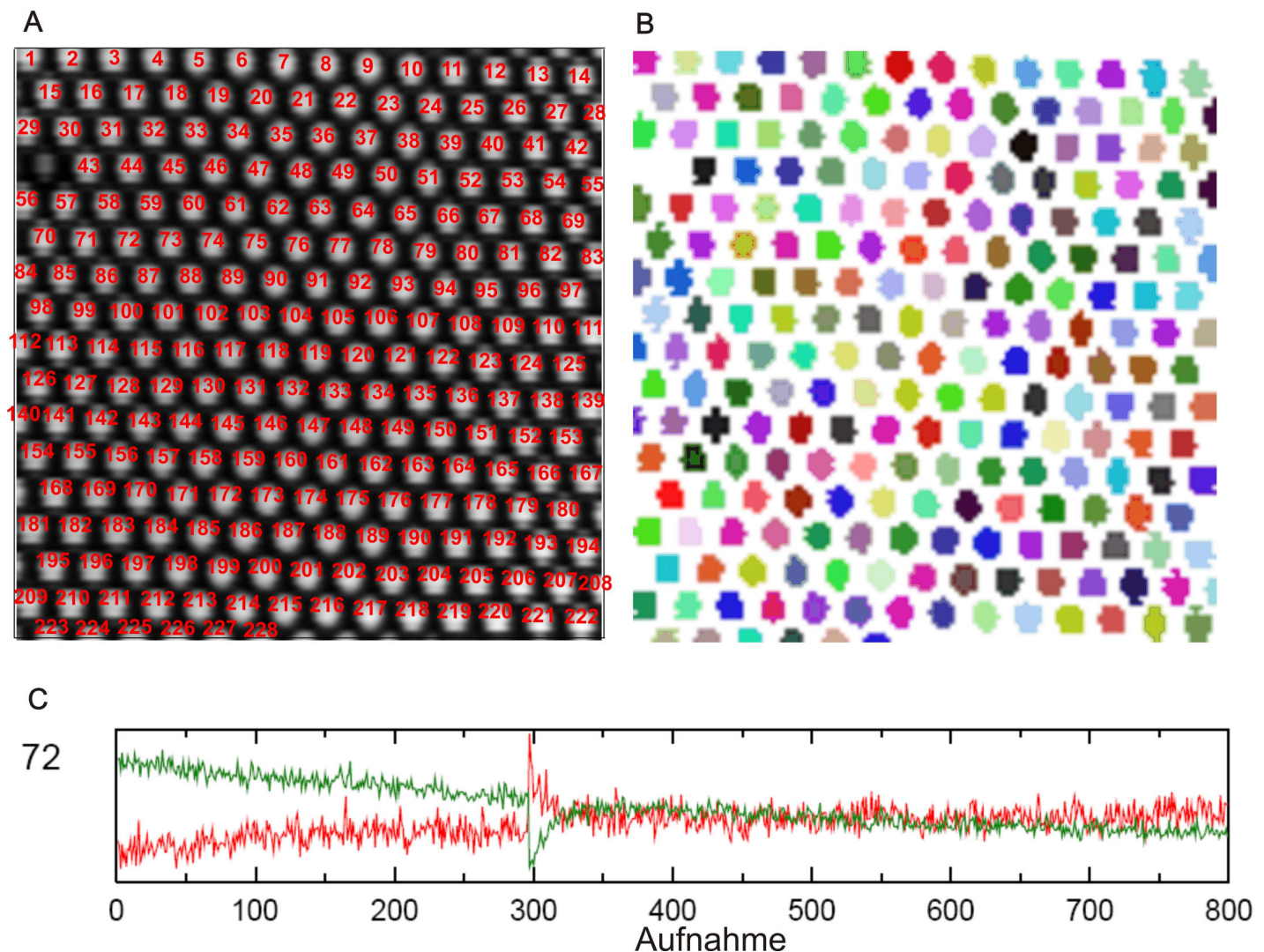

Abb. 4.40 A Fluoreszenzaufnahme von porenüberspannenden Membranen. Über die Fluoreszenzintensitäten wurden einzelne Poren wie in $\mathbf{B}$ gezeigt lokalisiert und nummeriert. C Intensitätsprofile der Texas Red- und Oregon Green-Fluoreszenz einer einzelnen Pore (Nr. 72) in Abhängigkeit von der Bildnummer einer Zeitserie. Ein Fusionsereignis kann durch den Anstieg der Texas Red-Fluoreszenz und den Abfall der Oregon Green-Fluoreszenz indentifiziert werden. Ein Beispiel für ein Fusionsereignis ist ab Aufnahme 300 zu finden.

Zum Vergleich verschiedener Experimente wurden in jeder Messung 800 Aufnahmen in einem Zeitintervall von $40.3 \mathrm{~s}$ von einem Bereich mit einer Größe von $25 \times 25 \mu \mathrm{m}$ gemacht und die Anzahl der in diesem Zeitraum detektierten Fusionsereignisse bestimmt. 
Die mittlere Anzahl an Fusionsereignissen ist für die unterschiedlichen Kombinationen an PNA-Peptiden in den Histogrammen in Abb. 4.41 aufgeführt.
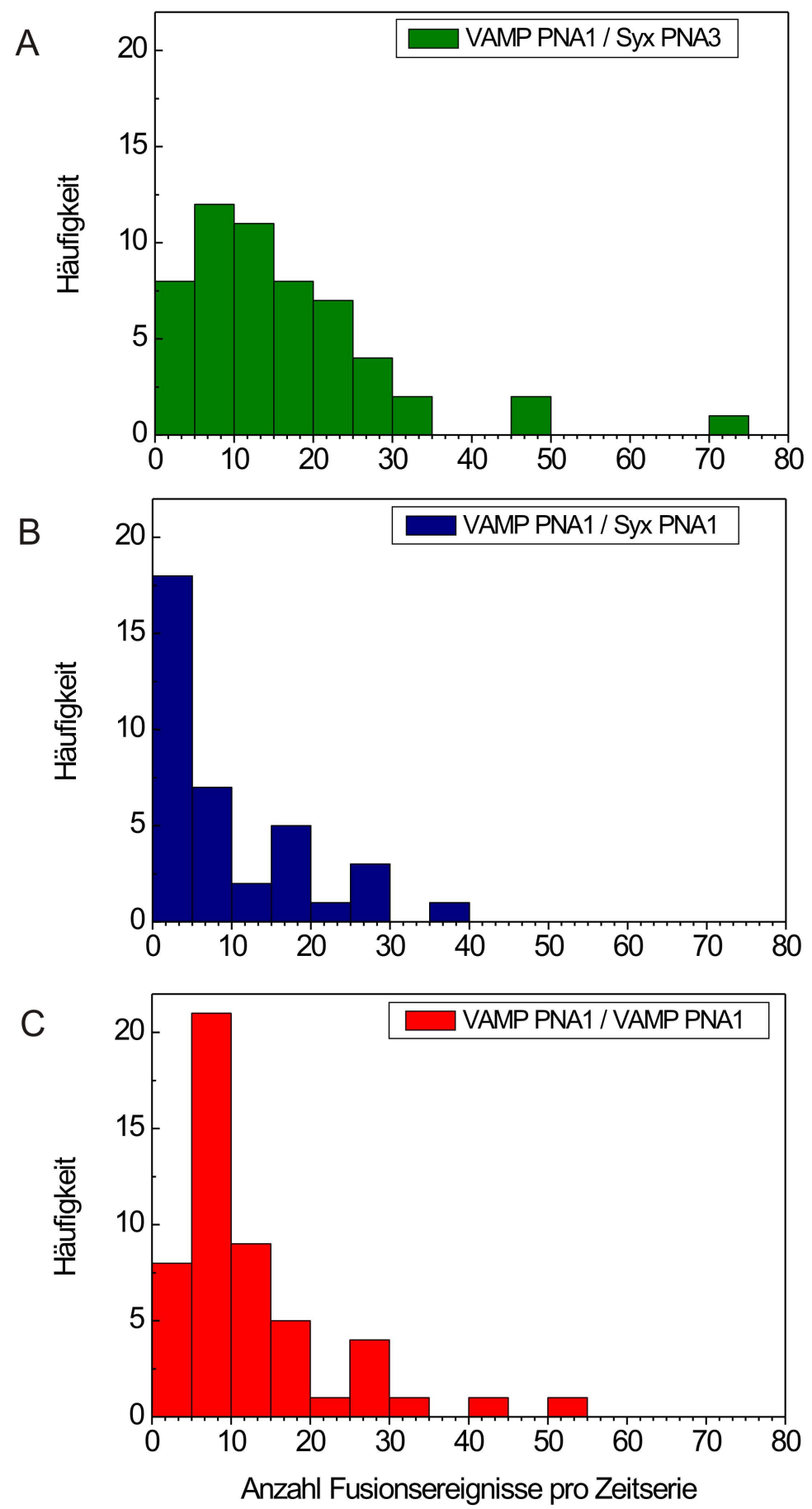

Abb. 4.41 Histogramm der Anzahl der Fusionsereignisse, die innerhalb einer Zeitserie $\left(25 \times 25 \mu \mathrm{m}^{2}\right.$, $40.3 \mathrm{~s}$ ) beobachtet wurden. In den entsprechenden Experimenten wurde die Fusion von Vesikeln (POPC/POPS/Texas Red 78:20:2, mit Syx PNA3 (A) bzw. Syx PNA1 (B) bzw. VAMP PNA1 (C)) im Verhältnis Lipid/Peptid $500: 1$ ) mit porenüberspannenden Membranen (DOPC/Oregon Green 98:2, VAMP PNA1 im Verhältnis Lipid/Peptid $500:$ 1) in KCl-haltigem Puffer (100 mM KCl, $10 \mathrm{mM} \mathrm{HEPES}, \mathrm{pH}=$ 7.4) beobachtet. 
Für die Kombination von VAMP PNA1/Syx PNA3 zeigen sich hauptsächlich Zeitserien mit 10 - 19 Ereignissen (19 Mal), nicht selten sind aber auch 20 - 30 Fusionsereignisse zu finden (13) und nur acht Zeitserien weisen weniger als fünf fusionierende Vesikel auf. In zwei Zeitreihen konnten sogar 46 und ein Mal 72 Fusionsereignisse gezählt werden.

Für den Fall, dass in den Experimenten Syx PNA1-tragende Vesikel zu VAMP PNA1haltigen porenüberspannenden Membranen gegeben wurden, konnten hauptsächlich Zeitserien mit 0 - 4 Fusionsereignissen ausgemacht werden (18 mal) während nur in 9 Zeitaufnahmen 5-14 Vesikel fusionierten. In neun Fällen wurden mehr als 15 Ereignisse gezählt, wovon vier allerdings über 25 Fusionen zeigten.

Die Paarung von gleichen PNA-Peptiden (VAMP PNA1/VAMP PNA1) ergab hauptsächlich Messungen mit weniger als 10 Ereignissen (29 Mal). 10 - 15 Fusionen von LUVs mit porenüberspannenden Membranen wurden 10 mal gezählt und über 15 Ereignisse traten in 12 Zeitserien auf. Im Durchschnitt ergibt sich daraus für alle Peptidkombinationen in etwa die gleiche mittlere Anzahl an Fusionsereignissen pro Zeitserie. Während in Experimenten mit VAMP PNA1-Peptiden in den porenüberspannenden Membranen und Syx PNA3 in LUVs im Mittel $\mathrm{N}=15 \pm 13$ Ereignisse in einer Zeitserie beobachtet wurden, wurden bei Austausch des Syx PNA3 in den Vesikeln gegen Syx PNA1 durchschnittlich $N=9 \pm 9$ Ereignisse detektiert. Wird VAMP PNA1 sowohl in die porenüberspannenden Membranen als auch in die Vesikel eingebaut, so konnten $\mathrm{N}=12 \pm 10$ Ereignisse pro Zeitserie gezählt werden. Die Verteilung im Histogramm zeigt jedoch, dass die Kombination von Syx PNA3 und VAMP PNA1 wesentlich fusogener zu sein scheint, als die Paarung von VAMP PNA1 mit Syx PNA1. Die geringste Fusionswahrscheinlichkeit wurde somit für VAMP PNA1/VAMP PNA1 gefunden.

Zusätzlich wurden Experimente durchgeführt, in denen nur in eine der zu fusionierenden Membranen PNA-Peptide eingebaut wurden. Die Zugabe von Syx PNA3-haltigen LUVs zu Peptid-freien porenüberspannenden Membranen führte zu folgenden Beobachtungen (Abb. 4.42). Vor der Zugabe von Vesikeln (A) ist die porenüberspannende Membran im grünen Kanal sichtbar, während im roten Kanal kein Signal detektiert wird. Nach der Zugabe von LUVs (B) ist die Struktur der porenüberspannenden Membran in beiden Kanälen zu beobachten. Die Tatsache, dass rote Fluoreszenz in der Ebene der planaren Membran zu sehen ist, spricht dafür, dass Fusion stattgefunden hat und, dass der rote 
Farbstoff auf diese Weise in die porenüberspannenden Membranen eingebaut wurde. Auf Grund einer zu geringen Datenmenge und schlechter Signal-zu-Rausch Verhältnisse in den Aufnahmen, wurde auf die Auszählung der Einzelfusionsereignisse in diesem Fall verzichtet.
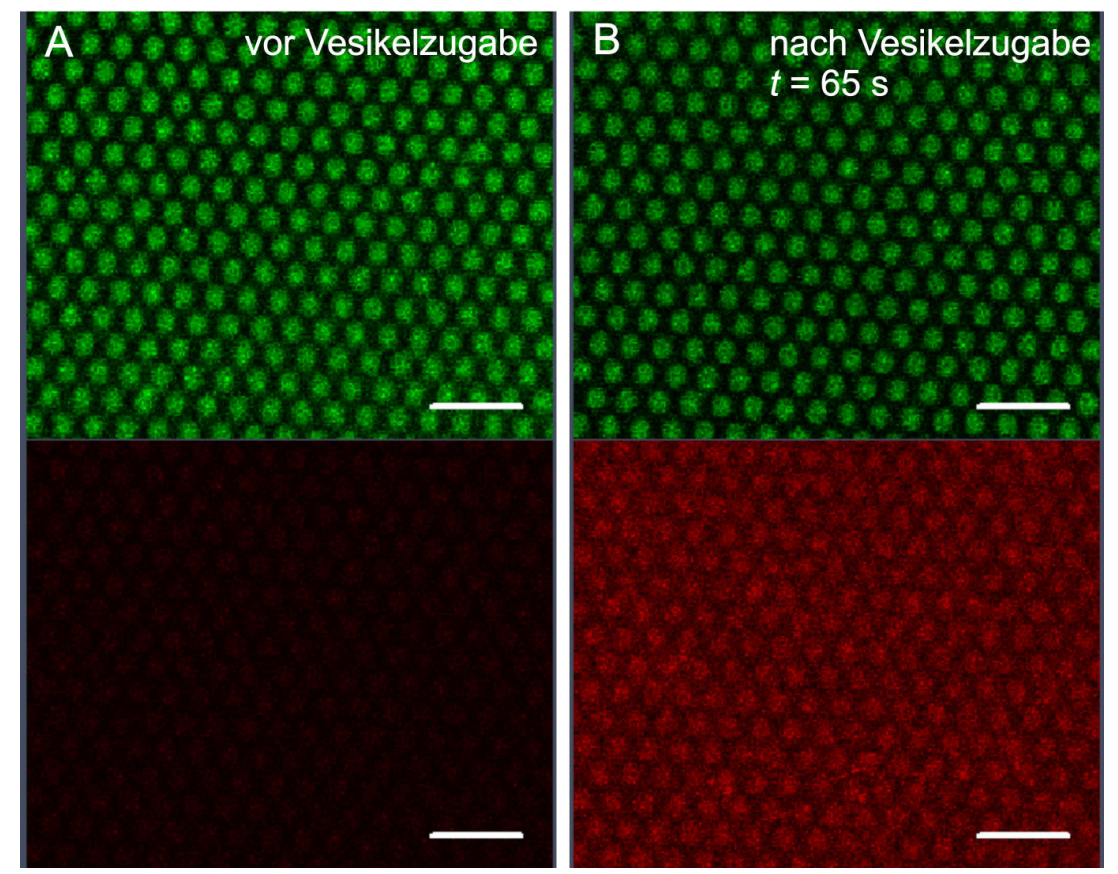

Abb. 4.42 Fluoreszenzmikroskopische Aufnahmen von porenüberspannenden Membranen (DOPC/Oregon Green 98:2, Funktionalisierung des Substrats: CPEO3) in KCl-haltigem Puffer (100 mM KCl, $10 \mathrm{mM}$ HEPES, pH = 7.4). A Vor der Zugabe von LUVs (POPC/POPS/Texas Red 78:20:2, Syx PNA3 im Verhältnis Lipid/Peptid $500: 1$ ) ist die porenüberspannende Membran nur im grünen Kanal sichtbar. B Nach der Zugabe von LUVs ist die Struktur der porenüberspannenden Membran auch im roten Kanal zu detektieren, was für einen Einbau des Farbstoffs in die planare Membran und somit für eine stattgefundene Fusion spricht. Der Maßstabsbalken entspricht $5 \mu \mathrm{m}$.

Werden im Gegensatz dazu peptidfreie LUVs zu VAMP PNA1-tragende porenüberspannende Membranen gegeben, so konnte in den Zeitserien kein einziges Fusionsereignis gezählt werden. Diese Beobachtung wird zusätzlich dadurch gestützt, dass in den Fluoreszenzbildern, die nach der Zugabe der LUVs aufgenommen wurden, die Texas Red-Intensität in den porenüberspannenden Membranen nicht signifikant ansteigt. In Abb. 4.43 ist zunächst die Aufnahme einer Zeitserie gezeigt, in der deutlich die Texas Red-dotierten Vesikel im roten Kanal zu sehen sind. Diese befinden sich in einer Ebene mit der Oregon Green-dotierten Membran. Nach dem Spülen der Probe zur Entfernung der Vesikel aus der Fokusebene wird deutlich, dass keine Texas RedMoleküle in die porenüberspannenden Membranen eingebaut wurden, da diese im roten 
Kanal nicht zu detektieren sind. Dementsprechend kann daraus geschlossen werden, dass in diesem Fall keine Fusion stattgefunden hat.
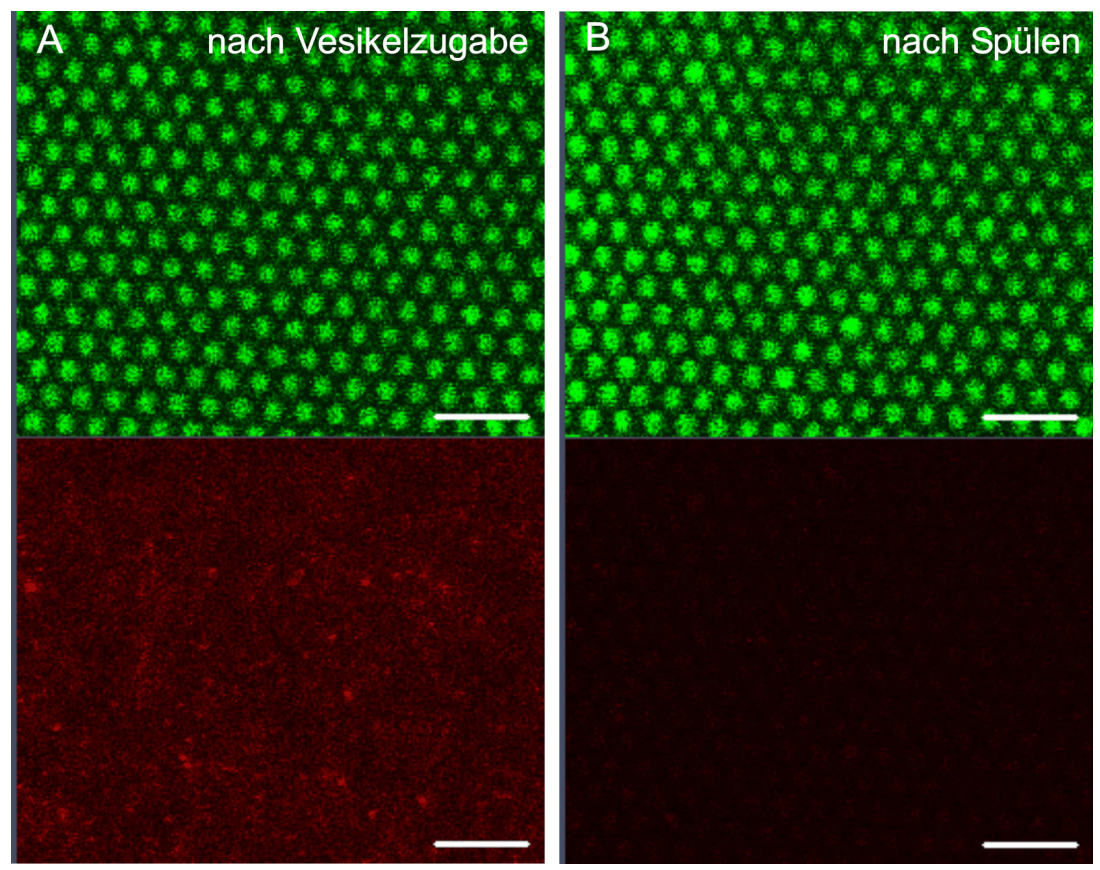

Abb. 4.43 Fluoreszenzmikroskopische Aufnahmen von porenüberspannenden Membranen (DOPC/Oregon Green 98:2, VAMP PNA1 im Verhältnis Lipid/Peptid 500 : 1, Funktionalisierung des Substrats: CPEO3) in KCl-haltigem Puffer (100 mM KCl, $10 \mathrm{mM} \mathrm{HEPES,} \mathrm{pH} \mathrm{=} \mathrm{7.4).} \mathrm{A} \mathrm{Nach} \mathrm{der} \mathrm{Zugabe} \mathrm{von} \mathrm{LUVs}$ (POPC/POPS/Texas Red 78:20:2) sind diese deutlich im roten Kanal im Bereich der porenüberspannenden Membranen zu erkennen. B Werden die Vesikel durch Spülen entfernt, so wird sichtbar, dass im roten Kanal kein Signal der Texas Red-Fluoreszenz mehr zu detektieren ist. Daraus kann geschlussfolgert werden, dass keine Texas Red-Moleküle durch Fusion der Vesikel in die porenüberspannenden Membranen eingebaut wurden und dementsprechenden keine Fusion stattgefunden hat. Der Maßstabsbalken entspricht $5 \mu \mathrm{m}$.

In einem weiteren Schritt wurde geprüft inwieweit sich die Fusion, mediiert durch die molekulare Erkennung komplementärer PNA-Sequenzen, durch die Veränderung der Membranstruktur inhibieren lässt. Die in Kapitel 1.1 beschriebene Stalk-Hypothese beschreibt die Fusionintermediate und zeigt Zwischenstufen, die sich besonders durch eine extreme Membrankrümmung auszeichnen. Dementsprechend kann durch Einbau von Molekülen, die diese Krümmung entweder unterstützen oder stören, der Fusionsprozess moduliert werden. Das Phospholipid Lysophosphatidylcholin (LPC) ist zum Beispiel bekannt dafür, dass es die Fusion inhibiert, wenn es in die gegenüberstehenden Lipidmonoschichten der $\mathrm{zu}$ fusionierenden Membranen eingebaut wird. 8, 9, 11, 100, 101 Der Grund dafür liegt in der Geometrie des Moleküls, das von der 
Kopfgruppe bis zum hydrophoben Ende einen inversen Kegel bildet. Deshalb wird von LPC-haltigen Membranen eine positive Krümmung, also eine Krümmung in Richtung der apolaren Kohlenstoffketten bevorzugt. Der erste Schritt des Fusionsprozesses führt jedoch über die Hemifusion, einer Zwischenstufe, in der die Membran in Richtung der Kopfgruppen gekrümmt ist. Diese Membrangeometrie, die von vornherein von einer Lipiddoppelschicht nicht favorisiert wird, kann nur schwer erreicht werden, wenn LPC in der Membran vorhanden ist. Aus diesem Grund wird der gesamte Fusionsprozess durch den Einbau von LPC in die Membran gehemmt. In den durchgeführten Versuchen wurde LPC gelöst in KCl-haltigem Puffer (100 mM KCl, $10 \mathrm{mM} \mathrm{HEPES,} \mathrm{pH} \mathrm{7.4)} \mathrm{zu} \mathrm{einer}$ Lösung Syx PNA3-haltiger Vesikel gegeben, so dass eine Konzentration von 5 mol\% LPC bezogen auf die Gesamtlipidmenge in der Vesikellösung erreicht wurde. Nach zweitstündiger Inkubation wurde die Vesikellösung zu VAMP PNA1-haltigen porenüberspannenden Membranen gegeben. Der Einbau von LPC führte zu einer vollständigen Inhibition der Fusion dieser Vesikel mit porenüberspannenden Membranen. Dies lässt sich aus den in Abb. 4.44 gezeigten Fluoreszenzaufnahmen schließen. In Abb. 4.44 A ist zunächst die Aufnahme einer Zeitserie gezeigt, in der deutlich die Texas Reddotierten Vesikel im roten Kanal in der fokalen Ebene der porenüberspannenden Membran zu sehen sind. Diese Vesikel haben auf Grund ihrer räumlichen Nähe zu der planaren Membran also die Möglichkeit mit dieser zu fusionieren. Werden die Vesikel aber durch Spülen mit Puffer entfernt (B), so wird deutlich, dass kein Einbau des roten Farbstoffs in die porenüberspannende Membran und somit keine Fusion stattgefunden hat, da im roten Kanal keine Fluoreszenz der porenüberspannenden Membran detektiert wird. 

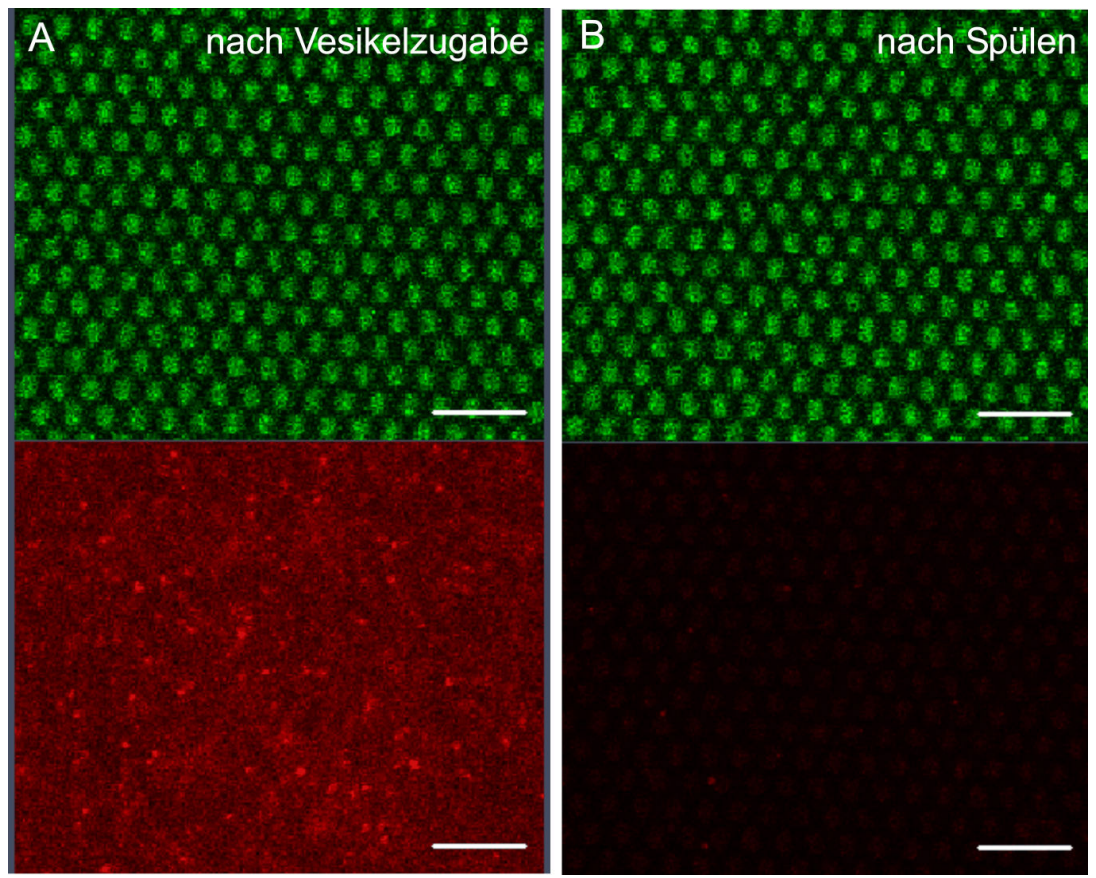

\begin{abstract}
Abb. 4.44 Fluoreszenzmikroskopische Aufnahmen von porenüberspannenden Membranen (DOPC/Oregon Green 98:2, VAMP PNA 1 im Verhältnis Lipid/Peptid $500: 1$, Funktionalisierung des Substrats: CPEO3) in KCl-haltigem Puffer $(100 \mathrm{mM} \mathrm{KCl}, 10 \mathrm{mM}$ HEPES, $\mathrm{pH}=7.4)$ zur Untersuchung des Einflusses von LPC (5 mol\% bezogen auf die Gesamtmenge Lipid in den Vesikeln) auf das Fusionsverhalten. A Nach der Zugabe von LUVs (POPC/POPS/Texas Red 78:20:2, Syx PNA 3 im Verhältnis Lipid/Peptid $500: 1$ ) sind diese deutlich im roten Kanal im Bereich der porenüberspannenden Membranen zu erkennen. B Werden die Vesikel durch Spülen entfernt, so wird sichtbar, dass im roten Kanal kein Signal der Texas RedFluoreszenz mehr zu detektieren ist. Daraus kann geschlussfolgert werden, dass keine Texas Red-Moleküle durch Fusion der Vesikel in die porenüberspannenden Membranen eingebaut wurden und dementsprechenden keine Fusion stattgefunden hat. Der Maßstabsbalken entspricht $5 \mu \mathrm{m}$.
\end{abstract}




\section{Diskussion}

\subsection{Untersuchung der Lipidvermischung während der Fusion von LUVs mit micro-BLMs}

Seit mehreren Jahren finden porenüberspannende Membranen Anwendung in verschiedenen biophysikalischen Studien und bieten vielversprechende Möglichkeiten zum Einsatz in Hochdurchsatzanalysen in der pharmazeutischen Forschung. ${ }^{59,61,102,103}$ In der vorliegenden Arbeit wurde dieses artifizielle Membransystem zum ersten Mal eingesetzt, um Einzelfusionsereignisse zu analysieren. Diese neue Art der Untersuchung des Fusionsmechanismus soll neue Erkenntnisse beispielsweise für die SNARE- und Viruspeptid-vermittelte Fusion bringen, in dem der entwickelte Aufbau wie in Kapitel 1.3 beschrieben, Nachteile bestehender in vitro-Assays überwindet.

Im Rahmen der Etablierung dieses neuartigen Assays konnte erfolgreich die Lipidvermischung, die im Folgenden gleichbedeutend mit dem Begriff Fusion verwendet wird, zwischen einem Vesikel und porenüberspannenden Membranen fluoreszenzmikroskopisch bewiesen werden. Zur Visualisierung der Lipidvermischung wurde die Dotierung der unterschiedlichen Lipiddoppelschichten mit einem FRETzeigenden Farbstoffpaar gewählt. Oregon Green DHPE wurde in die porenüberspannenden Membranen eingebaut, während mit Texas Red DHPE die Lipiddoppelschicht des Vesikels dotiert wurde. Die Kombination von Oregon Green DHPE als FRET-Donor und Texas Red DHPE als FRET-Akzeptor wurde bereits erfolgreich von Zwilling et al. und Cypionka et al. zur Untersuchung SNAREvermittelter Vesikel-Vesikel-Fusion eingesetzt. ${ }^{33,104}$ In anderen Studien wird in der Regel das FRET-Paar NBD-PE/Rhodamin-PE eingesetzt, um die Lipidvermischung während der Fusion nachzuweisen. ${ }^{24,}$ 29, 38, 98, 105, 106 Chan et al. berichteten jedoch im Rahmen eines Vesikelfusionsassays, dass die Farbstoffe NBD-PE und Rhodamin-PE zu unspezifischen Fusionsereignissen führten, die bei dem Einsatz von Oregon Green DHPE und Texas Red DHPE ausblieben. ${ }^{97}$

In den fluoreszenzmikroskopischen Aufnahmen (Abb. 4.3) sind die verwendeten microblack lipid membranes (micro-BLMs) sichtbar, die auf einem porösen Substrat mit 
einem Porendurchmesser von $1.2 \mu \mathrm{m}$ präpariert wurden. Über die Homogenität der Membranfluoreszenz konnte die Qualität der Membran kontrolliert werden. Das Fluoreszenzbild der micro-BLMs zeigt, dass Porenstege und membranüberspannte Poren deutlich voneinander unterschieden werden können. Durch die Löschung der Membranfluoreszenz auf den Porenstegen erscheinen diese schwarz, während im Bereich der Poren die grüne Fluoreszenz der Membran sichtbar ist. Dadurch erleichtert die Fluoreszenzmarkierung der Lipiddoppelschicht zusätzlich die Unterscheidung zwischen Fusionsereignissen mit festkörperunterstützten und freitragenden Bereichen der Membran. Die großen unilamellaren Vesikel (large unilamellar vesicles, LUVs) werden im roten Kanal detektiert. Die Verwendung von LUVs mit einem Durchmesser von im Mittel $600 \mathrm{~nm}$ ermöglichte die Beobachtung einzelner Vesikel und ihrer Interaktion mit den micro-BLMs. Die stattfindende Lipidvermischung wurde in den Fluoreszenzaufnahmen durch die radiale Verteilung des Texas Red-Farbstoffs in den porenüberspannenden Membranen und die gleichzeitig auftretende Löschung der Oregon Green-Fluoreszenz durch FRET indiziert. Die Verwendung von zwei lipidgekoppelten Farbstoffen war notwendig, da auf diese Weise während der Messung jeweils direkt der Beweis erbracht werden konnte, dass die beobachteten Vesikel mit intakten porenüberspannenden Membranen fusionieren. Auch in anderen Assays, die auf der Fusion von Vesikeln mit planaren Membranen basieren, stellt die Überprüfung der Membran eine wichtige Kontrolle dar. Zum Beispiel berichteten Liu et al., dass Vesikel auch an die Oberfläche eines Glassubstrats, wie es $\mathrm{zu}$ Herstellung von festkörperunterstützten Membranen verwendet wird, anbinden können und somit zu verfälschten Ergebnissen in der Quantifizierung der gedockten Vesikel führen. ${ }^{107} \mathrm{Im}$ Gegensatz zu der hier vorgestellten Methode wird in anderen Assays mit planaren Membranen lediglich vor der jeweiligen Messung die Fluoreszenz der planaren Membran kontrolliert. In den Fusionsexperimenten direkt wird in der Regel lediglich die Veränderung der Vesikelfluoreszenz detektiert. ${ }^{38,39,107}$ In dieser Arbeit wurde erstmals die Verwendung eines FRET-Paares in einem Assay zur Fusion von Vesikeln mit planaren Membran realisiert. Dabei bietet die Verwendung eines FRET-Paares in den zwei zu fusionierenden Membranen den Vorteil, dass die Vermischung der Lipide im Verlauf der Fusion durch die Löschung der Donorfluoreszenz indiziert wird. Dementsprechend wird in den vorgestellten Experimenten sowohl die radiale Verteilung der Texas Red DHPE-Moleküle in der planaren Membran als auch die der durch Texas 
Red gelöschten Oregon Green-Moleküle simultan beobachtet. In anderen Studien wurde die radiale Ausbreitung Vesikelfluoreszenz in der planaren Membran wie auch in dieser Arbeit der Lipidvermischung während der Fusion zugeordnet. ${ }^{39,}$ 48, 107 Das Integral der Fluoreszenzintensität, der um den Fusionsursprung liegenden Fläche, zeigte jeweils einen exponentiellen Abfall, der auf die radiale Verteilung der Farbstoffmoleküle in der planaren Membran zurückgeführt werden kann. In den Arbeiten von Domanksa et al. sowie von Liu et al. wurde die Diffusion der Lipide, die in die planare Membran übergehen, genutzt, um Hemifusions- und Fusionsereignisse zu quantifizieren. ${ }^{39,} 92$ Dieser Ansatz wurde in dieser Arbeit ebenfalls verwendet, um aus der beobachteten Texas RedVerteilung in den porenüberspannenden Membranen einen Diffusionskoeffizienten für die Ausbreitung der Lipide nach der Fusion zu extrahieren. Auf diese Weise wurde aus allen beobachteten Fusionsereignissen ein Wert von $D=(9 \pm 5) \mu \mathrm{m}^{2} / \mathrm{s}$ für die Texas Red DHPE-Verteilung in micro-BLMs ermittelt. Dieser stimmt gut mit dem Diffusionskoeffizienten überein, der in fluorescence recovery after photobleaching (FRAP)-Messungen für ein ähnliches System gefunden wurde. ${ }^{93}$ In der entsprechenden Arbeit analysierte Weiskopf die Diffusion von DPhPC in micro-BLMs basierend auf porösen Siliziumnitrid-Substraten mit einem Porendurchmesser von $2.0 \mu \mathrm{m}$. Die Übereinstimmung der ermittelten Diffusionskonstanten mit der FRAP-Analyse wurde als wichtiges Kriterium dafür erachtet, dass eine Vermischung der Lipide stattfand und die Texas Red DHPE-Moleküle tatsächlich in die micro-BLMs eingebaut wurden. Deshalb kann neben dem Auftreten eines FRETs die Diffusion der Texas Red DHPE-Moleküle in der planaren Membran als Indiz für eine stattgefundene Lipidvermischung gesehen werden. Als mögliche Ursache für die Verteilung der Texas Red-Fluoreszenz in den micro-BLMs ist neben der Fusion der Membranen auch das Platzen des Vesikels auf der Oberfläche der porenüberspannenden Membran denkbar. In den Arbeiten von Wong et al. und Chung et al. wird jedoch gezeigt, dass das Reißen von Vesikeln nicht zu einer Verteilung der Vesikellipide über die planare Membran führt. ${ }^{108,}{ }^{109}$ In beiden Studien wurden Riesenvesikel (giant unilamellar vesicles, GUVs) durch molekulare Erkennung an festkörperunterstützte Membranen gebunden. Nach dem spontanen Reißen der GUVs wurde keine Diffusion des Lipid-gekoppelten Farbstoffs, der zur Dotierung der GUVs verwendet wurde, detektiert. Somit spricht die Texas Red DHPE-Diffusion eindeutig für ein Verschmelzen von Vesikel- und porenüberspannender Membran und gegen ein Reißen oder Platzen des Vesikels an der Oberfläche. 
In den von Domanska et al. durchgeführten Experimenten zur Fusion synaptischer Vesikel mit festkörperunterstützten Membranen wurde nicht nur die Lipiddiffusion im Rahmen der Lipidvermischung bestimmt. Zusätzlich wurden aus den Intensitätsprofilen auch die Andock-Zeiten ermittelt. ${ }^{39}$ So wird die Zeit bezeichnet, die nach dem Andocken des Vesikels an die planare Membran vergeht, bevor eine Lipidvermischung im Zuge der Fusion stattfindet. Domanska et al. setzten dementsprechend den sprunghaften Anstieg der Fluoreszenzintensität als Startpunkt des Andockens und der beginnnende exponentielle Abfall des Signals wurde als Startpunkt der Fusion festgelegt. Aus der Differenz der beiden Zeitpunkte konnte dann die Verzögerung zwischen dem Andocken und der Fusion bestimmt werden. Diese Verweilzeit vor der Fusion ist ein interessanter Parameter in der Untersuchung von Fusionsprozessen, da dieses Zeitintervall beschreibt, wieviel Zeit eine Membranstruktur und die im Fusionsprozess involvierten Peptide oder Proteine für ihre Reorganisation benötigen. In den Studien von Domanska et al. wurden für die SNARE-vermittelte Fusion synaptischer Vesikel mit einer planaren Membran Verweilzeiten zwischen 10 und $250 \mathrm{~ms}$ mit einem Maximum bei $18 \mathrm{~ms}$ gefunden. In den Experimenten von Wang et al. binden in einem analogen System die Vesikel vor der Fusion für 5 - $50 \mathrm{~ms}$ an die planare Membran. ${ }^{43}$ Die in dieser Arbeit durchgeführten Experimente zur $\mathrm{Ca}^{2+}$-vermittelten Fusion von LUVs mit micro-BLMs wurden mit einer Zeitauflösung von mindestens 115 ms aufgenommen. Das Andocken der Vesikel konnte dabei in der Regel nicht beobachtet werden. Bei einem typischen Fusionsereignis war in einer Aufnahme das Auftreffen des Vesikels auf die planare Membran zu erkennen und im nächsten Bild wurde bereits die Verteilung Vesikellipide in den micro-BLMs sichtbar. Somit kann für die $\mathrm{Ca}^{2+}$-vermittelte Fusion von LUVs mit micro-BLMs eine Verweilzeit von $t<115 \mathrm{~ms}$ zwischen Andocken des Vesikels und anschließender Fusion festgelegt werden. Eine höhere Zeitauflösung wie in den TIRF (total internal reflection fluorescence)-Mikroskopie-Analysen von Domanska et al. oder Wang et al. konnte in den durchgeführten konfokalmikroskopischen Messungen nicht erreicht werden. ${ }^{39,43}$ Der Grund dafür liegt in den unterschiedlichen Messtechniken. Die zeitliche Auflösung in der Konfokalmikroskopie ist dadurch begrenzt, dass ein Bildausschnitt Punkt für Punkt abgerastert werden muss und dadurch die Aufnahme der Probe mit einer bestimmten Pixelzahl einen gewissen zeitlichen Aufwand erfordert. In der TIRF-Mikroskopie hingegen wird von der evaneszenten Welle immer ein kompletter Ausschnitt der Probe beleuchtet und die resultierende Fluoreszenz detektiert. Dadurch ist der Abstand 
zwischen zwei Aufnahmen lediglich durch die Zeitauflösung der Kamera, die im Millisekundenbereich liegen sollte, bestimmt. ${ }^{110}$ Eine Analyse des durchgeführten Assays mittels TIRF-Mikroskopie ist nicht möglich, da es sich bei den verwendeten Porensubstraten um nicht-transparente Proben handelt, die dementsprechend mit einem aufrechten Mikroskop untersucht werden müssen. Die TIRF-Mikroskopie erfordert hingegen eine inverse Beleuchtung der Probe.

Es wird erwartet, dass die Reorganisation der Lipide im untersuchten System sehr schnell stattfindet. Dabei kann besonders ein Einfluss des durch die Präparationsmethode eingetragenen Lösungsmittels auf eine kurze Verweilzeit des Vesikels vor der Fusion nicht ausgeschlossen werden. Perin und MacDonald zeigten in fluoreszenzmikroskopischen Aufnahmen die $\mathrm{Ca}^{2+}$-abhängige Anbindung von synaptischen Vesikeln an eine freitragende Membran. ${ }^{111}$ In diesem Zusammenhang wurde von Lösungsmittellinsen berichtet, die sich während der Anbindung der synaptischen Vesikel an Dekan-haltige Membranen bildeten. Diese Linsenbildung wird nicht beobachtet, wenn Squalen zur Präparation der freistehenden Membranen benutzt wurde. Squalen ist dafür bekannt sich schlechter in Membranen einzulagern und somit fast lösungsmittelfreie BLMs zu liefern. ${ }^{112}$ Das Phänomen der Linsenbildung bei Dekanhaltigen Membranen wird von Perin und MacDonald darauf zurückgeführt, dass sich das Lösungsmittel sammelt, um eine Vesikelanbindung zu erleichtern. ${ }^{111}$

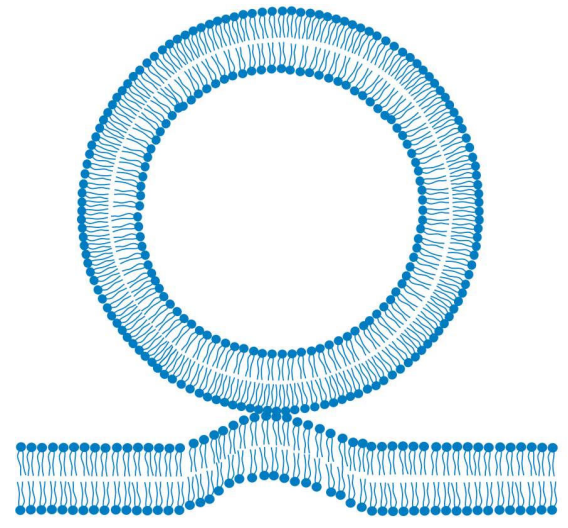

ohne Lösungsmittel

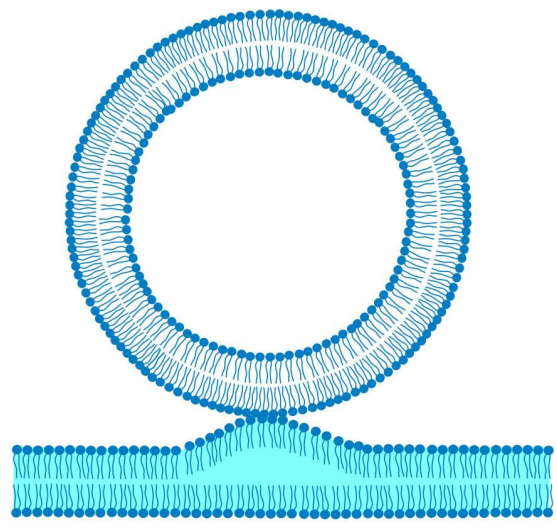

mit Lösungsmittel

Abb. 5.1 Schemtische Darstellung der Membranverzerrung nach Vesikelanbindung im Fall von lösungsmittelfreien und -haltigen Membranen 
Es wird argumentiert, dass die Anbindung eines Vesikels an die planare Membran eine gewisse Verzerrung erfordert (Abb. 5.1). Durch die Einlagerung des Lösungsmittels zwischen die beiden Lipidmonoschichten könnte eine zusätzliche Verkrümmung der zweiten Lipidmonolage vermieden werden, da strukturelle Veränderungen durch das Dekan kompensiert werden. Ein entsprechendes Szenario wäre auch für die Dekanhaltigen micro-BLMs denkbar. Diese erleichterte Umstrukturierung der Lipide in den micro-BLMs während der Fusion könnte so diesen Prozess beschleunigen und damit die Verweilzeit eines an die planare Membran gedockten Vesikels verkürzen.

Neben der Zeit zwischen Andocken und Fusion spielt die Wahrscheinlichkeit mit der ein Vesikel nach dem Auftreffen auf eine andere Membran fusioniert eine wichtige Rolle zur Bestimmung der Effizienz eines Fusionssystems. In den durchgeführten Experimenten zur $\mathrm{Ca}^{2+}$-vermittelten Fusion von LUVs mit porenüberspannenden Membranen beträgt die Fusionswahrscheinlichkeit ungefähr $100 \%$, da alle Vesikel, die die Oberfläche erreichen auch fusionieren bis ab einem gewissen Punkt die Probe gesättigt zu sein scheint. Domanska et al. berichten hingegen in ihren Untersuchungen zur SNAREvermittelten Fusion von Vesikeln mit festkörperunterstützten Membranen von einer Fusionsrate von $43 \%$, das heißt, dass nur $43 \%$ aller angedockten Vesikel fusionierten. ${ }^{39}$ Noch geringer ist die Fusionsrate in den Experimenten von Niles und Cohen, die in Abhängigkeit des osmotischen Gradienten Fusionsraten von 12 - $37 \%$ für die $\mathrm{Ca}^{2+}$ vermittelte Fusion von großen unilamellaren Vesikeln mit einer freitragenden Membran hergestellt nach der Montal-Müller-Methode beobachteten. ${ }^{113}$ Ähnliche Wahrscheinlichkeiten fanden auch Perin und MacDonald, die die Fusion von synaptischen Vesikeln mit potentiell lösungsmittelhaltigen Müller-Rudin-BLMs untersuchten. ${ }^{111}$ Die im Vergleich zu anderen Studien hohe Fusionswahrscheinlichkeit zwischen Vesikel und micro-BLMs kann in gewisser Hinsicht auch auf das zurückbleibende Lösungsmittel in den porenüberspannenden Membranen zurückgeführt werden. Anzai et al. konnten in einem Vergleich zeigen, dass das Lösungsmittel in einer freitragenden Membran einen direkten Einfluss auf die Anzahl an Fusionsereignissen hat. ${ }^{114}$ In dieser Studie wurde die Veränderung des elektrischen Stroms über eine BLM nach der Zugabe von Nystatin-haltigen $400 \mathrm{~nm}$ großen Vesikeln genutzt, um Fusionsereignisse zu quantifizieren. Dabei zeigte sich, dass die Anzahl an Fusionsereignissen bei gleichen Versuchsbedingungen für Membranen, die nach der 
Montal-Müller-Technik hergestellt wurden und dementsprechend quasi-lösungsmittelfrei sein sollten, bis zu dreimal geringer ist als für Müller-Rudin-Membranen, in denen ein Teil des organischen Lösungsmittels verbleibt. Somit sollte das Lösungsmittel nicht nur einen Einfluss auf die Schnelligkeit des Fusionprozess haben, sondern auch auf die Fusionswahrscheinlichkeit. Diese Vermutung wird zusätzlich durch erhaltene Ergebnisse an lösungsmittelfreien porenüberspannenden Membranen, die durch das Spreiten von GUVs erhalten wurden, gestützt. Die Fusion von LUVs mit diesen lösungsmittelfreien porenüberspannenden Lipiddoppelschichten wurde nicht beobachtet. Dies legt den Schluß nahe, dass in dem vorgestellten System der Verbleib des Lösungsmittels einen Einfluss auf die Fusionsrate haben muss.

Zusätzlich zu der Wirkung des Lösungsmittels kann die Membranspannung die Fusionseffizienz beeinflussen. In Simulationsstudien konnten sowohl Chanturiya et al. als auch Shillcock und Lipowsky zeigen, dass die Erhöhung der Membranspannung die Fusion von zwei Lipiddoppelschichten fördert. ${ }^{28,} 115$ In Indentationsexperimenten an porenüberspannenden Membranen zeigten Mey et al., dass diese Art der Lipiddoppelschichten eine hohe laterale Spannung aufweisen, die in diesem Zusammenhang auch als Vorspannung bezeichnet wird. ${ }^{95}$ In der genannten Studie wurde ein Wert von $\sigma=(18 \pm 3) \mathrm{mN} / \mathrm{m}$ für DPhPC-Membranen basierend auf Oktanthiolfunktionalisierten porösen Siliziumnitrid-Substraten mit einem Porendurchmesser von $1.2 \mu \mathrm{m}$ ermittelt. Diese Vorspannung könnte ausschlaggebend dafür sein, dass Vesikel mit einer relativ hohen Wahrscheinlichkeit nach dem Auftreffen mit den porenüberspannenden Membranen fusionieren. Auf den Einfluss der Membranspannung auf die Fusionsereignisse wird in Kapitel 5.5 noch einmal näher eingegangen. An dieser kann so postuliert werden, dass wahrscheinlich sowohl das verbleibende Lösungsmittel in den porenüberspannenden Membranen als auch die Membranspannung einen Einfluss auf die hohe Fusionswahrscheinlichkeit haben können und möglicherweise diese beiden Effekte synergetisch die Erhöhung der Fusionsrate hervorrufen.

Wie bereits erwähnt kann in den Fluoreszenzaufnahmen der micro-BLMs eindeutig zwischen den festkörperunterstützten Membranen auf den Porenstegen des Substrats und den freitragenden Lipiddoppelschichten unterschieden werden. In den Experimenten zur $\mathrm{Ca}^{2+}$-vermittelten Fusion von Vesikeln mit micro-BLMs wurde beobachtet, dass die Vesikel mit ähnlicher Wahrscheinlichkeit mit den Membranen auf den Stegen und den 
Membranen, die eine Pore überspannen, fusionieren. Deshalb soll an dieser Stelle noch einmal auf den Aufbau der micro-BLMs eingegangen werden. Wie in Abb. 5.2 gezeigt, wird auf den Porenstegen eine Hybridmembran zum einen aus der oberen 1,2Diphytanoyl-sn-glycero-3-phosphatidylcholin (DPhPC) / 1-Palmitoyl-2-Oleoyl-snglycero-3-phosphoethanolamin (POPE)-Lipidmonoschicht und zum anderen aus dem zur Funktionalisierung verwendeten Thiolipid 1,2-Dipalmityl-sn-glycero-3phospothioethanol (DPPTE) ausgebildet.

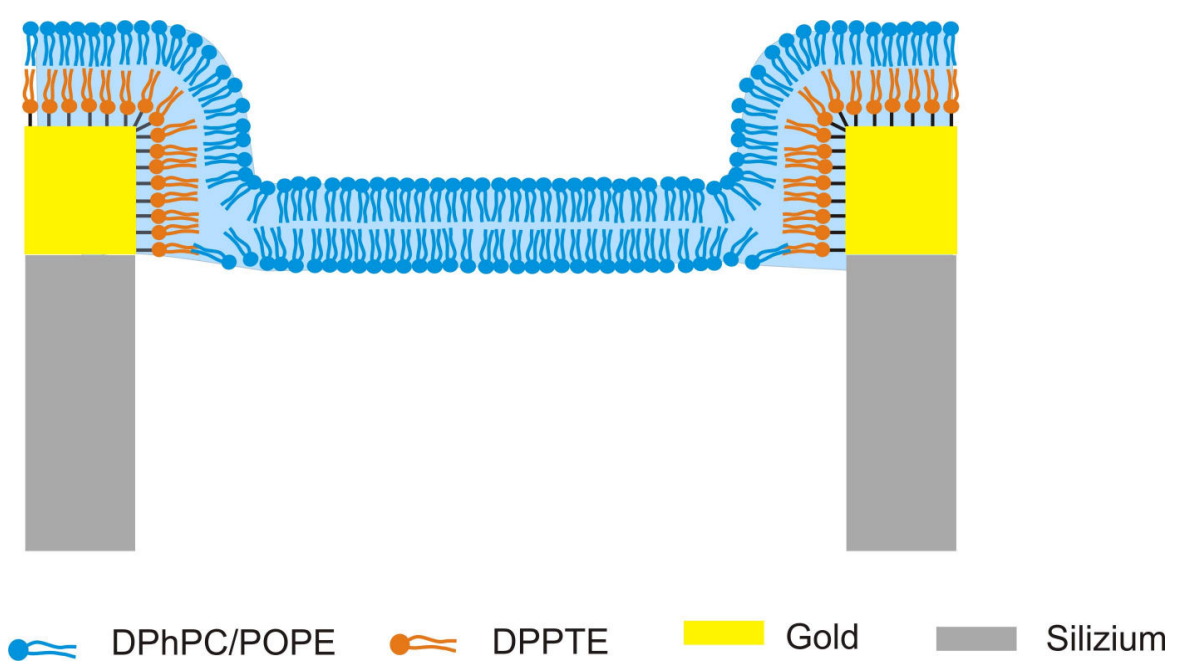

Abb. 5.2 Schematische Darstellung von micro-BLMs, die auf einem DPPTE-funktionalisierten Substrat präpariert wurden.

Die Pore hingegen wird von einer reinen DPHPC/POPE-Lipiddoppelschicht überspannt. Entsprechend dieser Anordnung müssen für die verschieden lokalisierten Fusionsereignisse mit der Membran auf dem Porensteg und dem porenüberspannten Bereich zwei unterschiedliche Szenarien in Betracht gezogen werden. Den einfachsten Fall stellt die Fusion des Vesikels mit der porenüberspannenden Membran dar. So ist wahrscheinlich, dass die Fusion nach dem in Kapitel 1.1 beschriebenen Mechanismus stattfindet und die Vesikellipide auf diese Weise in die freitragende Membran eingebaut werden - auf die daraus resultierende Strukturänderung wird in Kapitel 5.3 näher eingegangen. Im Bereich der Porenstege wird eine Lipidreorganisation, wie zum Beispiel für die Bildung der Fusionspore erforderlich, durch die Verankerung der unteren Monolage mit der Goldoberfläche unmöglich gemacht. Für diesen Fall kann also nicht der in Kapitel 1.1 beschriebene Fusionsmechanimus angenommen werden. Dementsprechend muss eine andere Beschreibung gefunden werden, wie die 
Vesikellipide während der Lipidvermischung in die verankerten Membranen auf den Porenstegen eingebaut werden. Dazu wurde die Wechselwirkung von Vesikeln mit selbstorganisierten Alkanthiol- bzw. Thiolipidmonoschichten, die während der Präparation von festkörperunterstützten Membranen genutzt wird, ${ }^{116}$ in Betracht gezogen. So formulierten Plant und Kalb et al. einen möglichen Mechanismus, nach dem Vesikel auf funktionalisierten Oberflächen spreiten. ${ }^{117,118}$

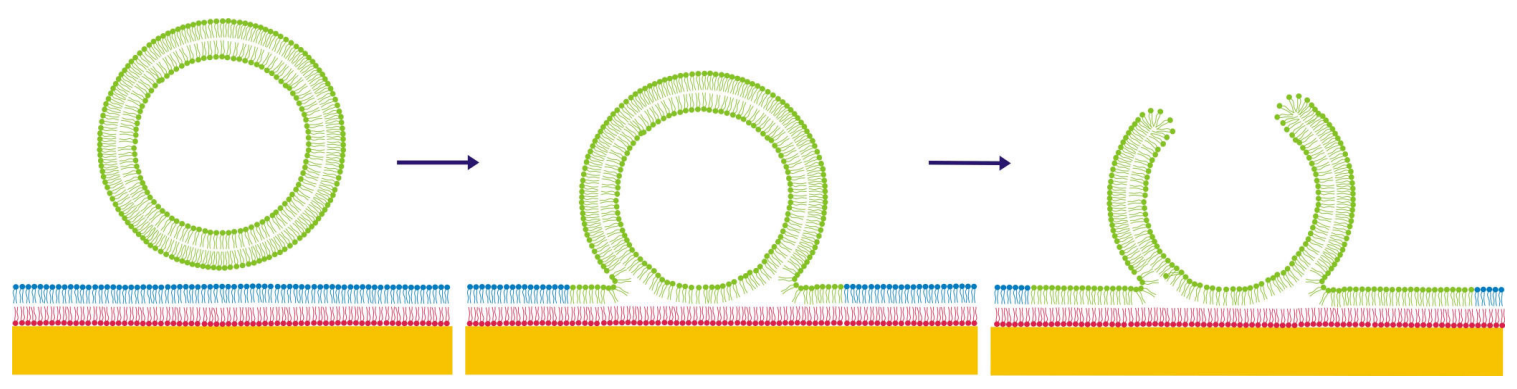

Abb. 5.3 Möglicher Ablauf der Fusion eines Vesikels mit den festkörperunterstützten DPPTEfunktionalisierten Stegbereichen des porösen Substrats in Anlehnung an den von Plant formulierten Mechanismus des Vesikelspreitens auf festkörperunterstützten Monolagen. ${ }^{17}$

In Anlehnung an diesen Mechanismus ist es vorstellbar, dass beim Auftreffen eines Vesikels auf den Porensteg zunächst die beiden benachbarten Lipidmonoschichten miteinander fusionieren, gefolgt von der Entstehung von Defektstellen, die zu einem Reißen des Vesikels und zum Einbau der restlichen Lipide führen.

Im Rahmen der Etablierung des hier beschriebenen Assays wurde gezeigt, dass die Fusion von POPC/POPS-haltigen LUVs mit DPhPC/POPE-haltigen micro-BLMs durch $\mathrm{Ca}^{2+}$-Ionen vermittelt wird. Auf diese Abhängigkeit soll im Folgenden eingegangen werden. Die $\mathrm{Ca}^{2+}$-vermittelte Fusion wurde seit den achtziger Jahren des vergangenen Jahrhunderts intensiv erforscht. ${ }^{48,}$ 105, 119-121 Die Tatsache, dass Membranen unter bestimmten Bedingungen auch in Abwesenheit von fusogenen Proteinen miteinander verschmelzen, regte das Interesse daran, den fundamentalen Mechanismus dieser rein lipidischen Fusion aufzuklären. Dabei wurden im Wesentlichen drei verschiedene Hypothesen aufgestellt, welche die Interaktion der $\mathrm{Ca}^{2+}$-Ionen mit negativ geladenen Lipiden, die zur Vermischung zweier Lipiddoppelschichten führt, erklären. Aus frühen Analysen wurde geschlossen, dass die $\mathrm{Ca}^{2+}$-Ionen Phasenübergänge induzieren, die schließlich zur Fusion führen. ${ }^{122}$ Des Weiteren wäre eine Verbrückung zweier Membranen durch die $\mathrm{Ca}^{2+}$-Ionen und damit die Überwindung der Hydratationsbarriere 
denkbar, die im weiteren Verlauf zur Vermischung der Lipiddoppelschichten führt. ${ }^{123}$ In anderen Veröffentlichungen wurde postuliert, dass die asymmetrische Bindung von $\mathrm{Ca}^{2+}$ Ionen an negativ geladene Lipide, die bei Zugabe von $\mathrm{Ca}^{2+}$-Ionen von außen nur in der äußeren Monoschicht des Vesikels stattfindet, eine laterale Spannung der Membran hervorruft, welche die Fusogenität des Vesikel erhöht. ${ }^{89,124,}{ }^{125}$ Der Grund für die Ausbildung einer erhöhten Membranspannung liegt demnach darin, dass durch die $\mathrm{Ca}^{2+}-$ Komplexierung die Kopfgruppen in der äußeren Monolage dehydratisiert vorliegen und somit näher zusammenrücken als in der inneren Monoschicht des Vesikels. Die letzte Hypothese wurde 2000 von Chanturiya et al. aufgegriffen und durch diverse Experimente verifiziert. ${ }^{89}$ In den Untersuchungen wurde sowohl die Fusion von Vesikeln miteinander als auch die Fusion von Vesikeln mit BLMs analysiert. Chanturiya et al. zeigten zunächst, dass Vesikel miteinander fusionieren, wenn $\mathrm{Ca}^{2+}$-Ionen nur im Medium außerhalb der Vesikel gelöst ist. Durch die Zugabe eines $\mathrm{Ca}^{2+}$-Ionophors wurde der Eintritt der $\mathrm{Ca}^{2+}$-Ionen in das Innere der Vesikel ermöglicht und führte direkt zu einem Stillstand der Fusion. Dadurch wird die dritte Hypothese, dass eine Fusion durch die asymmetrische Komplexierung von $\mathrm{Ca}^{2+}$-Ionen in der Membran und der dadurch hervorgerufenen Spannung, gestützt. Des Weiteren ergab die Analyse der $\mathrm{Ca}^{2+}$ vermittelten Fusion von Vesikeln mit BLMs, dass die Fusionsrate ausschließlich von der Ladung der Vesikelmembran, nicht aber von der Lipidzusammensetzung der BLM abhängt. Diese Beobachtungen gleichen den Befunden in den Experimenten zur Fusion von LUVs mit micro-BLMs gefunden, in denen ebenfalls Fusion stattfindet, obwohl nur in die Vesikel negativ geladene Lipide eingebaut wurden und nicht in die porenüberspannenden Membranen. Würde die Fusion nämlich wie häufig angenommen über die Verbrückung der Lipiddoppelschichten durch $\mathrm{Ca}^{2+}$-Komplexierung ablaufen, müssten in beiden Membranen negativ geladene Lipide vorhanden sein. So ist als mögliche Ursache der Fusion eher eine asymmetrische $\mathrm{Ca}^{2+}$-Komplexierung auf den beiden Membranseiten des LUVs und der damit hervorgerufenen Spannungserhöhung im Vesikel als Ursache der Fusion denkbar. Dabei stellt sich die Frage, warum keine zusätzliche Erhöhung der Spannung durch asymmetrische $\mathrm{Ca}^{2+}$-Komplexierung in den porenüberspannenden Membranen nötig ist, um die Fusion mit einem Vesikel zu initieren. Eine mögliche Erklärung, kann wiederum in der Vorspannung der micro-BLMs gefunden werden. So scheint diese Vorspannung, die im System bereits vorhanden ist, ausreichend zu sein, damit Fusionsereignisse eingeleitet werden. Ähnliches würde für die 
in der von Chatuyira et al. publizierten Studie verwendeten BLMs gelten, die ebenfalls eine gewisse Spannung aufweisen. ${ }^{126}$

Zusammenfassend zeigt sich, dass die gewählten Parameter des neuartigen Fusionsassays, wie Vesikelgröße, Porengröße des porösen Substrats und die gewählten Fluoreszenzfarbstoffe, gut geeignet sind, um Fusionsprozesse fluoreszenzmikroskopisch zu analysieren. Das Auftreten des FRET-Effekts und die Übereinstimmung des Texas Red DHPE-Diffunsionskoeffizienten mit FRAP-Daten belegen die Lipidvermischung zwischen Vesikeln und porenüberspannenden Membranen. Die Fusion wird unter den gewählten Bedingungen durch $\mathrm{Ca}^{2+}$-Ionen initiiert und zusätzlich durch vorhandenes Restlösungsmittel begünstigt. Weitere Beobachtungen führen zu der Annahme, dass die Membranspannung in den micro-BLMs einen erheblichen Einfluss auf die fusogenen Eigenschaften der porenüberspannenden Membranen hat.

\subsection{Untersuchung der Vesikelausschüttung während der Fusion von LUVs mit micro-BLMs}

Ein besonderer Vorteil eines Fusionsassays basierend auf porenüberspannenden Membranen besteht in der Möglichkeit, mit geschlossenen Poren zu arbeiten und den Vesikelinhalt nach der Fusion in diesen Kompartimenten aufzufangen, um damit die Ausschüttung des Vesikelinhalts nachzuweisen. Zunächst wurden poröse Substrate mit geöffneten Poren verwendet. Die Experimente wurden analog zu den in Kapitel 4.1 beschriebenen Lipidvermischungsexperimenten durchgeführt, mit dem einzigen Unterschied, dass der wasserlösliche Farbstoff Pyranin in die Vesikel eingeschlossen wurde. Die Lipidvermischung während der Fusion eines Vesikels mit micro-BLMs wurde wie zuvor durch die radiale Verteilung des Texas Red-Farbstoffs in der planaren Membran und die simultane Löschung der Oregon Green-Fluoreszenz angezeigt. Die Analyse der Texas Red DHPE-Verteilung lieferte dabei einen Diffusionskoeffizienten von $D=(14 \pm 9) \mu \mathrm{m}^{2} / \mathrm{s}$. Dieser Wert ist leicht erhöht im Vergleich zu den Ergebnissen der Experimente ohne Pyranin und der FRAP-Studie, die jeweils einen Diffusionskoeffizienten von $D=(9 \pm 5) \mu \mathrm{m}^{2} / \mathrm{s}$ ergaben. ${ }^{93}$ Dennoch stimmen die Daten im Rahmen ihrer Fehlergrenzen überein. Daraus wurde geschlossen, dass die Beobachtungen 
der Texas Red DHPE-Verteilung und Oregon Green-Löschung auch in den Experimenten mit Pyranin-gefüllten LUVs auf die Diffusion der Texas Red DHPE-Moleküle in den porenüberspannenden Membranen in Folge einer stattgefundenen Fusion zurückzuführen sind. Dementsprechend sollte das Verschwinden der Pyraninfluoreszenz innerhalb von 230 ms, das mit der Lipidvermischung zusammenfällt, der Ausschüttung des Vesikelinhalts während der Fusion zuzuordnen sein.

Die simultane Detektion von Vesikelausschüttung und Lipidvermischung während der Fusion stellt ein sehr wichtiges Ziel vieler in vitro-Assays dar, um zwischen den einzelnen im Fusionsprozess auftretenden Intermediaten unterscheiden zu können. Dabei steht in der Regel die Verfolgung dieser beiden Prozesse mittels Fluoreszenzdotierung im Fokus. In Untersuchungen zur Vesikel-Vesikel-Fusion wird häufig ein wasserlöslicher Fluoreszenzfarbstoff wie zum Beispiel 8-Aminonaphthalin-1,3,6-trisulfonsäure (ANTS) in eine Vesikelpopulation eingeschlossen, während in der zweiten zu fusionierenden Vesikelpopulation der entsprechende Löscher $p$-Xylen-Bispyridiniumbromid (DPX) zu finden ist. Die Vermischung der Vesikelinhalte kann dann mit Hilfe eines Fluoreszenzspektrometers anhand der Verringerung der ANTS-Fluoreszenz verfolgt werden. ${ }^{24,29,127,128}$ Auf ähnliche Weise wird die Vermischung zweier zuvor getrennter wässriger Vesikelkompartimente durch Fusion mit Hilfe von $\mathrm{Tb}^{3+}$-Ionen und Pyridin-2,6Dicarboxylat-Dianionen, die ebenfalls in zwei getrennte Vesikelpopulationen eingebaut werden, nachgewiesen. Kommen beide Moleküle in räumliche Nähe zueinander, so entsteht ein fluoreszierender Komplex, dessen Bildung ebenfalls fluoreszenzspektrometrisch untersucht werden kann. ${ }^{63-65,74,119,129-131}$ Die hauptsächliche Schwierigkeit bei diesen Untersuchungen, neben Limitierungen in der Präparation und dem Auftreten von Artefakten, besteht darin, dass keine einzelnen Fusionsereignisse untersucht werden, sondern eine Statistik über das gesamte Vesikelensemble gewonnen wird. Aus diesem Grund kann zum Beispiel die Vermischung des Vesikelinhalts nicht zeitlich mit der Lipidvermischung korreliert werden, da die Fluoreszenz gemittelt über alle Vesikel erhalten wird. Deshalb ist die Beobachtung von Fusionsintermediaten sowie deren Kinetik meist erschwert und die Untersuchung von Einzelfusionsereignissen wünschenswert. Dazu werden hauptsächlich Vesikel mit planaren Membranen untersucht und zur Markierung des Vesikelinhalts wird vorwiegend Calcein oder Carboxyfluorescein in selbstlöschenden Konzentrationen eingesetzt, so dass die Freisetzung des Vesikelinhalts durch einen Lichtblitz der Calcein- bzw. 
Carboxyfluoresceinfluoreszenz fluoreszenzmikroskopisch sichtbar wird. ${ }^{11,43,48,113}$ Die Schwierigkeit bei diesen Untersuchungen besteht dabei in der Lokalisierung der Fluoreszenz des ausgeschütteten Farbstoffs im wässrigen Medium. Denn werden freittragende BLMs fluoreszenzmikroskopisch untersucht, so kann nicht aufgelöst werden, ob der im Vesikel gefangene Fluoreszenzfarbstoff auf der Membranseite, auf der der Vesikel an die Lipiddoppelschicht dockte oder auf der gegenüberliegenden Seite ausgeschüttet wurde. ${ }^{48}$ Dementsprechend kann das Aufblitzen der Fluoreszenz auch durch das Reißen des Vesikels verursacht werden, durch das der Fluoreszenzfarbstoff seitlich aus dem Vesikel entweichen kann. Wang et al. postulierten, dass bei der Fusion eines Vesikels mit einer festkörperunterstützen Membran der Vesikelinhalt in den circa 1 - 3 nm dicken, mit Wasser bzw. Puffer gefüllten Raum zwischen der Membran und der Festkörperunterlage, in diesem Fall Glas, ausgeschüttet wird. ${ }^{43}$ Wäre dies der Fall, so würde der wässrige Farbstoff sich danach auf Grund der dünnen Schichtdicke zwischen Membran und Festkörper hauptsächlich nur in zwei Dimensionen ausbreiten. Die Ausschüttung des Farbstoffs auf Grund des Vesikelreißens in das wässrige Kompartiment oberhalb der Membran hingegen würde zu einer 3-dimensionalen Diffusion führen, da der Farbstoff sich dort ungehindert in alle drei Raumrichtungen ausdehnen kann. Die Diffusion des verwendeten Calcein wurde deshalb in den Arbeiten von Wang et al. durch Anpassung zweier unterschiedlicher Modelle zum einen für die 2D- und zum anderen für die 3D-Diffusion analysiert. Auf diese Weise wurde festgestellt, dass es sich bei den beobachteten Ereignissen nicht um Fusion im eigentlichen Sinn handelt, da der Vesikelinhalt, nicht wie zu erwarten wäre, auf der dem Vesikel gegenüberliegenden Seite ausgeschüttet wird. Stattdessen entweicht der Farbstoff wahrscheinlich durch einen Riss im Vesikel seitlich. In den Experimenten von Wang et al. ist die Fluoreszenz von Calcein (50mM) eines Vesikels mit $50 \mathrm{~nm}$ Durchmesser innerhalb von $10 \mathrm{~ms}$ komplett verschwunden. In den zu Beginn dieses Kapitels beschriebenen Experimenten zur Vesikelausschüttung während der Fusion von LUVs mit micro-BLMs wurde ein Verschwinden der Pyranin-Fluoreszenz innerhalb von mehreren hundert Millisekunden beobachtet. Entsprechend des von Wang et al. beobachteten schnellen Verlusts des Farbstoffsignals, kann vermutet werden, dass das im Vergleich langsame Verschwinden der Pyranin-Fluoreszenz auf die Vesikelausschüttung während der Fusion mit microBLMs zurückzuführen ist. 
Um diese Vermutung zu bestätigen, sollte der Farbstoff in membranüberspannten Kavitäten, die durch geschlossene Porenböden geschaffen wurden, aufgefangen und konfokalmikroskopisch nachgewiesen werden. Die in Kapitel 4.3 beschriebenen Vorversuche dienten dazu, die Pyranin-Konzentration zu bestimmen, die in den Vesikeln nötig ist, damit der Farbstoff nach der Fusion in den Porentöpfen nachgewiesen werden kann. Die Ergebnisse, in denen Pyranin in Porentöpfen eingeschlossen wurden und anschließend eine Membran präpariert wurde, zeigen, dass die gewählten Porenabmessungen und eingesetzte Pyraninkonzentration geeignet sind, um den fluoreszenzmarkierten Vesikelinhalt nach der Fusion in den Porentöpfen zu detektieren. Konfokalmikroskopische Studien zur Analyse der Fluoreszenz in solchen Kavitäten wurden bereits in anderen Studien berichtet. ${ }^{132}$ Jedoch wurde bisher noch nie der Transport von Farbstoffen in diese Poren hinein untersucht. In den Experimenten zur Fusion von LUVs mit micro-BLMs mit geschlossenen Porenböden wurde die Fusion durch die Texas Red DHPE-Verteilung angezeigt, allerdings konnte keine Oregon GreenLöschung beobachtet werden. Dies wurde darauf zurückgeführt, dass die auf den Substraten mit geschlossenen Porenböden präparierten micro-BLMs wesentlich schlechter ausdünnten als auf den ansonsten verwendeten porösen Substraten mit geöffneten Poren. Dadurch könnten Lösungsmittelreservoirs vorhanden sein, in denen neben Lipiden dann auch größere Mengen an Fluorophor-Molekülen gelöst wären. Die Löschung der Oregon Green-Moleküle durch die eintretenden Texas Red-Moleküle würde somit kaum sichtbar werden, da der Anteil an nicht gelöschten Oregon GreenMolekülen überwiegen würde. Außerdem konnte nur in wenigen Experimenten die Pyranin-Fluoreszenz beobachtet werden, da diese zuvor durch Fotobleichen zerstört wurde. Somit ist ein Nachweis der Pyraninfluoreszenz nach der Fusion nicht möglich.

Beide Schwierigkeiten sollten durch den Einsatz von GUVs überwunden werden. Trotz der größeren eingebrachten Menge an wasserlöslichem Farbstoff konnte kein PyraninSignal nach der Fusion in den Poren detektiert werden. Die Beobachtung, dass in Abb. 4.17 eine Pyraninfluoreszenzwolke oberhalb der porenüberspannenden Membran zu beobachten war, führte jedoch zu der Vermutung, dass das Pyranin unter Umständen seitlich durch einen Riss aus dem Vesikel entweicht, während die Lipiddoppelschichten miteinander wechselwirken und nicht durch die Bildung einer Fusionspore auf der anderen Seite der Membran in die Porentöpfe ausgeschüttet wird. Perin et al. untersuchten die $\mathrm{Ca}^{2+}$-vermittelte Fusion von LUVs mit planaren Müller-Rudin- 
Membranen. ${ }^{111}$ Durch selektive Löschung der Calcein-Fluoreszenz auf der cis- und transSeite der planaren Membran konnte aus den Experimenten geschlossen werden, dass in diesem Fall die Calcein-Blitze zu $50 \%$ durch einen Riss im Vesikel und zu $50 \%$ durch Vesikelfusion verursacht werden. Eine ähnliche Verteilung finden auch Niles und Cohen für die Wechselwirkung von GUVs ( $1-2 \mu \mathrm{m}$ Durchmesser) mit einer freitragenden Montal-Müller-Membran bei einer $\mathrm{Ca}^{2+}$-Konzentration von $20 \mathrm{mM}$. Die Verdopplung der $\mathrm{Ca}^{2+}$-Konzentration führt dazu, dass mehr Vesikel fusionieren und $69 \%$ aller CalceinBlitze durch Fusion der Vesikel mit der planaren Membran verursacht werden. ${ }^{113}$ Die $\mathrm{Ca}^{2+}$-Abhängigkeit der Rate zwischen fusionierenden und reißenden Vesikeln in den Experimenten von Niles und Cohen, ${ }^{113}$ legt die Vermutung nahe, das unspezifische Fusion vermehrt zum Reißen der Vesikel führt. Es kann angenommen werden, dass dies auch der Fall bei der Fusion von GUVs mit porenüberspannenden Membranen ist, da in verschiedenen Experimenten gezeigt wurde, dass GUVs im Gegensatz von LUVs unspezifisch in Abwesenheit eines Fusogens mit porenüberspannenden Membranen fusionieren. Durch die Interaktion eines großen Vesikels vergrößert sich die Kontaktfläche zwischen planarer Membran und Vesikel. ${ }^{133}$ Dadurch erhöht sich vermutlich die Fusionsrate, da die Wahrscheinlichkeit, dass innerhalb der vergrößerten Kontaktfläche Defektstellen auftreten, die den Fusionsprozess nachsichziehen, steigt. Somit erscheinen GUVs ungeeignet zur Untersuchung von Fusionsprozessen mit porenüberspannenden Membranen. Insgesamt wäre der Einsatz von LUVs wünschenswert, da diese bisher keine unspezifischen Fusionen zeigten. Des Weiteren wäre eine Reduktion des Lösungsmittels im System vorteilhaft. Diese könnte durch die Membranherstellung durch Spreiten von GUVs auf CPEO3-funktionalisierten Substraten erreicht werden. Eine erfolgreiche Präparation ist bisher auf den Substraten mit geschlossenen Porenböden nicht gelungen. Der Grund dafür könnte in der wesentlich höheren Porösität dieser Geometrie im Vergleich zu der Anordnung der offenen Substrate mit einem Porendurchmesser von $d=1.2 \mu \mathrm{m}$ zu finden sein. Durch geometrische Betrachtung kann die Porösität, die das Verhältnis zwischen Poren und Porenstegen angibt, berechnet werden. Für die Substrate mit einem Porendurchmesser von $8 \mu \mathrm{m}$ wurde für die Porösität ein Wert von $P=65 \%$ ermittelt. ${ }^{134}$ Diese ist fast doppelt so hoch wie die für die beschriebenen Substrate mit einem Durchmesser von $1.2 \mu \mathrm{m}$ berechnete Porösität von $P=36 \%$. Durch das geringere Verhältnis zwischen Poren und Porenstegen wird die Auflagefläche, die sich den GUVs während des Spreitprozesses bietet 
vermindert und der fehlende Kontakt zur Oberfläche könnte das Spreiten verhindern. Die Verwendung einer anderen Porengeometrie wäre somit nötig, um lösungsmittelfreie porenüberspannende Membranen auf Substraten mit geschlossenen Porenböden zu präparieren und damit neue Erkenntnisse zur Vesikelsausschüttung im Fusionsprozess zu gewinnen.

\subsection{Untersuchung der Morphologie von porenüberspannenden Membranen nach der Fusion von LUVs mittels Rasterionen- leitfähigkeitsmessungen}

Durch Fusion wird aus zwei zuvor getrennten Lipiddoppelschichten eine neue durchgängige Membran mit vergrößerter Oberfläche. Es ist möglich, diese strukturellen Veränderungen im Fall kleiner Vesikel mit rasterelektronenmikroskopischen Methoden aufzulösen, ${ }^{65,135,136}$ während die Umformung größerer Vesikel auch lichtmikroskopisch verfolgt werden können. ${ }^{137-140}$ Die Ergebnisse beider Messmethoden zeigen jeweils, dass die Fusion von zwei Vesikeln zur Bildung von größeren Liposomen führt. Teilweise traten auch Invaginationen auf. ${ }^{65,138}$ Die Bildung dieser Membraneinstülpungen wurde auf einen Überschuss an Lipidmaterial zurückgeführt, der während der Fusion zweier Vesikel entsteht, weil auf Grund der Kugelgeometrie die Oberflächenzunahme geringer als die Volumenzunahme ist. Wird die Fusion von Vesikeln mit planaren Membransystemen untersucht, so wird der Verbleib der zusätzlich in die Lipiddoppelschicht eingebrachten Lipide meist nicht untersucht. Bildet sich zum Beispiel im Fall der festkörperunterstützten Membranen eine gewellte Struktur aus, um die vergrößerte Oberfläche zu kompensieren oder breitet sich die Membran in Defekte oder in die Randbereiche des Substrat hin aus? Das hier vorgestellte artifizielle Membransystem der micro-BLMs zeichnet sich dadurch aus, dass strukturelle Veränderungen gut mit hochauflösenden Techniken wie der Rasterkraftmikroskopie oder der Rasterionenleitfähigkeitsmikroskopie (scanning ion conductance microscopy, SICM) untersucht werden können. Auf diese Weise ließen sich eventuell auftretende Änderungen der Membrantopologie nach der Fusion nachweisen.

In einigen Studien wird die Rasterkraftmikroskopie (atomic force microscopy, AFM) verwendet, um porenüberspannende Membranen auch im Nanometerbereich abzu- 
bilden. $^{95,96,141,142}$ Ein Nachteil dieser Messmethode besteht jedoch darin, dass durch den Kontakt zwischen Messspitze und Probenoberfläche immer eine gewisse Kraft auf die Probe ausgeübt wird. ${ }^{143}$ Fine et al. und Lorenz et al. untersuchten rasterkraftmikroskopisch zum einen basolaterale und zum anderen apikale Zellmembranen, die auf porösen Siliziumnitridsubstraten mit Porendurchmessern von $1.2 \mu \mathrm{m}$ präpariert wurden. ${ }^{141,144}$ In beiden Fällen wird berichtet, dass selbst bei geringen bilderzeugenden Kräften von 300 pN, Indentationen der Membranen in die Poren bis zu Tiefen von $200 \mathrm{~nm}$ beobachtet wurden. Lorenz et al. zeigten dabei, ähnlich wie Hennesthal et al. in AFM-Analysen von porenüberspannenden Membranen basierend auf porösen Aluminaten mit Porendurchmessern von $50 \mathrm{~nm}$, dass durch eine Erhöhung der Kraft die porenüberspannenden Membranen tiefer in die Pore hineingedrückt werden. ${ }^{96,141}$ In einer Studie zum Vergleich von Höhenunterschieden der porenüberspannenden Membranen würde sich dies nachteilig auswirken. Um mögliche Differenzen in den Tiefen der porenüberspannten Bereiche vor und nach der Fusion von Vesikeln zu beobachten, wurde deshalb in dieser Arbeit die Rasterionenleitfähigkeitsmikroskopie genutzt, um die Morphologie der Lipiddoppelschicht zu untersuchen. Der Vorteil besteht darin, dass es sich bei dieser Methode um eine kontaktfreie Technik handelt.

In den SICM-Abbildungen von porenüberspannenden Membranen (Abb. 4.20 A), können im Wesentlichen zwei Bereiche mit signifikant unterschiedlichen Höhen differenziert werden. Die membranüberspannten Poren des Substrats liegen dabei tiefer als die Stegbereiche. Dieser Befund wurde, wie bereits in Kapitel 4.4 beschrieben und illustriert, auf die Wechselwirkung der Membran mit den DPPTE-funktionalisierten Porenstegen zurückgeführt. Dadurch zieht sich die Lipiddoppelschicht entlang der Goldschicht in die Pore hinein. Studien von Böcker et al., in denen porenüberspannende Membranen ebenfalls mit Hilfe der SICM-Technik abgebildet wurden, zeigen eine ähnliche Membrantopologie. ${ }^{94,145}$ Zusätzlich wurde in den Analysen von Böcker et al. noch einmal der Vorteil dieser Methode gegenüber AFM-Untersuchungen belegt. In AFMMessungen kann das Abrastern einer porenüberspannenden Membran durch die applizierte Kraft zum Reißen der Membran führen. ${ }^{95,}{ }^{96}$ In den SICM-Experimenten von Böcker et al. konnte zwar das Reißen der Lipiddoppelschicht über einzelnen Poren beobachtet werden, allerdings geschah dies nie während die Pipette über die jeweilige Pore rasterte, so dass diese Beobachtung auf ein zufälliges Reißen der Membranen 
zurückzuführen und eine Beeinflussung der Lipiddoppelschicht durch die Messpipette auszuschließen ist.

In den Höhenprofilen zu den SICM-Messungen dieser Arbeit (Abb. 4.22 C) fällt auf, dass das Profil in der Mitte der Pore eher gekrümmt verläuft. In Berechnungen von Böcker wurde aus den geometrischen Abmessungen im System und der Membranspannung der Biegeradius, also der Radius in dem sich die Membran beim Übergang von festkörperunterstützten Bereich in den porenüberspannten krümmt, ermittelt. Dieser liegt bei $r=12 \mathrm{~nm}$ und somit eine Größenordnung unter dem Durchmesser der Pore. Deshalb wurde angenommen, dass die Membran innerhalb der Poren eben gespannt ist. Die Abweichung der SICM-Aufnahme von der Berechnung kann auf das begrenzte Auflösungsvermögen der Rasterionenleitfähigkeitmikroskopie zurückgeführt werden. ${ }^{146}$ Die Krümmung der Membran erstreckte sich über einen Bereich von ca. $20 \mathrm{~nm}$ und ist somit wesentlich kleiner als die bestimmten Veränderungen der Höhendifferenzen vor und nach Fusion, die sich zum Teil bis zu 210 nm ausdehnten. Deshalb ist die Auflösung ausreichend, um Höhenunterschiede vor und nach der Fusion zu bestimmen. Des Weiteren zeigt die Konsistenz der bestimmten Höhendifferenzen vor der Zugabe von Vesikeln in den verschiedenen Messungen und den Kontrollexperimenten, die immer Porentiefen um $90 \mathrm{~nm}$ ergaben, die Reproduzierbarkeit der Messungen und der dazugehörigen Auswertung. Folglich muss die Vergrößerung der Porentiefen nach der Zugabe von LUVs, von denen bereits in fluoreszenzmikroskopischen Messungen in Kapitel 4.1 nachgewiesen wurde, dass sie unter den gewählten Versuchsbedingungen sehr effektiv fusionieren, auf die Veränderung der Membranstruktur im Rahmen der Fusion zurückzuführen sein. Die Beobachtungen, dass die Porentiefen nach der Vesikelinkubation größer werden, wurden folgendermaßen interpretiert. Die Oberfläche der Membran vergrößert sich durch die zusätzlich eingebrachten Lipide und die porenüberspannenden Membranen kompensieren dies dadurch, dass sie sich tiefer in die Pore hineinwölben. Die Struktur der Membranen in dem dargestellten Modellsystem besteht wie bereits beschrieben aus der porenüberspannenden Lipiddoppelschicht und einer Hybriddoppelschicht, die sich aus einer Lipidmonolage und der chemisorbierten Schicht DPPTE auf den Porenstegen zusammensetzt. Durch die Chemisorption des DPPTE über die SH-Gruppe an die Goldoberfläche, wird das Thiolipid fest mit dem Festkörper verankert. Diese Bedeckung durch verankerte Moleküle stellt eine 
Diffusionsbarriere für die Lipide der unteren Monolage der porenüberspannenden Membranen dar. Diese Beeinflussung der Diffusion von Lipiden in der unteren Monolage von porenüberspannenden Membranen wurde von Weiskopf in FRAP-Untersuchungen an micro-BLMs analysiert. ${ }^{93}$ Wird die Fluoreszenz der unteren Lipidmonoschicht durch $\mathrm{CoCl}_{2}$ gelöscht, so ändert sich das FRAP-Verhalten der micro-BLMs nicht. In einem statistischen Vergleich der Diffusionskoeffizienten vor und nach der Löschung der Fluoreszenz der unteren Monolage wurde geschlussfolgert, dass die Regeneration der Fluoreszenz nach dem Bleichen nur durch die Diffusion der Lipide in der oberen Monoschicht erfolgt. Dementsprechend liefern die Lipide, die zwischen den DPPTEfunktionalisierten Porenstegen liegen, keinen Beitrag zur Regenerierung der Fluoreszenzintensität und diffundieren demnach nicht zwischen den Poren. Ähnliche Beobachtungen machte auch Gaßmann, der zeigen konnte, dass Membrandurchspannende Connexine nicht über die Stegbereiche in andere Poren diffundieren können. ${ }^{102}$ Die Beobachtungen in den SICM-Experimenten liefern ein weiteres Indiz für den Einfluss der Stegfunktionalisierung auf die Diffusion der porenüberspannenden Membranen. Eine Begründung dafür, dass sich die Poren auf Grund der Diffusionsbarriere nach der Fusion tiefer in die Pore und nicht nach oben aus der Pore herauswölben, soll in Kapitel 5.5 gegeben werden.

Die Tiefe bis zu der sich die porenüberspannenden Membranen nach der Fusion eines Vesikels in die Pore hineinziehen, wurde durch folgende Rechnung abgeschätzt. Dazu wurde davon ausgegangen, dass die Anordnung einer porenüberspannenden Membran, mit dem senkrechten Verlauf an den Porenwänden und dem horizontalen Verlauf innerhalb der Pore, nach der Fusion beibehalten wird. Somit kann für die Membran vor und nach Fusion eine einfache Zylindergeometrie angenommen werden (Abb. 5.4). Aus dem Raumanspruch der Lipide innerhalb dieses Zylinders mit bekanntem Radius $r$ und bekannter Höhe $h$ kann die erwartete Porentiefe nach dem Einbringen der Vesikellipide durch Lipidvermischung abgeschätzt werden. Für die Fläche, die die Lipiddoppelschicht innerhalb einer Pore einnimmt, gilt:

$$
A_{\text {vor Fusion }}=2 \pi r_{\text {Pore }}^{2} \cdot h_{\text {vor Fusion }}
$$

Dabei wurde eine mittlere Höhe entsprechend der SICM-Aufnahmen vor der Fusion von $h=90 \mathrm{~nm}$ angenommen. Es wird davon ausgegangen, dass ein Vesikel mit einem Durchmesser von $d=600 \mathrm{~nm}$ mit der Membran innerhalb einer Pore fusioniert und dass der Einbau der zusätzlichen Lipide zu einer Vergrößerung der Oberfläche der Membran 
in dieser Pore führt. Die Fläche, die die Lipide eines Vesikels mit einem Durchmesser von $d=600 \mathrm{~nm}$ einnehmen, ergibt sich aus der Oberfläche einer Kugel mit entsprechendem Radius:

$$
A_{\text {Vesikel }}=\frac{4}{3} \pi r^{3}
$$

Die Fusion des Vesikel mit der Membran in der Pore führt zu einer Flächenvergößerung von:

$$
A_{\text {nach Fusion }}=A_{\text {nach Fusion }}+A_{\text {Vesikel }}=2 \pi r^{2} \cdot h_{\text {nachFusion }}
$$

Da der Radius der Pore konstant ist, muss sich die Flächenvergrößerung auf die Höhe auswirken, so dass aus der Fläche, die die Lipide nach der Fusion einnehmen, die erwartet Höhenänderung berechnet werden kann.

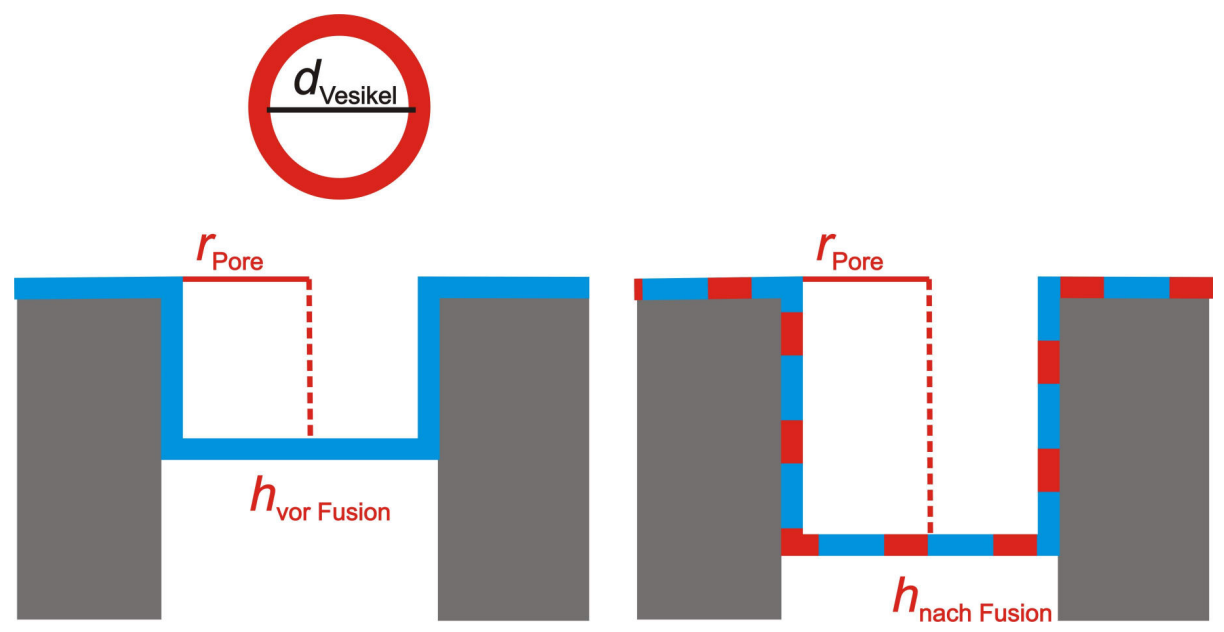

Abb. 5.4 Schematische Darstellung zur Höhenveränderung der Membran nach der Fusion eines Vesikels.

Demnach wird eine Vergrößerung der Porentiefe von 390 nm erwartet. Dieser Wert ist ungefähr doppelt so hoch wie die maximal beobachteten Höhenveränderungen in den SICM-Experimenten. Für die experimentellen Abweichungen gibt es jedoch mehrere mögliche Erklärungen. Zum einen wurden die Vesikel in den SICM-Messungen meist nicht direkt an der Stelle auf die Probe pipettiert, die mit Hilfe des SICM abgerastert wurde, so dass in den untersuchten Bereichen vielleicht eher kleine Vesikel fusionierten, die durch ihre geringere Größe und somit schnellere Diffusion früher als größere Vesikel auf die Probe gelangten. Dadurch könnten der Vesikeldurchmesser von $d=600 \mathrm{~nm}$, der 
in den Berechungen angenommen wurde, und die Menge an theoretisch eingebrachtem Lipidmaterial überbestimmt sein. Des Weiteren kann durch die SICM-Messungen nicht ausgeschlossen werden, dass ein Teil des Lipidmaterials auch in Invaginationen, die sich im Zuge der Fusion ausbilden könnten, verstaut wird. Solche Morphologien konnten in Vesikeln mit einem Durchmesser von $d=100 \mathrm{~nm}$ von Marsden in Cryo-TEMAufnahmen nach der Fusion vermittelt durch fusogene Peptide beobachtet werden. ${ }^{65}$ Weiterhin kann aber auch die Möglichkeit nicht ausgeschlossen werden, dass ein Teil des Vesikellipidmaterials, trotz der Barriere durch die DPPTE-Funktionalisierung, durch Diffusion auch über die Porenstege hinweg auf andere Poren verteilt wird. Die Oberflächenbelegung einer selbstorganisierten Monoschicht von DPPTE auf Gold gab Wieder mit $80-85 \%$ an. ${ }^{147}$ Der Anteil an 15-20\% Defektstellen in einer DPPTEMonoschicht kann den Lipiden der unteren Monoschicht der porenüberspannenden Membranen ermöglichen über die Stege in andere Poren zu diffundieren. Dieser Effekt wäre in den oben beschriebenen FRAP-Analysen wahrscheinlich nicht zu beobachten, da die Fluoreszenzregeneration innerhalb weniger Minuten beobachtet wurde, während die SICM-Aufnahmen über einen längeren Zeitraum bis zu einigen Stunden erfolgten. Die SICM-Experimente wurden ausschließlich auf Substraten mit DPPTE-Funktionalisierung durchgeführt. Ein Vergleich der Messungen mit unterschiedlich funktionalisierten Substraten ist eine interessante Möglichkeit, um den Einfluss der Diffusionsbarriere auf die Porenvertiefung nach der Fusion in weiterführenden Studien zu untersuchen. Eine an Gold chemisorbierte Monolage von CPEO3 zum Beispiel zeigt einen wesentlich geringeren Belegungsgrad von lediglich $65 \%{ }^{148}$ Dadurch sollte ein Austausch der Lipide zwischen den Poren des Substrats erleichtert sein, so dass die zusätzlich in die Membran eingebauten Lipide durch Diffusion auf das gesamte Substrat verteilt werden können. Dadurch würde der Beitrag eines Vesikels zu der Tiefenvergrößerung einer einzelnen Pore wesentlich geringer ausfallen.

Ein Vergleich der Porentiefenveränderungen vor und nach der Fusion zeigt, dass diese in verschiedenen Proben unterschiedlich ausfallen (Abb. 4.24). Wie bereits angedeutet, verläuft der Transport eines Vesikels an die Oberfläche des Substrats diffusionskontrolliert. Dieser Einfluss auf die Fusion der Vesikel mit einer planaren Membran wurde bereits von Akabas et al. und Niles et al. diskutiert. ${ }^{113,133}$ Niles et al. nutzten in Näherung zur Bestimmung der Diffusionskonstante eines Vesikels in Lösung 
die Stokes-Einstein-Beziehung und berechneten einen Wert von $D=8 \cdot 10^{-10} \mathrm{~cm}^{2} / \mathrm{s}$ für die in der entsprechenden Arbeit verwendeten Vesikel mit einem Durchmesser von $5 \mu \mathrm{m} .{ }^{113}$ Daraus folgt nach der Diffusionsgleichung $\left(\mathrm{x}^{2}=2 D t\right)$, dass ein Vesikel ungefähr 16 Stunden benötigt, um durch einen $100 \mu \mathrm{m}$ ungerührten Bereich zu diffundieren. Eine analoge Berechnung für die in dieser Arbeit verwendeten Vesikel mit einem mittleren Durchmesser von $d=600 \mathrm{~nm}$ ergibt eine Diffusionszeit von 2 Stunden. Die ungerührte Schicht wurde durch das Aufbringen der Vesikel mit Hilfe einer Pipette überwunden, dennoch kann die Anzahl an Vesikeln, die letztendlich durch Diffusion die Oberfläche der porenüberspannenden Membranen erreichen, variieren. Da die Vergrößerung der Porentiefe eine Funktion des eingebauten Lipidmaterials und somit der Anzahl der fusionierten Vesikel ist, spiegeln die Schwankungen sich letztendlich in den unterschiedlichen Veränderungen der Porentiefen in den verschiedenen Experimenten wider.

\subsection{Untersuchung der Fusion von Vesikeln mit porenüberspannenden Membranen vermittelt durch molekulare Erkennung}

\section{$\underline{H}_{6} \underline{W G C}:$}

Um neue Einblicke in die Intermembran-Wechselwirkung von Vesikeln mit porenüberspannenden Membranen zu gewinnen, wurde die Verbrückung der jeweiligen Lipiddoppelschichten über das Nonapeptid $\mathrm{H}_{6}$ WGC genutzt. Die Verknüpfung erfolgte zum einen über die kovalente Bindung des peptidischen Cystein-Rests an eine MaleimidKopfgruppe in den porenüberspannenden Membranen und zum anderen über die Komplexierung eines in der Vesikelmembran verankerten Nickel-Ions durch den Nterminalen His-Tag des Peptids (Kapitel 1.4). Dazu wurde mit lösungsmittelfreien Membranen gearbeitet, um eine Beeinflussung der Fusionsprozesse durch das Lösungsmittel, die in Kapitel 5.1 diskutiert wurde, zu verhindern. Vor der Untersuchung der Intermembranwechselwirkung wurde zunächst die erfolgreiche Anbindung des Nonapeptids an Maleimid-tragende porenüberspannende Membranen, die durch das Spreiten von GUVs erhalten wurden, untersucht. Die Ausbildung einer kovalenten Bindung zwischen einer terminalen Cystein-Gruppe und Maleimid-funktionalisierten 
Lipiden wurde bereits in früheren Studien ausgenutzt, um Peptide an Vesikel ${ }^{67,149}$ oder festkörperunterstützte Membranen zu koppeln. ${ }^{66,150}$ In dieser Arbeit konnte erstmals durch Nachweis einer FITC-Antikörperbindung die erfolgreiche Bindung eines Cysteinhaltigen Peptids an die Maleimid-Funktionlisierung von porenüberspannenden Membranen gezeigt werden. Das Peptid konnte bereits bei einem Gehalt von $2 \%$ 1,2-Dioleoyl-sn-glycero-3-phosphoethanolamin-N-[4-(p-maleimidomethyl)-cyclohexancarboxyamid] (MCC-DOPE) durch Detektion der Antikörperfluoreszenz nachgewiesen werden. Im Gegensatz dazu konnten Schuy et al. in Quartzmikrowaage-Messungen (quartz cristal microbalance, QCM) eine signifikante Frequenzabnahme und somit messbare Anbindung des Peptids an festkörperunterstützte Membranen erst bei einem MCC-DOPE-Gehalt von 5 mol\% beobachten. Die voneinander abweichenden Ergebnisse können auf die unterschiedlichen Sensitivitäten der beiden eingesetzten Methoden zurückgeführt werden. Die Negativ-Experimente, in denen keine Wechselwirkung des Antikörpers mit peptidfreien porenüberspannenden Membranen gefunden wurde, zeigen zweifelsfrei, dass der durchgeführte Nachweis spezifisch für die erfolgreiche Bindung des Peptids an die Maleimid-Kopfgruppen ist.

Werden zwei Membranen durch $\mathrm{H}_{6}$ WGC verknüpft, so sollte der Intermembranabstand an der Kontaktstelle durch die enge Bindung des Peptids zu den Rezeptoren in den zwei unterschiedlichen Lipiddoppelschichten signifikant verringert werden. Von Schuy et al. wurde die Dicke des Peptids auf $d_{\mathrm{H} 6 \mathrm{WGC}}=0.5 \mathrm{~nm}$ berechnet; mit Hilfe der QCM konnte die Schichtdicke in der entsprechenden Studie verifiziert werden. ${ }^{66}$ Die Länge des MCCDOPE-Spacers wurde von Treutlein mit $d_{\mathrm{MCC}}=0.83 \mathrm{~nm}$ angegeben. ${ }^{151}$ Für den Abstand der Ni-NTA-Gruppe von der Membranoberfläche sind keine experimentellen Daten bekannt, jedoch kann davon ausgegangen werden, dass dieser wesentlich kleiner ist als der für das im Vergleich größere Biotin-DPPE angegebene Abstand von $d_{\text {Biotin }}=1.2 \mathrm{~nm}$. Dementsprechend kann der Intermembranabstand bei erfolgreicher Verknüpfung der Lipiddoppelschichten auf kleiner als $d_{\mathrm{M}-\mathrm{M}}=2.53 \mathrm{~nm}$ angenommen werden. Der Wert liegt genau in dem Bereich, in dem starke repulsive Hydratationskräfte zwischen den Lipidkopfgruppen der zwei gegenüberliegenden Membranen eine weitere Annäherung der Lipiddoppelschichten aneinander und ihre Fusion erschweren. Durch die Verbrückung über das $\mathrm{H}_{6}$ WGC-Peptid sollte diese Barriere überwunden werden. Demnach ist die Vermittlung der Fusion von LUVs mit porenüberspannenden Membranen durch das Peptid $\mathrm{H}_{6} \mathrm{CGW}$ denkbar. 
Nach der Überprüfung der Spezifität der Wechselwirkung des Peptids $\mathrm{H}_{6}$ WGC mit den beiden Rezeptoren Maleimid in den porenüberspannenden Membranen und Ni-NTA in der Vesikelmembran, wurde der Einfluss der Rezeptordichte auf das Adhäsions- und Fusionsverhalten von LUVs mit porenüberspannenden Membranen untersucht. Die Lipidvermischung zeigte sich, wie in Kapitel 5.1 beschrieben, durch die Verteilung der Texas Red-Fluoreszenz in den porenüberspannenden Membranen und die Löschung der Oregon Green-Fluoreszenz. Aus den beobachteten Lipidvermischungsereignissen wurde ein mittlerer Diffusionskoeffizient von $D=(0.4 \pm 0.3) \mu \mathrm{m}^{2} / \mathrm{s}$ für die Texas RedVerteilung in den porenüberspannenden Membranen ermittelt. Dieser Wert ist um eine Größenordnung kleiner als der von Weiskopf in FRAP-Messungen ermittelte Diffusionskoeffizient von $D=(4 \pm 2) \mu \mathrm{m}^{2} / \mathrm{s}$ für porenüberspannende Membranen, präpariert durch GUV-Spreiten auf CPEO3-funktionalisierten porösen Substraten. Eine Beeinflussung der Diffusionsgeschwindigkeit durch den Einbau der Rezeptorlipide und die Anbindung des $\mathrm{H}_{6}$ WGC ist dabei denkbar. Jedoch zeigten Frese und Gaßmann, dass der Einbau von Bakteriorhodopsin bzw. Connexin $26-$ zwei großen Transmembranproteinen - den Diffusionskoeffizenten der porenüberspannenden Membranen kaum, aber auf keinen Fall um eine Größenordnung, verringern. ${ }^{102,}{ }^{152} \mathrm{Im}$ Vergleich dazu sollte ein lipidgekoppeltes Nonapeptid keinen so starken Einfluss auf die Diffusion der porenüberspannenden Lipiddoppelschicht haben.

In Experimenten ohne oder mit nur $0.1 \%$ Ni-NTA-Gehalt in den LUVs konnten erwartungsgemäß kaum Fusionsereignisse und fast ausschließlich die Anbindung der Vesikel an die porenüberspannende Membran mit oder ohne anschließende Wiederablösung beobachtet werden. Ähnliche Ereignisse wurden auch von Fix et al. und Domanska et al. für die SNARE-vermittelte Interaktion von LUVs mit festkörperunterstützten Membranen beschrieben und als Andocken und anschließendes Wiederablösen der Vesikel interpretiert. ${ }^{38,} 39$ Insgesamt stellen die Andock-Ereignisse die mit Abstand häufigste Wechselwirkung zwischen LUV und porenüberspannender Membran dar, die im Fall der Untersuchungen zur molekularen Erkennung durch $\mathrm{H}_{6}$ WGC beobachtet wurden. Der Grund für die Vesikelanbindung ohne anschließende Lipidvermischung, kann in der Abhängigkeit der Wechselwirkung zwischen den zwei Membranen von der Anzahl an gebildeten Verknüpfungen gesucht werden. Durch die geringe oder gar nicht vorhandene Anzahl an Verknüpfungen durch das Peptid könnte die Anziehung vermindert sein, so dass keine Fusion eingeleitet wird. Diese Abhängigkeit 
wurde in theoretischen Arbeiten von Lipowsky näher betrachtet. ${ }^{153}$ In seiner stickerTheorie geht Lipowsky davon aus, dass ein bestimmter Grenzwert an adhäsiven Molekülen in den Membranen überschritten werden muss, um eine Anziehung beider Lipiddoppelschichten zueinander zu erzielen. Experimentell wurde diese Theorie von Richard et al. für die Vesikel-Vesikel-Fusion vermittelt durch $\mathrm{Ni}^{2+}-$ Komplexierung durch Lipid-gekoppelte Bipyridine belegt. ${ }^{136}$ So wurde gezeigt, dass eine Konzentration von 2 $3 \mathrm{~mol} \%$ an Bipyridin-Rezeptoren in den Vesikeln überschritten werden muss, bevor Fusion beobachtet wurde, während bei geringeren Liganddichten ausschließlich die Aggregation der Vesikel detektiert wurde.

$\mathrm{Ab}$ einer Konzentration von $1 \%$ Ni-NTA in den porenüberspannenden Membranen ist eine Rezeptordichte erreicht, bei der häufiger als bei anderen untersuchten Ni-NTAKonzentrationen vollständige Lipidvermischung beobachtet wurde. Dabei ist zu beachten, dass die Fusionswahrscheinlichkeit im Vergleich $\mathrm{zu}$ den $\mathrm{Ca}^{2+}$-vermittelten Fusionen basierend auf micro-BLMs von $100 \%$ (Kapitel 5.1) sehr gering ist und dass nur $12 \%$ aller beobachteten Vesikel mit $1 \%$ Ni-NTA diese vollständige Lipidvermischung zeigten. Eine weitere Erhöhung der Rezeptordichte führte dabei nicht wie erwartet zu einer Erhöhung der Fusionswahrscheinlichkeit. Im Gegensatz dazu wurden bei einer NiNTA-Konzentration von $2 \%$ im Vergleich zu den anderen untersuchten Rezeptordichten am häufigsten unvollständige Fusionsereignisse gefunden, die aber auch hier nur $13 \%$ der insgesamt bei $2 \%$ Ni-NTA beobachteten Interaktionsereignisse ausmachten. Des Weiteren ist auffällig, dass mit steigender Ligandkonzentration in den Vesikeln auch die Anzahl an Ereignissen steigt, in denen nach Andocken und anschließendem Wiederablösen des Vesikels von der Membran oder nach der unvollständigen Fusion eines Vesikels immer ein gewisser Anteil Texas Red-Fluoreszenzintensität zurückbleibt. Eine mögliche Erklärung für dieses Phänomen wäre, dass die erhöhte Zahl von Verknüpfungen zwischen LUV und porenüberspannender Membran zu einer stärkeren Verbindung zwischen den zwei Lipiddoppelschichten führt. Damit ist gemeint, dass die Kontaktfläche vergrößert wird, wenn der Vesikel über eine größere Anzahl an Rezeptoren in der Vesikelmembran an die porenüberspannende Membran gebunden wird. Die vermehrten Wechselwirkungen an der vergrößerten Kontaktfläche hätten zur Folge, dass zum Beispiel im Fall der Einwirkung mechanischer Kräfte Teile der Vesikelmembran herausgerissen werden könnten. Gleichzeitig könnte der Teil des Vesikels, der über die bei $2 \%$ Ni-NTA-Gehalt vermehrten Rezeptor-Ligand- 
Wechselwirkungen an die porenüberspannende Membran gebunden ist, auf der planaren Lipiddoppelschichten haften bleiben. Ein Teil des Texas Red-Fluoreszenzsignals würde in Folge dessen im Bereich der porenüberspannenden Membranen zurückbleiben. Des Weiteren könnte die Ausbildung einer größeren Zahl Verknüpfungen, im Vergleich zu den möglichen Bindungen im Fall geringerer Rezeptorkonzentrationen im Vesikel, auch zu einer Deformation des Vesikels führen. Durch die Anbindung des Vesikels an die planare Membran über das Peptid könnte es so zu einer Abflachung des Vesikels an der Kontaktfläche kommen, je mehr Ligand-Rezeptor-Bindungen ausgebildet werden. Diese Destabilisierung könnte ein Reißen der Vesikelmembran zur Folge haben, um die Deformation zu kompensieren. Dabei könnten Vesikelfragmente in Lösung diffundieren und dort ein neues Aggregat bilden, während andere Vesikelteile auf der Membran zurückbliebe. Wong et al. und Chung et al. zeigten zum Beispiel, dass die Interaktion zwischen einem GUV und einer festkörperunterstützten Membran zum Reißen des Vesikels führt. ${ }^{108,} 109$ Die Anbindung des GUVs wurde von Chung et al. durch Hybridisierung Lipid-gekoppelter DNA-Einzelstränge realisiert, während Wong et al. die Bindung verschiedener Glykopeptide an Cholera Toxin zur Vermittlung des Membrankontakts ausnutzten. Der Verbleib des gerissenen GUVs und der nahe Kontakt $\mathrm{zu}$ der planaren Membran wurde von beiden Gruppen fluoreszenzmikroskopisch nachgewiesen. Für die Beobachtung der unvollständigen Fusion eines LUVs mit porenüberspannenden Membranen kann neben dem Vesikelreißen auch die Fusion eines einzelnen Vesikels, der Bestandteil eines Vesikelaggregats ist, als mögliche Erklärung für das Zurückbleiben eines gewissen Texas Red-Signalanteils herangezogen werden. Auch der Verbleib eines Vesikels im Hemifusionszustand (Kapitel 1.1, Abb. 1.1) kann in Betracht gezogen werden. Für die Hemifusion wäre eine gewisse Texas Red-Verteilung wie im Fall der Fusion zu erwarten, wenn sich die beiden benachbarten Lipidmonoschichten der fusionierenden Membran vermischen. Bleibt eine vollständige Fusion aus, so bleiben die distalen Monolagen der Membranen getrennt, so dass die Vesikellipide sich in den porenüberspannenden Membranen nicht weiter verteilen und somit eine erhöhte Texas Red-Fluoreszenz zurückbleibt. Fluoreszenzmikroskopische Aufnahmen von Hemifusionsereignissen von Vesikeln mit einer festkörperunterstützten Membran wurden in Arbeiten von Liu et al. veröffentlicht. ${ }^{107}$ In späteren Untersuchungen wurde dann die Existenz dieser Hemifusionszustände durch Fluoreszenzmarkierung des wässrigen Vesikelinhalts verifiziert. ${ }^{43,92}$ Dies wäre eine Möglichkeit, um auch in dieser 
Arbeit zu prüfen, ob die unvollständige Fusion auf die Fusion eines Vesikels in einem Aggregat, das Vesikelreißen oder die Hemifusion zurückzuführen ist.

Die Vesikel, die mittels $\mathrm{H}_{6}$ WGC-Bindung in Kontakt mit den porenüberspannenden Membranen gebracht werden, zeigen fast ausschließlich Wechselwirkungen im Bereich der Porenstege. In maximal $18 \%$ der Fälle bei einem Ni-NTA-Gehalt von $1 \%$ führen diese Anbindungen zur Fusion. Diese Ergebnisse stehen in Kontrast zu den Beobachtungen, dass LUVs mit micro-BLMs $\mathrm{Ca}^{2+}$-vermittelt mit einer Wahrscheinlichkeit von $100 \%$ fusionieren und zu gleichen Teilen sowohl mit den Porenstegen als auch mit den membranüberspannten Bereichen interagieren. Der Grund für die im Vergleich zu den anderen in dieser Arbeit untersuchten Fusionssystemen geringere Fusionsrate im Fall der $\mathrm{H}_{6}$ WGC-vermittelten Interaktion kann in der geringen Vesikeldestabilisierung liegen. Die Experimente der $\mathrm{Ca}^{2+}$-vermittelten Fusion von LUVs mit micro-BLMs (Kapitel 5.1) oder PNA-Peptid-vermittelten Fusion von LUVs mit lösungsmittelfreien porenüberspannenden Membranen (Kapitel 5.4) liefern Anzeichen dafür, dass eine Destabilisierung des Vesikels ausreicht, um die Fusion mit porenüberspannenden Membranen zu initiieren. Im Fall der $\mathrm{Ca}^{2+}$-vermittelten Fusion geschieht dies wahrscheinlich (Kapitel 5.1) durch die asymmetrisch $\mathrm{Ca}^{2+}$-Komplexierung negativ geladener Lipide im Vesikel. Es ist anzunehmen, dass die PNA-Peptid-haltigen LUVs durch den Einbau der Transmembranregion der nativen SNARE-Proteine destabilisiert werden (Kapitel 5.4). Zur $\mathrm{H}_{6}$ WGC-Anbdingung wurde in die Vesikel mit dem Ni-NTA-DOGS ein Kopfgruppen modifiziertes Lipid eingebracht. Dieses sollte keine Stabilitätsänderung nach sich ziehen, da die Membranintegrität in diesem Fall erhalten bleibt und somit eine geringere Fusionseffizienz nachsichziehen. Diese Theorie wird von einer Studie gestützt, die 2009 von Ma et al. veröffentlicht wurde. ${ }^{154}$ Darin wurde die Aggregation von Vesikeln, vermittelt durch die Ausbildung von Wasserstoffbrücken-bindungen zwischen jeweils Lipid-gekoppeltem Melamin und Cyanurat, untersucht. Die Fusion der Vesikel konnte diese Gruppe nur nachweisen, wenn das Peptid Magainin in die Membran eingelagert wurde. Dabei spielte es keine Rolle, ob Magainin als Transmembrananker an die Melamin-Funktionaliserung gekoppelt war oder zusätzlich in die Membran eingelagert wurde. Diese Analysen stützen die Vermutung, dass die reine Anbindung der Vesikel nicht ausreicht, um Fusion zu induzieren, sondern zusätzlich eine Destabilisierung der Membran erforderlich ist. 
Wird die $\mathrm{Ca}^{2+}$ - oder PNA-vermittelte Fusion betrachtet, so ist in den meisten Fällen die Annäherung eines Vesikels an die porenüberspannenden Membranen zu beobachten, gefolgt von einer sofortigen Lipidvermischung. Die Fusion findet sowohl mit der Lipiddoppelschicht auf dem Porensteg als auch mit der porenüberspannenden Membran statt. Im Gegensatz dazu binden Ni-NTA-tragende LUVs vorwiegend an die Porenstege und zeigen nach dem Andocken keine Mobilität mehr. Simonsson et al. untersuchten an Vesikeln mit einem Durchmesser von $d=100 \mathrm{~nm}$, die über DNA-Duplex-Bildung an festkörperunterstützte Membranen gebunden wurden, wie groß der Einfluss der Verknüpfungen auf die Mobilität der Vesikel ist. Eine Erhöhung des DNA/VesikelVerhältnis von 1 auf 50 führte $\mathrm{zu}$ einer fast 20fachen Verringerung der Diffusionskonstante von dem an die planare Membran gebundenen Vesikel von $D=0.77$ $\mu \mathrm{m}^{2} / \mathrm{s}$ auf $D=0.04 \mu \mathrm{m}^{2} / \mathrm{s} .{ }^{99}$ Der Einfluss auf die Diffusion eines im Vergleich größeren Vesikels sollte sich noch stärker auswirken, da die Diffusion von der Partikelgröße abhängt. Für die in der vorliegenden Arbeit verwendeten Vesikel wurde die Anzahl der darin vorhandenen Ni-NTA-Rezeptoren und somit die Anzahl an möglichen Verbindungen, die zur porenüberspannenden Membran gebildet werden können, berechnet. Dazu wurde von einem Vesikeldurchmesser von $d=600 \mathrm{~nm}$ und einem durchschnittlichen Raumbedarf eines Lipids von $70 \AA^{2}$ ausgegangen. ${ }^{155}$ Bei einer NiNTA-DOGS-Konzentration von $0.1 \%$ ergibt sich aus diesen Parametern, dass 1600 Rezeptormoleküle im Vesikel zugegen sind und potentiell eine Bindung zur porenüberspannenden Membran ausbilden könnten. Es ist zwar davon auszugehen, dass die Zahl, die berücksichtigt werden muss auf Grund sterischer Hinderung geringer ist, auf jeden Fall wird sie jedoch größer als die Anzahl von 50 Rezeptoren in den Untersuchungen von Simonsson et al. sein. Dieser Vergleich legt die Vermutung nahe, dass die Vesikel durch die Anbindung an den festkörperunterstützten Bereich wahrscheinlich fast vollständig immobilisiert werden.

Ungeklärt bleibt so jedoch die Beobachtung, dass die Vesikel im $\mathrm{H}_{6}$ WGC-System im Gegensatz zur $\mathrm{Ca}^{2+}$ - oder PNA-vermittelten Fusion keine Wechselwirkung mit den porenüberspannten Bereichen des Substrats zeigen. Der Grund hierfür könnte in der unterschiedlichen Präparation der porenüberspannenden Membranen und den unterschiedlichen Anbindungen der Vesikel an die planare Membran liegen. Im Gegensatz zu den micro-BLMs weisen die lösungsmittelfreien porenüberspannenden Membranen nach Mey et al. eine ungefähr 1.4-fach höhere Membranspannung auf. ${ }^{95}$ 
Bereits in Kapitel 5.1 wurde beschrieben, dass eine Erhöhung der Membranspannung die Fusogenität der Membran vergrößern könnte. Des Weiteren können strukturelle Umordnungen der Lipide während der Adhäsion von Vesikeln durch das fehlende Lösungsmittel schlechter kompensiert werden. Beide Faktoren könnten dazu führen, dass eine Anbindung der LUVs an die lösungsmittelfreie porenüberspannende Membran benachteiligt und die Wechselwirkung mit den Porenstegen favorisiert ist. Der Lösungsmittel- und Spannungseinfluss kann allerdings nicht für die Experimente, in denen die Fusion durch PNA-Peptide vermittelt wurde (Kapitel 4.5.2), als Argument für die erhöhte Fusionsrate angeführt werden. In diesen Experimenten wurde auch für das lösungsmittelfreie System der porenüberspannenden Membranen eine hohe Fusionswahrscheinlichkeit und die Fusion mit porenüberspannenden und Stegbereichen gefunden. Im Gegensatz zu den beschriebenen SNARE-analogen PNA-Peptiden erfolgt im Fall der Verbrückung durch $\mathrm{H}_{6} \mathrm{WGC}$ eine starre Verbindung zwischen den Lipiddoppelschichten. Während durch die Linkerregion bestehend aus 10 Aminosäuren in den PNA-Peptiden ein gewisser Abstand zwischen Membran und Erkennungseinheit geschaffen wird, besteht das verbrückende Peptid $\mathrm{H}_{6}$ WGC nur aus 9 Aminosäuren. Diese starre Verknüpfung könnte ausschlaggebend dafür sein, dass eine Wechselwirkung mit den spannungsfreien Membranen auf den Porenstegen bevorzugt wird.

Zum einen scheinen, die Vesikel auf den Porenstegen immobilisiert sein. Zum anderen besteht die These, dass zwar Wechselwirkungen mit der porenüberspannenden Membran und Vesikel stattfinden, diese aber vielleicht von nur kurzer Dauer sind und nicht zu Fusionen führen. Durch beide Beobachtungen kann so der Eindruck entstehen kann, dass ausschließlich Wechselwirkungen von LUVs mit stegunterstützten Membranen durch $\mathrm{H}_{6} \mathrm{WGC}$ vermittelt werden.

\section{SNARE-analoge PNA-Peptide:}

Neben der Verbrückung von Vesikeln mit porenüberspannenden Membranen durch $\mathrm{H}_{6}$ WGC wurden auch die fusogenen Eigenschaften eines Peptidsystem getestet, in dem die natürliche Bildung der coiled-coil-Strukturen von SNARE-Proteinen durch die Paarung komplementärer PNA-Stränge imitiert wurde. Dazu wurden PNA-Sequenzen gekoppelt an einen Transmembrananker, welcher der Transmembranregion nativer SNARE-Proteine entspricht, in GUVs rekonstituiert und durch Spreiten dieser GUVs 
lösungsmittelfreie porenüberspannenden Membranen präpariert. Um sicherzustellen, dass PNA-Peptide in GUVs eingebaut wurden und nach dem Spreiten dieser GUVs in die porenüberspannenden Membranen transferiert wurden, wurde zunächst die Anbindung von fluoreszenzmarkierter DNA, deren Struktur komplementär zu der Basenfolge in der verwendeten PNA ist, analysiert. Die spezifische Wechselwirkung der DNA mit PNAPeptidhaltigen porenüberspannenden Membranen bestätigte der erfolgreiche Rekonstitution von PNA-Peptiden in porenüberspannende Membranen. Außerdem konnte nachgewiesen werden, dass die untersuchten Fusionsereignisse spezifisch durch das gewählte Peptidsystem induziert werden. Der Einbau von Syx PNA3 in die Vesikelpopulation und von VAMP PNA1 in die porenüberspannenden Membranen führte zur Lipidvermischung, die, wie in Kapitel 5.1 beschrieben, fluoreszenzmikroskopisch verfolgt werden konnte. Die Verwendung der komplementären PNA-Sequenzen PNA1 und PNA3 und der zwei unterschiedlichen Transmembraneinheiten von Synaptobrevin (VAMP) und Syntaxin (Syx) zeigte fusogene Eigenschaften auch in dem von Lygina durchgeführten Assay. ${ }^{156}$ Darin wurde die Fusion von Vesikeln mit einem Durchmesser von $d=100 \mathrm{~nm}$ über die Veränderung der FRET-Effizienz untersucht. Die Vermittlung der Wechselwirkungen von LUVs mit porenüberspannenden Membranen durch diese Kombination an PNA-Peptiden konnte bestätigt werden. So wurde die Lipidvermischung während der Fusion durch die radiale Texas Red DHPE-Verteilung in den porenüberspannenden Membranen und die simultane Oregon Green-Löschung angezeigt (Abb. 4.39). Aus der Texas Red DHPE-Verteilung wurde ein mittlerer Diffusionskoeffizient von $D=(3 \pm 3) \mu \mathrm{m}^{2} / \mathrm{s}$ für die Diffusion der Vesikellipide in den porenüberspannenden Membranen bestimmt. Dieser Wert stimmt sehr gut mit den Ergebnissen der von Weiskopf durchgeführten FRAP-Studie überein. Darin wurde für die Diffusion in porenüberspannenden Membranen, präpariert durch Spreiten von GUVs, auf einem CPEO3-funktionalisiertem Substrat, ein Wert von $D=(4 \pm 2) \mu \mathrm{m}^{2} / \mathrm{s}$ ermittelt. $^{93}$ Die Andockzeit der Vesikel an die porenüberspannende Membran kann auf Grund einer Zeitauflösung von $50 \mathrm{~ms}$ in den aufgenommenen Zeitserien auf einen Wert von $t<50 \mathrm{~ms}$ bestimmt werden. (vergleiche Kapitel 5.1). Eine Verringerung der in den Membranen vorhandenen Peptide hätte unter Umständen dazu führen können, dass die Verknüpfung der Membranen durch die Hybridisierung der komplementären PNA-Stränge verlangsamt und somit die Zeit des Andockens vor der Fusion verlängert hätte. So untersuchten Lu et al. in einem Vesikelfusionsassay mit LUVs zur SNARE-mediierten Fusion die 
Abhängigkeit der Fusionskinetik von der Anzahl an rekonstitutierten SNARE-Proteinen in den Vesikeln. ${ }^{157}$ Es stellte sich heraus, dass die Verringerung des Lipid/ProteinVerhältnisses von 1:100 auf 1:200 zu Hemifusionszuständen führen, die nicht zu einer kompletten Lipidvermischung führen.

Zusätzlich zur Untersuchung der fusogenen Eigenschaften von VAMP PNA1 mit Syx PNA3 wurden weitere Kombinationen an PNA-Konstrukten in Vesikel und porenüberspannende Membran eingebaut und deren Einfluss auf das Fusionsverhalten untersucht. Im Vorfeld wurde erwartet, dass nur die Kombination der unterschiedlichen Transmembrananker, jeweils verknüpft mit den komplementären PNA-Strängen (VAMP PNA1 in porenüberspannender Membran/ Syx PNA3 in Vesikel), zur Fusion führen würden und identische PNA-Stränge, unabhängig von dem gewählten Membrananker (VAMP PNA1 in porenüberspannender Membran/ Syx PNA1 bzw VAMP PNA1 in Vesikel), keine Interaktionen zeigen, die zur Fusion führt. Durch den Einbau identischer PNA-Sequenzen in die unterschiedlichen Membranen sollte die molekulare Erkennung und damit die Initiation des Fusionsprozesses gestört sein, da die Lipiddoppelschichten erst gar nicht in engen Kontakt zueinander gebracht werden. Anders als in den Experimenten zur PNA-vermittelten Vesikel-Vesikel-Fusion, ${ }^{158}$ wurden jedoch für alle drei Kombinationen an PNA-Peptiden Fusionsereignisse in signifikanter Zahl detektiert. Deshalb wurden die Ereignisse quantifiziert und die Histogrammanalyse in Abb. 4.41 zeigt, dass die Fusionswahrscheinlichkeit von der Kombination der eingesetzten PNAPeptide abhängig ist. In den Experimenten wurde jeweils VAMP PNA1 in die porenüberspannenden Membranen eingebaut und die Peptidkomponente im Vesikel variiert. Wie erwartet zeigt die unterschiedliche Kombination von nativen Transmembranregionen und die Paarung der komplementären PNA die höchste Fusionswahrscheinlichkeit (Abb. 4.41). Die Häufigkeit an Fusionsereignissen ist für Vesikel mit Syx PNA3 viel höher als für VAMP PNA1. Die geringste Zahl an Fusionsereignissen findet sich bei Syx PNA1-haltigen Vesikeln. In Untersuchungen von Simonsson et al. wurde die Paarung von komplementären DNA-Einzelsträngen genutzt wurde, um Vesikel mit festkörperunterstützten Membranen zu untersuchen. ${ }^{99}$ Dazu wurden DNA-Einzelstränge mit komplementärer Sequenz von je 12 Basen über Cholesterin-Anker zum einen in Vesikel mit einem Durchmesser von $100 \mathrm{~nm}$ und zum anderen in festkörperunterstützte Membranen eingebaut. Es konnte gezeigt werden, dass 
die Hybridisierung der DNA-Stränge die Fusion der Vesikel mit der planaren Membran in Abhängigkeit der DNA-Konzentration initiiert. In den Experimenten dieser Arbeit scheint jedoch nicht allein die Hybridisierung der komplementären PNA-Stränge von Bedeutung für die Initiation von Fusionsereignissen zu sein. Auch der Einbau identischer PNA-Sequenzen in Vesikel und porenüberspannender Membran führt zu erfolgreicher Lipidvermischung, obwohl in diesem Fall keine komplementäre Paarung der PNAStränge stattfindet und sich somit die beiden Lipiddoppelschichten nicht über die molekulare Erkennung annähern. Dennoch kann eventuell eine Destabilisierung der Lipiddoppelschichten dazu führen, dass während der Interaktion von Vesikel und porenüberspannender Membran diese bei der Entstehung von Defektstellen helfen und somit die Reorganisation der Lipide während der Fusion erleichtern. Demnach würde dem Transmembranbereich eine zentrale Rolle bei der Fusion zukommen. Auch andere Untersuchungen mit SNARE-Proteinen zeigen, dass Mutationen und das Entfernen von Aminosäuren aus dem Transmembranbereich von SNARE-Proteinen zu einer starken Verminderung der Fusionsrate führt. Siddiqui et al. argumentierten, dass durch das Fehlen eines Teil des Transmembranankers die Verankerung und somit der gesamte SNARE-Komplex destabilisiert werden. ${ }^{159}$ McNew et al. ersetzten den Transmembrananker durch Phospholipide über die der wasserlösliche Rest der SNAREProteine VAMP und Syntaxin an die Lipidmembran gebunden wurden. ${ }^{160}$ In einem Vesikel-Vesikel-Assay wurde beobachtet, dass bereits bei Ersetzen der Transmembranregion nur einer Spezies eine starke Verminderung der Fusionsrate auftritt. Die Tatsache, dass die Vesikel aggregierten und nicht, führte McNew et al. zu der Schlussfolgerung, dass die Ausbildung des SNARE-Komplexes dazu führt, dass die Membranen zunächst auf Grund der molekularen Erkennung aneinander binden. Dabei entsteht gleichzeitig ein Zug an den Transmembranankern, der dazu führen kann, dass Lipide sich reorganisieren und so der Fusionsprozess eingeleitet wird. Diese Wirkung bleibt bei Fehlen eines Transmembranankers aus. Langosch et al. gingen noch einen Schritt weiter und bauten ausschließlich die Transmembranregionen von Synaptobrevin und Syntaxin in Vesikel ein und beobachteten ebenfalls effektive Vesikel-VesikelFusion. ${ }^{135}$ In Martini-Coarse-Grain-Simulationen konnten Risselada et al. kürzlich weitere Belege dafür liefern, dass die Ausbildung des SNARE-Komplex hauptsächlich für das Näherbringen der Membranen verantwortlich ist. Während an der Ausbildung der Hemifusion und den darauffolgenden Schritten im Fusionsmechanimus ausschließlich die 
Transmembrananker der SNARE-Proteine mitwirken. ${ }^{161}$ Die zwei letztgenannten Studien sind besonders interessant im Kontext dieser Arbeit. In den oben beschriebenen Analysen mit modifizierten Transmembranankern wird der Kontakt jeweils noch durch das Vorhandensein der SNARE-Motive mediiert. Im Fall der PNA-Peptide muss jedoch davon ausgegangen werden, dass diese attraktiven Wechselwirkungen zwischen den Membranen fehlen, da die identischen PNA-Stränge nicht spezifisch miteinander interagieren sollten. Demnach scheint in diesem speziellen Fall das Näherbringen der zwei Lipiddoppelschichten keinen signifikanten Einfluss auf das Fusionsverhalten zu haben, sondern maßgeblich die Destabilisierung der Membran. Dieser Befund ist ähnlich $\mathrm{zu}$ den Ergebnissen von Langosch et al., in denen ebenfalls in Abwesenheit von Erkennungseinheiten die Fusion allein durch den Einbau der SNARE-Membrananker eingeleitet wurde. ${ }^{135}$

Für den Einfluss des Transmembranankers auf die Fusionswahrscheinlichkeit spricht auch, dass der Einbau von Syx PNA 3 in die Vesikelmembran ausreichend ist, um diese mit peptidfreien porenüberspannenden Membranen zu fusionieren. Der Grund hierfür kann wahrscheinlich in der Vorspannung dieser Lipiddoppelschichten gesucht werden, deren Einfluss in Kapitel 5.5 ausführlich diskutiert wird. Ähnlich wie in den Experimenten zur $\mathrm{Ca}^{2+}$-vermittelten Fusion basierend auf micro-BLMs scheint somit die Destabilisierung des Vesikels, in diesem Fall durch den Einbau der SNARETransmembraneinheit, auszureichen, um Fusionsereignisse $\mathrm{zu}$ initiieren. Diese Vermutung kann durch Experimente, in denen die Lipiddoppelschichten durch den Einbau von Lysophosphatidylcholin (LPC) stabilisiert wurden, gestützt werden. So wurde in den Experimenten mit LPC-haltigen Membranen keine Fusion detektiert. Auf Grund der Versuchsdurchführung befindet sich LPC nicht nur in der Vesikelmembran, so dass es auch in die porenüberspannenden Membranen eingebaut sein kann. Die Beobachtungen, dass LPC $(c=0.14 \mu \mathrm{g} / \mathrm{ml})$ in PE-haltigen freitragenden Membranen die Spannung auf fast die Hälfte des Wertes herabsetzt, zeigt, wie groß der Einfluss dieses Lipids auf die Membranspannung ist. ${ }^{10}$ Eine alleinige Modifikation der porenüberspannenden Membranen durch LPC könnte weiteren Aufschluss über den Einfluss der Membranspannung der auf die Fusion geben.

Die Frage, die sich in Bezug auf die Destabilisierung der Vesikel durch den Transmembrananker und das daraus resultierende fusogene Verhalten stellt, ist, warum der Einfluss der Vesikeldestabilisierung in den Experimenten zur Vesikel-Vesikel-Fusion 
nicht beobachtet werden konnte. ${ }^{158}$ Es könnte postuliert werden, dass die SNARETransmembraneinheiten sowohl die Vesikel-Vesikel-Fusion als auch die von Vesikeln mit porenüberspannenden Membranen in gleichem Maße beeinflussen. In diesem Kontext muss jedoch berücksichtigt werden, dass der Vesikel-Fusionsassay diverse Unterschiede zu dem in dieser Arbeit vorgestellten System aufweist. Bei dem VesikelFusionsassay handelt es sich um eine Ensemble-Messung und liefert so Mittelwerte über die gesamte Vesikelpopulation. Im Gegensatz dazu werden in der Untersuchung der Interaktion von Vesikeln mit planaren Membranen einzelne Ereignisse erfasst, so dass die Sensitivität gegenüber der Ensemble-Messung erhöht sein sollte. Außerdem kann ein Annähern der Vesikel in Lösung dadurch erschwert sein, dass der Kontakt vor der Fusion zwischen zwei Vesikeln im Fall identischer PNA-Sequenzen und damit fehlender molekularer Erkennung nicht vermittelt wird. Die Notwendigkeit der molekularen Erkennung und der damit verbundenen Annäherung der Lipiddoppelschichten könnte im Fall der Messungen mit porenüberspannenden Membranen geringer ausfallen, da die Vesikel direkt auf die Oberfläche des porösen Substrats pipettiert werden. Auf Grund der Planarität der porenüberspannenden Membran kann sich dort sofort eine größere Kontaktfläche als im Fall von zwei Vesikeln zwischen den zwei zu fusionierenden Lipiddoppelschichten ausbilden. Dadurch könnte die Fusion begünstigt werden. Des Weiteren besteht auch die Möglichkeit, dass die Destabilisierung des Vesikels durch die SNARE-Transmembranregion zu einer geringeren Fusogenität führt als die, die in den porenüberspannenden Membranen durch die vorhandene Vorspannung erreicht wird. Dann könnte allein der Einbau der PNA-Peptide nicht ausreichen, um zwei Vesikel miteinander zu fusionieren. Dagegen spricht allerdings die Beobachtung von Langosch et $a l$., dass der Einbau der reinen SNARE-Membrananker auch zur Fusion von kleinen unilamellaren Vesikeln (small unilamellar vesicles, SUVs) untereinander führt. Im Gegensatz dazu kann in den durchgeführten Experimenten zur PNA-vermittelten Vesikelfusion jedoch eine sterische Hinderung durch die PNA-Einzelstränge, die auf der Außenseite der Vesikelmembran lokalisiert sind, nicht ausgeschlossen werden, so dass dadurch die Annäherung im Fall identischer PNA-Konstrukte, in dem keine molekulare Erkennung gegeben ist, in den benachbarten Membranen erschwert sein könnte.

In den Experimenten zur PNA-Peptid-vermittelten Fusion von LUVs mit porenüberspannenden Membranen, konnte belegt werden, dass durch diese Art der molekularen Erkennung Fusionsereignisse eingeleitet werden können. Die Studien 
zeigten auch, dass eine Destabilisierung der Vesikelmembran, höchstwahrscheinlich durch den Einbau der Transmembranregionen der SNARE-Proteine ausreicht, um die Vermischung der zwei Lipiddoppelschichten zu initiieren. Dabei hat wahrscheinlich die Spannung der porenüberspannenden Membran einen signifikanten Einfluss. Auf diesen Sachverhalt soll jedoch im folgenden Kapitel näher eingegangen werden.

\subsection{Betrachtung der unterschiedlichen Fusionssysteme im Kontext der Membranspannungen}

In diesem Kapitel sollen die unterschiedlichen untersuchten Fusionssysteme $\left(\mathrm{Ca}^{2+}\right.$, $\mathrm{H}_{6}$ WGC und PNA-Peptide) noch einmal vor dem Hintergrund der Membranspannung im verwendeten Modellmembransystem diskutiert werden. Die eingesetzten porenüberspannenden Membranen weisen eine laterale Spannung auf, wie von Mey et al. mit Hilfe von Indentationsexperimenten nachgewiesen wurde. ${ }^{95}$ Die Spannung in microBLMs aus DPhPC auf einem Substrat mit einem Porendurchmesser von $1.2 \mu \mathrm{m}$ und einer Oktanthiolfunktionalisierung beträgt $\sigma=18 \mathrm{mN} / \mathrm{m}$, der Wert für lösungsmittelfreie porenüberspannende Membranen auf dem gleichen Substrat liegt bei $\sigma=26 \mathrm{mN} / \mathrm{m}$. In Tabelle 2 sind die Lateralspannungen verschiedener Modellmembransysteme zusammengefasst. Der Vergleich macht deutlich, dass die im System der porenüberspannenden Membranen herrschende Spannung erhöht gegenüber der von BLMs ist und generell wesentlich größer als in anderen Modellmembransystemen wie Vesikeln oder festkörperunterstützten Membranen ist, die als spannungsfrei gelten. 
Tab. 2 Übersicht über laterale Spannungen in verschiedenen Modellmembransystemen

\begin{tabular}{|c|c|}
\hline Membransystem & Laterale Spannung $\sigma[\mathrm{mN} / \mathrm{m}]$ \\
\hline micro-BLMs $1.2 \mu$ m Poren ${ }^{95}$ & 18 \\
\hline $\begin{array}{l}\text { Porenüberspannende Membran durch } \\
\text { Spreiten von GUVs, } 1.2 \mu \mathrm{m} \text { Poren }^{95}\end{array}$ & 26 \\
\hline GUVs $162-164$ & $\sim 0.1$ \\
\hline BLM (Dekan) ${ }^{126}$ & 3.8 \\
\hline BLM (Squalen) ${ }^{126}$ & 1.5 \\
\hline
\end{tabular}

Diese Vorspannung sollte berücksichtigt werden, wenn Fusionsprozesse beobachtet werden. Die Lipidreorganisation stellt einen energieaufwendigen Prozess dar. Es ist denkbar, dass die Umwandlung einer stark gespannten Membran zu einer energetisch begünstigten weniger gespannten Struktur zur Senkung der Gesamtenergie im System führt. Eine mögliche Erklärung wie diese Senkung in den porenüberspannenden Membran realisiert werden könnte, soll im Folgenden erläutert werden. Es wird angenommen, dass eine porenüberspannende Membran die in Abb. 5.5 gezeigte Anordnung aufweist. Dabei ziehen sich zunächst die Hybriddoppelschicht aus dem zur Funktionalisierung verwendeten Thiolipid und dem Membranlipid entlang der Goldschicht in die Pore hinein. Am Ende der Goldschicht verbiegt sich die Membran nach diesem Modell dann in der Art, dass sie horizontal in der Pore verläuft und am anderen Ende wieder senkrecht entlang der Porenwand verläuft. Der Grund für diese Anordnung ist in der Wechselwirkung zwischen den hydrophoben Teilen der chemisorbierten Thiollipide und der Membranlipide zu suchen. Durch die Adhäsion der oberen Lipidmonoschicht an die funktionalisierte Goldoberfläche ist der Kontakt an die Substratoberfläche favorisiert. Dementsprechend versuchen möglichst viele Lipide den Kontakt zu der funktionalisierten Goldoberfläche zu gewinnen und die Membran zieht sich in die Pore hinein. 
A

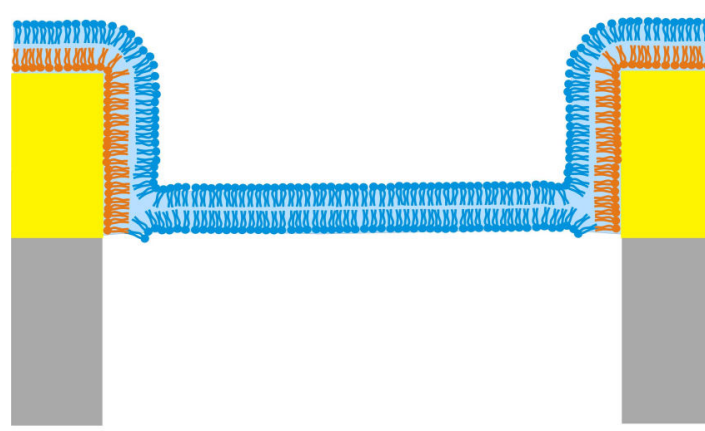

$\propto$

$\mathrm{DPhPC} / \mathrm{POPE}$

$\approx$ DPPTE

Gold

B

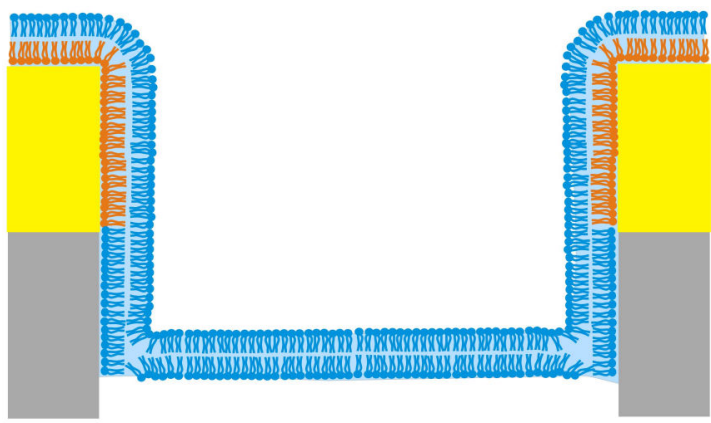

Silizium

Abb. 5.5 Schematische Darstellung zur Veranschaulichung der möglichen Membrangeometrie von porenüberspannenden Lipiddoppelschichten vor (A) und nach (B) der Fusion von Vesikeln. In A folgt die Membran senkrecht der Funktionalisierung in die Poren hinein und nimmt dann innerhalb der Pore einen waagerechten Verlauf ein. Nach der Fusion (B) bleibt diese Geometrie erhalten, abgesehen davon, dass die Membran zum Teil auch an die unfunktionalisierte Porenwand haftet.

Wird nun zusätzliches Lipidmaterial durch Fusion eines Vesikels eingetragen, so könnten sich die porenüberspannenden Membranen noch tiefer in die Pore hineinziehen - so wie es mit Hilfe von SICM-Experimenten belegt werden konnte (Kapitel 5.3). Da bereits vor der Fusion die funktionalisierte Goldoberfläche vollständig von einer Membran bedeckt wurde, würden die zusätzlich eingebachten Lipide mit der Siliziumnitrid-Oberfläche der Porenwand wechselwirken und an diesen Stellen an die Oberfläche adherieren. Wird nun das Verhältnis zwischen Lipiden, die im Kontakt zum Festkörper stehen in ein Verhältnis $\mathrm{zu}$ den freitragenden Lipiden gesetzt, so ist dieses nach der Fusion größer, weil die gleiche Menge an Lipiden die porenüberspannte Fläche bilden, während sich der Anteil an Lipiden auf dem Festkörper vergrößert hat. Dementsprechend sollte bis zu einem gewissen Grad die Fusion gefördert sein. Ab einem gewissen Punkt stellt sich wahrscheinlich ein Gleichgewichtszustand ein, ab dem weitere Fusion von Vesikeln keinen zusätzlichen Energiegewinn mehr bringt und die Fusion weiterer Vesikel so zum Erliegen kommt. Anderson et al. fanden für die Adhäsionsenergie von DMPC an eine Siliziumdioxidoberfläche einen Wert von $W=0.5-1.0 \mathrm{mN} / \mathrm{m} .{ }^{165}$ Dieser Wert entspricht in etwa auch der Größenordnung für die laterale Spannung, die Mey in Indentationsexperimenten an porenüberspannenden Membran, die auf porösen Substraten präpariert wurden, die zuvor nicht mit Gold und einem Thiolipid oder Alkanthiol funktionalisiert wurden. ${ }^{95}$ Dadurch wird deutlich, dass die Adhäsion der Membran an die 
unfunktionalisierte Porenwand weniger begünstigt ist als die Adhäsion des oberen Lipidmonolage an die hydrophoben Ketten der DPPTE-Funktionalisierung, dennoch sollte ein gewisser Energiegewinn vorhanden sein. Dieser könnte die Fusion fördern. In diesem Zusammenhang wäre es interessant in zukünftigen Studien mit Hilfe von Indentationsexperimenten die laterale Spannung der porenüberspannenden Membranen vor und nach der Fusion zu bestimmen. Dadurch könnte das Postulat gestützt werden, dass durch das Einbringen der Vesikellipide die Spannung der porenüberspannenden Membranen verringert wird.

Sowohl in der $\mathrm{Ca}^{2+}$-vermittelten Fusion von LUVs mit micro-BLMs als auch in den Experimenten zur PNA-Peptid-vermittelten Fusion schien eine Destabilisierung der Vesikelmembran auszureichen, um Fusionsereignisse einzuleiten. Dies legt die Vermutung nahe, dass die porenüberspannende Membran durch ihre Vorspannung an sich schon genügend fusogen ist und dementsprechend kein Einbau eines Fusionspeptids oder Bindung von $\mathrm{Ca}^{2+}$-Ionen nötig ist, um Fusion auszulösen. Dabei ist zu beachten, dass bereits Chanturiya et al. ebenfalls beobachteten, dass eine $\mathrm{Ca}^{2+}$-Abhängigkeit der Fusion nur von der negativen Ladung der Vesikel beeinflusst wird. ${ }^{89}$ In den entsprechenden Experimenten wurde mit BLMs gearbeitet, die eine ähnliche Spannung aufweisen wie micro-BLMs, so dass durch diese Beobachtungen ein weiteres Indiz für die vorgestellte Theorie liefern.

Im $\mathrm{H}_{6}$ WGC-Peptidsystem konnte der Einfluss der Vesikeldestabilisierung nicht überprüft werden, da die Funktionalisierung mit dem Peptid hier lediglich in den porenüberspannenden Membranen stattfand.

Zu der Erkenntnis, wie groß die Rolle der Membranspannung im Fusionsprozess ist, gelangen auch neue Studien zur Untersuchung der Funktion von Synaptotagmin im SNARE-vermittelten Fusionsprozess synaptischer Vesikel. ${ }^{166-168}$ Darin wird postuliert, dass Synaptotagmin-1 durch $\mathrm{Ca}^{2+}$-Komplexierung eine Konformationänderung eingeht, die eine Krümmung der Zielmembran in Richtung des Vesikels hervorruft. Dadurch wird die Membranspannung erhöht. Somit ist die Ausbildung der coiled-coil-Struktur von SNARE-Proteinen zwar ein wichtiger Faktor für die Verküpfung der Membranen, die eigentliche Initiation der Fusion, wird jedoch durch die Verbiegung der Lipidoppelschicht durch Synaptotagmin hervorgerufen. ${ }^{168}$ Insgesamt steht somit die Membrankrümmung und damit ihre laterale Spannung auch in biologischen Systemen 
stark im Fokus. In verschiedenen Beobachtungen spiegelt sich wider, dass diese Membranspannung auch in den in dieser Arbeit durchgeführten Experimenten eine entscheidende Rolle spielt.

Die Spannungen der porenüberspannenden Membranen können durch Veränderung der Goldfunktionalisierung oder durch Auslassen der Funktionalisierung modifiziert werden. Dementsprechend bieten die porenüberspannenden Membranen als Basis für einen in vitro-Fusionsassays neben diversen anderen Vorteilen eine ganz neue Möglichkeit, um den Einfluss der Membranspannung auf den Fusionsprozess zu untersuchen. Studien zu entsprechenden Auswirkungen während der Interaktion von Membranen wurden von Sun et al. bereits mit zwei durch Mikropipetten-Aspiration kontrollierten GUVs mit verschiedenen Spannungen durchgeführt. Allerdings wurden in diesem System Hemifusion und nicht eine volle Fusion analysiert. ${ }^{169}$ Heuvingh et al. untersuchten ebenfalls den Einfluss der Membranspannung auf die DNA-Basenpaarung-vermittelten Fusionseigenschaften von GUVs mittels Mikropipetten-Aspiration. ${ }^{170}$ Eine künstliche Erhöhung der Membranspannung in den GUVs von $0.01 \mathrm{mN} / \mathrm{m}$ auf $0.5 \mathrm{mN} / \mathrm{m}$ zeigte jedoch keinen Anstieg der Fusionswahrscheinlichkeit. Diese Werte liegen allerdings in einem Bereich, der um drei bzw. zwei Größenordnungen kleiner ist als die des porenüberspannenden Membransystems. Bei der Betrachtung von Riesenvesikeln besteht des Weiteren der Nachteil, dass die Geometrien von zwei GUVs nicht die Verhältnisse zwischen einem synaptischen Vesikel und einer dazu fast planaren Synapsenmembran widerspiegeln. Die Fusion von Vesikeln mit porenüberspannenden Membranen hingegen geben die Krümmungsverhältnisse wesentlich besser wieder.

Weiterhin muss im Zusammenhang von Fusionsvorgängen berücksichtigt werden, dass Neuronen über Aktinfilamente an das Cytoskelett gebunden ist. Durch dieseVerankerungspunkte entstehen per se bereits gewisse laterale Spannungen. Diese liegen im Bereich von $0.02-0.12 \mathrm{mN} / \mathrm{m},{ }^{171,}{ }^{172}$ wobei nicht bekannt ist, ob diese Spannung auch im Bereich der Synapse erzeugt wird und inwieweit die oben beschriebene durch Synaptotagmin hervorgerufene Membrankrümmung eine zusätzliche Rolle spielt. Auf jeden Fall liegen diese Werte in der Größenordnung von Spannungen, die in den Indentationsexperimenten an porenüberspannenden Membranen auf unfunktionalisierten Substraten gefunden wurden. So könnte das vorgestellte Membransystem in naher Zukunft genutzt werden, um die Spannungsverhältnisse zu modulieren und den Einfluss auf die Membranfusion zu analysieren. Auf diese Weise 
können neue Einblicke in die SNARE-vermittelte Fusion mit Hilfe eines Fusionsassays basierend auf porenüberspannenden Membranen gewonnen werden, die in anderen Analysen nicht berücksichtigt werden. 


\section{Zusammenfassung}

Die Fusion von Lipiddoppelschichten spielt eine essentielle Rolle in vielen biologischen Prozessen, weshalb die Aufklärung des genauen Mechanismus im Fokus vieler Forschungsarbeiten steht. Die Arbeiten an Modellmembransystemen haben dabei viel zu dem heutigen Wissensstand über die Membranfusion beigetragen. Dennoch sind einige Aspekte des Fusionsprozesses, wie zum Beispiel die genaue Wirkweise von fusogenen Peptiden und Proteinen, bis heute nicht aufgeklärt. Der Einsatz von porenüberspannenden Membranen als Basis für einen Fusionsassays, dessen Etablierung im Fokus dieser Arbeit stand, soll eine neue Möglichkeit eröffnen Limitierungen bestehender Untersuchungsmethoden zu überwinden.

Die Untersuchungen zur Lipidvermischung zeigen, dass porenüberspannende Membranen geeignet sind, um Fusionsereignisse zu analysieren. Zunächst wurde die $\mathrm{Ca}^{2+}$-vermittelte Fusion von Vesikeln mit micro-black lipid membranes (micro-BLMs) untersucht. Der Einsatz von großen unilamellaren Vesikeln mit einem mittleren Durchmesser von $600 \mathrm{~nm}$ ermöglichte die Beobachtung von Einzelfusionsereignissen. Die porenüberspannende und die Vesikelmembran wurden mit den fluoreszenzmarkierten Lipiden Oregon Green DHPE und Texas Red DHPE dotiert. Auf diese Weise wurde die Lipidvermischung während der Fusion durch die Löschung der Oregon Green-Fluoreszenz, hervorgerufen durch den abstandsabhängigen Förster Resonanz Energie Transfer, indiziert. Der Einbau der Vesikellipide in die porenüberspannende Lipiddoppelschicht wurde zusätzlich durch die Diffusion der Texas Red DHPE-Moleküle in der planaren Membran bestätigt. Aus den Daten konnte für die Verteilung des roten Texas Red-Farbstoffs in micro-BLMs ein Diffusionskoeffizient von $D=(9 \pm 5) \mu \mathrm{m}^{2} / \mathrm{s}$ bestimmt werden. Dieser Wert stimmt gut mit der Diffusionskonstante überein, die in früheren fluorescence recovery after photobleaching-Analysen ermittelt wurde. $^{93}$

Durch die Fusion von Vesikeln wird zusätzliches Lipidmaterial in die porenüberspannenden Membranen eingebaut. Um zu untersuchen, ob und inwieweit dadurch die Membrantopologie im System verändert wird, wurden micro-BLMs vor und nach der Fusion von Vesikeln mit Hilfe der Rasterionenleitfähigkeitsmikroskopie abgebildet. Eine Analyse der erhaltenen Höhenprofile ließ den Schluss zu, dass das 
Einbringen von zusätzlichen Lipiden dazu führt, dass die porenüberspannenden Membranen sich tiefer in die Pore hineinwölben. Die chemisorbierten Thiolipide, die zur Funktionalisierung der goldbedeckten Porenstege eingesetzt wurden, scheinen eine Diffusionsbarriere für die untere Monolage der porenüberspannenden Lipiddoppelschichten $\mathrm{zu}$ bilden. Es wird vermutet, dass aus diesem Grund die durch Fusion eingebrachten Lipide sich nicht durch Diffusion über die gesamte Probe verteilen, sondern in der Membran innerhalb einer Pore verbleiben, so dass sich die porenüberspannende Membran tiefer in die Pore zieht.

Neben der $\mathrm{Ca}^{2+}$-vermittelten Fusion von Vesikeln mit micro-BLMs wurde der Einfluss der molekularen Erkennung auf die Interaktion von großen unilamellaren Vesikeln mit lösungsmittelfreien porenüberspannenden Membranen untersucht. Die Vermittlung des Membrankontakts durch Bindung des Nonapeptid $\mathrm{H}_{6} \mathrm{WGC}$ an Kopfgruppenfunktionalisierte Lipide führte vorwiegend $\mathrm{zu}$ der Anbindung der Vesikel an die porenüberspannenden Membranen. Im Gegensatz dazu wurde durch die Insertion von PNA-Einzelsträngen gekoppelt an den nativen SNARE-Transmembrananker hauptsächlich die Fusion von Vesikeln mit porenüberspannenden Membranen mediiert. Dabei spielt die Sequenz der PNA-Einzelstränge, identisch in beiden Membranen oder komplementär zueinander in Vesikel und porenüberspannender Membran, eine untergeordnete Rolle für die Initiation des Fusionsprozesses. Ein Vergleich mit bereits bekannten Studien zur SNARE-vermittelten Fusion legt den Schluss nahe, dass der Einbau eines Transmembranankers und die damit verbundene Störung der Membranintegrität entscheidend für die Initiation der Fusion sind.

Zusätzlich wurde gezeigt, dass eine Destabilisierung des Vesikels entweder durch asymmetrische Bindung von $\mathrm{Ca}^{2+}$-Ionen oder durch Einbau der PNA-Peptide ausreichend ist, um Fusionsereignisse einzuleiten. So wird vermutet, dass die Spannung in den porenüberspannenden Membranen ihre Fusogenität so stark erhöht, dass keine zusätzliche Wechselwirkung mit einem Fusogen oder eine Destabilisierung notwendig ist, um die Membranvermischung zu initiieren. 
- 151 - 


\section{Appendix}

Geometrische Überlegungen zur Bestimmung der Eindringtiefe des Laserlichts in die Poren der verwendeten porösen Substrate:

Die axiale Auflösung eines Konfokalmikroskops ist gegeben durch:

$$
d_{a x}=\frac{1.4 \lambda n}{N A^{2}}
$$

Darin steht $\lambda$ für die Wellenlänge des verwendeten Laserlichts. $n$ ist der Brechungsindex des Mediums, welches das Objektiv umgibt, und $N A$ ist die Numerische Apertur des Objektivs. Bei dem in dieser Arbeit verwendeten Objektiv betrug die Numerische Apertur $N A=1.0$. Der Brechungsindex von Wasser liegt bei $\mathrm{n}=1.33$. Somit kann bei der zur Anregung verwendeten Wellenlänge von $\lambda=488 \mathrm{~nm}$ maximal eine axiale Auflösung von $d_{\mathrm{ax}}=908 \mathrm{~nm}$ erreicht werden. Daraus resultiert, dass die Eindringtiefe des Laserlichts in die Pore größer als $908 \mathrm{~nm}$ sein muss, damit der wasserlösliche Farbstoff in den Poren unterhalb einer porenüberspannenden Membran von dieser optisch abgetrennt detektiert werden kann.

Um die theoretische Eindringtiefe des Lichtkegels in die Porenöffnung zu bestimmen, wurden folgende Berechnungen durchgeführt. Aus der Numerischen Apertur NA kann der Öffnungswinkel, mit dem das Licht auf die Probe fokussiert wird, berechnet werden:

$$
\sin \alpha=\frac{N A}{n}
$$

Daraus wird für den Öffnungswinkel des verwendeten Objektivs ein Wert von $\alpha=48.7^{\circ}$ errechnet. 
Der Lichtkegel des fokussierten Laserlichts dringt in die Pore mit einem Durchmesser $d$ bis zu einer Höhe $h$ ein:

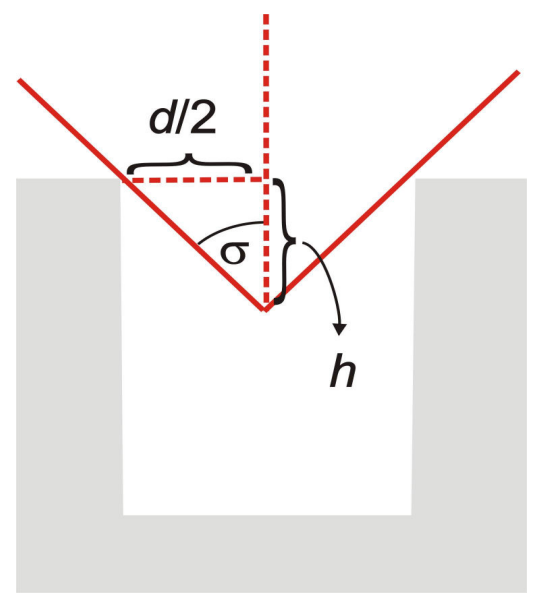

Aus der Tangensbeziehung von Öffnungswinkel, Höhe und halbem Durchmesser der Pore, kann der Porendurchmesser berechnet werden, der benötigt wird, damit das Laserlicht bis zu einer Tiefe von $h>908 \mathrm{~nm}$ in die Pore eindringen kann.

$$
\tan \alpha=\frac{d / 2}{h}
$$

Bei einer numerischen Apertur von NA $=1.0$ und dem entsprechenden Öffnungswinkel von $\sigma=48.7^{\circ}$ wird so ein Wert für den Porendurchmesser von $d>2 \mu \mathrm{m}$ erhalten. 


\section{Literatur}

1. Luckey, M., Membrane Structural Biology. 1. ed.; Cambridge University Press: New York, 2008.

2. Kozlov, M. M.; Markin, V. S., [Possible mechanism of membrane fusion]. Biofizika 1983, 28, (2), 242-7.

3. Chernomordik, L. V.; Melikyan, G. B.; Chizmadzhev, Y. A., Biomembrane fusion: a new concept derived from model studies using two interacting planar lipid bilayers. Biochim Biophys Acta 1987, 906, (3), 309-52.

4. Zimmerberg, J.; Chernomordik, L. V., Membrane fusion. Adv Drug Deliv Rev 1999, 38, (3), 197-205.

5. Chernomordik, L. V.; Zimmerberg, J.; Kozlov, M. M., Membranes of the world unite! J Cell Biol 2006, 175, (2), 201-7.

6. Rand, R. P.; Parsegian, V. A., Hydration forces between phospholipid bilayers. Biochim Biophys Acta 1989, 988, 351-376.

7. Israelachvili, J. N.; Mitchell, D. J., A model for the packing of lipids in bilayer membranes. Biochim Biophys Acta 1975, 389, (1), 13-19.

8. Chanturiya, A.; Leikina, E.; Zimmerberg, J.; Chernomordik, L. V., Short-chain alcohols promote an early stage of membrane hemifusion. Biophys $J$ 1999, 77, (4), 2035-45.

9. Basanez, G.; Goni, F. M.; Alonso, A., Effect of single chain lipids on phospholipase C-promoted vesicle fusion. A test for the stalk hypothesis of membrane fusion. Biochemistry 1998, 37, (11), 3901-8.

10. Chernomordik, L. V.; Kozlov, M. M.; Melikyan, G. B.; Abidor, I. G.; Markin, V. S.; Chizmadzhev, Y. A., The shape of lipid molecules and monolayer membrane fusion. Biochim Biophys Acta 1985, 812, 643 - 655.

11. Chernomordik, L.; Chanturiya, A.; Green, J.; Zimmerberg, J., The hemifusion intermediate and its conversion to complete fusion: regulation by membrane composition. Biophys J 1995, 69, (3), 922-9.

12. Blumenthal, R.; Clague, M. J.; Durell, S. R.; Epand, R. M., Membrane fusion. Chem Rev 2003, 103, (1), 53-69. 
13. Martens, S.; McMahon, H. T., Mechanisms of membrane fusion: disparate players and common principles. Nat Rev Mol Cell Biol 2008, 9, 543 - 556.

14. Jahn, R.; Scheller, R. H., SNAREs--engines for membrane fusion. Nat Rev Mol Cell Biol 2006, 7, (9), 631-43.

15. Jahn, R.; Lang, T.; Südhof, T. C., Membrane fusion. Cell 2003, 112, (4), 519-33.

16. Lin, R. C.; Scheller, R. H., Mechanisms of synaptic vesicle exocytosis. Annu Rev Cell Dev Biol 2000, 16, 19-49.

17. Bonifacino, J. S.; Glick, B. S., The mechanisms of vesicle budding and fusion. Cell 2004, 116, (2), 153-66.

18. Sutton, R. B.; Fasshauer, D.; Jahn, R.; Brunger, A. T., Crystal structure of a SNARE complex involved in synaptic exocytosis at 2.4 A resolution. Nature 1998, 395, (6700), 347-53.

19. Ungermann, C.; Langosch, D., Functions of SNAREs in intracellular membrane fusion and lipid bilayer mixing. J Cell Sci 2005, 118, (Pt 17), 3819-28.

20. Lin, R. C.; Scheller, R. H., Structural organization of the synaptic exocytosis core complex. Neuron 1997, 19, (5), 1087-94.

21. Pobbati, A. V.; Stein, A.; Fasshauer, D., N- to C-terminal SNARE complex assembly promotes rapid membrane fusion. Science 2006, 313, (5787), 673-6.

22. Jesorka, A.; Orwar, O., Liposomes: technologies and analytical applications. Annu Rev Anal Chem (Palo Alto Calif) 2008, 1, 801-32.

23. Wilschut, J.; Hoekstra, D., Membrane fusion: lipid vesicles as a model system. Chem Phys Lipids 1986, 40, (2-4), 145-66.

24. Eastman, S. J.; Hope, M. J.; Wong, K. F.; Cullis, P. R., Influence of phospholipid asymmetry on fusion between large unilamellar vesicles. Biochemistry 1992, 31, (17), 4262-8.

25. Lentz, B. R.; McIntyre, G. F.; Parks, D. J.; Yates, J. C.; Massenburg, D., Bilayer curvature and certain amphipaths promote poly(ethylene glycol)-induced fusion of dipalmitoylphosphatidylcholine unilamellar vesicles. Biochemistry 1992, 31, (10), 2643-53.

26. Cevc, G.; Richardsen, H., Lipid vesicles and membrane fusion. Adv Drug Deliv Rev 1999, 38, (3), 207-232. 
27. Malinin, V. S.; Frederik, P.; Lentz, B. R., Osmotic and curvature stress affect PEGinduced fusion of lipid vesicles but not mixing of their lipids. Biophys $J$ 2002, 82, (4), 2090-100.

28. Shillcock, J. C.; Lipowsky, R., Tension-induced fusion of bilayer membranes and vesicles. Nat Mater 2005, 4, (3), 225-8.

29. Duzgunes, N.; Allen, T. M.; Fedor, J.; Papahadjopoulos, D., Lipid mixing during membrane aggregation and fusion: why fusion assays disagree. Biochemistry 1987, $26,(25), 8435-42$.

30. Hoeckstra, D.; deBoer, T.; Klappe, K.; Wilschut, J., Fluorescence Method for Measuring the Kinetics of fusion between Biological Membranes. Biochemistry 1984, 23, 5675 - 5681 .

31. Pantazatos, D. P.; MacDonald, R. C., Directly observed membrane fusion between oppositely charged phospholipid bilayers. J Membr Biol 1999, 170, (1), 27-38.

32. Garcia, R. A.; Pantazatos, S. P.; Pantazatos, D. P.; MacDonald, R. C., Cholesterol stabilizes hemifused phospholipid bilayer vesicles. Biochim Biophys Acta 2001, 1511, (2), 264-70.

33. Cypionka, A.; Stein, A.; Hernandez, J. M.; Hippchen, H.; Jahn, R.; Walla, P. J., Discrimination between docking and fusion of liposomes reconstituted with neuronal SNARE-proteins using FCS. Proc Natl Acad Sci U S A 2009, 106, (44), 18575-80.

34. Yoon, T. Y.; Okumus, B.; Zhang, F.; Shin, Y. K.; Ha, T., Multiple intermediates in SNARE-induced membrane fusion. Proc Natl Acad Sci U S A 2006, 103, (52), 19731-6.

35. Yoon, T. Y.; Lu, X.; Diao, J.; Lee, S. M.; Ha, T.; Shin, Y. K., Complexin and $\mathrm{Ca}^{2+}$ stimulate SNARE-mediated membrane fusion. Nat Struct Mol Biol 2008, 15, (7), 707-13.

36. Smith, E. A.; Weisshaar, J. C., Docking, Not Fusion, as the Rate-Limiting Step in a SNARE-Driven Vesicle Fusion Assay. Biophys J 100, (9), 2141-50.

37. Christensen, S. M.; Mortensen, M. W.; Stamou, D. G., Single vesicle assaying of SNARE-synaptotagmin-driven fusion reveals fast and slow modes of both docking and fusion and intrasample heterogeneity. Biophys $J$ 100, (4), 957-67.

38. Fix, M.; Melia, T. J.; Jaiswal, J. K.; Rappoport, J. Z.; You, D.; Sollner, T. H.; Rothman, J. E.; Simon, S. M., Imaging single membrane fusion events mediated by SNARE proteins. Proc Natl Acad Sci U S A 2004, 101, (19), 7311-6. 
39. Domanska, M. K.; Kiessling, V.; Stein, A.; Fasshauer, D.; Tamm, L. K., Single vesicle millisecond fusion kinetics reveals number of SNARE complexes optimal for fast SNARE-mediated membrane fusion. J Biol Chem 2009, 284, (46), 3215866.

40. Bowen, M. E.; Weninger, K.; Brunger, A. T.; Chu, S., Single molecule observation of liposome-bilayer fusion thermally induced by soluble $\mathrm{N}$-ethyl maleimide sensitive-factor attachment protein receptors (SNAREs). Biophys $J$ 2004, 87, (5), 3569-84.

41. Domanska, M. K.; Kiessling, V.; Tamm, L. K., Docking and fast fusion of synaptobrevin vesicles depends on the lipid compositions of the vesicle and the acceptor SNARE complex-containing target membrane. Biophys J 99, (9), 2936-46.

42. Groves, J. T.; Parthasarathy, R.; Forstner, M. B., Fluorescence imaging of membrane dynamics. Annu Rev Biomed Eng 2008, 10, 311-38.

43. Wang, T.; Smith, E. A.; Chapman, E. R.; Weisshaar, J. C., Lipid mixing and content release in single-vesicle, SNARE-driven fusion assay with 1-5 ms resolution. Biophys $J$ 2009, 96, (10), 4122-31.

44. Wagner, M. L.; Tamm, L. K., Tethered polymer-supported planar lipid bilayers for reconstitution of integral membrane proteins: silane-polyethyleneglycol-lipid as a cushion and covalent linker. Biophys J 2000, 79, (3), 1400-14.

45. Wagner, M. L.; Tamm, L. K., Reconstituted syntaxin1a/SNAP25 interacts with negatively charged lipids as measured by lateral diffusion in planar supported bilayers. Biophys J 2001, 81, (1), 266-75.

46. Müller, P.; Rudin, D. O.; Tien, H. T.; Wescott, W. C., Methods for the formation of single bimolecular lipid membranes in aqueous solution. J Phys Chem 1963, 67, (534- 535).

47. Montal, M.; Mueller, P., Formation of bimolecular membranes from lipid monolayers and a study of their electrical properties. Proc Natl Acad Sci U S A 1972, 69, (12), 3561-6.

48. Chanturiya, A.; Chernomordik, L. V.; Zimmerberg, J., Flickering fusion pores comparable with initial exocytotic pores occur in protein-free phospholipid bilayers. Proc Natl Acad Sci U S A 1997, 94, (26), 14423-8.

49. Anzai, K.; Masumi, M.; Kawasaki, K.; Kirino, Y., Frequent fusion of liposomes to a positively charged planar bilayer without calcium ions. J Biochem 1993, 114, (4), 487-91. 
50. Woodbury, D. J.; Miller, C., Nystatin-induced liposome fusion. A versatile approach to ion channel reconstitution into planar bilayers. Biophys $J \mathbf{1 9 9 0}, 58$, (4), 833-9.

51. Cohen, F. S.; Niles, W. D.; Akabas, M. H., Fusion of phospholipid vesicles with a planar membrane depends on the membrane permeability of the solute used to create the osmotic pressure. J Gen Physiol 1989, 93, (2), 201-10.

52. Römer, W., Impedance analysis and single ion channel recordings on poresuspending lipid bilayers based on highly ordered pore arrays. Dissertation 2004.

53. Römer, W.; Steinem, C., Impedance analysis and single-channel recordings on nano-black lipid membranes based on porous alumina. Biophys $J$ 2004, 86, (2), 955-65.

54. Florin, E. L.; Gaub, H. E., Painted supported lipid membranes. Biophys J 1993, 64, (2), 375-83.

55. Müller, P.; Rudin, D. O.; Tien, H. T.; Wescott, W. C., Reconstitution of cell membrane structure in vitro and its transformation into an excitable system. Nature 1962, 194, (979 - 980).

56. Schmitt, E. K.; Steinem, C., Electrically insulating pore-suspending membranes on highly ordered porous alumina obtained from vesicle spreading. Soft Matter 2008, $4,250-253$.

57. Kepplinger, C.; Höfer, I.; Steinem, C., Impedance analysis of valinomycin activity in nano-BLMs. Chem Phys Lipids 2009, 160, (2), 109-13.

58. Weiskopf, D.; Schmitt, E. K.; Kluhr, M. H.; Dertinger, S. K.; Steinem, C., MicroBLMs on highly ordered porous silicon substrates: rupture process and lateral mobility. Langmuir 2007, 23, (18), 9134-9.

59. Schmitt, E. K.; Vrouenraets, M.; Steinem, C., Channel activity of OmpF monitored in nano-BLMs. Biophys $J$ 2006, 91, (6), 2163-71.

60. Gaßmann, O.; Kreir, M.; Ambrosi, C.; Pranskevich, J. N.; Oshima, A.; Röhling, C.; Sosinsky, G.; Fertig, N.; Steinem, C., The M34A mutant of Connexin26 reveals active conductance states in pore-suspending membranes. J Struct Biol 2009, 168, $168-176$.

61. Schmitt, E. K.; Weichbrodt, C.; Steinem, C., Impedance analysis of gramicidin D in pore-suspending membranes. Soft Matter 2009, 5, 3347-3353.

62. Pilz, C. S.; Steinem, C., Modulation of the conductance of a 2,2'-bipyridinefunctionalized peptidic ion channel by Ni2+. Eur Biophys $J$ 2008, 37, (6), 1065-71. 
63. Stengel, G.; Simonsson, L.; Campbell, R. A.; Hook, F., Determinants for membrane fusion induced by cholesterol-modified DNA zippers. J Phys Chem B 2008, 112, (28), 8264-74.

64. Chan, Y. H.; van Lengerich, B.; Boxer, S. G., Lipid-anchored DNA mediates vesicle fusion as observed by lipid and content mixing. Biointerphases 2008, 3, (2), FA17.

65. Robson Marsden, H.; Elbers, N. A.; Bomans, P. H.; Sommerdijk, N. A.; Kros, A., A reduced SNARE model for membrane fusion. Angew Chem Int Ed Engl 2009, $48,(13), 2330-3$.

66. Schuy, S.; Treutlein, B.; Pietuch, A.; Janshoff, A., In situ synthesis of lipopeptides as versatile receptors for the specific binding of nanoparticles and liposomes to solid-supported membranes. Small 2008, 4, (7), 970-81.

67. Lorenz, B.; Keller, R.; Sunnick, E.; Geil, B.; Janshoff, A., Colloidal Probe Microscopy of Membrane-Membrane Interactions: from Ligand-Receptor Recognition to Fusion Events. Biophys Chem 2010, 150, (1-3), 54 - 63.

68. Nielsen, P. E.; Haaima, G., Peptide nucleic acid (PNA). A DNA mimic with a pseudopeptide backbone. Chem Soc Reb 1997, 26, 73 - 78.

69. Lakowicz, J. R., Principles of Fluorescence Spectroscopy. Plenum Press: New York, 1983.

70. Wedler, G., Lehrbuch der Physikalischen Chemie. Wiley-VCH: Weinheim, 1997; Vol. 4. Auflage.

71. Grabriel, O., Vibronische Übergänge zur Veranschaulichung des Franck-CondonPrinzips. $\quad$ http://commons.wikimedia.org/wiki/File:Franck-Condon-Prinzip.svg 2007.

72. Abbe, E., Beiträge zur Theorie des Mikroskops und der mikroskopischen Wahrnehmung. Archiv für Mikroskopische Anatomie 1873, 9, (1), 413-418.

73. Minsky, M., Memoir on inventing the confocal scanning microscope. Scanning 1988, $10,128-138$.

74. Lee, J.; Lentz, B. R., Evolution of lipidic structures during model membrane fusion and the relation of this process to cell membrane fusion. Biochemistry 1997, 36, (21), 6251-9.

75. Kreye, S.; Malsam, J.; Sollner, T. H., In vitro assays to measure SNARE-mediated vesicle fusion. Methods Mol Biol 2008, 440, 37-50. 
76. The pH-dependent absorption spectra of 8-hydroxypyrene-1,3,6-trisulfonic acid (HPTS). http://www.invitrogen.com/site/us/en/home/References/Molecular-ProbesThe-Handbook/pH-Indicators/Probes-Useful-at-Near-Neutral-pH.html 2011.

77. Förster, T., Zwischenmolekulare Energiewanderung und Fluoreszenz. Annalen Physik 1948, 2, 55 - 75.

78. Keller, R., Aggregation und Fusion His-Tag-funktionalisierter Liposomen mittels nicht-kovalenter molekularer Erkennung Diplomarbeit 2008.

79. Hansma, P. K.; Drake, B.; Marti, O.; Gould, S. A.; Prater, C. B., The scanning ionconductance microscope. Science 1989, 243, (4891), 641-3.

80. Nitz, H.; Kamp, J.; Fuchs, H., A Combined Scanning Ion-Conductance and ShearForce Microscope. Probe Microscopy 1997, 1, 187-200.

81. Novak, P.; Li, C.; Shevchuk, A. I.; Stepanyan, R.; Caldwell, M.; Hughes, S.; Smart, T. G.; Gorelik, J.; Ostanin, V. P.; Lab, M. J.; Moss, G. W.; Frolenkov, G. I.; Klenerman, D.; Korchev, Y. E., Nanoscale live-cell imaging using hopping probe ion conductance microscopy. Nat Methods 2009, 6, (4), 279-81.

82. Elliott, J. T.; Prestwich, G. D., Maleimide-functionalized lipids that anchor polypeptides to lipid bilayers and membranes. Bioconjug Chem 2000, 11, (6), 83241.

83. Angelova, M. I.; Dimitrov, D. S., Liposome electroformation. Faraday Discuss Chem Soc 1986, 81, 303-311.

84. Pott, T.; Bouvrais, H.; Meleard, P., Giant unilamellar vesicle formation under physiologically relevant conditions. Chem Phys Lipids 2008, 154, (2), 115-9.

85. Schmitt, E. K., Hochohmige porenüberspannende Lipidmembranen: Elektrochemische Untersuchungen zur Aktivität von Gramicidin und Bacteriorhodopsin. Dissertation 2009.

86. Matsuura, H.; Sagawa, T., Anomalous conformational behavior of short poly(oxyethylene) chains in water: An FT-IR spectroscopic study J Mol Liq 1995, 65-66, 313-316.

87. Höfer, I.; Steinem, C., A membrane fusion assay based on pore-spanning lipid bilayers. Soft Matter 2011, 7, 1644 - 1647.

88. Redwood, W. R.; Pfeiffer, F. R.; Weisbach, J. A.; Thompson, T. E., Physical properties of bilayer membranes formed from a synthetic saturated phospholipid in n-decane. Biochim Biophys Acta 1971, 233, (1), 1-6. 
89. Chanturiya, A.; Scaria, P.; Woodle, M. C., The role of membrane lateral tension in calcium-induced membrane fusion. J Membr Biol 2000, 176, (1), 67-75.

90. Lakowicz, J. R., Radiative decay engineering: Biophysical and biomedical applications. Analytical Biochemistry 2001, 298, (1), 1-24.

91. Ritchie, G.; Burstein, E., Luminescence of dye molecules adsorbedat a Ag surface. Phys Rev B 1981, 24, (8), 4843 - 4846.

92. Liu, T.; Wang, T.; Chapman, E. R.; Weisshaar, J. C., Productive hemifusion intermediates in fast vesicle fusion driven by neuronal SNAREs. Biophys $J \mathbf{2 0 0 8}$, 94, (4), 1303-14.

93. Weiskopf, D., Stabilität und laterale Mobilität von porenüberspannenden Membranen auf porösen Siliziumsubstraten. Dissertation 2009.

94. Bocker, M.; Muschter, S.; Schmitt, E. K.; Steinem, C.; Schaffer, T. E., Imaging and Patterning of Pore-Suspending Membranes with Scanning Ion Conductance Microscopy. Langmuir 2009.

95. Mey, I.; Stephan, M.; Schmitt, E. K.; Muller, M. M.; Ben Amar, M.; Steinem, C.; Janshoff, A., Local membrane mechanics of pore-spanning bilayers. J Am Chem Soc 2009, 131, (20), 7031-9.

96. Hennesthal, C.; Drexler, J.; Steinem, C., Membrane-suspended nanocompartments based on ordered pores in alumina. Chemphyschem 2002, 3, (10), 885-9.

97. Chan, Y. H.; van Lengerich, B.; Boxer, S. G., Effects of linker sequences on vesicle fusion mediated by lipid-anchored DNA oligonucleotides. Proc Natl Acad Sci U S A 2009, 106, (4), 979-84.

98. Gong, Y.; Ma, M.; Luo, Y.; Bong, D., Functional determinants of a synthetic vesicle fusion system. J Am Chem Soc 2008, 130, (19), 6196-205.

99. Simonsson, L.; Jonsson, P.; Stengel, G.; Höök, F., Site-specific DNA-controlled fusion of single lipid vesicles to supported lipid bilayers. Chemphyschem 2010, 11, (5), 1011-7.

100. Amatore, C.; Arbault, S.; Bouret, Y.; Guille, M.; Lemaitre, F.; Verchier, Y., Regulation of exocytosis in chromaffin cells by trans-insertion of lysophosphatidylcholine and arachidonic acid into the outer leaflet of the cell membrane. Chembiochem 2006, 7, (12), 1998-2003.

101. Ohki, S.; Arnold, K., Experimental evidence to support a theory of lipid membrane fusion. Colloids Surf B Biointerfaces 2008, 63, (2), 276-81. 
102. Gaßmann, H. A. O., Integration von Connexonen in Lipidmembranen auf porösen Oberflächen. Dissertation 2010.

103. Ambrosi, C.; Gassmann, O.; Pranskevich, J. N.; Boassa, D.; Smock, A.; Wang, J.; Dahl, G.; Steinem, C.; Sosinsky, G. E., Pannexin1 and Pannexin2 channels show quaternary similarities to connexons and different oligomerization numbers from each other. J Biol Chem 285, (32), 24420-31.

104. Zwilling, D.; Cypionka, A.; Pohl, W. H.; Fasshauer, D.; Walla, P. J.; Wahl, M. C.; Jahn, R., Early endosomal SNAREs form a structurally conserved SNARE complex and fuse liposomes with multiple topologies. Embo J 2007, 26, (1), 9-18.

105. Morris, S. J.; Gibson, C. C.; Smith, P. D.; Greif, P. C.; Stirk, C. W.; Bradley, D.; Haynes, D. H.; Blumenthal, R., Rapid kinetics of $\mathrm{Ca}^{2+}$-induced fusion of phosphatidylserine/phosphatidylethanolamine vesicles. The effect of bilayer curvature on leakage. J Biol Chem 1985, 260, (7), 4122-7.

106. Struck, D. K.; Hoeckstra, D.; Pagano, R. E., Use of Resonance Energy Transfer to monitor Membrane Fusion Biochemistry 1981, 20, 4093 - 4099.

107. Liu, T.; Tucker, W. C.; Bhalla, A.; Chapman, E. R.; Weisshaar, J. C., SNAREdriven, 25-millisecond vesicle fusion in vitro. Biophys $J$ 2005, 89, (4), 2458-72.

108. Chung, M.; Lowe, R. D.; Chan, Y. H.; Ganesan, P. V.; Boxer, S. G., DNA-tethered membranes formed by giant vesicle rupture. J Struct Biol 2009, 168, (1), 190-9.

109. Wong, A. P.; Groves, J. T., Molecular topography imaging by intermembrane fluorescence resonance energy transfer. Proc Natl Acad Sci U S A 2002, 99, (22), $14147-52$.

110. Cornish, P. V.; Ha, T., A survey of single-molecule techniques in chemical biology. ACS Chem Biol 2007, 2, (1), 53-61.

111. Perin, M. S.; MacDonald, R. C., Fusion of synaptic vesicle membranes with planar bilayer membranes. Biophysical Journal 1989, 55, 973 - 986.

112. White, S. H., Formation of "solvent-free" black lipid bilayer membranes from glyceryl monooleate dispersed in squalene. Biophys $J$ 1978, 23, (3), 337-47.

113. Niles, W. D.; Cohen, F. S., Video Fluorescence Microscopy Studies of Phospholipid Vesicle Fusion with a Planar Phospholipid Membrane. The Journal of General Physiology 1987, 90, 703-735.

114. Anzai, K.; Ogawa, K.; Ozawa, T.; Yamamoto, H., Quantitative comparison of two types of planar lipid bilayers--folded and painted--with respect to fusion with vesicles. J Biochem Biophys Methods 2001, 48, (3), 283-91. 
115. Chanturiya, A.; Scaria, P.; Kuksenok, O.; Woodle, M. C., Probing the mechanism of fusion in a two-dimensional computer simulation. Biophys $J$ 2002, 82, (6), 307280 .

116. Steinem, C.; Janshoff, A.; Ulrich, W. P.; Sieber, M.; Galla, H. J., Impedance analysis of supported lipid bilayer membranes: a scrutiny of different preparation techniques. Biochim Biophys Acta 1996, 1279, (2), 169-80.

117. Plant, A. L., Supported Hybrid Bilayer Membranes as Rugged Cell Membrane Mimics. Langmuir 1998, 15, 5128-5135.

118. Kalb, E.; Frey, S.; Tamm, L. K., Formation of supported planar bilayers by fusion of vesicles to supported phospholipid monolayers. Biochim Biophys Acta 1992, $1103,(2), 307-16$.

119. Hoekstra, D., Kinetics of Intermixing of Lipids and mixing of Aqueous Contents During Vesicle Fusion. Biochim Biophys Acta 1982, 692, 171-175.

120. Papahadjopoulos, D.; Nir, S.; Duzgunes, N., Molecular mechanisms of calciuminduced membrane fusion. J Bioenerg Biomembr 1990, 22, (2), 157-79.

121. Miller, C.; Arvan, P.; Telford, J. N.; Racker, E., $\mathrm{Ca}^{++}$-induced fusion of proteoliposomes: dependence on transmembrane osmotic gradient. J Membr Biol 1976, 30, (3), 271-82.

122. Papahadjopoulos, D.; Vail, W. J.; Newton, C.; Nir, S.; Jacobson, K.; Poste, G.; Lazo, R., Studies on membrane fusion. III. The role of calcium-induced phase changes. Biochim Biophys Acta 1977, 465, (3), 579-98.

123. Portis, H.; Newton, C.; Pangborn, W.; Papahadjopoulos, D., Studies on the mechanism of membrane fusion: evidence for an intermembrane $\mathrm{Ca}^{2+}$-phospholipid complex, synergism with $\mathrm{Mg}^{2+}$ and inhibition by spectrin. Biochemistry 1979, 18 , 780-790.

124. Helm, C. A.; Israelachvili, J. N.; McGuiggan, P. M., Molecular mechanisms and forces involved in the adhesion and fusion of amphiphilic bilayers. Science 1989, 246, (4932), 919-22.

125. Ohki, S., A mechanism of divalent ion-induced phosphatidylserine membrane fusion. Biochim Biophys Acta 1982, 689, (1), 1-11.

126. Hladky, S. B.; Gruen, D. W. R., Thickness Fluctuations in Black Lipid Membranes. Biophys J 1982, 38, 251-258.

127. Duzgunes, N.; Wilschut, J., Fusion assays monitoring intermixing of aqueous contents. Methods Enzymol 1993, 220, 3-14. 
128. Ellens, H.; Bentz, J.; Szoka, F. C., $\mathrm{H}^{+}$- and $\mathrm{Ca}^{2+}$-induced fusion and destabilization of liposomes. Biochemistry 1985, 24, (13), 3099-106.

129. Wilschut, J.; Papahadjopoulos, D., Ca2+-induced fusion of phospholipid vesicles monitored by mixing of aqueous contents. Nature 1979, 281, (5733), 690-2.

130. Wilschut, J.; Duzgunes, N.; Fraley, R.; Papahadjopoulos, D., Studies on the mechanism of membrane fusion: kinetics of calcium ion induced fusion of phosphatidylserine vesicles followed by a new assay for mixing of aqueous vesicle contents. Biochemistry 1980, 19, (26), 6011-21.

131. Dennison, S. M.; Bowen, M. E.; Brunger, A. T.; Lentz, B. R., Neuronal SNAREs do not trigger fusion between synthetic membranes but do promote PEG-mediated membrane fusion. Biophys J 2006, 90, (5), 1661-75.

132. Hemmler, R.; Bose, G.; Wagner, R.; Peters, R., Nanopore unitary permeability measured by electrochemical and optical single transporter recording. Biophys $J$ 2005, 88, (6), 4000-7.

133. Akabas, M. H.; Cohen, F. S.; Finkelstein, A., Separation of the osmotically driven fusion event from vesicle-planar membrane attachment in a model system for exocytosis. J Cell Biol 1984, 98, (3), 1063-71.

134. Frese, D., unveröffentlichte Ergebnisse.

135. Langosch, D.; Crane, J. M.; Brosig, B.; Hellwig, A.; Tamm, L. K.; Reed, J., Peptide mimics of SNARE transmembrane segments drive membrane fusion depending on their conformational plasticity. J Mol Biol 2001, 311, (4), 709-21.

136. Richard, A.; Marchi-Artzner, V.; Lalloz, M. N.; Brienne, M. J.; Artzner, F.; GulikKrzywicki, T.; Guedeau-Boudeville, M. A.; Lehn, J. M., Fusogenic supramolecular vesicle systems induced by metal ion binding to amphiphilic ligands. Proc Natl Acad Sci U S A 2004, 101, (43), 15279-84.

137. Haluska, C. K.; Riske, K. A.; Marchi-Artzner, V.; Lehn, J. M.; Lipowsky, R.; Dimova, R., Time scales of membrane fusion revealed by direct imaging of vesicle fusion with high temporal resolution. Proc Natl Acad Sci U S A 2006, 103, (43), 15841-6.

138. Lei, G.; MacDonald, R. C., Lipid bilayer vesicle fusion: intermediates captured by high-speed microfluorescence spectroscopy. Biophys $J$ 2003, 85, (3), 1585-99.

139. Marchi-Artzner, V.; Gulik-Krzywicki, T.; Guedeau-Boudeville, M. A.; Gosse, C.; Sanderson, J. M.; Dedieu, J.-C.; Lehn, J. M., Selective Adhesion, Lipid Exchange and Membrane-Fusion Processes between Vesicles of Various Sizes Bearing 
Complementary Molecular Recognition Groups. Chemphyschem 2001, 2, 367 376.

140. Tanaka, T.; Yamazaki, M., Membrane fusion of giant unilamellar vesicles of neutral phospholipid membranes induced by $\mathrm{La}^{3+}$. Langmuir 2004, 20, (13), 51604.

141. Lorenz, B.; Mey, I.; Steltenkamp, S.; Fine, T.; Rommel, C.; Muller, M. M.; Maiwald, A.; Wegener, J.; Steinem, C.; Janshoff, A., Elasticity mapping of poresuspending native cell membranes. Small 2009, 5, (7), 832-8.

142. Goncalves, R. P.; Agnus, G.; Sens, P.; Houssin, C.; Bartenlian, B.; Scheuring, S., Two-chamber AFM: probing membrane proteins separating two aqueous compartments. Nat Methods 2006, 3, (12), 1007-12.

143. Benoit, M.; Holstein, T.; Gaub, H. E., Lateral forces in AFM imaging and immobilization of cells and organelles. Eur Biophys J 1997, 26, 283-290.

144. Fine, T.; Mey, I.; Rommel, C.; Wegener, J.; Steinem, C.; Janshoff, A., Elasticity mapping of apical cell membranes. Soft Matter 2009, 5, 3262-3265.

145. Böcker, M., Entwicklungen in der Rasterionenleitfähigkeitsmikroskopie und Untersuchungen von porenüberspannenden Lipidmembranen. Dissertation 2009.

146. Rheinlaender, J.; Schäffer, T. E., Image formation, resolution, and height measurement in scanning ion conductance microscopy. J . Appl. Phys. 2009, 105, 094905.

147. Wieder, H., Festkörperunterstützte Lipid-Modellmembranen auf Gold zur Rekonstitution von Membranproteinen. Dissertation 2000.

148. Williams, L. M.; Evans, S. D.; Flynn, T. M.; Marsh, A.; Knowles, P. F.; Bushby, R. J.; Boden, N., Kinetics of the Unrolling of Small Unilamellar Phospholipid Vesicles onto Self-Assembled Monolayers. Langmuir 1997, 13, 751 - 757.

149. Frisch, B.; Boeckler, C.; Schuber, F., Synthesis of Short Polyoxyethylene-Based Heterobifunctional Cross-Linking Reagents. Application to the Coupling of Peptides to Liposomes. Bioconjug Chem 1996, 7, (2), 180 - 186.

150. Svedhem, S.; Dahlborg, D.; Ekeroth, J.; Höök, F., In Situ Peptide-Modified Supported Lipid Bilayers for Controlled Cell Attachment. Langmuir 2003, 4, (19), $6730-6736$.

151. Treutlein, B., In situ coupling of oligopeptides to solid supported bilayers. Diplomarbeit 2007. 
152. Frese, D., Rekonstitution von Bacteriorhodopsin in porenüberspannenden Membranen und dessen Einfluss auf die laterale Mobilität der Matrixlipide. Diplomarbeit 2009.

153. Lipowsky, R., Adhesion of Membranes via Anchored Stickers. Phys Rev Lett 1996, $77,(8), 1652-1655$.

154. Ma, M.; Gong, Y.; Bong, D., Lipid membrane adhesion and fusion driven by designed, minimally multivalent hydrogen-bonding lipids. J Am Chem Soc 2009, 131, (46), 16919-26.

155. Nagle, J. F.; Tristram-Nagle, S., Structure of lipid bilayers. Biochim Biophys Acta 2000, 1469, (3), 159-95.

156. Lygina, A. S.; Meyenberg, K.; Jahn, R.; Diederichsen, U., Transmembrane Domain Peptide/Peptide Nucleic Acid Hybrid as SNARE Protein Model in Vesicle Fusion. Angew Chem Int Ed Engl 2011.

157. Lu, X.; Zhang, F.; McNew, J. A.; Shin, Y. K., Membrane fusion induced by neuronal SNAREs transits through hemifusion. J Biol Chem 2005, 280, (34), 30538-41.

158. Lygina, A. S., Design, Synthesis and Fusion Activity of PNA/Peptide Hybrids as SNARE Protein Models. Dissertation 2011.

159. Siddiqui, T. J.; Vites, O.; Stein, A.; Heintzmann, R.; Jahn, R.; Fasshauer, D., Determinants of synaptobrevin regulation in membranes. Mol Biol Cell 2007, 18, (6), 2037-46.

160. McNew, J. A.; Weber, T.; Parlati, F.; Johnston, R. J.; Melia, T. J.; Sollner, T. H.; Rothman, J. E., Close is not enough: SNARE-dependent membrane fusion requires an active mechanism that transduces force to membrane anchors. J Cell Biol 2000, 150, (1), 105-17.

161. Risselda, H. J.; Kutzner, C.; Grubmüller, H., Caught in the Act: Visualization of SNARE-Mediated Fusion Events in Molecular Detail. ChemBioChem 2011, 12, 1049-1055.

162. Duwe, H. P.; Engelhardt, H.; Zilker, H.; Sackmann, W. E., Curvature elasticity of smectic A lipid bilayers and cell plasma membranes. Mol. Cryst. Liq. Crys. 1987, $152,1-7$.

163. Bo, L.; Waugh, R. F., Determination of bilayer membrane bending stiffness, by tether formation from giant, thin-walled vesicles. Biophys $J$ 1998, 55, 2123-2128. 
164. Evans, E.; Rawicz, W., Entropy driven tension and bending elasticity in condensedfluid membranes. Phys. Rev. Lett. 1990, 64, 2094 - 2097.

165. Anderson, T. H.; Min, Y.; Weirich, K. L.; Zeng, H.; Fygenson, D.; Israelachvili, J. N., Formation of supported bilayers on silica substrates. Langmuir 2009, 25, (12), 6997-7005.

166. Hui, E.; Johnson, C. P.; Yao, J.; Dunning, F. M.; Chapman, E. R., Synaptotagminmediated bending of the target membrane is a critical step in $\mathrm{Ca}^{2+}$-regulated fusion. Cell 2009, 138, (4), 709-21.

167. Groffen, A. J.; Martens, S.; Diez Arazola, R.; Cornelisse, L. N.; Lozovaya, N.; de Jong, A. P.; Goriounova, N. A.; Habets, R. L.; Takai, Y.; Borst, J. G.; Brose, N.; McMahon, H. T.; Verhage, M., Doc2b is a high-affinity $\mathrm{Ca}^{2+}$ sensor for spontaneous neurotransmitter release. Science 327, (5973), 1614-8.

168. McMahon, H. T.; Kozlov, M. M.; Martens, S., Membrane curvature in synaptic vesicle fusion and beyond. Cell 140, (5), 601-5.

169. Sun, Y.; Lee, C. C.; Huang, H. W., Adhesion and merging of lipid bilayers: a method for measuring the free energy of adhesion and hemifusion. Biophys $J 100$, (4), 987-95.

170. Heuvingh, J.; Pincet, F.; Cribier, S., Hemifusion and fusion of giant vesicles induced by reduction of inter-membrane distance. Eur Phys J E Soft Matter 2004, 14, (3), 269-76.

171. Dai, J.; Ting-Beall, H. P.; Sheetz, M. P., The secretion-coupled endocytosis correlates with membrane tension changes in RBL 2H3 cells. J Gen Physiol 1997, $110,(1), 1-10$.

172. Morris, C. E.; Homann, U., Cell surface area regulation and membrane tension. $J$ Membr Biol 2001, 179, (2), 79-102. 


\section{Symbolverzeichnis}

$\begin{array}{ll}A & \text { Fläche } \\ C & \text { Teilchenzahldichte } \\ c & \text { Konzentration } \\ D & \text { Diffusionskoeffizient } \\ d & \text { Durchmesser, Dicke, Abstand } \\ F & \text { Fluoreszenzintensität } \\ f & \text { Frequenz } \\ h & \text { Höhe } \\ I & \text { Strom } \\ M & \text { Molare Masse } \\ N A & \text { Numerische Apertur } \\ n & \text { Brechungsindex } \\ Q & \text { Quantenausbeute } \\ r & \text { Radius } \\ t & \text { Zeit } \\ U & \text { Spannung } \\ \varepsilon & \text { Elektrische Feldkonstante } \\ \mathcal{E}_{\mathrm{r}} & \text { Dielektrizitätskonstante } \\ \lambda & \text { Wellenlänge } \\ \sigma & \text { Lateralspannung }\end{array}$




\section{Abkürzungsverzeichnis}

\begin{tabular}{|c|c|}
\hline AFM & Raszerkraftmikroskopie (atomic force microscope) \\
\hline ANTS & 8-Aminonaphthalin-1,3,6-trisulfonsäure \\
\hline BLM & schwarze Membran (black lipid membrane) \\
\hline CLSM & $\begin{array}{l}\text { konfokales Laserrastermikroskop (confocal laser scanning } \\
\text { microscope) }\end{array}$ \\
\hline CPEO3 & Cholesterylpolyethylenoxythiol \\
\hline d & Tag \\
\hline DHPE & 1,2-Dihexadekanoyl-sn-glycero-3-phosphoethanolamin \\
\hline DNA & desoxyribonucleic acid \\
\hline DOPC & 1,2-Dioleoyl-sn-glycero-3-phosphocholin \\
\hline $\mathrm{DPhPC}$ & 1,2-Diphytanoyl-sn-glycero-3-phosphatidylcholin \\
\hline DPPTE & 1,2-Dipalmityl-sn-glycero-3-phospothioethanol \\
\hline DPX & $p$-Xylen-Bispyridiniumbromid \\
\hline FITC & Fluoresceinisothiocyanat \\
\hline FRAP & fluorescence recovery after photobleaching \\
\hline FRET & Förster-Resonanz-Energie-Transfer \\
\hline GUV & riesiger unilamellarer Vesikel (giant unilamellar vesicle) \\
\hline $\mathrm{h}$ & Stunde \\
\hline ITO & Indiumzinnoxid (indium tin oxide) \\
\hline LPC & Lysophosphatidylcholin \\
\hline LUV & großer unilamellarer Vesikel (large unilamellar vesicle) \\
\hline M & molar \\
\hline MCC-DOPE & 1,2-Dioleoyl-sn-glycero-3-phosphoethanolamin-N-[4-(p- \\
\hline & maleimidomethyl)-cyclohexan-carboxyamid] \\
\hline MES & 2-(N-Morpholino)ethansulfonsäure \\
\hline $\min$ & Minute \\
\hline Ni-NTA-DOGS & $\begin{array}{l}\text { 1,2-Dioleoyl-sn-glycero-3-[(N-(5-amino-1-carboxypentyl)imino- } \\
\text { diessigsäure)succinyl }]\end{array}$ \\
\hline PNA & Peptid-Nukleinsäure (peptide nucleic acid) \\
\hline POPC & 1-Palmitoyl-2-Oleoyl-sn-glycero-3-phosphocholin \\
\hline
\end{tabular}


POPE

POPS

QCM

ROI

$\mathrm{S}$

SICM

SNARE

SUV

Syb

Syx

TIRF
1-Palmitoyl-2-Oleoyl-sn-glycero-3-phosphoethanolamin

1-Palmitoyl-2-Oleoyl-sn-glycero-3-phosphoserin

Quartzmikrowaage (quartz cristal microbalance)

region of interest

Sekunde

Rasterionenleitfähigkeitsmikroskop (scanning ion conductance microscope)

soluble $N$-ethylmaleimide-sensitive-factor attachment receptor

kleiner unilamellarer Vesikel (small unilamellar vesicle)

Synaptobrevin

Syntaxin

total internernal reflection fluorescence 


\section{Chemikalien, Materialien und Geräte}

\section{Chemikalien:}

$\begin{array}{ll}\text { Argon } & \text { Linde (München) } \\ \text { Chloroform } & \text { VWR International (Darmstadt) } \\ n \text {-Dekan } & \text { Sigma-Aldrich (Steinheim) } \\ \text { DOPC } & \text { Avanti Polar Lipids (Alabaster, USA) } \\ \text { DPhPC } & \text { Avanti Polar Lipids (Alabaster, USA) } \\ \text { DPPTE } & \text { Avanti Polar Lipids (Alabaster, USA) } \\ \text { Ethanol } & \text { Fluka (Neu-Ulm) } \\ \text { FITC-Anti-His6-tag-Antikörper } & \text { ICL LAB (Newberg, USA) } \\ \text { HEPES } & \text { Carl Roth GmbH (Karlsruhe) } \\ \text { KCl } & \text { Carl Roth GmbH (Karlsruhe) } \\ \text { Mes } & \text { Carl Roth GmbH (Karlsruhe) } \\ \text { Mucasol } & \text { Merck (Darmstadt) } \\ \text { Kaliumchlorid } & \text { Applichem (Darmstadt) } \\ \text { MCC-DOPE } & \text { Avanti Polar Lipids (Alabaster, USA) } \\ \text { Ni-NTA-DOGS } & \text { Avanti Polar Lipids (Alabaster, USA) } \\ \text { Oregon Green } 488 \text { DHPE } & \text { Invitrogen (Eugen, USA) } \\ \text { POPC } & \text { Avanti Polar Lipids (Alabaster, USA) } \\ \text { POPE } & \text { Avanti Polar Lipids (Alabaster, USA) } \\ \text { POPS } & \text { Avanti Polar Lipids (Alabaster, USA) } \\ \text { Pyranin } & \text { Acros Organis (Geel, Belgien) } \\ \text { Sucrose } & \text { Carl Roth (Karlsruhe) } \\ \text { Texas Red DHPE } & \text { Sigma-Aldrich (Taufkirchen) } \\ & \end{array}$




\section{Materialien:}

Eppendorf-Cups

Eppendorfpipetten

Titan-Target

Hämatokritmasse

ITO-Gläser

Kupferband

Parafilm

Petrischalen

Platindraht, $\varnothing 0,3 \mathrm{~mm}$, geglüht

Porensubstrate (offen, $1.2 \mu \mathrm{m}$ )

Schleifpapier P100

Schwingquarz-Kristall für MTM10

Silberdraht, $\varnothing 1,0 \mathrm{~mm}$, geglüht

Teflonfolie

Titan-Target
Eppendorf (Hamburg)

Eppendorf (Hamburg)Kalrez ${ }^{\circledR}$

Elektronen Optik Service GmbH (Dortmund)

Brand GmbH (Wertheim)

Präzisions Glas \& Optik GmbH (Iserlohn)

Präzisions Glas \& Optik GmbH (Iserlohn)

Pechiney Plastik Packaging (Chicago, USA)

VWR International GmbH, Nürnberg

Goodfellow (Huntington, UK)

fluXXion (Eindhofen, Niederlande)

AEG (Frankfurt/Main)

Elektronen Optik Service (Dortmund)

Goodfellow (Huntington, UK)

Saint Gobain-Performance Plastics (Wayne, USA)

Elektronen Optik Service GmbH (Dortmund)

\section{Geräte:}

Konfokales Laserrastermikroskop

LSM 710 Examiner

Carl Zeiss AG (Jena)

\section{Rasterionenleitfähigkeitsmikroskop}

ICnano

ionscope (London, UK)

\section{Kathodenzerstäuber}

Sputter Coater 108 auto

Cressington (Watfort, USA)

Thickness Controller mtm 20

Cressington (Watfort, USA) 


\section{Reinstwasseranlage}

Milli Elix 5

Milli Gradient A10

\section{Sputter Anlage}

Sputter Coater 108 auto

Thickness Controller mtm 20

\section{Plasmacleaner}

Plasma Cleaner PDC 32 G-2

\section{Sonstige Geräte}

Ohaus (Feinwaage)

Frequenzgenerator Agilent 33220A

$\mathrm{pH}-\mathrm{Meter}$

Ultraschallbad Bandelin Sonorex RK 255 H

Vakuumtrockenschrank VD 23
Millipore (Eschborn)

Millipore (Eschborn)

Cressington (Watfort, USA)

Cressington (Watfort, USA

Harrick Plasma (Ithaca, USA)

Pine Brook (New York, USA)

Agilent Technologies (Santa Clara, USA)

Knick (Berlin)

Bandelin (Berlin)

Binder GmbH (Tuttlingen) 
- 176 - 


\section{Lebenslauf}

\section{Ines Höfer}

geboren am 02.07.1982 in Einbeck

Staatsangehörigkeit: deutsch

\section{Schulausbildung}

08/1989-07/1993 Grundschule Pestallozi-Schule Einbeck

09/1993-07/1995 Orientierungsstufe Sohnrey-Schule Einbeck

09/1995-06/2002 Gymnasium Goethe-Schule Einbeck

$06 / 2002$

Abitur Goethe-Schule Einbeck

\section{Studium}

10/2002-10/2007 Studium der Chemie an der Georg-August-Universität Göttingen

$10 / 2004$

Vordiplom im Fach Chemie an der Georg-August-Universität Göttingen

12/2006-07/2007 Diplomarbeit im Arbeitskreis von Prof. Dr. Claudia Steinem am Institut für Organische und Biomolekulare Chemie der GeorgAugust-Universität Göttingen zum Thema „Untersuchung des Einfluss der Oberflächenfunktionalisierung auf die Ausbildung und Stabilität von nano-BLMs“"

$09 / 2007$

Diplom im Fach Chemie an der Georg-August-Universität Göttingen

Seit $01 / 2008$

Promotion im Arbeitskreis von Prof. Dr. Claudia Steinem am Institut für Organische und Biomolekulare Chemie der GeorgAugust-Universität Göttingen zum Thema „Entwicklung eines Fusionsassays basierend auf porenüberspannenden Membranen " 



\section{Veröffentlichungen und Tagungsbeiträge}

$02 / 2011$

$01 / 2011$

$09 / 2010$

$07 / 2010$

$02 / 2010$

$07 / 2009$

$07 / 2009$
Vortrag „Fusion mediated via molecular recognition investigations based on pore-spanning membranes" im Rahmen der Winter School des SFB 803, Eisenach, Deutschland

Fachartikel: Höfer, I., Steinem, C. (2011) A membrane fusion assay based on pore-spanning lipid bilayers. Soft Matter, 7, 16441647

Poster ,Investigation of the influence of molecular recognition mechanisms on the fusion of vesicles with pore-spanning membranes" im Rahmen des Symposiums SFB 803, Göttingen, Deutschland

Poster ,A membrane fusion assay based on pore-spanning lipid bilayers" im Rahmen des FEBS International Workshop Physical Chemistry of Biointerfaces, San Sebastian, Spanien

Vortrag ,A membrane fusion assay based on pore-spanning lipid bilayers" im Rahmen der Winter School des SFB 803, Hofgeismar, Deutschland

Poster ,A membrane fusion assay based on pore-spanning lipid bilayers", EBSA European Biophysics Congress, Genua, Italien

Poster „Entwicklung eines Fusionsassays basierend auf porenüberspannenden Membranen", GDCh-Jungchemikerforum, Göttingen, Deutschland 



\section{Danksagung}

An erster Stelle danke ich Frau Prof. Dr. Claudia Steinem für die Bereitstellung eines interessanten Themas, an dem ich sehr gerne gearbeitet habe. Außerdem bedanke ich mich für die stete Unterstützung, die fachlichen Diskussionen und wertvollen Anregungen, die zu dieser Arbeit beigetragen haben.

Prof. Dr. Schroeder danke ich für die Übernahme des Korreferats und die Betreuung im Rahmen des GAUSS-Promotionsprogramms.

An Prof. Dr. Burkhard Geil richtet sich mein Dank für die Entwicklung der Software zur Quantifizierung der Fusionsereignisse.

Antonina Lygina synthetisierte die in dieser Arbeit verwendeten PNA-Peptide. Für die gute Zusammenarbeit und die unkomplizierte Versorgung mit Peptid-Nachschub danke ich ihr.

Christoph, Daniel, Alex, Ingo, Christian, Dany, Ole, Lando, Henrik und Michaela haben mich durch gewissenhaftes Korrekturlesen in dieser Arbeit unterstützt - ein Dankeschön auch an Euch.

Ich bedanke mich bei meinen Diplomanden Steffi und Oleg, die mich eine Zeit lang in der Welt der Membranfusion begleitet haben. Ich danke Euch für Eure Unterstützung.

Außerdem möchte ich unseren technischen Assistenten Jutta, Michaela und Hans Jörg für ihre tatkräftige Hilfe danken.

Bei Frau Gastrock und Marianne bedanke ich mich für die Unterstützung in allen organisatorischen Angelegenheiten. 
Ein großer Dank geht selbstverständlich an den Arbeitskreis Steinem, der durch das tolle Arbeitsklima und den unübertroffenen Zusammenhalt von vielen tollen Menschen jeden Labortag, sei er auch noch so trist und hoffnungslos gewesen, ein wenig mit Sonnenschein füllte. Ich danke euch für eure Unterstützung in allen Lebenslagen und für den vielen Spaß und Unsinn, den wir gemeinsam erlebt haben. Ich werde die Zeit mit Euch nie vergessen.

Sabine, Dany, Gretel und Julia danke ich für die vielen schönen gemeinsamen Abende, die ich sicher sehr vermissen werde.

In Björn habe ich durch das Studium einen wahren Freund fürs Leben gefunden. Ich danke dir für die Unterstützung und den Zusammenhalt in all den Jahren. Ich bin froh über alles, was wir in den letzten Jahren so erlebt haben. Du und Deine Küche werden mir fehlen.

Ich danke Anne, Kathi und Christian für unsere Freundschaft, die trotz einer Entfernung von so vielen Kilometern Bestand hat.

Mit großem Respekt und aus tiefstem Herzen danke ich meiner Familie für ihre grenzenlose Unterstützung und dafür, dass sie mir alles mitgegeben haben, um mein Leben, zu dem auch diese Arbeit gehört, zu meistern. 

